

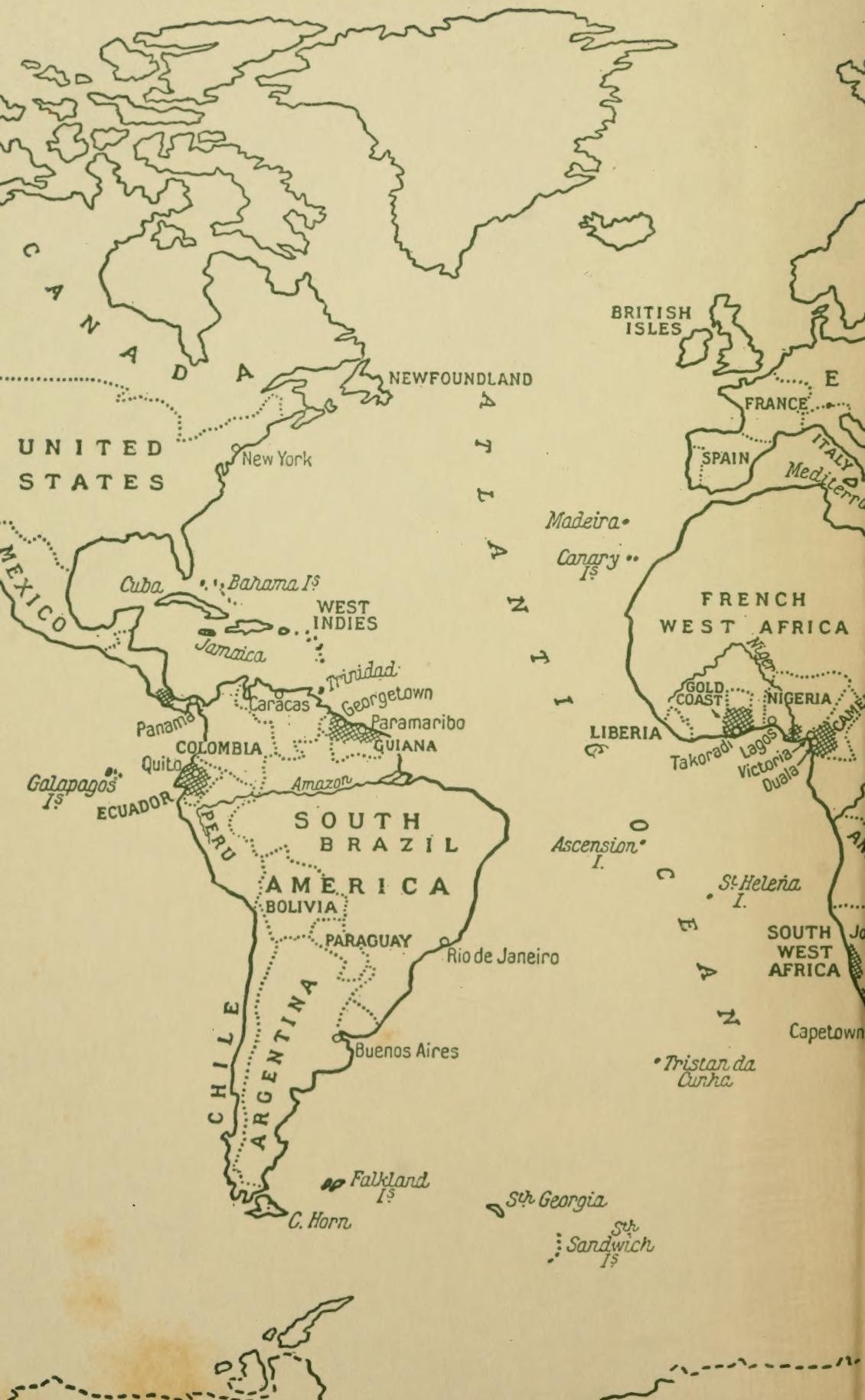




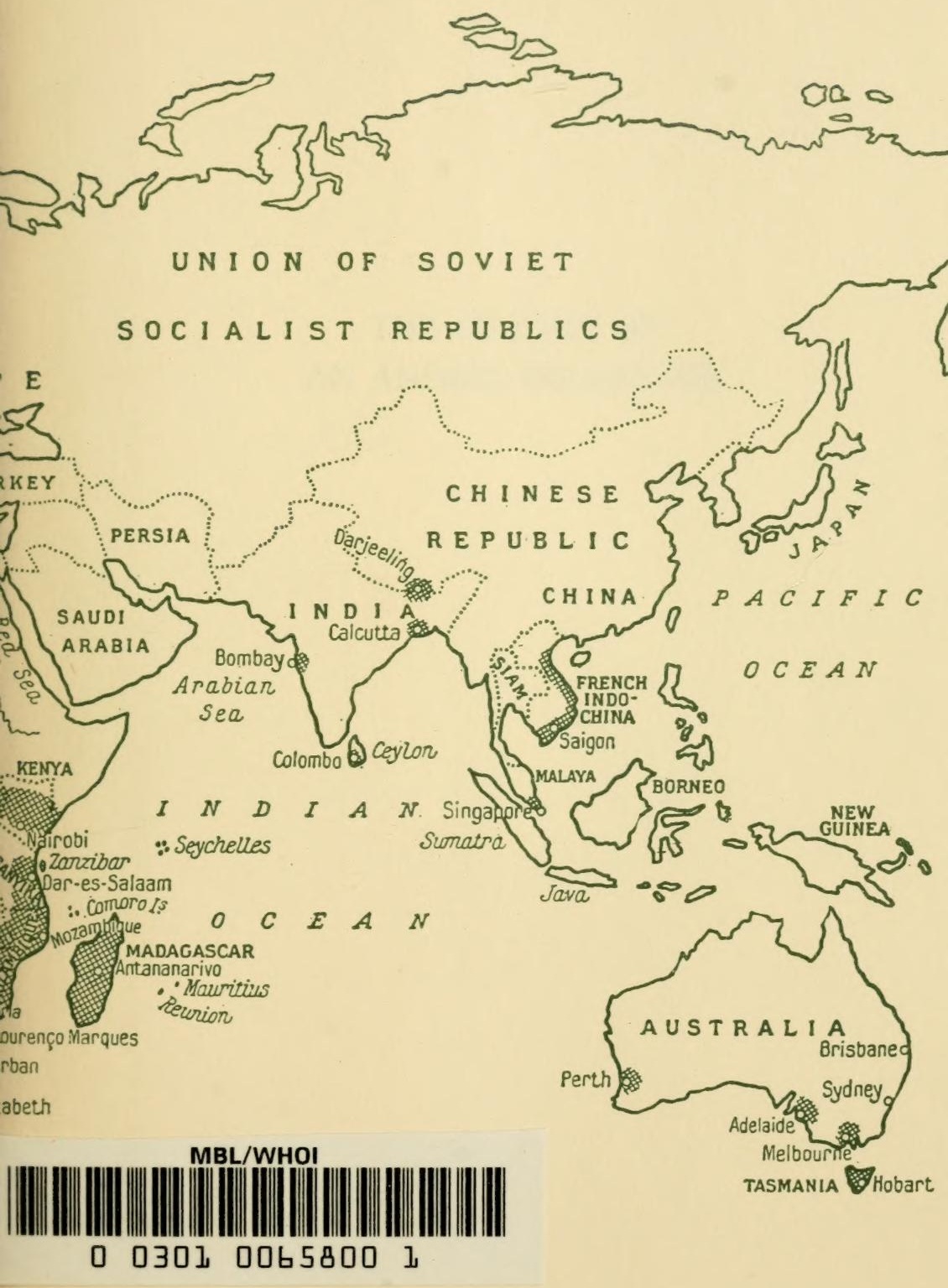



THE ODYSSEY OF AN ANIMAL COLLECTOR 




\section{THE ODYSSEY OF}

\section{AN ANIMAL COLLECTOR}

\section{CECIL S. WEBB}

Superintendent of the Dublin Zoo

INTRODUCTION BY

DR. G. M. VEVERS, F.R.C.S., F.Z.S.

Superintendent of the London Zoo, 1923-1948

\section{Illustrated}

LONGMANS, GREEN AND CO.

$$
\text { NEW YORK - LONDON - TORONTO }
$$

I 954 
LONGMANS, GREEN AND CO., INC.

55 FIFTH AVENUE, NEW YORK 3

LONGMANS, GREEN AND CO. LTD.

6 \& 7 CLIFFORD STREET, LONDON W 1

LONGMANS, GREEN AND CO.

20 CRANFIELD ROAD, TORONTO I6

THE ODYSSEY OF AN ANIMAL COLLECTOR

COPYRIGHT $\cdot 1953$

BY CECIL S. WEBB

ALL RIGHTS RESERVED, INCLUDING THE RIGHT TO REPRODUCE THIS BOOK, OR ANY PORTION THEREOF, IN ANY FORM

FIRST EDITION

LIBRARY OF CONGRESS CATALOG CARD NUMBER 54-II442

Printed in the United States of America 
To

DORIS MARIA 



\section{FOREWORD}

When Curator of Mammals and Birds at the London Zoo I had numerous inquiries from boys about to leave school asking how it would be possible for them to obtain such a post, and if it would be necessary to undertake special studies or pass examinations.

It was perhaps only natural that such inquiries should take me back to the beginning of my own career. What did I do to become a Zoo curator? The answers are in this book, though I am not suggesting that any schoolboy should set out on such a crazy path in order to obtain a similar post. For one thing the path would be too long and, I am afraid, too strenuous for most, but for me it was just one long glorious adventure.

In my case the position was not a goal, but was reached by accident rather than design. I merely set out to lead a care-free existence, traveling round the world collecting strange and wonderful birds and mammals in tropical countries; but alas, after thirty years of this freedom, I have found myself becoming a slave to people, to routine, and to possessions. Owing to presentday difficulties such as sterling control, long waiting-lists for steamers, immigration laws, and many other irksome restrictions, traveling to a time-table is more of an ordeal than a joy-hence my reluctant decision to take root for a while.

For me this was almost terrifying, for previously I had for most of my life lived on my wits, which even if hazardous was in itself great fun. It was also great fun being a migrant; every year I planned to leave England in early winter and return the following spring. My idea was to choose a new tropical country each time, or at least a different part of one I had already visited, and in so doing I was able to emulate the swallows and follow the sun.

At no time had I much desire to see the things that tourists normally make for when "doing" a foreign country-museums, bull-rings, cathedrals, mosques, ruins and, perhaps, night-life. All 
these things are products of civilization-such as are to be found in most cities of the world. To me the life and soul of any tropical country is its wild life and its unspoiled natives. In short, I am merely a nature lover with an explorer's insatiable curiosity.

Most of my expeditions have been made alone, but on three occasions my brother Leslie linked up with me, and on five successive trips I was accompanied by my Australian-born niece, Delys. Her desire to see something of the world was, I think, gratified, for she went with me to the interior of the Gold Coast, Tanganyika, and Madagascar, and saw something of the wonders of the Himalayas and of the Andes of Ecuador.

Other expeditions took me to Madagascar (twice), South Africa (many times), Portuguese East Africa (four times), Kenya (three times), Tanganyika (twice), French Cameroons, British Cameroons, British Guiana (twice), and Costa Rica, Indo-China, Australia, and Tasmania. One of the joys of going to these places was that other interesting countries and islands could be visited en route. Undoubtedly travel is the ideal way of learning geography; and speaking of learning, I believe that taking an interest in something that forever lures one on to discover more, is one of the main sources of contentment in life.

Much of this book has been written from memory, but with the kind permission of the editor of the Avicultural Magazine, I have drawn freely from my articles in that journal on the birds encountered during various collecting expeditions. 


\section{CONTENTS}

Introduction by Dr. G. M. Vevers, F.R.C.S., F.Z.S.

xiii

Chapter I Early Days

II South Africa

III Mozambique Territory, Portuguese East Africa (I) 22

IV Mozambique Territory (II)

$\mathrm{v}$ Indo-China

vi Mozambique Territory (III)

viI Madagascar (I)

viII Portuguese East Africa (South)

Ix British Guiana (I)

$\mathrm{x}$ Kenya (I)

xI Tanganyika (I)

133

xII Australia

142

xIII French Cameroons

I55

XIv Madagascar (II)

I70

$\mathrm{xV}$ India

I80

xvi Gold Coast

I92

xviI Ecuador

215

xviıI Tanganyika (II)

xIx Madagascar (III)

244

xx Madagascar (III)-contd.

278

xxi Kenya (II)

292

xxII British Guiana (II)

xxiII British Cameroons

Conclusion

Index 


\section{LIST OF ILLUSTRATIONS}

Dicksie, African Elephant

Frontispiece

\section{Following page 80}

Typical view of denuded highlands, Central Madagascar Hand-reared baby Cheetahs

Flooded Antsihanaka village, Lake Alaotra, Madagascar

Demidoff's Galago

Coastline, Antongil Bay, northeast Madagascar, showing evergreen forests

Bara native thatching hut, near Ihosy, south-central Madagascar Warthog: monstrosity from Africa

Koala Bear and young, Australia

Distant view of the snow-capped peaks, Himalayas

Crested Porcupine in defensive attitude

Formasin's Tree Frog, Portuguese East Africa

Sampans, Annam, Indo-China

Hippos basking in sunshine

Brazil nut and egg emptied by Aye-aye, showing how hole is gnawed and contents extracted by long finger

Aye-aye, a curious specialized Madagascar Lemur

Hoatzin: adult and young, showing wing-hooks of latter

Young Brazilian Tapir, British Guiana

Brazilian Tree Porcupine

Thylacine, or Tasmanian Wolf

Hammerkop, or Hammerhead

Uganda Leopard Sandy

Black Rhinoceros, Kenya Colony

Toto, young male Lesser Kudu, Kenya Colony

White Cranes, Calcutta Zoo

Delys, author's niece, on the trail to Santo Domingo, Ecuador 
Author's porters on the march, Ivohibe Mountains, southeast Madagascar

Sub-desert vegetation showing the curious cigar-shaped Pachypodium lamairei, south Madagascar

\section{Following page 160}

Blacksmith Plover

Male Wattled Starling in breeding head-dress

Colobus Monkeys and Chimpanzee, Kenya Highlands

Brazza’s Monkeys, Mount Elgon, Kenya Colony

Baby Cheetah, three weeks old, showing juvenile coloration

Cheetahs, four months old, showing remarkable color change

Uganda Chimpanzee with his caretaker, an Italian ex-prisoner-ofwar

Jackson's Chameleon, Kenya Colony, a creature much feared by most African natives

Colobus Monkey with adopted Colobus baby, Kenya Highlands

Girlie, female Baringo Giraffe, Kenya Colony

Raymond Hook with hybrid Grevy's Zebra x Arab mare, Nanyuki, Kenya Colony

Gerenuk, or Giraffe-necked Antelope, Northern Kenya

Farewell to Dicksi, Mombasa Harbor

Battening cages prior to sailing, Mombasa Harbor, Kenya

\section{Following page 304}

We meet the Pygmies, Ituri Forest, Belgian Congo

Pygmy Ant-eater in defensive attitude

Two-toed Sloth in normal walking position

Tamandua Ant-eater and young, British Guiana

Three-toed Sloth, British Guiana

\section{Facing page 336}

Gray-necked Picathartes, British Cameroons

Cholmondley the Chimp, British Cameroons 
Facing page 337

Long-tailed Pangolin, or Scaly Ant-eater

Scaly Ant-eater coiled in defensive position

Line-Drawings by L. R. Brightwell

Flue net

Snare for trapping Antelopes

Annamite carrying Rheinart's Pheasant

Great Indian Hornbill-cock feeding sitting hen

Jacana, or Lily-trotter

Two-toed Sloth

Platypus

Potto-showing hand and foot

Sword-billed Humming-birds feeding on Brugmansia

Seasonal plumage changes in the Wattled Starling

by W. C. Osman Hill, M.D., F.R.S.E. 303 


\section{INTRODUCTION}

FIFTY years ago, when I was a schoolboy, I was a regular reader of a monthly magazine whose slogan was "Truth is stranger than fiction." It had an intense appeal for me because the stories in it were true stories, peopled by real people who had real adventures and performed real feats of endurance and heroism.

The Odyssey of an Annimal Collector, in which a very old friend and colleague ${ }^{1}$ tells in his simple modest way the story of his own life, reminds me very vividly of those old-time tales. There was nothing exaggerated or sensational about them, nor will readers find this book packed with highly colored and sensational episodes. The author (Webbie to his many friends) writes as he talks, taking everything quietly in his stride. He makes the most arduous and hazardous search for some rare animal in a tropical jungle seem like a pleasant Sunday afternoon walk.

His book is packed with solid facts and achievements and contains many new and original observations on the habits and physiology of animals. But do not imagine for a moment that it is a book for the zoologist only-it is a book which the general reader will find intensely interesting and instructive, and above all I commend it to the intelligent type of boy with a taste for adventure who wants to do something "out of the ordinary."

The Odyssey of an Animal Collector is an apt title, for this is what-after World War I-the author set out to become; first of all in a modest way by bringing home small collections of living birds for the pet departments of the great stores, then a period of specialization in ornithological rarities for rich amateurs and zoos, and-after World War II-becoming official collector to the Zoological Society of London, during which time he was mainly

${ }^{1}$ Webbie and I first met in an orchard in Mailly-Maillet during the Battle of the Somme in 1916. Derek McCulloch (Uncle Mac of the B.B.C.) was in that same orchard at the same time but we did not know it until years later when we met in "Children's Hour," to which both of us have made contributions. 
responsible for restocking the London and Whipsnade Zoos. After this came three years as Curator of Mammals and Birds at Regent's Park.

The collecting of wild animals, their boxing and transport by land, sea or air, is one of the most exacting jobs imaginable, with very little financial return at the end of it, but it has its compensations. It takes one all over the world and provides a never-ending variety of interests that few other callings can offer. During his search after specimens, Webbie has visited every continent in the world, in many cases traveling through hitherto unexplored jungles and forests. His patience is monumental, not only with animals but with human beings, for on many occasions he has spent days overcoming superstitions and legends which semihostile tribes associated with the rare creatures he wished to collect.

Although the greater part of his life has been spent in the capturing of wild animals, he has an intense hatred of cruelty and suffering and has always taken the greatest care and trouble to prevent this by devising traps and methods of trapping which do not involve pain and distress to wild creatures. Many of the traps described in this book are unique and their details have not been published elsewhere. He has always made a point of bringing back his specimens in perfect condition. He deprecates the modern tendency of crowding animals into small boxes and crates to save space and gain money. During his collecting days his motto was always quality before quantity, and he was respected for it.

No animal is too large or too small for him. I have seen him dealing with a fractious elephant and calming a bunch of nervous giraffes with perfect equanimity, and to see him handle a humming-bird or a pygmy shrew is to realize his complete understanding of wild creatures.

His experiences in Madagascar, where he was marooned for six years during the Second World War, are particularly interesting, especially when he became for a time an unofficial British agent during the Vichy régime on the island. He has never kept a day-to-day diary so that most of this book has been written from memory, no mean feat in itself, for there is a wealth of detail about events that happened many years ago.

He has an unconquerable spirit and a quiet sense of humor that 
has helped him through many trying situations. His standard of values is very real and he has no use for the self-seeking careerist.

To be a collector of animals and to know how to care for them in captivity means that one has to study their habits most carefully in their natural haunts. It is because the author is a great field naturalist that he is also a great collector, and because he is a great collector and knows how to handle and acclimatize animals to the artificial surroundings and substitute diets necessitated by captivity he is, above all, the right man to have the care of animals in captivity. Today, as I write these words, he starts on yet another adventure-as Superintendent of the Dublin Zooand I can think of no man more fitted for such a post.

Geoffrey Vevers, F.R.C.S.

Whipsnade,

August Ist, I952 



\section{Chapter One}

\section{EARLY DAYS}

$\Upsilon \mathrm{O}$ be unspoiled it is not a bad idea to be the youngest of a fam1 ily of four boys. At least in my case life was very tough from the beginning, for I was the victim of every practical joke initiated by my three brothers, all of whom, so I thought, had a warped sense of humor.

My eldest brother, intrusted with my welfare, used to take me out in a pram to the top of a hill and then let go of the handlea game which probably gave him immense satisfaction, especially when I was finally shot out into a ditch. I say finally, for when a muddy, brawling brat in a battered pram was presented to my mother she had definite ideas about my future welfare. In later years I was frequently the victim of gross injustice; whenever I practised scales on the piano, which was usually when my brothers were doing their homework, books and threats were hurled at me with much gusto. If asked why I never became a pianist I have a ready answer.

The great event of my schooldays was the annual visit to my grandparents at Ashford in Kent, during the summer holidays. My grandpa, in the grand style, used to hire a large horse-drawn brake and pack it with uncles, aunts, cousins, and ourselves, plus cooked ham and chicken, etc., for the big picnic. We then set off for Dymchurch-on-Sea, stopping at various country inns to give the horses a rest and to allow the elders to sample liquid refreshment. Dymchurch was a wonderful place in those days-it consisted of sand, a sea-wall, a pub, a few fishermen's cottages, and a church. The picnic which took place on the sea-wall was, by modern standards, a feast for the gods, but as good feeding was a cus- 
tom in those days and not merely a stroke of good fortune, it is hardly worth dwelling on. The event of note was the family dip. The technique for the ladies was to wade through shallow water to a bathing hut on wheels when the tide was coming in. By the time they had disrobed and then got into all the garments deemed necessary for the function of wetting the body, the sea had risen sufficiently for them to descend the steps and crouch in about three feet of water. We were then treated to distant views of mother and various aunts garbed in fantastic knickerbockers (showing quite a bit of leg below the knee) and frilly bathing caps. The overclad water-nymphs then clung to a rope and bobbed up and down in daredevil fashion.

My schooldays came to an end in the spring of rgrr. Unfortunately, or perhaps fortunately, I was not qualified to do anything in particular; no special studies had been undertaken as no one had any ideas as to my career.

Mathematics, science, and Latin were the only subjects at which I shone at school and were hardly helpful to a young lad seeking an open-air life. The outlook might have been grim had it not been for the fact that my father, although a City man and member of the London Stock Exchange, had his heart in the country. He rented a small country estate whenever he could afford to do so and from there went daily to London. When I left school we were living on a small estate in Essex near Hainault Forest. My brother Leslie had already started poultry-farming at home and it was agreed that I should join him.

We went in for exhibition as well as utility poultry and quickly had a number of successes showing Buff Orpingtons. The preparation of birds for shows was quite an art in itself; the exhibits had to be perfectly tame and sheltered from the sun and rain for weeks beforehand, then came the final washing and brightening up of comb, wattles, and legs.

In my spare time I drove my father to the station in a pony trap and met him at night, looked after and milked two Jersey cows, and kept an eye on a small flock of sheep which occasionally had to be treated for foot-rot.

My experience with poultry was fairly extensive as we kept a number of pure-bred varieties and hatched hundreds of chicks 
in incubators, many of which were sold as soon as hatched and the rest reared in "foster-mothers." On the utility side we built up our own laying strains by trap-nesting and selection with excellent results. But this venture soon fizzled out as we found that the exhibition side, although very profitable for successful exhibitors, was full of snags. The worst of these was that there was a clique of judge-exhibitors who had the spirit of mutual aid highly developed, so that when one of the band was judging the rest scooped all the best prizes. Having the adventurous spirit we decided to sell up and go abroad. In this we were distinctly fortunate in having a father who was well connected in City circles. He knew a number of directors of companies with interests in the colonies and foreign lands, so we had the choice of going to Sumatra on a rubber plantation or to the northern Transvaal on a large experimental farm. We decided on the latter and were appointed as assistant overseers. This appointment did not mean that we had been pushed into a soft job. We started off with practically no money and had to repay the passage money out of our eventual earnings.

South Africa before the First World War seemed to me a delightful place with plenty of sunshine, an exhilarating atmosphere, and a good living for anyone who cared to take his coat off and work.

The farm was in the bushveldt and was studded with high kopjes-making the scenery delightfully varied. Compared with English farms it was enormous, being about ten thousand acres. Over a hundred natives were employed but only two other Europeans. The chief crop was maize, but all kinds of experimental crops such as ground-nuts, soya beans, cotton, teff grass, lucerne, velvet beans, etc., were grown, all of which I learned to sow and reap. The planter was pulled by oxen not well trained for the job, and their constant zigzagging was a source of embarrassment, as every farmer likes to see neat, parallel lines of growing crops, whereas these were destined to resemble isotherms on a chart. Planting was done in the heat of the summer, for that was the rainy season. The power of the sun was greater than one imagined until experience had taught its lesson. The first time I left my planter at midday in order to have some lunch I learned that an 
iron seat should never be exposed to the sun for any length of time-that is, if one wants to avoid having a blistered posterior.

In the way of livestock there were four hundred head of Afrikander cattle which had to be rounded up frequently and dipped to rid them of ticks. These were numerous and were carriers of such tick-borne diseases as redwater and gall sickness, which were causing heavy mortality among stock. To locate and treat sick animals on such an estate, a large proportion of which was a wilderness, was in itself a big undertaking. One of the worst troubles arose when the first rains came after a long dry season. By then there was hardly any grass left and even this was reduced to dried stumps. The cattle, ravenous for something green, devoured everything that sprang up after the first downpour, and unfortunately a poisonous weed used to come up quicker than the grass. We often found cattle blown out like balloons and frothing at the mouth. Some died, but we saved a lot by dosing and by puncturing to let out the wind. The long-horned native cattle are fairly hardy but are very slow-growing and give very little milk; the oxen (bullocks), however, are excellent for draft purposes. To improve the meat and milk yield, pedigree Hereford and Friesland bulls were imported for crossing. Other livestock were mules, donkeys, pigs, and ostriches.

The last were very profitable in those days owing to the great demand for the feathers. One of my jobs was to catch the birds when they were due to be plucked. Anything more calculated to test the nerve of a tyro could hardly be imagined. The birds were kept in a large paddock and one by one were driven by nativesall armed with long branches of thorn trees-into a corner. When the ostrich saw that it was being hemmed in it invariably tried to double back and break through the ranks. As no native had the nerve to catch one of these birds this was the moment when I had to do my stuff and show that white men are without fear. It meant acting quickly if one wanted to avoid the long tedious business of rounding up the bird again, and so I had to step aside to induce the bird to dash through the gap between me and the fence.

As the bird, with mighty strides, made its terrifying dash towards me at the speed of a train I had to leap through the air 
almost horizontally and catch it one-handed by the neck. Having successfully "fielded" the bird it was necessary to hold its neck horizontally, or with its head held as low as possible, for in that position an ostrich is unable to kick. Failure to accomplish this promptly would probably spell disembowelment, for a downward thrust with the bird's powerful claw is quite sufficient to rip one open from head to foot. The white man's prestige has always to be considered, so the indignity of disembowelment had to be avoided at all costs. Assuming that one has survived this ordeal, one has to slip a sock (carried for the purpose in one's pocket) over the bird's head. This effectively blindfolds him and renders him helpless, and in this condition he can be led, by throwing an arm over his back and holding him tightly, into a pen where the feather-plucking business takes place.

In the breeding season the ostriches were put in pairs into separate paddocks, as at that season the cocks become very aggressive to one another and are then extremely dangerous to human beings. Getting to and from our house, which was situated in one of these paddocks, was rarely without excitement. At daybreak the cock bird was invariably hanging round the house-sometimes pecking at the window while we were eating breakfast-and always ready to dash at either of us if we poked our heads out of a door. At this early hour in the invigorating morning air he was aggressive beyond words. To get out of the house I used to open the back door and heave a bucket of water over him as he was about to strike. This so infuriated him that his attention was glued momentarily on this particular door. At this moment my brother used to shoot out of another door and run like a rabbit to the fence which was twenty-five yards away-vaulting it in his stride. The ostrich usually spotted this maneuver, but was so intent at having a go at me that he was too slow in getting off the mark to make up the necessary leeway. It was then my brother's turn to entice him along the fence sufficiently far from home for me to make the dash. At such times I often used to think of the legend-undimmed by time-of the ostrich burying his head in the sand to hide from an enemy. What I would have given for this bird to hide his for a few moments!

When incubating their eggs, ostriches do twelve-hour shifts- 
the sexes changing over at dusk and dawn. The chicks are delightful things. I remember that one brood, which we used to shut up with the mother in a stable at night, used to perform the most amusing antics on being let out in the morning. The whole lotmother included-used to spend the first five or ten minutes dancing, pirouetting and doing zig-zag runs until they had got over the joy of being let out. The mother used to like crossing the river through a shallow ford to a green patch on the opposite side where she used to feed. The chicks were forced to swim, which they do quite well. When it rained miles away in the hills this narrow river had a habit of rising suddenly many feet although there had been no local rain. Through this we lost some chicks one day: the mother ostrich had swum the fast-flowing, flooded river, but the chicks, in trying to follow, were swept downstream among the reeds and drowned. Ever after, this bird was accompanied by a herd boy.

Once I was caught on the wrong side of the river when it rose in this way. I had crossed only a few hours before on horseback, when the water at the ford was not more than a foot deep, but now I was faced with a torrent of doubtful depth. As the water was still rising and I had no desire to pass the night on the veldt, I decided to risk crossing. A native, also stranded, sat on the horse behind me. About half-way across, the horse began to float and the speed of the current did the rest. We went downstream and were washed off his back. My immediate concern was for the boy's safety as he was a non-swimmer, but he had the presence of mind to grab the horse's tail, and so was towed safely to shore. In the meantime I drifted downstream rapidly, and gained the shore at my leisure, but swimming with trousers and boots on is never a joy.

It was an ideal existence for a lad-plenty of hard work, and recreation in the form of swimming, shooting, fishing, and horseback riding. The birds were wonderful-the most conspicuous being hornbills, blue rollers, bee-eaters and Glossy Starlings. The latter have iridescent plumage and look wonderful in flocks in the sunshine. The clearness of the atmosphere is one of the most surprising things to a new arrival. I remember seeing from the top of a kopje a herd of cattle on a farm twenty miles away. They 
looked like specks but were clearly discernible. In the stillness of the night we could hear the evening train leave Potgietersrust, which was twenty miles away in a direct line, with a range of hills between. It is, too, the night sounds that linger in one's memorythe distant howl of the Black-backed Jackal and the air filled with the music of frogs and crickets.

The daily train to Pretoria passed our nearest siding at 4 A.M., so that if one wished to catch it one had to make the journey before dark because of the rocky path. On the only occasion that I made this journey I rode the thirteen miles to the siding on horseback and then dozed by the track waiting for the train. My boy returned with the horses. The hard ground and the mosquitoes kept me awake, so there was time enough to have all the weird noises of the night impressed upon me. To stop the train, one had to light a newspaper and wave it wildly on the track, which caused some anxious moments, for the siding was exposed to the strong winds of the Springbok flats and failure to get the paper alight at the right moment meant waiting twenty-four hours for another train.

Being out all day on some part or other of the farm brought me in constant contact with wild life. Antelopes were not numerous but occasional duiker or steinbock could nearly always be put up if one got off the beaten track. Guinea-fowl and francolins were plentiful and were cleverly snared by the natives. Every boy carried a knobkerry and if anything like a hare or francolin got up at close range the knobkerry was thrown with surprising accuracy. Once when working in the fields we put up a hare, and all it had to do to escape was to run straight. This was the first time I saw what a bewildering effect noise can have on an otherwise fleet-footed animal. All the boys gave chase, cleverly spreading out and yelling at the tops of their voices-the nearest throwing their knobkerries at the fleeing animal. I thought they were quite mad to chase a hare, but it became more and more confused and zigzagged all over the place, so that whichever way it turned it found itself heading for the yelling natives on the flanks. To my complete surprise they clubbed it after a very short run and at the end it seemed to be too terrified to progress normally owing to the effect of the din. 
This delightful existence might have gone on indefinitely, but one morning news came through that war had been declared. Shortly afterwards I was sent to one of the company's farms north of Pietersburg where the manager had been called to the Forces as he was a reservist. My job was to collect a horse that had been running loose on the farm and ride it back to our place, where it could be looked after. With the help of a gang of natives we eventually lassoed the horse and got it saddled, so I set off on my long journey. It was a frisky half-trained stallion, and I had just over a hundred miles to go. Many times he tried to bolt when I dismounted, and this he managed once, fortunately near a farmhouse, so that I was eventually able to corner him in a small paddock. I accomplished the trip in three days. As I had done very little riding up to this point, my posterior began to feel the worse for wear, so for comfort I took the precaution to stuff my spare shirt in the seat of my trousers on the second day. Even so an otherwise interesting journey became more and more painful. On the third day the heat was tropical, and it was a couple of very weary specimens that at last reached the farm.

Having by now learned enough Shangaan to understand almost anything the natives said, I began inquiring about some of their curious customs and beliefs. Once when I was approaching a stockaded native village I came to a long sapling that had been planted in the ground near the entrance path. Dangling from the top of the pole was a wild root resembling a yam. For the life of me I could not imagine the significance of this, but my boy explained solemnly that the root had the power of keeping lightning away from the village, also snakes and burglars. Natives are often reluctant to discuss their legends and superstitions, but I could not resist asking how he supposed a root could repel reptiles and brigands. He replied that at night the magic root would make the road into the village appear as a sheet of water and so the nocturnal prowlers would turn back.

On another occasion I was out repairing a boundary fence with a native, when we disturbed a snake. It was almost certainly a harmless species, but to most natives all snakes are venomous. My boy explained that this one was very bad, and if a man were bitten by it the only cure was to go home and sleep with his sister! 
In those days the natives had not absorbed European ideas and so were simple and happy. They loved squatting round a log fire at night discussing the events of the day. Being eloquent speakers, they dramatically described the most trivial happenings, and the most amusing similes added color to the story. Frequently the narrator was interrupted by the whole company bursting into fits of laughter.

When working on the farm far from headquarters, they always gave vent to a sort of ditty or cry of joy when the signal was given for them to cease work for the day. A slightly refined version would be:

Work is now finished, we are going to our homes, We are going to get food and to make love to our women, Make love to our women.

This ditty was voiced with so much gusto that it sounded like a war cry.

The Shangaan women were garbed in loin cloths, and wore pounds of heavy wire round the wrists and ankles as bangles. It always amazed me to see them walking majestically for miles in the heat of the day carrying all this weight plus babies on their backs, and enormous pots of maize or millet on their heads. The men on the other hand carried nothing except knobkerries and spears, though you might see a civilized fellow carrying his boots on his head for comfort and to save wearing them out. They were never meant to fit, and were worn only when passing through a village to impress the simple barefoot folk. Sometimes I saw one of these aristocrats walking along with a stone on his head, which puzzled me until I found that this was the natives' way of carrying stamps.

About the time war was declared my brother was made manager of a ranch in the remote part of the Rustenburg district, and a few days after his departure I received a note from the District Commissioner instructing me to be ready with horse and rifle to do combat, as rebels were heading for our district. I expected to be called into action any minute, but fortunately they changed direction at the last moment. The rebels were soon defeated, and the 
South African Government's attention was then focused on German South-West Africa. At this time a number of Commandos were formed to fight the Germans. There was no question of volunteering as everyone was commandeered.

I was ordered to report at Naboom Spruit, where a number of young farmers assembled, and we formed a detachment of the Waterberg Commando. In this detachment I was the only Englishman in a crowd of backveldt Dutchmen, and Afrikaans was the only language spoken. We were given horses and rifles and as we could all ride and shoot we were, ipso facto, full-blown cavalrymen. We were shuffled off to Kimberley, where we took part in practice cavalry charges over the veldt.

My horse was the biggest I have ever seen and appropriately named Olifant (meaning elephant). It was always difficult to mount him neatly, as he had the habit of moving forward as soon as one put a foot in the stirrup. Owing to this and to his great height, a huge leap upward and forward was necessary to land in the saddle. To add to my difficulties, my army riding breechesthe largest in stock-were never meant for a fellow of my height (6 ft. 5 in.), so I had the greatest difficulty in bending my knees sufficiently to mount. When the time came for us to shift to the final camp near Cape Town prior to embarking for South-West Africa, it fell to my lot to assemble somehow most of the kitchen utensils on my horse. By the time I had finished, the sides and rear of the saddle were adorned with large kettles and dixies. To this was added my personal kit and blankets, and of course my rifle, bandolier full of cartridges, and filled water-bottle had to be carried. I was weighted like a knight in armor, and was a little dubious as to whether I should ever get into the saddle.

At the crucial moment I gave a terrific leap, hoping to clear the mountain of impedimenta surrounding the saddle, but alas, Olifant was more impatient than ever. He moved forward quickly the instant he felt my weight in the stirrup, and I landed on the wrong side of the pots and pans, etc. The fun was now on, for he strongly objected to my sitting on his rear end, and before I had time to slide off he burst into a canter and I slid farther and farther back. The rattling of the dixies added to his annoyance and he fairly tore through the tent lines, out of control. I hung on to the 
saddle for quite a while but he tripped over a tent rope and then shot off like the wind. My predicament was thoroughly enjoyed by the entire camp who, by this time, were in convulsions. As I finally slid off the horse's rump and turned several somersaults there was a great roar of laughter.

Our final camp was at Rondebosch, a beautiful spot at the foot of Table Mountain. My great joy was to get a pass and ride to Muisenberg, the popular resort a few miles away. Olifant loved the sea and nothing pleased him more than to walk out and face the oncoming rollers. He used to go on and on until I was washed off his back. Needless to say, I was in bathers and was riding barebacked.

Soon we were embarked for Walvis Bay, South-West Africa, with all our horses. It was a sandy desert that greeted us, and being the height of the summer season (December), the heat averaged $\operatorname{II} 2^{\circ} \mathrm{F}$. in the shade through the greater part of the day. Flies were there in millions and the water was brackish and unreliable, and I soon succumbed to ptomaine poisoning.

After lying in the full blast of the sun for hours in the sand, I was taken on a stretcher to a field dressing station. I had acute dysentery and vomiting with a high temperature, and could keep nothing down. Unknown to me a cable was sent by the military to my parents in England: Your son dangerously ill believed enteric. In incredible heat I was put on a train at Walvis Bay en route for Swakopmund Hospital. To make room for my stretcher the kit in the guards van-tin trunks, kit-bags, etc.-were piled to the roof on either side of it. After going some distance in this inferno the swaying of the train brought the whole pile of luggage down on top of me. Fortunately there was a guard around, who eventually unearthed me. I vaguely remember being asked if I was hurt-a kindly remark that might have invited a sarcastic retort in a healthy person, but I was too weak to exercise any sense of humor.

After a few days at Swakopmund I recovered sufficiently to be transferred to Wynberg Hospital, a lovely place situated at the foot of Table Mountain not far from Rondebosch. Here I spent weeks convalescing though there was nothing really wrong with me, but as my papers had gone astray no one knew what to do with me; in fact I was more or less abandoned. It was taken for granted 
that I had had enteric fever, so I feasted on a special diet of eggs, chicken and stout, etc. At this I did not complain-but I was much too energetic to stand this lazy life for long. At last I protested to the medical board that I was fit and well, and demanded to be discharged from hospital. They agreed to this but insisted that I should have three months' sick leave before rejoining the regiment. A free railway warrant to any place in the Union was granted, so I decided to go and stay with my brother on his farm up in the Rustenburg district, some twelve hundred miles to the north. My only means of getting from Rustenburg station to his farm-a distance of seventy-five miles-was by his ox-wagon which he sent to meet me. Twenty-five miles a day is good going by this means of transport, so I was three days on the road. At this stage I celebrated my nineteenth birthday and life was just beginning.

I spent three glorious months living on the fat of the land and traveling round by ox-wagon visiting remote spots of interest along the Limpopo River. Although by then the big game had disappeared from most of the Transvaal, a few herds of hartebeeste and a number of wild ostriches still existed in this inaccessible district. When my three months were up it was with mixed feelings that I made my departure. We had had a great time together and I think my brother did not relish the thought of being left on his own with only an occasional Boer farmer to chat to. On the day that I reached Rustenburg, in July, I915, to report to the local commandant, news came through that the Germans had surrendered in South-West Africa. My return to Cape Town was stopped and two days later I was given my discharge. Being under an obligation to serve my company I had no alternative but to return immediately to the farm in the Waterberg.

A few weeks later the military called for volunteers for overseas to form a regiment of heavy artillery. My brother wrote and told me that he had already volunteered, so I did likewise. We sailed for England and trained at Cooden in Sussex. Our guns were 6-inch howitzers, and our particular battery-the 7ist Siege Battery-was made up of men recruited mostly from the Transvaal. We were the first South African regiment to arrive in England in the First World War and received a great welcome.

Having passed our gunnery test at Lydd, near Dungeness, we 
embarked for France and were soon in action at Mailly-Maillet, near Albert. Soon afterwards we were engaged in the first battle of the Somme. One of those strange coincidences that may sometimes affect the whole course of events in one's life happened here. The Medical Officer posted to our brigade was a young doctor, Geoffrey M. Vevers. I never saw much of him for the simple reason that I was never sick, and as my battery was shifted shortly afterwards to do battle at Ypres, we never met again during the war. At that time he was just a young English doctor and I was merely a budding farmer from South Africa, and little did we think that our meeting in a French village was the seed of a friendship that would grow throughout the succeeding years, and that we should be closely connected in our postwar work. (From I923I948, Dr. G. M. Vevers was Superintendent of the London Zoo.)

During two and a half years in France I was granted leave to England on two occasions only, each for ten days, and once a local leave of four days. These were the only occasions during this long period that I was out of the firing line except when we were changing position to another sector... .

Exceptional conditions, whether good or bad, inevitably come to an end. When our troopship steamed into Table Bay in May, I9I9, it seemed wonderful to be alive. The first glimpse of Table Mountain, the heliographs flashing messages from shore stations, the fishing boats and sea-birds, the glorious sunshine, and many other things that had been shut out of our lives for years, suddenly came upon us. A strange feeling of wonderment came over me. It was hard to realize that it was true and that all the horrors had been left behind. A great welcome awaited us. A march to the Drill Hall was arranged, someone made a speech, and we were given a glass of ginger beer and a bun! It was all over.

Having been blown up, blown down, and gassed many times during the war, but never sufficiently mutilated to merit being shifted from the firing line, my nerves were in a poor state when I was demobilized. The outlook was interesting-no job, a small gratuity, plus a willingness to have a go at anything. 


\section{Chapter Two}

\section{SOUTH AFRICA}

CUMMER in the Cape with its "Mediterranean climate" is, at $\checkmark$ all times, very pleasant, but to me, after four years of misery in France, it seemed like heaven. The sunshine, sparkling atmosphere, lovely flowers, and mountain scenery, gave the feeling that everything had been worth while. The horrors of war were things of the past, and the world was now taking on a new aspect. I had already learned that it is easier to appreciate to the full the finer things of life if one has suffered all sorts of discomforts and misfortunes.

The pendulum had now swung, and as I sat in the warm sunshine in the Cape Town Botanical Gardens, with doves cooing softly on all sides, I felt at peace with the world. Birds have always fascinated me, as they seem such cheerful souls compared with any other form of animal life, and at the moment, as I was watching the graceful movements of a Cape Robin-chat, I longed to become more closely associated with them in some way. How, I did not know, but all sorts of hare-brained ideas that might take me into exciting uncivilized places passed through my mind. This was pleasant thinking, but the stark fact that capital, consisting of a small gratuity, was fast running out made me realize, somewhat sadly, that the commercial aspect of whatever I undertook must be uppermost and that pleasure and business would be hard to link together. My brother's views coincided with mine, and we both wondered if something could be done in the way of supplying zoos and private aviculturists with exotic birds. It was an idea we had often toyed with but we had little notion how to go about 
it-in fact, I think our sole qualification was unbounded enthusiasm.

At this stage we were perhaps fortunate in hearing of a storekeeper in the Transvaal whose hobby was collecting birds and who had amassed a large number during the war, of which he now wished to dispose. They were all in large and beautiful aviaries, and had been well cared for by a man who was obviously an expert on the subject. Being well seasoned to captivity, they were all delightfully tame, and I shall never forget my first view of so many different species of South African waxbills, bishop birds, whydahs, weavers and lovebirds, all busily feeding, bathing, displaying, preening, or making nests.

We were not long in coming to terms, and so I took the lot by train, over a thousand miles, to the Cape.

In September, I9I9, a few months after our arrival back in South Africa, I embarked on a Union Castle boat on my way back to England with the entire collection. The financial outcome of the venture was in the air, so to speak, as I had not the vaguest idea what such a collection was worth, and was not even sure where I could dispose of them. To save expense, and in the hope that all would go well, my brother remained behind to build up another collection with the help of our storekeeper friend.

My birds, all in suitable wooden traveling cages, were stowed on the boat deck-the uppermost-which was private as far as the passengers were concerned. An enormous crowd had assembled on the Cape Town docks to see us off. A band played and streamers were flowing in hundreds from the decks to the quayside. As the tugs slowly pulled the vessel away and the streamers strained and broke, there was a tremendous burst of cheering. At this moment I felt constrained to leave my birds for an instant to gaze on the animated scene below. To my embarrassment everyone seemed to be looking up at me and cheering. Surely my departure after so brief a stay could not occasion such an outburst of approval! A glance to my left showed that, standing by the rails at the end of the next lifeboat, was a solitary distinguished figure. $\mathrm{He}$ answered the crowd's cheers with repeated hand-waving and obvious emotion. As we pulled out and got under way, he turned from the land he had served so well-for he was none other than 
the returning Governor-General, Earl Buxton, who after having served the usual period of office, continued until the war ended. After the tenseness of the last few hours-the farewell speeches and good-bys to friends-he seemed surprised and relieved on turning away from the ship's side to see my birds and to gaze, by way of a change, on a different form of animal life.

The voyage was a pleasant one, and my collection arrived safely at Southampton. On leaving the ship I saw people becoming excited at the thought of getting a few pieces of baggage through the customs and on to the train. How I envied these folk with their simple problems. Here was I with hundreds of delicate birds needing every care and attention, compelled to rush hither and thither trying to settle clearance formalities, with which I was unfamiliar.

On arrival in London I rang up the livestock department of one of the big stores, and with their approval took my consignment to them pending an assessment of the value of everything and a satisfactory settlement over price. The manager-having what might be called a highly developed business instinct-tried to take advantage of my predicament by offering me a ridiculously low price, but to his annoyance and surprise I refused to bargain with him and immediately got in touch with a rival firm. They jumped at the opportunity of receiving such a collection and promptly sent a motor-van to fetch it, but the change-over was anything but easy. The manager, seeing his chance of exploiting me slipping through his fingers, became obstinate and unhelpful. We were on the third floor, and I was told that I could not make use of the service lift; so I went down and searched the streets. On a nearby corner stood a young fellow with his hands in his pockets and his mouth open. He looked like an out-of-work, so I tapped him on the shoulder and said in my best cockney, "Want to earn a few bob, cock?" When he had recovered from the shock, he followed me meekly up the stairs and in a few minutes we were struggling down three flights, each sharing a somewhat cumbersome box which had to be kept level to avoid disturbing the birds. It took numerous trips to complete the task and I was thankful to be able to sit on the running-board of the van and relax.

This second firm treated me generously, and in a few days 
everything was settled and I handed over the entire collection. Buyers flocked to the place to restock their war-depleted aviaries, so the birds were soon comfortably settled. The whole venture, if somewhat trying at times, had been a great success. I cabled the news to my brother and he, too, left with a consignment while I loafed in England. His collection was disposed of to the same firm, but as he decided to get married I made the voyage back to Africa alone and continued on my own account.

This time I went to the Rustenburg district of the Transvaal and stayed on a farm doing most of my own trapping. I think I must have had a natural aptitude for keeping birds in captivity, for quite early in my career I found myself looking after a number of things usually regarded as difficult or impossible to keep.

I stayed with the storekeeper, of German origin, who had supplied me with the birds for my first consignment. In his possession was a Gray Parrot whose powers of mimicry I have never known in any other bird. His best effort, when his cage was outside, was to throw out seed from his food-pot and cluck in the manner of a cock calling hens to some dainty morsel he has found. When the hens arrived he invariably went through the courtship display of a cock, spreading one wing and pirouetting in a half-circle, then giving vent to a lusty crow.

Another amusing trick he had, when the storekeeper's baby was nearby in its cot, was to mutter sweet lullabies in German, in the mother's voice, until the baby went fast asleep. Then, as if possessing a distorted sense of humor, he would let out a prolonged ear-splitting screech which was quite alarming in its intensity. This not only woke the baby but caused it to cry aloud, which always set dear Polly off into a fit of laughter lasting until mother came and quieted the two of them.

I had an introduction to many families of birds, different species of which I was to meet in later years in other African territories. In setting out to trap these for the first time I learned a tremendous lot about their habits and their requirements in captivity. My collection comprised a number of beautiful insectivorous birds, and their arrival in England in tip-top condition put me on the map in the avicultural world, especially as they came so soon after the war when few exotic birds were available. 
The most striking of these were some Burchell's Crimsonbreasted Bush-shrikes, the colors of whose under parts is quite startling, though the back is black with a white wing-bar. They were nowhere plentiful and were found always in pairs. Like most of the shrike family, they lived within strict territorial limits, which meant that as far as their own species was concerned this area was strictly private, and woe betide any interloper! The type of country they frequented was grassland interspersed with clumps of bushes. These birds like the seclusion of such places and prefer not to come out into the open except to fly from one clump to another. Their flight being weak, they prefer to live where a distance of fifty yards or so is sufficient to find them in another safe retreat.

Catching them was fairly simple. Having found a clump of bushes harboring a pair of these birds, I drove them out, watching where they went. I then crawled into the middle of the clump, scraped a clear patch on the ground, and cleared away some vegetation so that this could be easily seen. A spring net-trap was then set on the patch and a couple of struggling meal-worms pinned to the cork which acted as the trigger. A few dried leaves were sufficient to conceal everything except the worms. Then all I had to do was to go to the next clump of bushes, drive the birds back, quietly approach the clump, and lie down and listen. When I heard a dull thump I knew the net-trap had been sprung, and could crawl in to release the bird. To catch the mate the operation was repeated, though everything did not always work to plan.

Other shrikes in my collection were the Bakbakiri Bush-shrike, the Greater Puff-back Shrike and the Long-tailed Shrike.

There were some fine representatives of the thrush family, especially the White-throated Robin-chats, whose plumage of gray, orange-red, black and white was most striking. The rest included the Cape Robin, the Mountain Chat, the Groundscraper Thrush, the Olivaceous Thrush and the Short-toed Rockthrush.

The largest birds were some Crowned Lapwings, a few of which subsequently bred in the London Zoo, making their nest in the snow at Christmastime in an outside aviary within a foot of the passing public! At the other extreme were a number of the tiny Red-vented Tit-babblers, and three species of sunbirds. 
For sheer beauty, various members of the sunbird family probably eclipse most of the other brilliantly colored birds which are such a feature of the tropics.

There are many kinds in Africa, and in the majority the males have wonderful iridescent plumage that glitters and changes color every time a different angle of view is presented by the bird's movements. They suck nectar from flowers with their long doublebarbed tongues, and this diet is supplemented with small flying insects and spiders. They seem to have some extraordinary ability to locate flowers-especially those tubular kinds which contain a good supply of nectar-even when these are in the most out-of-theway places and in concealed situations. This is of the same order as the vulture's power of locating a carcass, even when hidden under a tree.

In captivity sunbirds can be kept on a sweet liquid food, which is given in a small glass container with a drip-feed spout, so that the liquid is extracted only by suction. This prevents it from becoming fouled, and the birds from getting the sticky fluid on their plumage. There is no recognized standard recipe for making up this liquid food but I have found the following very satisfactory:

To half a pint of water add 3 teaspoonfuls of Mellin's Food

$\begin{array}{lll}2 & \quad & \text { glucose } \\ \text { I } & \text { honey } \\ \text { sweetened condensed } & \text { milk }\end{array}$

About this time I had mastered the use of flue nets, which are indispensable for trapping birds without possible injury. They are of different sizes, and are hung in gaps in foliage either near the ground or even in treetops; when viewed against a suitable background, they are almost invisible. The making of these nets by hand is an art which few people can master. Fine but strong black cotton is necessary-black being the only color that is inconspicuous-and the net itself must be free from knots with projecting 

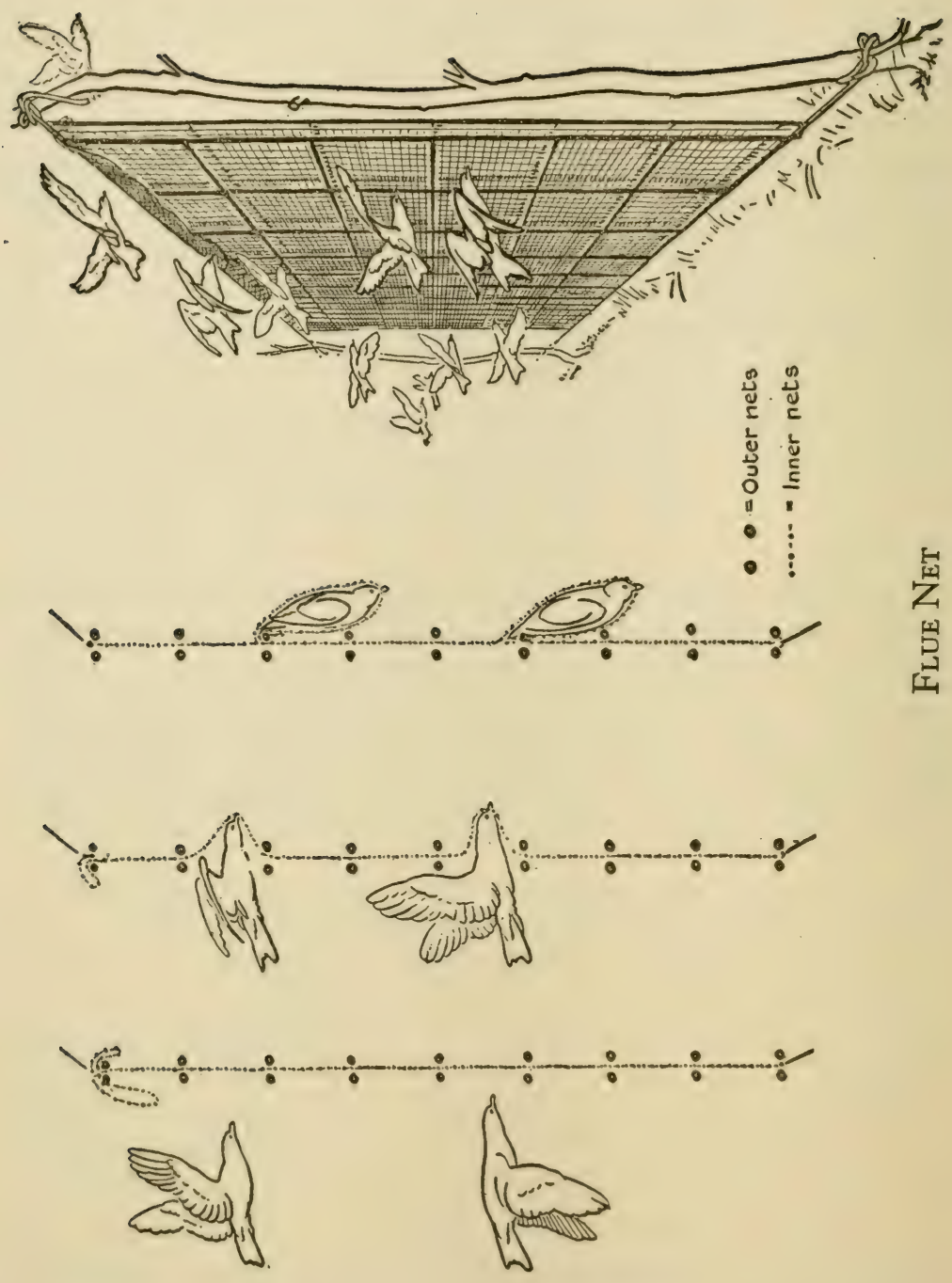
ends, as these stop it from running freely. Mine were made for me by an old fellow in England who was a master of the art. Alas, he is now no more, and satisfactory nets are extremely difficult to get; the machine-made article is useless for small birds. The average-size net will catch the smallest bird up to the size of a dove, and in nets with larger pockets even waterfowl can be captured. As I shall be mentioning these nets from time to time, it may be of interest to explain how they work.

A flue net is actually three nets in one, there being a center net of small $(3 / 4$-inch) mesh which is sandwiched between two nets with large mesh (about 6-inch). All these are joined together at their four corners, and the large squares or meshes of the outer nets coincide. The center net is eighteen inches larger each way than the others, making it slack when the others are tight. From each corner there is a cord with which to fix the net between branches. The corner strings are drawn very tight, thus making the two outer nets taut, while the inner net, through its greater size, remains slack. The overlapping portion, called the bagging, is pulled upwards until the center net is tight, and then this bagging is folded and rested on the top strands of the other nets. On whichever side the bird hits the net, when flying through a gap, it will pass through the larger mesh of the outer net, and the force of the impact will drive the fine-meshed inner net through the corresponding large mesh opposite. In doing this the slack, or bagging, that was resting lightly on the top, is pulled down and used up in forming a pocket. The outer nets, being very tight, do not give with the impact, and so the inner one is forced through until it is more or less the shape of a heron's beak, with the bird inside at the apex. Instantly the bird's own weight causes the pocket to fall, and in doing so overlaps the strand of the outer net forming the bottom of the pocket. Thus, force of gravity keeps it imprisoned, and any struggling only complicates matters, for it then gets hopelessly entangled in the net. The bird, however, cannot do itself any injury. 
Chapter Three

\section{MOZAMBIQUE TERRITORY, PORTUGUESE EAST AFRICA (I)}

$\mathrm{O}$

$\mathrm{N}$ my return to England after this expedition to the Transvaal, my father died while in the act of bowling a cricket ball. His sudden death while apparently in good health was a great blow to us, but as he was such a lover of cricket, I am sure he would have chosen this way to go. This meant a complete change of plans for me as I had to stay with my mother to fix up her affairs. We moved first to Herne Bay-where I shocked a good many of the local inhabitants by going out fishing in the roughest winter weather in a light canvas boat-then to Newington, near Sittingbourne, where we rented a lovely house in its own grounds. As my brother came to stay there too, I suppose it was only natural that we should rack our brains to do something to make ourselves independent. In those days there were private bus owners; in fact anyone could start up anywhere provided he passed the efficiency test and the authorities were satisfied that the bus, or buses, would not fall to pieces. The idea appealed to us, so in answer to an advertisement we proceeded to London to inspect a second-hand single-decker bus. About the only thing in its favor was its cheapness. It was left to me to drive it home; and to perform this (to me) hair-raising feat, after only a few driving lessons, we left Town at 2 A.M. to avoid the traffic. Although empty, the old bus jibbed at all the steep hills, but she eventually arrived home hot and tired with steam belching from her "innards.". 
After tinkering with the old girl and applying a bit of make-up, I took her to Gillingham, where she had to submit to a sort of medical examination-inside and out. It was all very embarrassing considering her ripe old age, but by some oversight she was declared fit, and that was all that mattered. It was my turn next to show the authorities that I was not subject to fits; also, I was asked to read something in letters the size of a house, to prove to them conclusively that I was not totally blind. The successful conclusion of these formalities enabled us to obtain a license to transport people and their shopping-bags from Sittingbourne to Chatham.

The day we hit the trail was, I think, a red-letter day in local history. Staff problems were easily solved, as I was the driver and my brother handled the money.

On Saturdays we were crowded out with country folk going to Sittingbourne and Chatham to do the week's shopping, and as there was no separate cabin for the driver, I heard much of the good-natured banter as the old vehicle swayed and backfired. Many of our patrons came, I fear, out of curiosity or pity rather than from expediency.

Unfortunately for us, the large bus companies looked upon small owners as pirates and were even warring on one another to get the monopoly. The ascendant company put on two small fast buses with no time schedule, one to keep in front of us and another behind, so that when the first stopped to pick up passengers, the other took the lead. Under these conditions the business was, of course, unprofitable and we were compelled to give up after three weeks.

For quite a time after this the bus was used for family outings and private shopping expeditions, which caused some amusement among the locals.

After a few more equally unsuccessful ventures, my enthusiasm for starting anything in England faded out. Africa called me back, so without more ado I packed my bags and set out to do some more collecting.

I had long thought how interesting it would be to go beyond the confines of the Union of South Africa into Portuguese East 
Africa, though I had heard many reports on the unhealthiness of the country.

With the collector's urge to get something new and exciting, I boarded the train at Cape Town en route for Beira. This took me through Bechuanaland and Rhodesia over a route more than 2,000 miles long, at that time a five-day journey. I was scanning the scenery for bird-life nearly the whole of the way and toward the end was getting very weary, so the final descent from the pleasant atmosphere of the Rhodesian plateau to the oppressive heat of the Beira littoral was all that was needed to put the cap on a tiring journey.

We eventually reached the limit of British territory at Umtali, which is the eastern gateway to Rhodesia. It is a delightful spot situated in picturesque mountainous country. After leaving this we descended to Manicaland through typical savanna country and then through the magnificent Amatongas forest, which shows some fine examples of the African mahogany tree.

Beira in those days had no docks and was rather a dirty town with sandy streets. The only means of conveyance was by trolleys on a Deceauville railway which ran along every street. These trolleys were all privately owned, and every householder had two boys who were detailed to do the pushing at a jog-trot whenever one had to make an excursion. There was only one good hotel, which I could not afford, and so I was reduced to another which accommodated a very mixed clientele.

On making inquiries, I learned that Vila Pery was a good spot for birds and had the advantage, from my point of view, of having some English farmers in the district. The town is on the Umtali-Beira railway about one hundred and twenty-five miles inland, and fortunately the station-master there owned a farm twenty-five miles from the railway and close to the Revue River.

This seemed an ideal out-of-the-way spot for collecting, so I got in touch with him, and was told that I could stay out there with his manager as long as I wished. This meant retracing my steps towards the Rhodesian border and I reached Vila Pery rather late at night. I was saved the trouble of asking which hotel it was impossible to live in so that I could choose the other, as there 
was only one in the place. My knowledge of Portuguese was poor at that time, but at least I understood that the only room available had three beds in it. I cannot say I enjoy sharing a room with complete strangers, but as there was no alternative, I accepted. I was delighted to find I was the sole occupant of the room, so turned in for what I thought would be a peaceful night, lulled to sleep by the community singing of the local bullfrogs.

About midnight the storm broke as two Portuguese burst into the room. They were both obviously very drunk. One sat on his bed playfully trying to find his own feet, hoping apparently to catch up with them in order to remove his boots, but his efforts were in vain and he finally sank into oblivion. There was nothing like this about the other fellow-in him a thousand devils were having a whale of a time. He bellowed at the top of his voice, brandishing a large knife; sweat poured off his face while he shouted heavenwards, evidently in a frenzy of religious mania. By his mad and excitable behavior I was convinced that either suicide or murder was in the air, and needless to say the former would have come as a great relief. My anxiety caused considerable heartthrobbing under the sheets, and to avoid trouble I pretended I was asleep, with my head almost covered up but with one eye watching his movements so that I could land out and kick him in the stomach if the worst came to the worst. Fortunately his fanatical display of knife-brandishing suddenly came to an end. The rum had had its fling and now let him down with a flop; no longer was he slashing at the heavens with his machete but lay on the floor as if anesthetized.

At the first sign of dawn I needed no prompting to rise, and while my companions were still comatose I packed my bags and went. The fruits of civilization, in this part of the world at any rate, seemed to me a trifle over-ripe and unpalatable, and so I welcomed the impending change even if it should mean living under primitive conditions.

As arranged, my host for the next few months was at the station early in the morning, having traveled overnight in a wagon drawn by eight oxen. I was anxious to meet him and see what sort of fellow he was, as we had to suffer each other's company for some months and from that there would be little escape. 
He turned out to be an elderly man, rather rough and obviously tough-typical of the Dutch farm managers I had met in the Transvaal. Actually he had been a Cape farmer and was half English, half Boer; for the purpose of this book I shall call him Krantz. I soon found that there were a number of characters of British origin farming in this district-the Chimoio district-all previously from South Africa, and owing to the fertile nature of the soil and freedom from droughts, they were producing far more maize than the average in Rhodesia or South Africa. Most of them had black wives and half-caste children, but fortunately Krantz was not one of these.

As we moved slowly along the dusty road-the oxen averaging less than three miles an hour-I heard something of his past life, which he related in his quiet way. Some of the more interesting episodes he never mentioned, but I found them out later from one of his closest friends.

He was farming peacefully in the Cape when he was caught up, like so many others, in the gold rush to the Transvaal. This was in the early days of the Rand, and he set off on horseback from Kimberley with a friend, before the railway was built to the Transvaal, to seek a quick fortune. His friend concentrated on the area now known as Johannesburg and eventually became a millionaire, but poor Krantz favored the more speculative diggings in the Barberton district and lost most of his money. He went back to farming, married a young Dutch girl, and all went well until she started playing him up. He found that on one occasion, when he was away on business, she had even sold some of his cattle and pocketed the money. This so upset poor Krantz that he just walked out of the house, leaving her and his belongings for good. For weeks he wandered looking for work, and eventually found his way into Portuguese East Africa, where he found employment on the Busi sugar estates near Beira. Now here he was as manager of a farm, leading a very primitive bachelor existence, apparently perfectly sober, hard-working and efficient. The first of these virtues I found was spasmodic, depending entirely upon cash in hand, and the period since his last lapse from grace.

We duly arrived at the house, a two-roomed affair with no 
furniture except for two beds made on the spot from rough poles across which sacking was nailed, one rickety old table, and two chairs. Fowls swarmed outside, but as there was no shade they spent most of their time on the veranda; two very matey birds insisted on laying their eggs under my bed on the concrete floor. The breed had to be seen to be believed-their necks were naturally bare, and their feathers were mostly turned up the wrong way. Any temporary absence from the kitchen-a rondavel about twenty yards from the house-on the part of the cook was the signal for a mass attack by the monstrous hens, who perched on any uncovered pots, devouring the contents and leaving their droppings all over the kitchen table.

I found out afterwards that the neighboring farmers were greatly amused at the thought of me, a young Englishman, sharing the conditions under which old Krantz lived, and they wondered how long I would stick it. Their fears were soon justified, for I contracted a very bad attack of diarrhea which remained with me for more than a fortnight. However, such trifles did not dull my enthusiasm. The local bird-life was interesting, and I noted the haunts of many rare species I hoped to collect. During mealtimes I learned much from Krantz of the local native customs and the activities of the witch-doctors. Many of their more inhuman customs had vanished in face of European law and influence, but still existed in the more remote parts. Disease is not well understood by primitive peoples, and here death was usually attributed to some sort of spell cast on the victim by an enemy. It was customary in such cases for the relatives to consult a witch-doctor to find the culprit. These all-powerful creatures were not concerned with doing any detective work or hearing the evidence of various witnesses; their method was much more simple and direct. Any suspect was compelled to drink a powerful poison, made up from a certain powdered bark, in front of the local assemblage. If he managed to vomit this deadly concoction he was declared innocent; if not, his guilt was assured and he quickly died an agonizing death.

Another revolting habit was the putting to death of twins by burying them alive in hot ashes, because they were supposed to be harbingers of misfortune. 
I had soon rigged up an outhouse as a bird-room and a carpenter's shop for making my traveling boxes. One of my first captures was a Heuglin's Robin-chat, a sprightly bird of the chat tribe that lives in thickets.

It has been so often repeated that Africa has no songbirds that I cannot do better than quote a description by R. E. Moreau-an authority on East African birds-of this bird's song:

“. . . in its power to stir the listener this robin-chat is not second even to the nightingale. Not only does the crescendo of the song rouse the listener's expectancy to the highest pitch, but most of the bird's notes down to the smallest and lightest are charged with passion."

Another species of the same genus, the Natal Robin-chat (Cossypha natalensis), was also here, but in different situations, and I was not long in capturing a specimen. This bird is of striking appearance with its orange head, blue-gray upper parts, and orange-red under parts, and though it lacks the song of some of the other robin-chats, it has a variety of pleasing call-notes and a soft whistle. This one became particularly tame, and when I gave him his breakfast he always cocked his head on one side, inspected it, and then poured out his whistling notes for fully a minute before attempting to satisfy his hunger. This was a daily performance, and one morning I called Krantz to witness this wild-caught bird refusing to eat even the most tempting tit-bit until he had sung his little song of thanks. Krantz, although fallen so low in his standards of living, came of good stock, and being basically a gentleman was most sentimental over things which touched his finer instincts. He was incredulous when I brought him to the door of my bird-room, thinking perhaps that I was pulling his leg, but after I had fed the robin-chat and we had remained silent for a few moments, the sweetest call-notes rang out and continued even longer than usual. When this was over, I turned to Krantz for his approval, but the old man was overcome with emotion and was wiping the tears from his eyes.

In his later life things were but few

That touched his finer senses,

But now his very soul was roused

By Cossypha natalensis. 
Robin-chats are not difficult to catch once their haunts are known. This one was caught in a spring-net trap baited with meal-worms. The trap is merely a wire frame jointed in the middle, and across which some fine-mesh string-netting is fixed; it is pegged to the ground and concealed with leaves and grass. A cork acts as a plate, and to this same meal-worms are pinned by their tails. They struggle constantly to get free and are soon detected by a bird, if the trap is set in the right place. A tug on the worm sets off the trigger and over flies the net.

It is strange that birds regard meal-worms as a small boy regards a cream bun, although they may never have seen them before; in fact, they seem to know by instinct that they are something delicious. Meal-worms are bred commercially on the Continent, from where they are sent all over the world to zoos and vendors of bird-foods who cater for private requirements.

The term "worm" is unfortunate, for they are in fact the larval stage of the meal-beetle and, having smooth leathery skins, are not at all objectionable to handle. If kept in a warm place and supplied with plenty of bran to eat, they quickly change from worms to grubs (pupae) and then to beetles. These breed and lay eggs which change into worms, and so the cycle goes on. A metal box with a perforated lid and a plentiful supply of meal-worms is an essential part of the collector's kit when he sets off for some tropical country in search of new specimens. They are not only convenient bait for traps, but are essential as food for newly caught birds while they are becoming accustomed to the artificial food on which they must eventually subsist.

This food consists generally of dried flies, ants' eggs (pupae), and sweet biscuit meal, mixed together with melted fat and honey. This will keep almost indefinitely, and to the daily quantity required some finely chopped hard-boiled egg can be added. When dried flies and ants' eggs are not available, shrimp- or meatmeal is a good substitute. Although most insectivorous birds come to like this artificial food, it is essential to give them a few live meal-worms daily, not only to keep them fit, but also to make them tame, for they are then always watching their owner to see if he is bringing a worm, which, when offered, is readily taken from the fingers. 
The place abounded in predatory animals-all of nocturnal habits. These included lions, leopards, genets, servals and civetcats, but the leopards were the most numerous and the most troublesome.

The fowls all roosted in a small tree by the cook-house, and one night as we were about to retire we heard an ear-splitting squawk from one of them, but no further sound. It was obvious that one had been taken, and our guess was a leopard. We dashed out with hurricane lamps and guns but heard nothing and saw nothing. There were no tell-tale feathers and no spoor. Soon after we retired to bed we were roused by another squawk, so out we dashed again and were as mystified as before. We then hung a lamp on the tree and there was no further trouble. In the morning two hens were missing and we inspected the tree minutely for claw-marks and the ground for spoor, but without the slightest clue. It then became obvious that the fowls must have been carried off by air, and I knew that the only nocturnal creature capable of this feat was the Giant or Milky Eagle-owl; the fact that it returned so quickly for a second fowl suggested that there was a family to be fed somewhere near at hand. Krantz summoned his head boy and instructed him to send boys into the surrounding bush to look for such a nest.

It was on the second day that a boy came in and told us he had found an owl's nest in a tall tree, and that there were two young birds. They were indeed Giant Eagle-owlets, and the parents, as we expected, turned out to be the culprits, for we found chicken feathers round about. For me it was a most happy ending as the owlets were added to my collection, and delightful creatures they were.

The adult Giant Eagle-owl is most imposing and is the largest of the African nocturnal birds-of-prey. It will carry off anything from newly-born antelopes, guinea-fowl, and even fish, down to insects such as locusts and beetles. In spite of its ferocity in the wild state when hungry, even an adult-caught specimen becomes the most docile creature imaginable in confinement, allowing itself to be nursed and fondled like a baby. It is quickly able to distinguish strangers from those who normally care for it, and 
often remonstrates by snapping its mandibles and puffing itself up in a threatening attitude if an unfamiliar face appears. This is, of course, a form of bluff, as it will never attack.

By now the collection was growing rapidly, and although one day was much the same as the next, there always seemed to be something happening which townspeople would probably call exciting. Perhaps even the most hardened bushman would have been perturbed if he had shared the experiences of two of Krantz's pickaninnies. In the vicinity there were many kopjes covered with thick bush, which were the haunts of numerous baboons, monkeys, wild pigs, bushbuck, and leopards. The baboons were a real curse, as they used to descend at daybreak before anyone was around and raid the maize fields. The amount of damage a troop can do in a single raid is unbelievable, as they march through tearing down cob after cob, nibbling one occasionally and then throwing it away in favor of another. At a rough estimate they probably damage twenty times the amount they actually eat. To stop this nonsense, Krantz induced two pickaninnies to spend the night in a small grass shelter bordering the maize fields in order to keep off the early morning marauders. These shelters had been erected to shade boys stationed there to scare monkeys by day, and merely consisted of two thatched sides like a roof planted on the ground, open at both ends and just sufficiently long for a person to lie down with his head at one opening and his feet at the other. On the night in question, which was at the time of the full moon, the youngsters were huddled up together when one awoke and saw a huge form sniffing at his feet. In true native fashion he had the presence of mind to keep still, and the creature, evidently not hungry, moved on. I was present when the two arrived at our door and related excitedly how a lion had sniffed at their feet and passed on. The grown-up natives thought this a highly amusing episode and shrieked with delight, but the pickaninnies had other views and refused to do any more night-work. They had our sympathy after we had inspected the place and seen for ourselves, by the spoor, that they had not merely been having bad dreams.

My only night out was of a different sort and had a curious 
ending. Krantz had one of his cattle taken by a lion, so he constructed a hide in a tree overlooking the carcass. There we sat, on a bright moonlit night, not daring to speak and enduring à mass attack of mosquitoes. It seemed hours before anything happened, and our patience was nearly exhausted when a dark form appeared from out of the shadows. It walked slowly to the carcass in a suspicious sort of way, and just as I was pondering as to whether it really was the lion returning to his kill or merely a hyena, Krantz fired. It is very difficult to distinguish things by moonlight, especially when there are numerous shadows, so we were both a trifle dubious as we descended the tree to inspect the dead animal. Krantz's doubts were changed to annoyance mingled with anger when he saw what he had shot. It was a large ridge-back dog-a species commonly used for hunting-that had strayed some miles from a neighbor's farm. The owner, on hearing of the incident, cursed the luckless Krantz in no uncertain fashion, and he suffered a lot of leg-pulling after that.

Sometimes Krantz used to accompany me on my bird-hunting expeditions, and this had one great advantage, for no matter where we were, on the mountains, a kopje, or in thick bush, his houseboy rarely failed to track us down, bringing a large jug of "bush" tea. Ploughing through dense bush, up hill and down dale in the sweltering heat of Mozambique, produced a thirst unknown to those who dwell in temperate zones, so the boy's arrival was always one of thankfulness and surprise to me.

One day after a particularly strenuous time Krantz and I sat on a rock mopping the sweat from our brows. We were surrounded by fairly thick bush, and it was impossible to see more than a few yards. We had only just finished saying what we could do to a cup of tea when, to our amazement, his boy-true to form -burst through the bushes close by, carrying the usual quart jug of tea. He was certainly an intelligent fellow, and according to Krantz he used to start off by asking farm boys the general direction in which we had gone, then he resorted to tracking and finally, of course, he was guided by sound.

Bush tea (or Rooibosch tea, as it is called in South Africa) makes a most refreshing drink and has certain tonic properties. It 
is made from the spiny-pointed leaves of a shrub (Aspalathus) which grows in the Western Province of South Africa, from where Krantz used to import it by the sack. In those days it cost about 3 d. a pound.

It was here that I first came in contact with the all-powerful and much-feared witch-doctors. Krantz had already told me quite a lot about their strange activities as he got much information, usually barred to visiting Europeans, through his personal servants. He believed in their occult powers and related to me how a certain European settler in the district once lost one of his cattle. It had been missing for a fortnight when he decided to consult a witchdoctor about it. This gentleman, probably having made exhaustive inquiries from natives far and wide as to where the cow really was, duly "threw the bones." Witch-doctors usually carry an assortment of tiny bones - they may be from birds, reptiles or small mammals - and various teeth and small shells. When telling fortunes they squat on the floor and cast these oddments onto a tiny mat while they jabber incessantly. The performance is repeated a number of times and final judgment is based on positions of the various pieces, all of which have some significance. The witchdoctor in question told the farmer where his cow was-right over some hills about ten miles away-and on a search being made, sure enough the cow was found.

As Krantz also lost a cow while I was staying with him, he decided it was worth while spending a few shillings with the local witch-doctor, especially as I was keen on seeing one of these gentry in action. The man himself was quite a fearsome object, and his performance was no less impressive. He told Krantz that his cow was still alive and was in such and such a place some miles to the north. The next day the cow was discovered, dead, quite near home and to the south. It had been dead for days. This rather shook Krantz's implicit faith in witch-doctors.

There is an extraordinary belief which is not confined to any one district of Portuguese East Africa, but is current among widely separated tribes speaking different languages. The story concerns the civet-cat and is based on circumstantial evidence. Many Euro- 
peans told me about it and firmly believed it themselves, partly through natives' stories, but in some cases through their own observations.

The story goes that, for the sake of convenience, the civet-cat withholds its excrement for long periods by means of a wad of coarse twisted grass which it inserts into the rectum. This wad remains in position until the civet decides to evacuate and it is then removed, allowing the accumulated waste to pass. The wad is left behind and a new one used for the next occasion. In fact quantities of civet-cats' excrement are to be found in certain spots, and are always accompanied by a wad or wads of grass-the explanation being that civet-cats prefer to perform these duties where they, or members of their kind, have done so before, and that they devour, as roughage, quantities of coarse dried grass which passes through the intestinal tract without being masticated. The grass is remarkably free from excrement, which fact contributes to the fallacy of the manufactured "wad."

Such stories are so deeply rooted in the minds of natives that no explanation will shake their belief in them. This is hardly surprising when one considers our own stupid legend about the ostrich burying its head in the sand.

Around any native village of the Manica tribe the newcomer will be struck by something looking like a large log laid horizontally in the higher branches of any big tree. These are native-made beehives, or bee-traps, which are designed to attract the queen bee in her nuptial flight, so that the colony will take up residence and produce honey for the owner. Judging from the number I saw occupied, the swarming bees must regard these objects as ideal for home-making. Certainly they are plentiful enough, and I should say much more convenient than the average hole in a tree or crevice in a rock. The making of these hives is simple. A fairsized tree, of a kind from which the bark can be easily removed, is chosen, and two circular cuts are made right round the tree, one somewhere near the ground and the other about four feet above it. A vertical incision is then made to join the two cuts, which enables the bark to be removed in one piece. This is then fixed in its original cylindrical form, and the two ends stopped with a circular mat of plaited grass, a small hole being left in the center of 
each. The hive is now ready for setting, and as all natives are passionately fond of honey, great is their excitement when a swarm is seen or heard in the vicinity. When the time comes for taking the honey the bees are partly stupefied by smoke; stings are inevitable, but little notice is taken of these comparative trifles

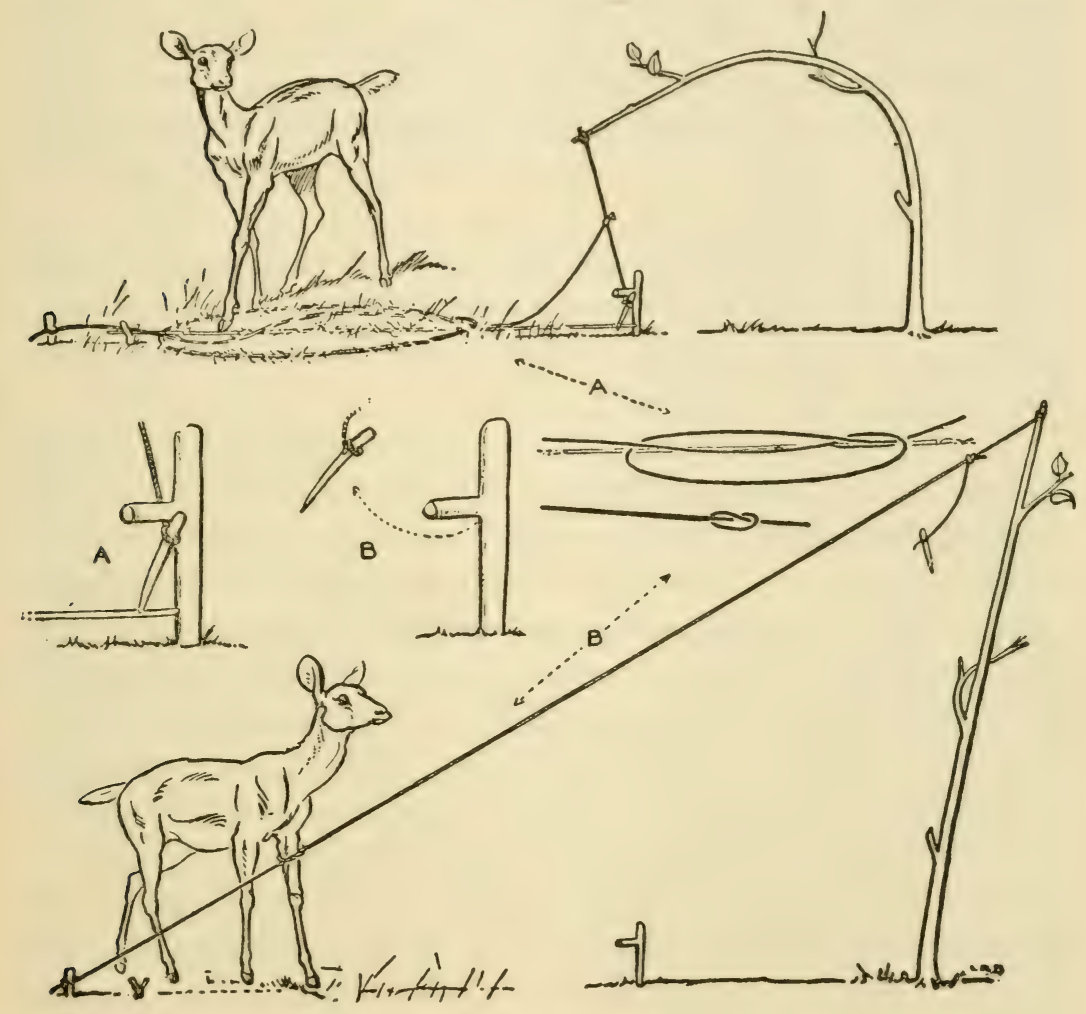

Snare for Trapping Antelopes

when a feast is in store. Everything is eaten and relished, no matter whether the comb contains honey or young bees.

Throughout much of Portuguese East Africa it is a common sight to see traps, consisting of a sapling and cord, set on animal tracks or footpaths where antelopes occur.

The place chosen for the purpose is usually between bushes or other natural obstacles which prevent the animal from avoiding the trap. To one side of the path a strong springy sapling, ten to 
twelve feet long, is planted firmly in the ground and to the top of it the rope is fixed. At the loose end of the rope a running noose, or snare, is made, and the length of the rope has to be adjusted so that when the sapling is bent right over, the noose can be opened out and spread on the ground across the track. At the same time, it must be so arranged that when the sapling springs upright, the taut snare is several feet above the ground. To set this, and to retain it in position a piece of stick, about two inches long, is attached at its middle to the cord near the running end of the noose and this stick is inserted under a hooked peg in the ground. (See drawing.)

This, in turn, is prevented from springing off by a thin stick which is placed across the path a few inches above the ground, and which engages the loose end of the small stick that has been placed under the hooked peg.

The slightest touch by an animal on this cross-stick releases the trigger, and the sapling flies upwards, pulling the noose tight and catching the animal by the leg. The rope slants upwards at such a high angle, and the tension is so great, that the noose grips tightly high up the leg, thus preventing any chance of escape. The sapling is strong and pliable, so that even a large animal cannot break away, and the possibility of injury is minimized by the fact that any sudden rush on the part of the animal is brought to a gradual end instead of with a violent jerk, owing to the springlike action of the sapling as it bends under pressure.

Sometimes a small hole is made in the animal track just below the cross-stick, which in this case is almost level with the surrounding earth, and then a number of small sticks are thrown over this so that if an animal treads near the cross-stick without actually touching it, the pressure on the others will set it off.

Very few of the Mozambique natives were of any use to me in catching birds, as they are only used to snaring things for the pot and therefore are quite indifferent about injury to any living creature; but I found one exception. He was a lad who seemed to specialize in the capture of Button Quail with a cage trap made of split cane. Button Quails, known also as hemipodes, reverse the general rule in birds that the male is the more prettily marked. In this family not only is the mother more handsome, but she is 
the larger, and feels that her duty towards the perpetuation of the species has ended when she has laid her eggs. So poor father, with his drab looks and strong paternal instinct, incubates the eggs and tends the young, while mother clears off and seeks another mate. To bring about this unusual state of affairs nature conveniently arranges the sexes so that the males predominate. On quitting the misguided fellow who has obligingly condescended to sit on her eggs, the lady of leisure sets up a booming call-note-a special clarion call to any unattached males-to advertise the fact that she is ready and willing.

Although superficially resembling common quails in appearance, Button Quails can be distinguished at once by their toes, which number only three-the hind toe being absent. Anatomically they are more closely related to pigeons, and there is also something about their habits that reminds one of certain grounddoves. In the wild state they love running along native footpaths bordered by long overhanging grass, for here they can keep under cover and find with ease the seeds, supplemented with insects, which form their staple diet.

In a few days my specimens became so tame that I could handle them like day-old chicks. Every day I dug up a portion of a termites' nest and put it on the floor of my bird-room, and then liberated the quails. This was their daily treat, and mine, for it was grand to watch them running around excitedly mopping up termites as fast as they emerged from the interior of their broken honeycombed nest, and dashing fearlessly between my legs and over my boots in chase of the few odd termites which managed to crawl some distance while their fellows were being gobbled up.

While digging up these termites' nests I often came across patches of whitish cellular spawn (Mycelium) cultivated by the termites themselves, and used by them as special food. At a certain time of the year this spawn produces mushrooms. They reach the surface often from a depth of two or three feet, and on several occasions after the first rains Krantz brought in a number of long-stemmed specimens which were excellent eating.

One evening Krantz became very ill, so I cycled ten miles to a neighbor to get some brandy (a form of medicine that would not keep in Krantz's house). Long before I got back night had fallen, 
and I was anything but happy cycling through dense jungle without a light or a gun. I kept thinking that my silent mode of progression would land me on top of some carnivorous beast before it was aware of my presence, and so attack me in selfdefense. Several times I disturbed something, probably bushbuck, which crashed away into the jungle, and each time a shudder went up my spine. Krantz had one of his cattle killed by a lion quite close to the house only the night before, so perhaps it was the thought of this that gave me a slight attack of the jitters. When I eventually arrived home I was greatly relieved, but not more so than Krantz. At the sight of the bottle he brightened up as if touched by a magic wand, and after a few liberal drafts of the heavenly nectar, he beamed once more and by morning the cure was complete. The neighbor in question had informed me that this would be so, and was rather amused at the idea of my cycling all that distance merely to raise Krantz out of his state of depression.

Some weeks later he had to go to Vila Pery on business, and this again put him in a wonderful humor. He set off by ox-wagon and was supposed to be back three or four days later, but evidently the temptations of civilization proved too much for him, for days went by with still no word of Krantz. From the beginning I had to take over the management of the farm myself, and besides all the livestock to look after, there were about twenty natives who had to be allotted their daily tasks and issued their rations of maize meal. At the end of three weeks he returned quite happy and unrepenting.

Two days later I said a sad good-by to Krantz as I was due to catch the boat at Beira for England. I had spent three months with him and had amassed a really fine collection of birds, consisting of Cinnamon Rollers, Purple-crested Touracos, Robinchats, Water Thick-knees, Gray-headed Bush-shrikes and Peters' Spotted Waxbills - to mention a few of the rarer species. Krantz was one of those rough diamonds with a lovable character, and although he had certain weaknesses, his heart was of gold. I had sometimes mentioned my mother to him, and as I left he handed me, with obvious emotion, a huge native-made earthenware pot full of delicious wild honey, remarking, "Please give this to your 
mother as a little gift from me." A few weeks after my arrival in England a letter from a friend announced poor Krantz's death. This was one of my saddest days.

Many well-intentioned people, whose prejudices are often based on ignorance, have suggested or told me outright that the capture of live birds is cruel and should be stopped. It is difficult to answer this charge in a few words, but I think I should explain my point of view and aims before proceeding with the story.

The science of keeping and breeding birds in captivity is, as most people know, called aviculture. It is firmly established throughout the world and is of ancient origin. Most people have benefited from it in one way or another if only when admiring a collection of ornamental waterfowl in some public park. These birds are usually wild species, or their progeny, and are perfectly happy. The same applies to the numerous waterfowl, flamingoes, cranes, etc., in zoos and private collections. It must also be remembered that all pheasants have, at one time or another, been introduced, and some species although preserved in numbers in captivity, are almost extinct in the wild state. We even owe all our varieties of fowls originally to aviculture as they have all been evolved from the common wild jungle fowl of India, by years of selection in captivity. Another popular branch of this science is the breeding of various parrakeets, lovebirds, and other members of the parrot tribe, and this has led to the budgerigar cult. Not many years ago the true wild budgerigar-a small Australian parrakeet, mainly green with a yellow head and throat-was the only variety of the species in captivity. Now yellow, blue, sky-blue, violet, cobalt, white, and cinnamon-winged varieties-to mention just a few-have been evolved and there are budgerigar clubs all over with thousands of members.

The breeding of exotic birds in aviaries is a pleasant and harmless pastime, and much knowledge is gained of their songs, habits, displays, and plumage changes that might otherwise remain unknown.

There is, of course, no justification whatever for indulging in avicultural pursuits unless the task is undertaken seriously. There are many bird-keepers who are by no means aviculturists, and 
this includes those who buy some newly introduced bird merely to keep it for the show-bench. Aviculture itself suffers from the sad fact that some of its adherents are people who simply must keep birds but who have only the vaguest idea of their pets' requirements in captivity. The same food out of packets is given every day of the year with no thought that some variety might be beneficial. Often public sentiment is roused against the activities of these well-meaning people, which is not good for aviculture as a whole.

The advancement of the finer side of aviculture is suffering through the breaking up of country estates, as many of the leading exponents have been compelled to give up. There is still, however, a great interest in the keeping of small birds, and those that are kept under ideal conditions, as in most zoos, are probably better off than in the wild state. Longevity records in these institutions show that many small birds live for more than twenty years.

It is the importation of birds that leaves much to be desired; many arrive sick through being overcrowded and not having expert attention on the way home. All too often they are written off as a necessary loss, in the same way as rotting fruit in a consignment, and are doomed to a miserable end. It is the unscrupulous type of dealer who is mainly responsible for this traffic-the type who has no real love for birds but is concerned solely with his own selfish interests. $\mathrm{He}$, of course, could not survive without patronage from buyers who are not greatly concerned about methods of importation so long as their requirements can be satisfied at a reasonable price.

Attempts to remedy this state of affairs have met with little sympathy from a number of aviculturists, mainly because putting the importation of birds on a wholly humane basis would inevitably mean a slight rise in prices.

For my own part I can say, with some pride, that I have never let such things as the saving of freight interfere with my determination to keep everything in my charge in perfect health, and such things as personal comfort when traveling long distances on trains, or on stormy seas, have invariably been sacrificed to the welfare of my charges. In this way, I think I can say, they 
have always arrived perfectly fit, and if it had been otherwise I should have bowed my head in shame.

If the keeping of birds is undertaken, it should be done at the highest level of efficiency or not at all.

The most difficult part of the art is when treating newly captured specimens, and then common sense is needed to keep them happy until they have lost their fear of man, and to bridge the change-over from their natural diet to a partly artificial one. 


\section{Chapter Four}

\section{MOZAMBIQUE TERRITORY (II)}

$\mathrm{M}$

Y next expedition, in 1926, was again to the Mozambique I was accompanied by my brother, who had become a little tired of life in England.

Our objective was Caia on the lower Zambezi, headquarters of the big British concern, the Sena Sugar Estates, and as we had arranged to catch a ship back to England which left Beira only six weeks after our arrival, we had to get busy. The Zambezi delta is flat and intensely hot; swamps are numerous and mosquitoes abound, so it is not surprising that blackwater and malaria fever were prevalent. One of the most depressing sights during our short stay was the almost daily funeral of some unfortunate halfcaste or black who had succumbed to fever. In this foul climate we ourselves began to feel that if we did not stick to our original plans and get out after six weeks, we might take our turn in the daily procession.

Caia lies on the right bank of the river, and looking northwards one sees the hills of Nyasaland. The country around Caia is subject to amazing floods caused by the Zambezi overflowing its banks. Near the river one sees piles of rubbish stuck in the treetops, indicating the height of the last flood. Surprisingly enough, the mighty river almost entirely disappears near its mouth in the dry season. In its wide bed are a number of rivulets and pools, but the bulk of the running water seeps away underground. In this state the river-bed attracts large flocks of ibises, hammerkops, herons, marabous and sandpipers. During the annual flood, numerous depressions far from the river are filled with water and with 
fish which are trapped as the flood waters subside. Then as the water in these depressions evaporates and becomes shallow, the fish are killed by the great heat. I saw one such place surrounded by marabou storks and it was quite a revolting spectacle. Putrid fish were floating everywhere on the water and the marabousthemselves revolting-looking creatures-were devouring the stinking offal with much relish. As scavengers, of course, they were serving a very useful purpose.

The natives here were clever at trapping water-birds, and among other things we were brought a variety of herons. These were not very difficult to accustom to an artificial diet, though to encourage them to eat in the first instance we employed small boys to catch the tree-frogs which were numerous in the banana plantations. Where the banana leaf joins the stem there is a cavity which is always moist or filled with water, and this is the ideal place for these highly colored creatures to shelter from the heat and their diurnal enemies. They issue forth at night, clinging to smooth leaves and stems with great facility owing to nature's provision of toes with suction pads instead of claws, and then music is in the air; in fact their incessant chirruping is one of the most unforgettable things of the tropical night.

We also acquired three quaint birds of the heron order, known as hammerkops. Their peculiar appearance has given rise to many superstitions in different native tribes. They have somber plumage, and spend most of their time along watercourses catching small fish, crabs, etc., and have little fear of man; in fact where the natives are concerned the boot is on the other foot. They build a nest, which is an enormous mound of sticks, usually on a boulder overhanging a river though sometimes in a tree. The nest may be six feet in diameter and is dome-shaped, with the entrance hole on one side. Many are the legends of the hammerkop. On one occasion I went to a place to investigate the natives' story that there existed a "one-eyed" bird in the district. They all agreed that the bird possessed only one eye-not that this convinced me in any way. However, I was determined to get to the bottom of the story, and after much hedging by the locals I was reluctantly shown a specimen of the hammerkop. When I pointed out, with some sarcasm, that the bird had two eyes like any other bird, they 
tried to explain matters away by saying that it always kept one eye shut-which, in any case, was not true.

Our specimens refused to eat and could not be tempted with anything. The heron tribe are easy to cram as they have large gullets, so all one has to do is to push a lump of food down the throat, and then work it down the neck into the crop from the outside with one's fingers. This, however, did not work with the hammerkops; everything was ejected with ease even when pushed to the very bottom of their long necks. As this procedure was getting us nowhere, we tried the experiment of tying a ribbon round the base of the neck after the food had been worked well down. The skin of these birds' necks is loose and any food passing down (or up) causes a bulge, so the ribbon prevented the bulge from passing upwards. The birds quickly realized that it was useless trying to perform the regurgitating act, and soon commenced feeding normally on their own.

There was very little here to compensate one for the discomfort and intense heat, and when the sun went down the mosquitoes were unbearable. Sometimes we got our boy to push our meals under our mosquito nets while we sat on our beds and fed-in this way avoiding the thousands of bloodthirsty brutes that seemed to spend their entire lives under the dining-room table waiting to pounce on people's legs.

A little light relief came one day when a hubbub started near the quarters of the boys who worked on the sugar estates. I looked up and found them giving chase to a baboon. This one must have got cut off from the rest of the troop, and he was quite bewildered by the number of natives who bobbed up in his path. Natives in most parts of Africa are quick to turn out and chase an animal that has wandered on to their lands, and they are surprisingly successful in blotting them out with primitive weapons. Meat is something they get irregularly and then only by chance, so when an opportunity occurs there is a spontaneous call to action. Grabbing a knobkerry or spear they tear off after the animal, spreading out so that some are wide on the flanks. The fleeing animal can hear noise coming from all directions-for any native ahead hearing the din immediately joins in-becomes confused, and sooner or later makes the mistake of turning and making off in a differ- 
ent direction. It then sees the boys running like hares on the flanks, becomes more bewildered and probably doubles back, only to be met by the people behind. As it tries to dodge them, they throw their knobkerries and soon slow it down with a direct hit or two, which allows someone to catch up and deliver the coup de grace.

The poor baboon was the victim of these tactics and was running in half-circles, when a flying knobkerry hit him. This caused him to stop and chatter with rage. Another native then rushed up to sling his knobkerry at close quarters, but the baboon knowing that he was cornered was now full of fight, and just as the boy was about to throw his stick the animal rushed at him. Instead of fighting it out, the boy turned and ran. Always quick to laugh at another's predicament or misfortune, the natives who were at a safe distance were rendered helpless with laughter at the sight of this fellow being chased by the baboon, so much so that I think the latter might have escaped if it had not been so bewildered. The baboon's attack was, of course, a defensive measure, and was only continued until it had the desired effect of driving off the enemy. The poor beast was soon finished off; the laughter, however, continued far into the night while the boys, squatting round a camp fire and recalling the day's adventures, plucked pieces of roast baboon out of the ashes.

Not many tribes in Africa will eat baboons or monkeys, but here at Caia nothing seemed to come amiss. Some of the native employees, who belonged to a rather primitive Nyasaland tribe, were even reputed to eat all their food raw, and others were not averse to eating snakes. In this motley gathering most of the tribes of East Africa were represented, and some of the native overseers came from the sugar-fields of Jamaica and Demerara-being descendants of the liberated African slaves.

This was the first occasion on which I had met any African (except the one in the Snake Park at Port Elizabeth) who was unafraid of snakes, and moreover who could handle them with impunity. This man, who hailed from Nyasaland, arrived one day and asked if we wanted some live snakes. On saying that we did, he unrolled a loin-cloth and shot three fairly large venomous snakes on the ground for us to inspect. They were rather placid, 
as many snakes are when they have been in captivity a little while, but it surprised me to see this fellow calmly pick them up by the tail and put them one by one back in his loin-cloth. His price was rather high so I tried the customary bargaining, but he was much too independent and went on his way. I asked my boy why the man had not accepted my price as no one else in the place would buy live snakes. "Oh," he said, " 'e go cook 'em."

Among our collection of water-birds were some specimens of the Jacana or Lily-trotter. This bird is plover-like in some respects and rail-like in others, and has a bare plate on the head like a coot. Its distinguishing features are its long legs, striking colorationblack, white, yellow, maroon and chestnut-and its remarkably large feet; the hind toe alone is three inches long. This is a provision to support the bird while running over floating vegetation, such as water-lilies, etc., while in search of its natural food-seeds and foliage of certain aquatic plants, and aquatic insects. It was delightful to see them running over floating plants always near reeds where they could retreat for safety, and a feature of any large swamp in this area was their resounding cries.

Besides the water-loving creatures we had a large variety of bush- or savanna-dwelling birds. Among these were flycatchers, sunbirds, and numerous waxbills, but perhaps the most interesting was a pair of Little Bee-eaters. I was watching these birds perched on an acacia tree one day, going through their usual acrobatics of occasionally darting in the air to capture a flying insect and returning to the tree, when one flew onto an open patch of ground and disappeared. After waiting some minutes for it to rise againwithout result-I went to the spot and found several rat-holes, and then realized that this was a ground-nesting species, unlike most bee-eaters, which nest in holes in banks, and that it employs disused rat-holes for the purpose.

As these birds in the wild state "hawk" all their food, it is a most difficult business teaching them to eat anything-even live insects-in captivity, and to accomplish the complete changeover about three weeks of perseverance and patience were necessary.

Sometimes birds have to be tempted with very alluring bait before they will enter a trap, and this applies mostly, of course, 
to fruit-eating birds. Fruit, to be attractive to birds, must be different from that which they already have access to, however nice it may be, and it is of little use putting a trap in a fruit-bearing tree, baited with the same kind of fruit. It is also very difficult, contrary to popular belief, to find attractive wild fruits in the tropics, so it was with the idea of overcoming this obstacle that, before leaving England, I visited a large store where they kept a good stock of artificial fruits and berries.

I came away with an assortment of wonderful cherries of various colors, strawberries, and some fruits which were evidently the product of someone's imagination. I couldn't help chuckling as I thought of some tropical bird, accustomed to eating half-ripe, unattractive-looking berries, being suddenly confronted with this delicious assortment. Would its heart stop beating, or would it dislocate its neck in its eagerness to get into the trap? I decided that the answer probably lay between these two extremes, and the bird would walk in like a lamb.

To try these out, the trap employed was the home-made box type of wire-netting with a drop front, and the idea of the experiment was to capture some Purple-crested Touracos. These are particularly handsome birds, and become confidingly tame in captivity. They are about the size of a pigeon, with a glossy purple head and crest, green under parts, lilac-blue back and tail, and coppery-red wings. The latter coloration is the result of a coppery substance in the feathers known as turacin, which is said to be soluble in water.

Having located a fruit-bearing tree frequented by several pairs of these graceful birds, I fixed a long pole horizontally across the center of the tree among the upper branches. Touracos love to run along a straight branch while looking for their food, rather than clamber around on thin twigs, and their feet are well adapted for this purpose. In fact they bound about in trees more like monkeys than birds and are always running or jumping.

The experiment was a great success and I captured two pairs of these much-coveted birds.

Artificial fruit has many advantages in the tropics; it is not attacked by ants, and does not get spoiled when a bird is caught, so it obviates the need for searching the countryside for something 
suitable as bait. Its use is, of course, limited, for although it will deceive certain birds, it is useless for squirrels and galagos or any other fruit-eating mammals, as they are guided by smell rather than by sight.

Artificial flowers, preferably red and of the tubular kind, are sometimes quite useful in deceiving nectar-feeding birds, though where sunbirds are concerned the flowers must look very real before being effective.

As well as birds, we had collected a variety of small mammals, the most interesting of which were some Moholi Galagos. These are small nocturnal creatures with lovely fur and large eyes, which thrive in captivity on a diet of milk, fruit, and a few insects. They are related to lemurs and make delightful pets as long as they are not liberated in a room at night where there are canaries! Alas, if given the chance they become partly carnivorous.

After much loss of sweat with few exciting adventures, we were ready to depart, and did so with no great regrets, though the collection-especially of water-birds-was excellent.

The voyage home on the Union Castle boat was uneventful until we were nearing Britain, when one morning on uncovering the birds which were on deck I found feathers all over the place as if something had tried to attack them through the bars of the cages. I naturally suspected rats and informed the chief officer, who said no rat had ever been reported on board, and as it was an oil-burning ship he doubted if there were any. Anyway, he produced a lot of traps, which I set, but the same thing happened the following night and one bird was injured, though nothing showed up in the traps. By this time I had got most of the crew worked up. The following night I inspected the place every halfhour with an electric-torch, and at about II P.M. saw two large eyes shining under the canvas covering. I knew at once that they were those of a galago, and that this was the villain of the piece. I caught him quickly and silently and put him back with his mates before anyone saw what was taking place. As he was one of a dozen I had not noticed his escape, especially as they always remained huddled together in a heap during the day. He must have been smaller than the rest and squeezed through an in- 
credibly tiny space between the bars of the traveling box; having nothing else to eat, he tried to satisfy his hunger by catching the birds. This, I found afterwards, is one of their bad habits in any case.

There was no more trouble on board, but having made all sorts of sarcastic remarks to various members of the crew on the subject of allowing rats to run round the ship, I felt rather small. Knowing that the laugh would be on me if I told the whole story, I contented myself by saying that there was no recurrence of the trouble, and that I was beginning to doubt if it really was a rat after all! 


\section{Chapter Five}

\section{INDO-CHINA}

$\mathrm{A}^{\mathrm{T}}$ the suggestion of Monsieur Jean Delacour, the well-known in 1927 to Annam, the northeast province of Indo-China. We embarked at the London docks on a Japanese boat which took us as far as Singapore, and here we spent some days before proceeding in a French ship to Saigon, the capital of Indo-China.

At Singapore we were able to get our first glimpse of Chinese life. The rickshaw boys were most in evidence as they fairly swarmed the narrow streets, and itinerant vendors could be seen carrying everything on bamboo poles balanced on their shoulders, even to portable stoves in full operation, with a variety of hot dishes aboard which were served in the street to anyone interested. Other nationalities were prominent too, especially Japanese ladies, who could be seen riding around in rickshaws smiling at any likely client.

We arrived at the entrance to the Saigon River, on which Saigon stands, late one afternoon and it was dark before we got very far. The winding course was very tricky at night, and our big French liner got stuck temporarily several times on the way. The up-river trip took about six hours.

Saigon seemed to us to be hotter than Singapore, but provided plenty of interest for the few days we were there, especially its Botanical Gardens and the Chinese sampans clustered along the river banks.

We were naturally anxious to get on, and as we had just missed the coastal boat that would have taken us north to Annam we decided to go by the overland route. This meant taking the train 
to Nhatrang, the terminus of the railway. Tourane, our next jump, lay some two hundred and fifty miles north of this on the coast bordering the China Sea, and to get there we took advantage of the Government motor-coach service from Nhatrang. The journey north along the coastal road was interrupted by numerous wide lagoons which had to be traversed by ferry. This was a tedious business as the ferry was often on the wrong side when we arrived, and the method of propulsion was the old-fashioned one of punting, which was done in the most leisurely fashion. To compensate for this the scenery was magnificent, the lagoons themselves presenting a perfect picture with placid sparkling water encompassed by coconut palms. It is a pity that Indo-China has always been little known to the traveler and tourist, as it offers some of the most beautiful scenery in the world; also interesting people and magnificent relics of an ancient culture. The French authorities had arranged travel on this route exceedingly well, and I have no doubt conditions were similar in other parts of the territory. The roads were good, and there were excellent resthouses at convenient intervals, with modern sanitation, where one could stay the night.

At Tourane, a small port, there is a coastal railway northward to Quangtri passing through Hué, the capital of Annam. Here we were to meet Monsieur J. Jabouille, the Governor and wellknown ornithologist. With Monsieur Delacour he did a tremendous lot of good work to make known the birds of this territory, the results of their efforts being incorporated in the four volumes of Birds of Indo-China. Having met this genial soul who was to be our guardian while in Annam, we arranged to set up our collecting base at an unoccupied forestry station at Thua Luu, a village near the coast between Hué and Tourane. Thua Luu is a small and typical Annamite village, surrounded by rice-fields which the inhabitants work on a communal basis, the whole village turning out to harvest each person's rice crop. West of the flat rice-field belt lay the forested range called the Col des Nuages, and here are found many remarkable birds-little known at that time-such as Edward's Blue Pheasant, Rheinart's Argus Pheasant, Elliot's Pitta, Chaulet's Cissa, and Renauld's Ground Cuckoo, all of which have a restricted distribution. 
The thing that impressed us most about the Annamites was their capacity for hard work. The roads were dotted with men carrying loads of produce to market in Chinese fashion, more or less equal loads being fixed to the opposite ends of a bamboo pole. With this on his shoulder an Annamite will go along at a jog-trot for miles. This seems to be the sole means of transport among these country folk, there being no carts in evidence. Life was evidently not easy here, for the natives would undertake almost anything for money, and this proved to be of immense help to us. It was an unbelievable contrast to anything we had come across in Africa, and every morning someone arrived offering such things as fresh fish, crabs, oysters, incredibly cheap.

Through a French-speaking interpreter we soon contacted the villagers who knew the ways of the forest and were expert trappers. One of the main objects of our trip was to get a collection of the rarer pheasants, particularly the long-tailed Rheinart's Pheasant, whose home lay in the higher parts of the Col des Nuages in places where the forest undergrowth offered natural protection. A few Europeans may have got a glimpse of this bird crossing some forest road or track, but I am not sure if anyone has ever seen it otherwise in spite of its great size, and yet one has only to fire a gun up in these hills and immediately their loud challenging call-notes will come as a response from widely dispersed haunts. This ability of concealment is found in most birds of terrestrial habits that dwell in forests, and accounts for so many being easy to trap though almost impossible to see. Some of the pheasants, the Spicifer Peafowl, and the wild jungle fowl, were found at the lower levels, especially the last, the cocks of which could be heard crowing everywhere with a much shorter crow than our domesticated fowls which are their direct descendants.

We soon got under way and a number of trappers set off for the higher slopes of the forested range where I understood they slept in rude shelters made by themselves from branches and leaves, and here they would stay for a week or more. All the ground-dwelling birds are cleverly snared by these people, the snares being made of string from fibrous bark attached to springy bamboo sticks and set in a variety of places, such as in narrow animal tracks along which pheasants wander, or in small open 
clearings in the undergrowth where there is room for the cocks to display. Sometimes barriers of brushwood are constructed, forming a long fence in which convenient gaps are left at intervals to allow the pheasants to pass through, and here ordinary snares are set and not the spring type.

To set the former, a bamboo sapling is pressed into the earth on one side of the selected spot, and is then bent over sufficiently for the snare to be spread flat across the path; it is set and operated in much the same way as the ones described in an earlier chapter

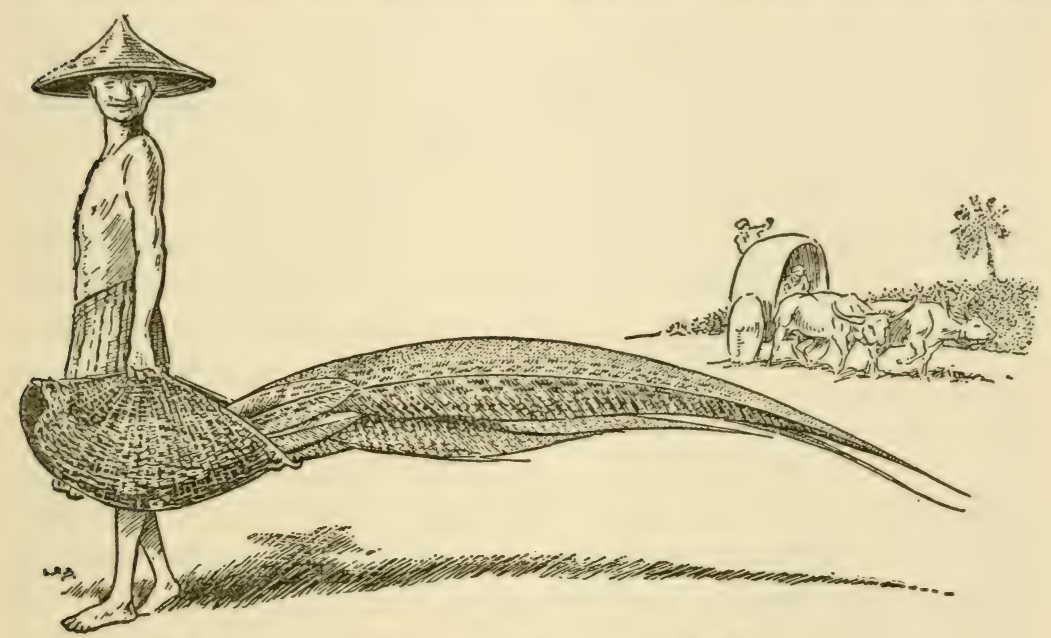

Annamite Carrying Rheinart's Pheasant

for catching antelopes. A cross-stick acts as the trigger, this being laid across a slight hollow in the path and covered with small sticks and leaves. The slightest pressure on this, made by the passing pheasant, releases the trigger and the sapling springs up, pulling the snare taut and catching the bird firmly by the leg or legs. Powerful birds like Rheinart's would quickly injure themselves to such an extent as to be useless if put in an ordinary crate or basket immediately after capture, for like all ground-dwelling birds they rise with great force when frightened; so special precautions have to be made to prevent them from banging their heads against the top and splitting the skin where a bare patch would always remain. The Annamites have a clever way of coping with this. They weave a sort of pliable basket, the same size 
as the pheasant, so that it fits close to the body like a waistcoat, and into this the bird is pushed. It is then fastened and the bird finds himself squatting in a tailor-made basket in which he has to remain in a sitting position without being able to move his wings, with his long tail sticking out of a hole at one end. In this way he can be carried about without doing himself the slightest injury, or even making any attempt to struggle. It is rather a comical sight to see an Annamite walking along carrying a small basket, a tail as long as a peacock's protruding from it with the rest of the bird concealed.

All the pheasants of this region are caught in the same manner, and also other ground-dwelling birds such as pittas and ground cuckoos. The former belong to a family of gorgeously marked birds about the size of a thrush, or larger according to species, though more plump and with short tails; the most beautiful one here was called Elliot's Pitta. This is not only one of the prettiest of a very beautiful family, but is surpassed by few Asiatic birds in any other group. The cock has back and breast pale green, under parts golden yellow barred with transverse black stripes, bright blue tail, and middle of the belly deep indigo blue. Up to 1927 this species was known only by two skins in the Paris Museum. As far as I know no European has ever seen this bird alive in the wild state, but it is actually quite common in the forests above Thua Luu. The Annamites brought us a number of them in baskets, which they had no difficulty in trapping.

Pittas, which are mainly Asiatic birds-though a few species are found in Africa and Australia-are undoubtedly more common than is generally supposed. They all live on the floor of tropical forests, and as they have an acute sense of hearing, are fast runners, and are clever at concealing themselves, they have little difficulty in escaping detection. Any person encroaching on their domain is bound to make some warning noise, however slight, whilst walking over leaves and sticks or pushing through undergrowth.

During the months that I spent trapping in the Indo-Chinese forests I saw pittas only twice, and they were a large species known as the Annamese Pitta, with a green back, bluish head and rump, and with under parts buff tinged with mauve. On both occasions I was sitting quite still on a log watching the bird-life- 
this being the only way of ever getting a glimpse of such shy creatures-and even then it was a question of luck. Several of these I caught in spring-net traps baited with meal-worms and set in damp places in the forest, without having seen the birds beforehand.

Another pitta, called Swinhoe's, did not make its appearance till later on, it being a migrant from Formosa. We brought all three species home alive, this being their first importation to Europe.

Renauld's Ground Cuckoo was another inhabitant of the denser parts of these forests that had remained almost unknown until Delacour's expeditions to Indo-China in the 'twenties. This cuckoo is terrestrial in habits, being as shy and retiring as any of the pheasants, but it is not parasitic and apparently nests in trees. It is a striking bird about the size of a fowl, with red beak and legs, bronzy-black head, neck and breast, gray back, and pale yellow under parts. A number were brought to us by the same trappers who brought in the pheasants, and they quickly became tame and thrived on our insectile mixture with addition of minced raw meat and chopped hard-boiled egg. We brought home twelve of these quaint denizens of the forest.

This is another instance of trappers bringing to light apparently conspicuous birds which, through their secretive mode of life in impenetrable forest thickets, would probably have remained unknown if collecting were limited to the usual method of obtaining specimens with shotguns. Although it is among the grounddwelling birds of the forest that there are such large gaps in our knowledge of their numbers and habits, occasionally one comes across a fairly large bird of arboreal habits, specimens of which have somehow managed to escape spending their after-life in a museum drawer.

There is a very beautiful cissa, or hunting crow, known as Chaulet's Cissa, that inhabits the Col des Nuages. It is conspicuous enough, being the size of a jay, with bright yellow under parts and greenish upper parts with a golden tinge. Prior to our visit it was known only by the type specimen and no European had ever seen it alive. Cissas, being mainly insectivorous, like to sit on a low horizontal branch and watch the forest bed for signs of any moving insect on which they can pounce. 
To be a successful trapper, especially when operating in a new field, one must forever be thinking up new ideas. Some will inevitably misfire, but even in failure one invariably learns something about the habits of birds. After a week or two in the Col des Nuages I had not had a glimpse of Chaulet's Cissa, nor heard a cry which might belong to one. Some of the lower forest levels were not difficult to walk through, and in fact one could see quite a distance through the trees, so I said to myself one day when wondering how one could ever possibly catch a tree-dwelling bird one had never seen: If I were a cissa flying through this forest what conspicuous perching-place would attract my attention? I covered a lot of ground and there was no such place. It became evident then that in this part of the forest there were no horizontal branches, they all slanted up at an angle of about forty-five degrees. I could find no convenient perch for a hungry bird looking for ground-dwelling insects. The answer was simple. Why not make one?

In a quiet little forest glade-a sort of natural canopied avenue -where the view was uninterrupted for fifty yards or more, I slung a long pole horizontally between two trees, about four feet above the ground. As there was little undergrowth here it could be seen from most angles. On the ground a patch was cleared of leaves and sticks, not directly below the pole but at an angle of forty-five degrees so that it could be more easily seen, and on this a spring-net trap, baited with live meal-worms, was set. The framework of the trap was concealed with leaves so that all that remained visible was a cork to which some struggling meal-worms had been pinned by their tails. In the first instance it was the pole rather than the trap that would attract any birds, but half the battle in trapping any rare bird of no fixed abode is to get it to come in contact with one's traps. Once on the pole, no bird could fail to be attracted by the patch below cleared of dead leaves with some meal-worms struggling in the middle of it. He would pounce down, give a sharp tug and over would fly the net, holding him captive beneath it. That, in fact, is the simple story of the capture of six Chaulet's Cissas-a bird known to science till then by only one skin. They were caught singly over the period of a 
fortnight in the same trap without its being moved, and not a single bird did I see before it was captured.

My excitement on finding the first of these rare birds in my trap can be imagined, and I felt on top of the world as I made my way along a narrow trail that had been cut along the hillside. How important it is to remain alert in such places, and not let one's mind wander into a haze because of some exciting success, was all too apparent by the time I reached home with my prize.

As I was walking along the trail, which followed the contour of a steep hill, I came round a sharp bend and found myself confronted by a domestic buffalo bull which was standing right in my path. These creatures are quite docile with Annamites, and it is a common sight to see children riding on their backs to confine them to the grass verges separating rice-fields, but their attitude to Europeans is unpredictable. There was no way round as the hillside was steep, rising abruptly to my right, and descending at such an angle to my left that any attempt was out of the question without sliding. Furthermore, the hill here was covered with dense, tangled second growth.

At this point there was no need for further deliberation: the bull snorted and charged at close quarters. My only path was downwards, so I leapt off the trail and crashed through the undergrowth, sliding downhill on my back and holding my precious Chaulet's Cissa to my body to protect it. A second after I left the track there was a loud crash behind me, but I never found out if the bull in his furious onslaught was unable to stop himself and crashed over the side. My smaller stature had enabled me to slide a considerable distance under the tangled vegetation, and I was well clear by the time I was brought to a halt, suffering only from minor scratches. It was a difficult business regaining the path, which I took good care to do at some distance from the scene of excitement.

I was very interested in the tree shrews here, which were not uncommon. They are very squirrel-like in size, form, and habits, though the snout is pointed and the teeth those of an insectivore. Certain cerebral characteristics have caused them to be placed near the primates in the systematic order, though other anatomical 
features indicate affinities with the marsupials. It is certainly rather startling to learn that this squirrel-like creature is remotely related to man, though the more rational view is that it belongs to a very distinct branch of the insectivores possessing certain anatomical affinities with some of the lower primates.

I caught several of these by setting a home-made box-trap, with a drop door, in a tree. This was baited with various fruits. Although able to climb with the agility of squirrels, tree shrews spend much of their time on the ground hunting for insects, and I saw them on several occasions keeping company with those extraordinary mixed companies of birds that move slowly through the forest partaking in a communal insect hunt. It was an exciting business transferring a tree shrew from the trap to a sack while standing on a branch high up in a tree, and using both hands to carry out the operation.

By far the most conspicuous birds in these forests were the jaythrushes or laughing-thrushes, which could always be located by their frequent bursts of laughter-like call-notes. They go about the forest in parties, spending much of their time scratching in leaves for insects. The species here, all of which I captured alive, were White-cheeked Jay-thrushes, Diard's Jay-thrushes, Pasquier's Jay-thrushes, and Fries' Scimitar-billed Babblers, the latter remarkable loud-voiced birds with very long curved bills.

Most of our captures were rare insect-eating birds and many of them were most difficult to establish in captivity. The Elliot's Pittas, for instance, would eat nothing but earthworms and it took a long time to get them accustomed to an artificial diet. Other birds, such as a pair of Green Bee-eaters-a magnificent species of chestnut, green and silky blue-were even more difficult, as they had to be gradually trained to eating artificial food from a receptacle, whereas their natural food is flying insects caught on the wing.

We captured some gorgeous species of kingfishers here, their predominant colors being blue and white. One, the Black-capped Kingfisher, had the crown black and the back shining cobalt blue.

What with our own captures and people arriving with baskets of birds, we were hard put to it to get all the necessary traveling cages made. To help us we employed a local Annamite carpenter 
who could not speak a word of French, and as we had long since disposed of an interpreter it was amusing, to say the least, explaining to the fellow what we wanted done. My brother would draw lines on boards that needed sawing and planing. Then doors had to be made, hinges put on, and the box finally put together and nailed. All this was done expertly by our carpenter by the simple expedient of one of us making signs and suitable sounds to him. He worked from daylight until dark, seven days a week, and his wages then were the equivalent of fourpence a day. This was the standard rate, and as he could buy all the food he wanted in the local market for the equivalent of a penny, he was really quite well off.

One day I had the opportunity of visiting another forestry station in the Col des Nuages at a higher altitude. A high-ranking official offered to take me there by car, so we set off to see what the prospects were of collecting different rarities. This man was an opium-smoker and after meals his servant prepared the opium pipe, which his master enjoyed while lying on a grass mat. It was not long before the pipe was put aside, and a loud snoring indicated that master was in the land of pleasant dreams.

The day of our visit was very hot, particularly in the abandoned forestry station, which was hemmed in by trees and second growth that had encroached upon it. Our lunch was cold but in the French style was washed down with red wine. It needed only a few whiffs of opium to send my friend off into a peaceful slumber. The combination of heat and wine were enough to make anyone feel like a siesta, but I was here to explore and it seemed to me to be much cooler in the forest than in the low-roofed forestry station. Before lying on his mat my companion found the heat so trying that he stripped to the waist, and thus attired in his trousers only, I left him asleep. After exploring the forest for a while, I returned to discuss the prospects of returning some day to do some collecting. A most remarkable sight greeted my eyes. My friend was still fast asleep, and his rather fat naked body was smothered with thirsty horse-flies all digging in their proboscises to get their fill of blood. These loathsome parasites normally give one a pronounced prick as they pierce one's skin, but I doubt if the sleeper would have felt anything short of a 
bayonet at this moment, so deep was his slumber. It was useless to drive the persistent creatures away, so I covered his naked trunk with his shirt and towel, which to some extent saved him from further attacks. There I left him and resumed my birdwatching but did not observe much that I had not already seen at Thua Luu.

The Annamite trappers were slow at first in bringing in any owls, though they existed in great variety. No doubt superstitions were rife about them as they are in most countries, but after one or two people had broken the ice and had brought us specimens, the lure of money seemed too much for the rest, and we received an astonishing assortment. These included several of the handsome Oriental and Yellow-legged Fish-owls, which are large birds with ear-tufts and long, almost bare legs, that live mainly on fish in the wild state but thrive on meat and mice in captivity.

At the opposite extreme were several tiny owls not much larger than sparrows, that appeared to live entirely on insects. Some refused to eat anything and these were liberated, but one real pygmy, known as La Touche's Owl, we managed to establish. This was known previously by three skins only.

Of the four Oriental Scops Owls in our possession, I captured one myself. It was sitting fairly high up in a tree near the edge of the forest, and to attempt to get it I cut two long saplings, joined them together, and tied a stick of bird-lime on the end. By carefully guiding this long wobbly apparatus through the branches, I managed to touch his flank with the end and to this he stuck, and I was able to haul him safely to earth. This actually is an established method of trapping in India, especially in the forests of the lower Himalayas. In the heat of the day, when many birds are rather inactive, a trapper will creep under a tree and quietly pass a rod, to which is fixed a limed stick, up towards the resting bird. The rod is in sections like a fishing-rod, and when one section has been raised to head height another is added, so up and up goes the limed stick, the sight of which, strangely enough, never seems to create any suspicion in the mind of the bird. A slight touch against it is all that is necessary, for when it tries to take off it invariably loses balance and gets well and truly caught and is then quickly brought to hand. 
Some very curious birds new to aviculture were the Black Racket-tailed Magpies which frequented the open bushy country, and of which we brought home twelve specimens. They became very tame in captivity and, besides insect food and fruit, were particularly fond of raw meat. Perhaps the most striking thing about them is their cobalt-blue eyes, which contrast with their sleek dark-green plumage that has a coppery sheen. Their tail feathers are long and spatulate.

It was the first week in March when we started collecting in Thua Luu and we left at the end of April. During this all-tooshort period we had to establish numbers of delicate insectivorous birds and make suitable traveling cages. Out of the forty species of rare birds collected, twenty-two were imported for the first time into Britain.

The collection of pheasants comprising Rheinart's Argus, Edward's Blue, Fireback, Bel's Silver, and Ghigi's Peacock Pheasants was an important one. Some of the previous attempts to transport the Indo-Chinese pheasants had been unsuccessful owing to the birds contracting the fatal avian diphtheria. This is a highly contagious disease which is difficult to cure but can be easily prevented. On the advice of Monsieur Delacour we added a small quantity (0.025 per cent) of corrosive sublimate daily to the drinking water and this warded off all trouble. This powerful poison, even at the strength given, was sufficient to corrode metal containers, and would certainly have killed or badly upset most mammals, but had no bad effects at all on the pheasants.

We arrived at Marseilles at the end of May after a voyage of a month, traveling to Paris by fast goods train with our mixed and valuable collection, which was housed for a while in the Jardin des Plantes.

The day after our arrival was a public holiday and to our surprise the Jardin des Plantes was closed. We, however, had to get at our birds very early in the morning to get them fed and cleaned. Having climbed in, we were walking down a main drive to the building where our charges were housed when we were confronted by two police officers, who informed us that it was a jour de fête and that no one was allowed in the gardens. I explained that we had arrived from Indo-China with a valuable col- 
lection of birds and mammals and that, with the Director's sanction, they were housed temporarily in the Zoo. Further, we were in charge of them and if we were not allowed to get to them early they would die. This explanation might have been aimed at one of the Zoo animals for all the effect it had; the officers were unyielding and insisted that no one was allowed in the grounds that day. After further explanations about the importance of feeding certain delicate birds early in the morning, and without making the least impression upon the law, I became slightly heated at their impossible attitude. They, too, were becoming wildly excited at our audacity in arguing. When for the umpteenth time one of them insisted that no one was allowed in on that day, I replied: "In that case what are you doing here? I am as much on duty as you." Then the fun started. They drew their truncheons and gesticulated wildly.

At this stage I saw the folly of further argument, and so we meekly made our way under escort to the gate where a small gathering was watching the drama. The only thing left was to find the Director. His servant informed us that he was still in bed, but I insisted on seeing him, and presently he appeared in his pajamas and I explained our dilemma. He, at least, was most sympathetic and we were asked to wait while he dressed. The second meeting with the police officers took on an entirely different air. Now that we were with the Director they were most apologetic; if only they had known that we had come in to look after our livestock they would never have interfered-so they said.

Some of our birds went to Monsieur Delacour's aviaries at Clères, and the rest we took to London, where they were distributed between a few well-known aviculturists and the London Zoo. 


\section{Chapter Six}

\section{MOZAMBIQUE TERRITORY (III)}

Y third trip to Portuguese East Africa was again with my
brother. This was in 1928 . On this occasion we went to the Siluvu Hills some sixty-five miles inland from Beira. This group of quaint-looking high stony kopjes, situated on the western extremity of the vast and swampy Pungwe flats, is in a district that was then subject to much malaria and blackwater fever. The kopjes were well wooded with thick undergrowth, and abounded with leopards, baboons, and monkeys. An unusual feature of these hills was that in the dry season there was a total lack of water; in fact, the nearest water-hole was some ten miles away in the plains, and was certainly never visited by the monkeys and baboons.

By day the heat was intense but the early morning revealed heavy dews, and it is possible that various mammals were able to quench their thirst by this medium. Access to drinking water is something that most people regard as a necessity for the survival of most forms of animal-life, especially in the tropics, but this is a fallacy. A number of birds, and some mammals, never or rarely drink in the wild state, for example bee-eaters, hornbills, and certain sub-desert gazelles. These creatures get sufficient moisture from the food they eat, whether it be insects, fruit or vegetation. Of the various bee-eaters I have kept, I have never known one to drink, and unlike some non-drinkers they never acquire the habit in captivity. Here in the Siluvu Hills was a wealth of bird-life so restricted to this habitat that it would never venture on to the open plain, and was therefore cut off from any water supply. Our own water came from a well. 
Beira, although primitive in those days, was on the verge of some revolutionary changes, thanks to British enterprise. Up to now all boats anchored off-shore, as there were no docks, but these were under construction, and much stone was needed for the purpose. The Siluvu Hills with their wealth of granite rock were the nearest source of supply, and so this previously uninhabited spot was the center of much activity. The sole European here was an aged Englishman who had been enterprising enough to start up quarrying, and supplied Beira with tons of stone, both broken and in blocks. Between two and three dozen natives with their families had been recruited from other districts, and were housed in specially built rondavels.

Our host, whom I shall call Peters, had built a house of stone at the top of a high kopje. The approach to this from any direction meant a stiff climb which was an effort in the heat of the day, but seemed worth while once the crest was reached, for here the slight breeze was heavenly after the sweltering heat of the valleys below. Peters was a successful business man and had made enough money, I think, to live on comfortably, but for some reason, at which we could only guess, he had quitted his home town in England and sought solitude in the African wilderness.

One of the most conspicuous birds in the Siluvu Hills was the Trumpeter Hornbill. This is a big black-and-white fellow with a large cylindrical casque on the upper mandible, giving him a top-heavy appearance. This casque, which looks like an additional bill, seems to serve no other purpose than that of ornamentation and is therefore akin to the development of a fancy crest, or plumes, such as occur in the Crowned Crane and birds-of-paradise. These grotesque hornbills, with their ridiculously short legs and heavy heads, are comical in the extreme when they hop from branch to branch looking for their favorite wild fruits. In flight they give one the impression that the whole thing is a very laborious business, for they progress by rapid wing-beats followed by a gliding movement with wings extended as if pausing for breath.

Trumpeter Hornbills are gregarious birds and a flock used to pass over our abode daily en route for a fruit-bearing tree in the forest about a mile away. Being on a hill-top we could follow their dead-straight course right to the particular tree they wanted. 
As the weeks went by and the fruits of different trees became ripe, the hornbills always made a bee-line from one fruit-bearing tree to another, however distant. To us, looking down on the scene, all the trees of the forest looked alike, but no searching on the part of the birds was ever observed; to find a particular tree buried among thousands of others surely requires some guiding instinct. There is no doubt that hornbills are highly intelligent and have excellent memories, and this may have a bearing on their precision flights.

One of their favorite fruits is the wild fig, of which there are many species. Some of the trees reach an enormous size, but frequently the fruits are no bigger than cherries or at most damsons, and so are easily swallowed whole by the hornbills. Their bills, although having the appearance of being ungainly, are really instruments of great delicacy, and are ideal weapons for the business of fruit-plucking. You may wonder how a hornbill gets its food from the tip of its long bill down its throat. The technique is to toss it up, at the same time opening the bill wide so that the tit-bit drops right into the gullet.

When feeding, these birds keep up a constant bleating noise very much resembling that of goats.

They are long-lived creatures, and one of the pair that I caught here died only recently after twenty-one years in the London Zoo.

While in the Siluvu Hills, I witnessed for the first time the nesting habits of hornbills. They always choose a hole in a tree which is walled up with self-made plaster, leaving a narrow slit through which the male feeds his imprisoned mate. In this retreat she elects to sit during the whole of the incubation period, relying entirely on the male to bring her food. It was thought once upon a time that the male alone was responsible for the business of building the prison walls, but it now seems that both take part until the work is nearing completion, then the female enters the nest and finally seals herself in. This is evidently a protective measure and one that is very long-established, for all the hornbills of Africa and the Far East have the same peculiar nesting habits.

The substance used for this wall-making, according to observations made on certain hornbills in the wild state, is earth brought 


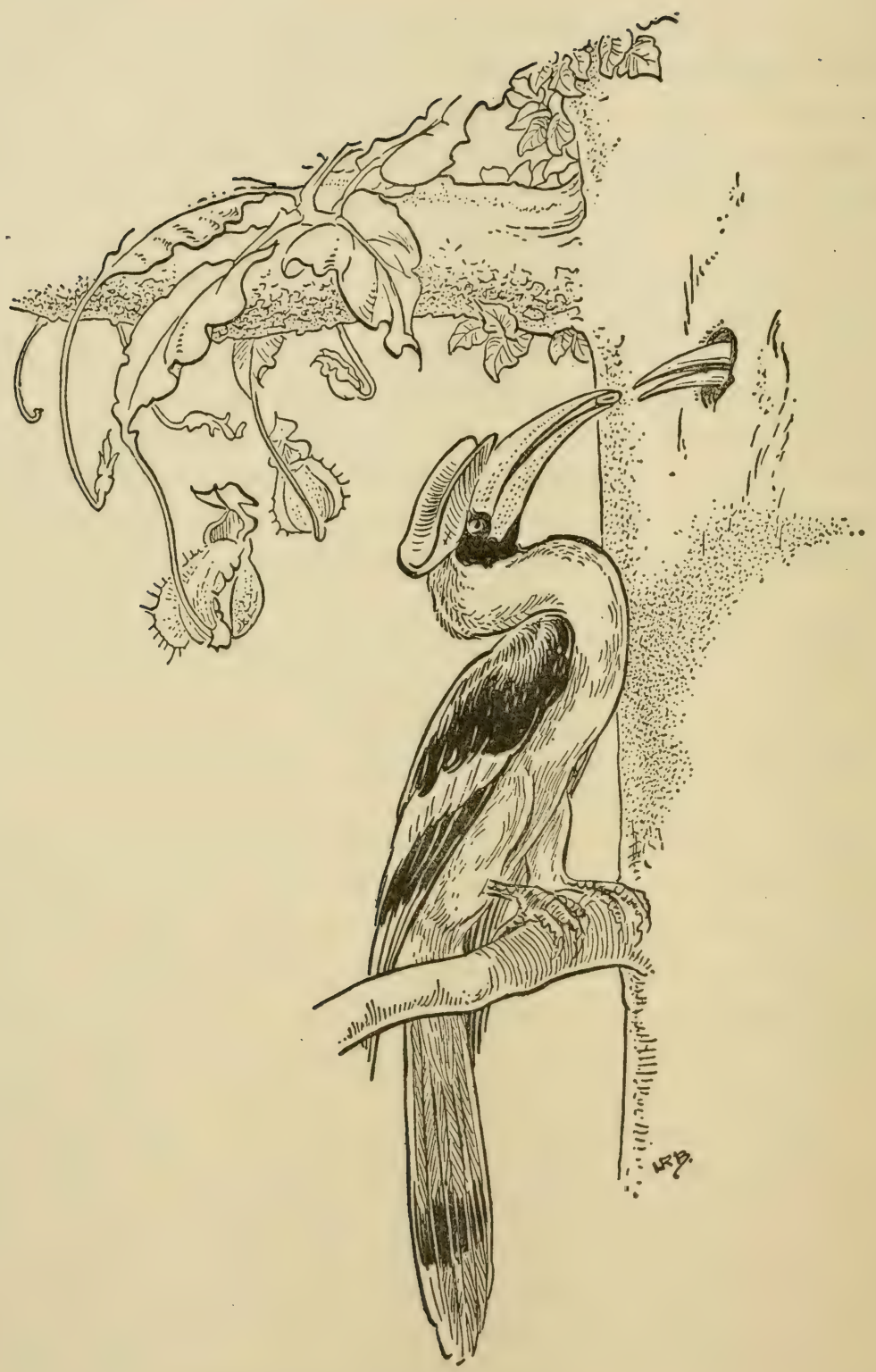

Great Indian Hornbillcock feeding sitting hen 
by the male, but employed by the female, which probably owes its setting properties to the presence of the bird's saliva, though in captivity the Great Indian Hornbill has been seen to use mainly its own excrement and regurgitated food for this purpose. The male feeds his mate by regurgitation, and a comical sight it is to see her face appear at the "window" when she hears him arrive.

Some of these sitting hornbills have an exceedingly uncomfortable time. Once, in rather thick savanna country, I found the nest of a smaller species, the Crowned Hornbill, by seeing the male flying to a hole which, surprisingly enough, was only about ten feet from the ground. The sealed part of the hole looked very much like the surrounding wood, and had set quite hard. The tree was situated in a hollow, and having very few branches the trunk caught the full heat of the sun. I chipped away the "plaster" and found the hole inside to be almost as hot as an oven. Reaching down I found the female about two feet below the hole. She nipped me, but without much vigor, and when I pulled her out she was obviously weak and looked the picture of misery. Once home, I put her in a roomy box in a cool place and kept her quiet.

For a while she was unable to stand but gradually recovered, and in a week she looked a different bird. This accomplishment was due in no small measure to the untiring efforts of a pickaninny whom I employed to hunt grasshoppers, beetles and their grubs, lizards and frogs, all of which were safely stowed away by this one bird. The rather small savanna-dwelling hornbills are mainly insectivorous, whereas most of their forest-dwelling cousins are chiefly fruit-eaters.

One thing leads to another, and by watching the flight of the Trumpeter Hornbills I located a tree laden with fruit resembling wild plums. On examining the fallen fruits, I noticed that quite a few were partly eaten and obviously not by hornbills. There were plenty of small birds such as bulbuls and barbets that were probably partly responsible, but some fruits bore the distinct pattern of tooth marks.

Immediately galagos came to mind. Here there were two species-the small Moholi Galago that lives largely on insects, and a much larger one, Garnett's Galago, that subsists mainly on fruit. 
They are related to lemurs, are nocturnal, and in Africa go under the name of bush babies.

I brought a cage-trap into action and set it in the tree-tops baited with ripe bananas and pawpaw. These luscious cultivated fruits were something they had never before confronted and proved an irresistible lure. On inspecting the trap in the early morning I found it to contain a Garnett's Galago. It was reset and on six successive nights produced an additional specimen. Five of these were females and proved to be a productive group, for each one of them produced a baby, some at our base camp and others on board on the way home. Close confinement did not affect their successful rearing in the slightest degree. The birth of all five within a few weeks of each other illustrates the very definite and restricted mating season of these animals.

Before this episode, I used to go out with a hunting lamp at night in an attempt to track down bush babies. This is rather like a bicycle lamp with a strong reflector, and is strapped to one's hat, while a thin rubber tube connects the lamp to an acetylene generator that is fixed to one's belt. The concentrated beam of light is directed forward, so it follows that no matter in what direction the wearer turns, his eyes are looking straight along the beam. A dark night is the best time for this exciting experience, for one is soon plunged into a sea of eyes.

Walking along a track or footpath, I turn my head slowly from side to side, to throw the light on every portion of the ground covered. There is thick bush on all sides as well as open places, and any animal in range will automatically, out of curiosity, look at the light. This intrigues but does not frighten the beast, and no matter if it is standing in a dense thicket, its presence will be revealed by the reflection from its eyes. This is remarkably strong so long as one's own eyes are looking along the beam. For example, a person accompanying the lamp-bearer and standing close at his side may see nothing when an animal "lights up." One quickly learns to identify the different animals by these reflections; this is done by intensity and color of the eyes, the space between them, height off the ground, their movement, and by the situation of the creature. 
The eyes of carnivores show up more strongly than most others and one will not proceed far without being suddenly confronted with two flaming "bull's-eyes" situated close together and near the ground. These will almost certainly be those of a genet, which is a small nocturnal cat-like animal with a pointed face and long banded tail, that has a scent bag like the civet. At night he issues forth in search of rodents, which form his principal food.

Next one may see two large eyes, not very bright but remaining perfectly still. The creature is standing in a thicket and imagines he is out of view. He is the bushbuck, the most common antelope in these parts. Sometimes a real thrill is in store, for suddenly two red lights flash on of unbelievable intensity. They remain still a few seconds and then shut off, and this is even more exciting, for you wonder where they are going to bob up again. It may be this side or that, for the animal moves partly round the light to try to see what it really is, but his curiosity does not usually last very long; he probably scents what is behind the lamp and disappears. This is the leopard.

Most interesting is when the beam catches some eyes in a tree. They are like those of the carnivores and are intensely bright, but are those of the bush baby. We go a little closer, and, becoming apprehensive, he springs to another branch (they can leap colossal distances). His eyes, being so large, can be seen as he leaps through the air, so that they appear like balls of flame shooting through the branches. In all these cases, unless one is within a few yards, the animal itself is never seen.

Having located bush babies, which are usually in pairs, the important thing is to remember where you are and to mark the spot, so that it can be found again the following day. These animals never wander far, and will almost certainly remain near where they were seen. This is because they have a permanent home, a hole in a tree where they sleep (by day).

In the case of the large galagos, a trap in any tree where they were seen will usually bring forth the desired result, if some strong-smelling fruit, such as guava, is used to draw them to the spot. For the Moholi Galagos, live meal-worms are better, and three or four pinned belly upwards by their tails to a cork fitted in 
the cage can be seen a long way off, as they are always struggling to right themselves.

The eyes of wild pigs do not reflect, and I remember cautiously stalking a curious rustling noise with my beam trained on the spot; on this occasion, as always, I wore crêpe-soled shoes. I got nearer and nearer and was quite bewildered by some sort of activity, but no eyes showed up. I stood still almost at the center of disturbance, and then made out the form of a pig rooting in the ground for all he was worth. As he was partly hidden, I moved to get a better view, and at that moment trod on a stick. This was the signal for a mighty roar as a whole family stampeded through the undergrowth. This shows the extraordinary manner in which a light puts some animals off their guard, for without one I could not have approached anywhere near them. Wild pigs are nocturnal creatures and however numerous are rarely seen, as they rest in the daytime in the most inaccessible dense jungle far from the peregrinations of man.

For most of the year they remain fairly safe, but toward the end of the dry season when the bush, interspersed with long grass, burns so easily, the pig's life is not an enviable one. At this season the natives organize drives; they wait till there is a favorable strong wind, and then set off to a spot to the leeward side of a large patch of dense bush and grass. They are armed with spears and knobkerries and are accompanied by numerous mangy dogs that know all about hunting. When all is ready, other natives set fire to the bush-perhaps half a mile away. In the heat of the day the flames leap high into the air, while the wind drives the fire at great speed. The terrific roar of thousands of sticks exploding under the heat, and the smell of smoke coming nearer and nearer, is a signal for all forms of animal life to clear out.

The pigs stampede from their hiding-places, following paths and animal tracks, or anywhere where progress is not hindered by thick bush. The natives, of course, know more or less where they will pass, and wait concealed with their spears poised, and with the dogs ready to pounce out and stop any passing pig and bring it to bay. When this happens the nearest natives leap out and spear it. In this way there is a huge slaughter annually, and 
the natives have meat-eating orgies which last day and night, till all the meat has gone and they themselves are as bloated as overfed vultures.

I have rarely seen so many baboons as existed in the Siluvu Hills. They went around in large troops, and it was great fun watching the antics of the babies playing together, and often being scolded by their mothers. Baboons, being mainly terrestrial, make off when disturbed by running on terra firma even when among trees. My biggest thrills were when progressing silently on my bicycle. I would round a corner on a track, to find a large troop right in my path. On these occasions I always put on speed just to see the mothers excitedly snatching up their babies, amidst great chattering, as I charged upon them. The very young ones usually cling underneath their mothers, but it is a common sight to see the older ones riding their parents like jockeys.

I have heard many stories about baboons attacking people, and of their tactics in trying to surround single persons, but as far as my own experience goes I have never seen any sign of aggression, even when I have suddenly come upon them at close quarters. Much of my experience has been in places where they had never been shot at, and therefore had no reason to fear humans. Such animals are often very curious, and provided one is not actually walking toward them, they may approach quite near, and then appear threatening while standing up to get a better view. Under these circumstances a timid person could easily imagine himself to be outflanked, but that they have no evil intentions I have proved myself when being followed. On occasions I have turned round suddenly and raced towards the nearest baboons, which has had the effect of startling the whole troop and putting them to flight.

On my way back to Peters' house from these excursions I often passed the rondavels-built of mud and grass-where the native women were pounding maize into meal, which is the staple diet of the country. They usually performed this daily task in pairs, showing rhythmic beauty as each in turn raised, double-handed, her large wooden pestle to stamp it into the single mortar, alternately straightening and bending with bare breasts dancing in 
rhythm. This was often accompanied by a chant, as is so often the case when natives are performing any sort of manual labor.

The finely ground meal is finally winnowed, and it is only natural that in the various processes-all very primitive-a certain amount of meal should be spilt. The smaller seed-eating birds like this, and here the charming and tiny firefinches (in southern Africa called Ruddy Waxbills) had built up a camaraderie with the native women. They hopped around almost between the legs of the millers, and sometimes went right inside their huts, but were never molested. There is probably some superstition or legend about them, for when I asked a woman the native name of these confiding midgets her reply, translated, was "God's children."

In spite of the intense heat and other things beyond our control, we both remained fairly healthy, which speaks well for our constitutions at that time. The cook knew only the rudiments of preparing food and nothing whatsoever of hygiene. Peters insisted on having boiling soup, even when the temperature was $110^{\circ} \mathrm{F}$. in the shade, and this invariably contained a few well-fed house flies, though the monotony was broken occasionally by a bluebottle or an assortment of ants. Only twice did Peters suspect that there was something amiss with the cuisine, though he was usually philosophical over such things. The first occasion was when the cook produced a salad of oranges, bananas and onions, which merely caused our host to remark dryly, "When the devil are we supposed to eat this; as an hors d'oeuvre or a dessert?" The second was at breakfast, and this time he became quite belligerent and threatened to sever certain parts of the cook's anatomy with the bread knife. It has been said that time is of no consequence in Africa, but time had now changed Peters' breakfast egg from a tasty snack to a miniature gasometer. When he smote the top with his spoon the gas escaped and we made a quick getaway from the table. Peters was furious and let off a flow of swear words quite startling in view of his usual placid nature.

As we left for Beira in a special truck that was hitched to the mail train, Peters stood on the hill by his house and waved- 
his white hair and beard making him a distinctive character even at that distance. He was a lone figure, and in his mode of life reminded me much of Krantz.

Ever since our first few expeditions, we had arranged to take our consignments straight to the London Zoo, thanks to the courtesy of our old friend Dr. Geoffrey Vevers, who was Superintendent. The Zoo had first choice of our rarities, and the rest went to other zoos and private aviculturists. 


\section{Chapter Seven}

\section{MADAGASCAR (I)}

NLY two hundred and fifty miles from the coast of East Africa lies the great island of Madagascar. Viewed as it usually is, on a map alongside Africa, one gets little idea of its real size, and it comes as a surprise to many to learn that the area of the island is equal to that of France, Belgium, and Holland combined, being a thousand miles long by three hundred and fifty miles wide.

The rail system serves only the eastern region, TamataveTananarive, with branch lines to Lake Alaotra and Antsirabe. This leaves some four hundred miles to the north and south, as well as the west coast and the country west of Tananarive, with no railway and few roads.

In 1929 an Anglo-Franco-American ornithological expedition to the island had been organized, with Monsieur Delacour at its head, and I welcomed the opportunity of joining it to collect living specimens. The expedition proper was engaged in obtaining specimens for their three national museums.

I set off in early May from Marseilles on a Messageries Maritimes boat, and was agreeably surprised to find on board Dr. Errol White, who had been sent out by the British Museum (Natural History) to join the expedition to collect fossils.

On our way round the northern tip of Madagascar we put in at the port of Diego Suarez to coal. This is a wonderful landlocked natural harbor, but the town is uninteresting and we did not relish staying there in the heat while the boat got covered from end to end with coal dust. We were told that the best thing 
to do was to take a taxi to Joffreville up in the hills some sixteen miles from the town, where there was a quiet and peaceful hotel and a pleasantly cool climate. This was all arranged and we were delighted at the prospect of getting from the ship for a while and coming to grips with nature in a country that was new to us both.

Little did I know then what a big part Madagascar was to play in my life in later years.

My entry into Madagascar was auspicious, for some mild excitement greeted us on the evening of our arrival at Joffreville. We went for a short walk before dinner in the bright moonlight, and had not gone far when a dark form slithered across the road in front of us. We ran up and saw that it was a Madagascar Boa Constrictor. This was an opportunity too good to be missed, so I seized it by the tail and ran towards the hotel. Each time it doubled up with its head near my hand, appearing to be about to strike, I dropped the creature, waited for it to straighten out, and then grabbed it again by the tail. In this way we eventually arrived at the hotel and shouted to the proprietor for a sack. As he saw us arriving at the porch carrying a boa, I had the feeling he thought we were like all Englishmen-completely crazy and therefore to be pitied. Anyway we got the prize, about eight feet long, safely in the bag. Next morning I smuggled it on board and, to avoid panic on the part of the cabin steward, locked it in a drawer.

We duly arrived at Tamatave, and as the customs and immigration authorities had been advised of our arrival, we had no difficulties at all. I had wondered how the customs would view the importation of a boa constrictor into a country which, for all I knew, was alive with them, and which was not even on the ship's manifest.

On reaching Antananarivo (Tananarive to the French), after a fourteen-hour train journey, we met the rest of the expedition, including Monsieur Delacour. Having inquired quickly the number of my room at the hotel, I personally carried the mysterious and weighty sack upstairs and locked it in the wardrobe.

After a few days fitting out, I set out for Lake Alaotra with Delacour and the late Willoughby Lowe-the latter being the 
official collector to the British Museum. This meant retracing our steps by rail towards the east coast as far as Moramanga and then taking the branch line north to the lake. We occupied some station buildings on the lakeside at Ambatosoratra, the terminus, as the last few miles from Andréba had not then been opened.

My first duty was to make a comfortable wooden cage for my boa. This done, I managed to catch a live rat, which was introduced as food; but feeding boas is not as simple as all that. They may go for weeks or even months without food. The day after being introduced, the rat was still there apparently quite unconcerned about the large coils of snake which he sat on or hid behind. I gave him food and water and the pair lived happily together for weeks, the rat using the center of the boa's coils as a sleeping place, and sitting up on the reptile's back to clean his face and whiskers with his paws. I was quite prepared to encourage a continuance of this apparent friendship, but the rat could not resist gnawing the sides of the wooden box, doing considerable damage, especially at night. Reluctantly I was compelled to destroy him, and left his body there to see what the boa's reaction would be. When I next looked in the box, the rat had gone. After this I always offered my boa dead rats, which he accepted readily when hungry. The end of this story is that this reptile became perfectly tame, and lived for eleven years in the London Zoo.

My mission was, in the main, to collect waterfowl, and Lake Alaotra, with its shallow waters covering an area of twenty-five miles by seven miles, and supporting a deep fringe of reeds on the west side of several miles, appeared to be the ideal place. The lake is subject to inundations in the rainy season, October to May, and then it covers a considerably larger area, often flooding the native villages on the west side. The waters are teeming with edible fish, some, such as paratilapia, which is a blackish perch-like fish, are indigenous, while others, such as carp, have been introduced. The latter are exceedingly plentiful and are caught and smoked by the professional native fishermen.

Waterfowl abound, but they are well dispersed during the rainy period. It is when the lake starts to shrink rapidly in July and August that one sees great gatherings of Hottentot Teal feeding on the shallow foreshores, and equally large numbers of Fulvous 
and White-faced Tree Ducks. Some of the waterfowl prefer to sleep on the open water, making excursions at night to the neighboring rice-fields to feed.

My companions stayed only a fortnight-a busy one for them, as not only did they shoot a large variety of birds themselves, but native hunters with guns added to the daily bag, and these specimens all had to be measured, skinned, cleaned and preserved.

Meanwhile I had got the loan of a dugout canoe and spent much time among the reed-beds, becoming familiar with the different species of waterfowl and learning something of their habits. I was quickly able to distinguish all the species by their flight and became familiar with their calls.

The more I got to know of the lake, the more fascinating it became. At its northern end it is particularly picturesque as there it is flanked by high hills, and its winding shores are studded with promontories on which hamlets of the Sihanaka tribe are perched.

The view from any adjacent hill-top is delightful as one can get some idea of the varied animal-life which the fringe of the lake supports. Native cattle, pigs and geese, feeding in the herbage in the swamps; flocks of ibises probing in the mud for insects; jacanas, gallinules, stilts, moorhens and rails, seeking their food in and around the reed-beds, are some of the things which add to the glory of the general view.

It is an unforgettable experience to thread one's way quietly through the reeds in a native dugout canoe, getting close-up glimpses of numerous water-loving birds, and then to find oneself on the edge of a pool hemmed in by papyrus and covered with blue water-lilies and the beautiful mauve flowers of the waterhyacinth (Eichornia crassipes). In these ideal surroundings Pygmy Geese and White-backed Duck while away their time.

Occasionally a native may be seen sitting motionless in his canoe ready to strike with his barbed spear at some unsuspecting fish, while nearby a heron with a statue-like poise is bent on the same purpose.

The native pigs here have developed hippopotamus-like habits in their eagerness to devour the floating water-hyacinths which they adore. In canoeing I frequently came across odd pigs in a 
mass of floating vegetation with just their heads protruding, and sometimes one would disappear as if diving for food.

On the west side of the lake there is a fringe of reeds several miles wide, and unless one knows the channels well it is easy. to get completely lost in a maze with apparently no way out. I once made the trip with a missionary to an isolated shore-side village called Anororo. As the wind in the afternoon can be treacherous to small craft, we made the voyage at daybreak when all was calm. It was a large dugout canoe with four paddlers and was full of Malagasy natives returning with purchases they had made in exchange for dried fish. We crossed the open water in about two hours and then entered the vast reed-beds, and as we threaded our way through winding channels we passed several tiny inhabited islands-some so small that the few reed-huts on them left little room except for beaching the canoes. The people in these places gain their livelihood by catching fish and fresh-water shrimps-the former are smoked and the latter sun-dried and then exchanged for rice and cloth, etc.

The fish were caught with rod and line by using either paste prepared from cassava root, or worms, as bait. The swollen leafstalks of the water-hyacinths, the interiors of which are made up of loose spongy tissue, are invariably used as floats as they are as buoyant as any cork.

The women spend their time in making mats from young papyrus reeds. These are always in demand as they are used for floor coverings as well as beds in almost every Malagasy hut.

The numerous swamp-warblers in the reed-beds provided us with plenty of music, but the greatest joy came fom watching the beautiful Madagascar Bee-eaters perched in favorable positions on the edges of clumps of papyrus, and darting over the water every now and then to catch flying insects.

It seems opportune to say something of the curious reed-dwelling mammals of the lake, though it was later that I became familiar with them. The most conspicuous mammals in Madagascar are its lemurs, but these are almost entirely inhabitants of the forests, though the Ring-tailed Lemur is more baboon-like in its habits, wandering in troops over the ground in fairly open spaces. Lemurs are rather monkey-like in their mode of life and 
in form, except for their long muzzles, which give the face a foxy appearance. When one has become familiar with the many forestdwelling species, which are very agile, it comes as a surprise to learn of the lemurs in Lake Alaotra that spend their entire lives in the reed-beds, where their movements are so restricted that they have become sluggish, and if put on open ground are unable to run at the speed of man.

These interesting animals, which belong to the same genus as the Gentle Lemurs (Hapalemur), are known to the Sihanaka tribe as Bandro. Being localized and of specialized feeding habits they are probably a distinct species, though this has not yet been recognized. Their fur is short and thick, and in captivity they become very docile and make excellent pets. In the western reedbeds they are very common, but being mainly nocturnal they are rarely seen except by people who hunt them. Their food is composed almost entirely of reeds, particularly the cane-like bararata (Phragmites communis). This is felled by gnawing through the stem at its base, and the animal then grasps the cane with its two hands and tears off the outer hard covering with its teeth in order to get at the juicy core. Its fondness for food of a tough or fibrous nature was illustrated to me by one I kept in captivity. Unlike all the forest-dwelling lemurs, this one took no interest at all in banana fruit but regarded the skins as a great delicacy. It is little wonder that this lemur is sluggish, for it lives where its food is always close at hand and where there are apparently no natural enemies excepting, occasionally, man. In captivity it will eventually get to like fruit but loves chewing young bamboo or sugarcane shoots, and will even eat a certain amount of grass.

Sometimes large areas of reeds, covering several acres and bound together by a mass of aquatic plants, break loose from the main reed-beds in times of severe storms and drift about in the centre of the lake for weeks. Not infrequently reed-lemurs become marooned in this way, but as a rule their isolation is but temporary, for as soon as the dry season begins, the wind is less variable and blows strongly from the east, and as the lake takes some time to subside after the rainy season, these floating islands are thus blown westwards to their former home before they have a chance to establish themselves elsewhere. 
The native method of catching reed-lemurs, which are confined to Lake Alaotra, is to set fire to the reeds towards the end of the dry season, when the old dead vegetation burns easily. This drives them from their hiding-places out into the open where they are easily captured owing to their inability to move at great speed.

Anororo consisted of a single street lined on both sides with reed huts almost touching one another. These numbered about two hundred and fifty, and the whole village of well over one thousand inhabitants covered an area of only four hundred yards by fifty yards. The land side of the village was for most of the year so swampy as to be impassable, and intercourse with other lakeside villages was so cut off that these people had developed a dialect and customs peculiar to their own village. The influence of missionaries has broken down many of their quaint customs, but until very recently the entire lives of the inhabitants were governed by superstition. There were lucky and unlucky days, and these were determined by some complicated system with which no outsider was familiar. Fishing and hut-building, and in fact any form of work that had not necessarily to be performed daily, was never attempted on the stipulated bad days, and intercourse with outside people for the purpose of selling fish was confined to the lucky ones. If a stranger arrived on an unlucky day, he had to wait outside the village until the following day, for otherwise, it was said, he would either die in the village, become violently ill and lose his senses, or get lost and perish on his attempt to depart by canoe.

It was amusing to see shrimps spread out on mats in the streets to dry, with some old native woman sitting in the shade in a nearby doorway with a long papyrus rod with which she shooed off fowls when they came too near. Fowls are persistent creatures, and as they also love shrimps they frequently caught the watchers off guard when they were attending to something inside their huts. The shrimp population of the lake must be considerable judging by the ease with which they are caught and the quantity obtained. It is the women who do the catching and they wade in shallow water dragging their baskets, through which the water is sieved, leaving behind the shrimps.

In the swamps on the land side of the village two large earth 

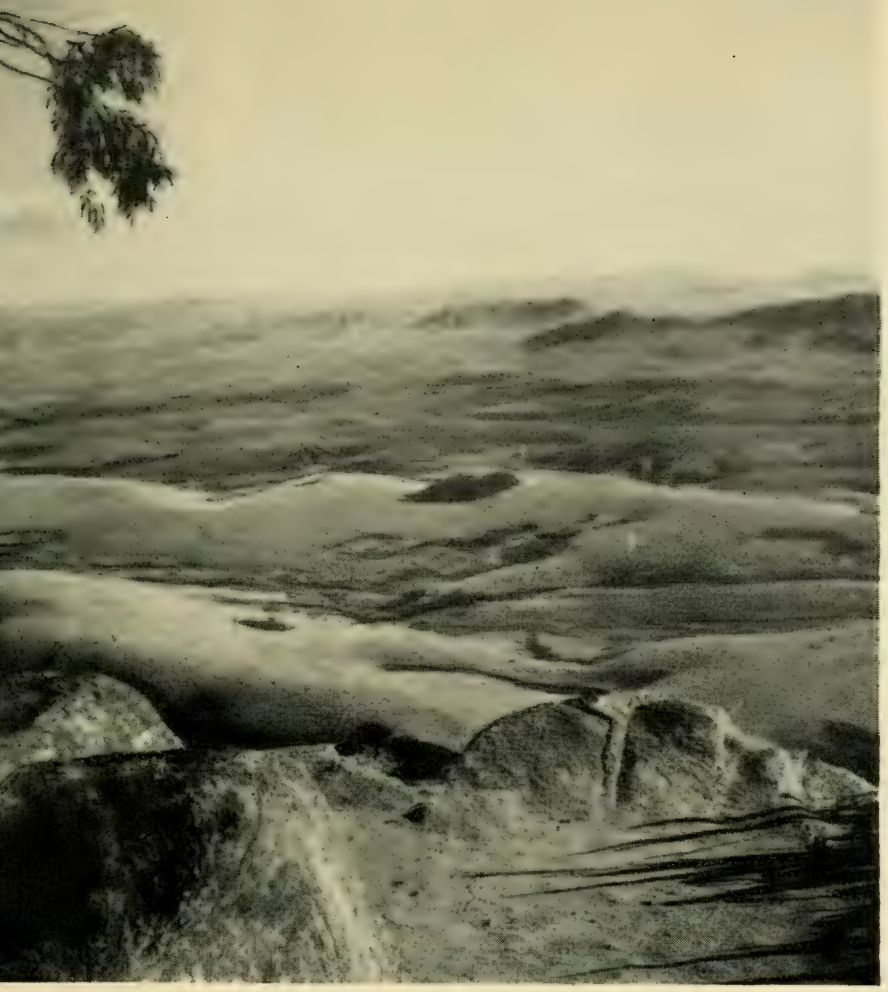

C. S. Webb
Typical view of denuded highlands, Central Madagascar

C. S. Webb

Hand-reared baby Cheetahs

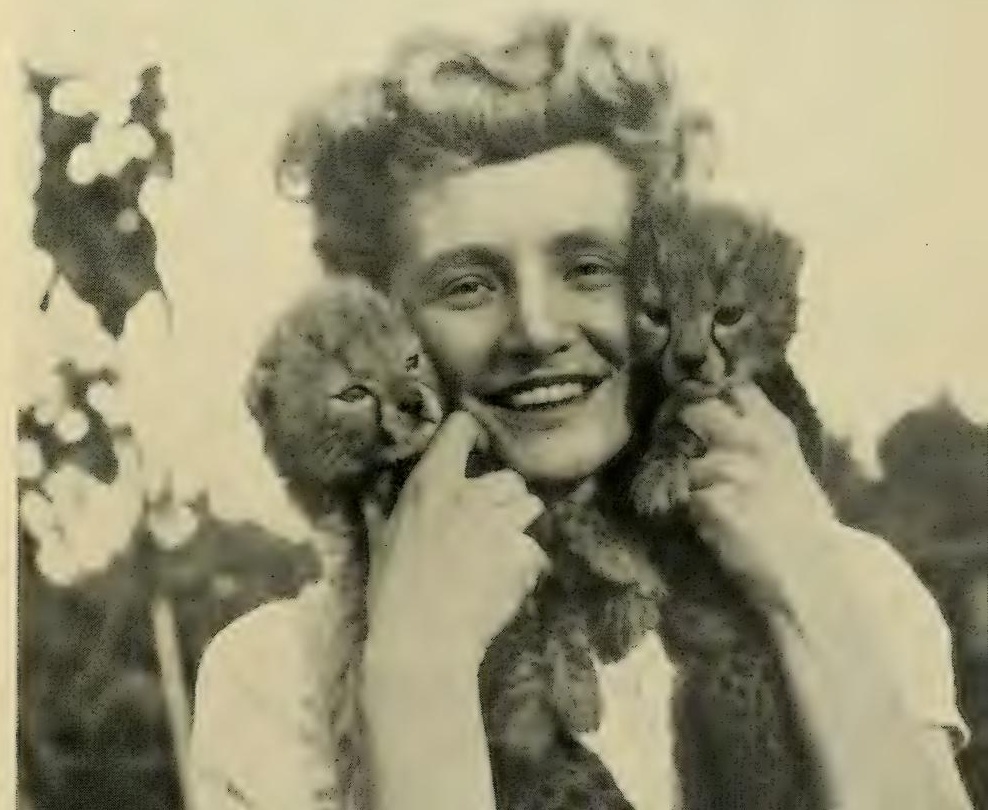




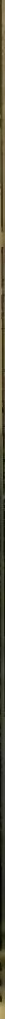

Flooded Antsihanaka village, Lake Alaotra, Madagascar

Demidoff's Galago

Zoological Society of London

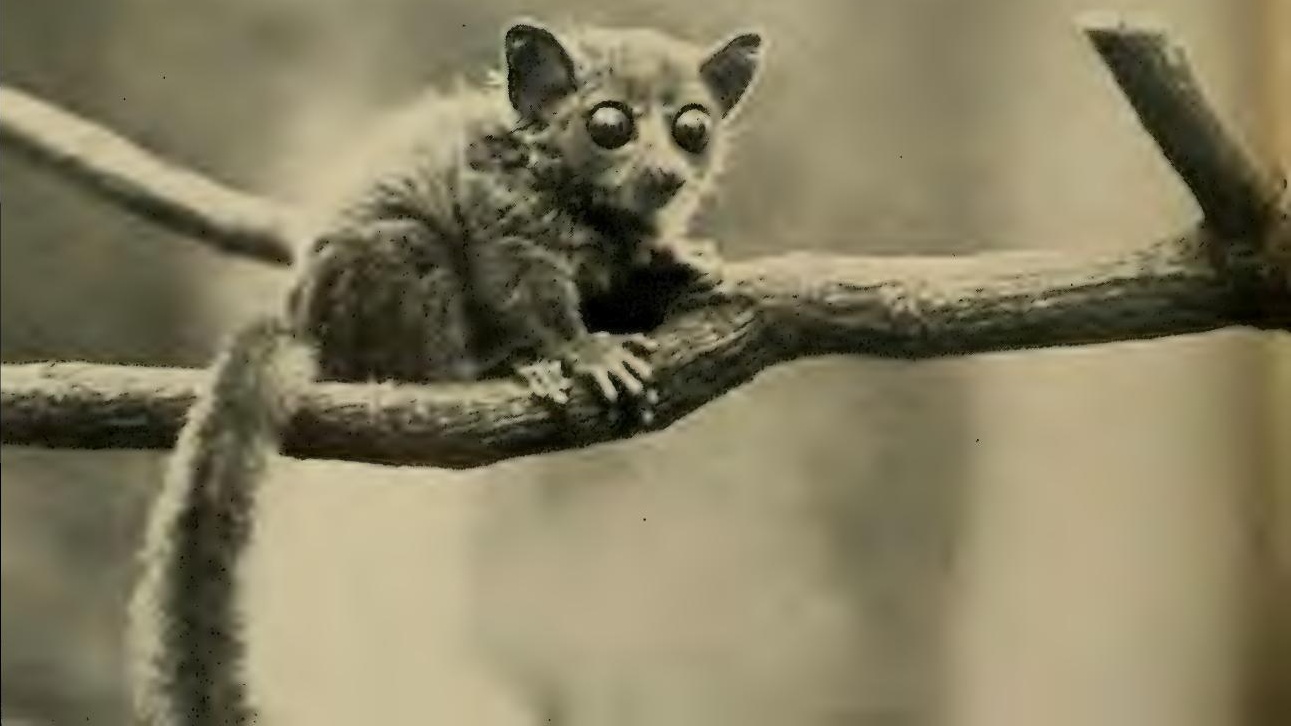




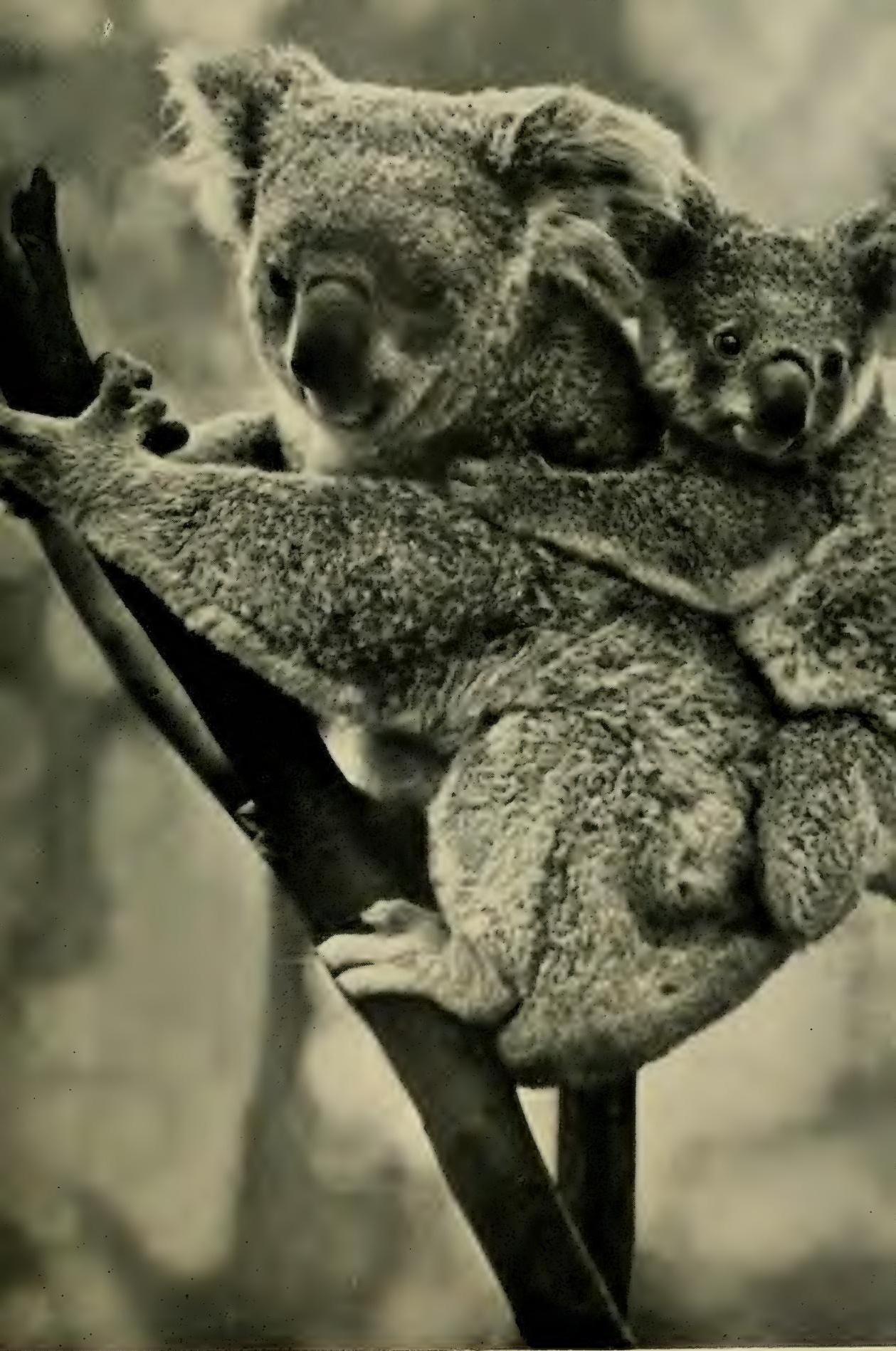

Koala Bear and young, Australia 


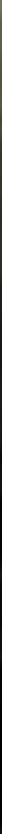

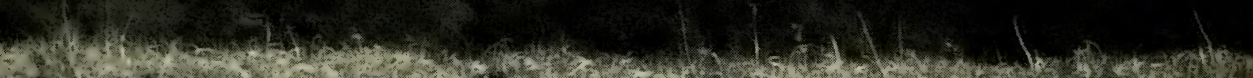
I.W.

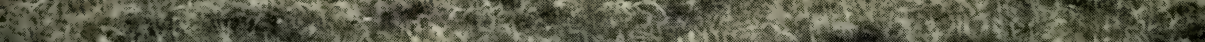

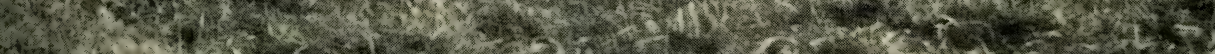

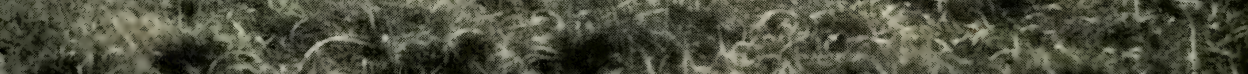
Ly (3) (4)

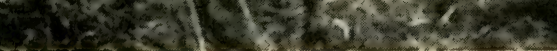

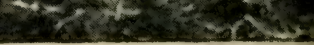

Royal Geographical Society

Distant view of the snow-capped peaks, Himalayas 


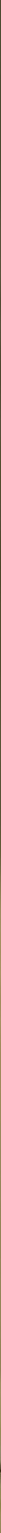

Hoatzin. Adult and young, showing wing-hooks of latter

(Drawing by W. C. Osman Hill, M.D.) 
-

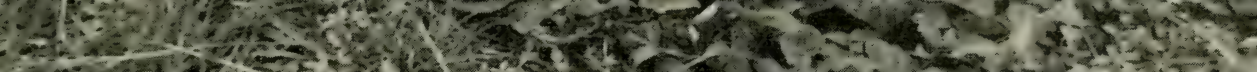

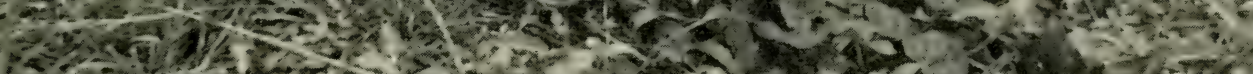

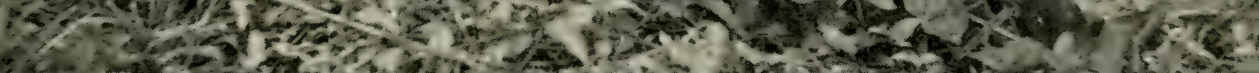

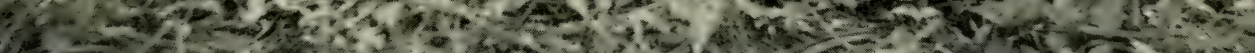

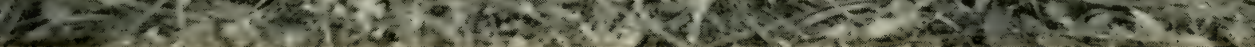

Young Brazilian Tapir, British Guiana

N. J. Smith

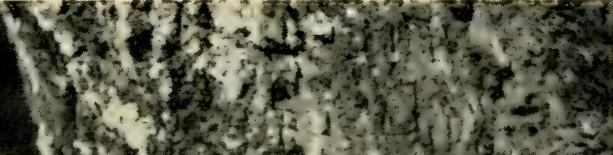

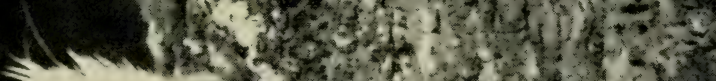

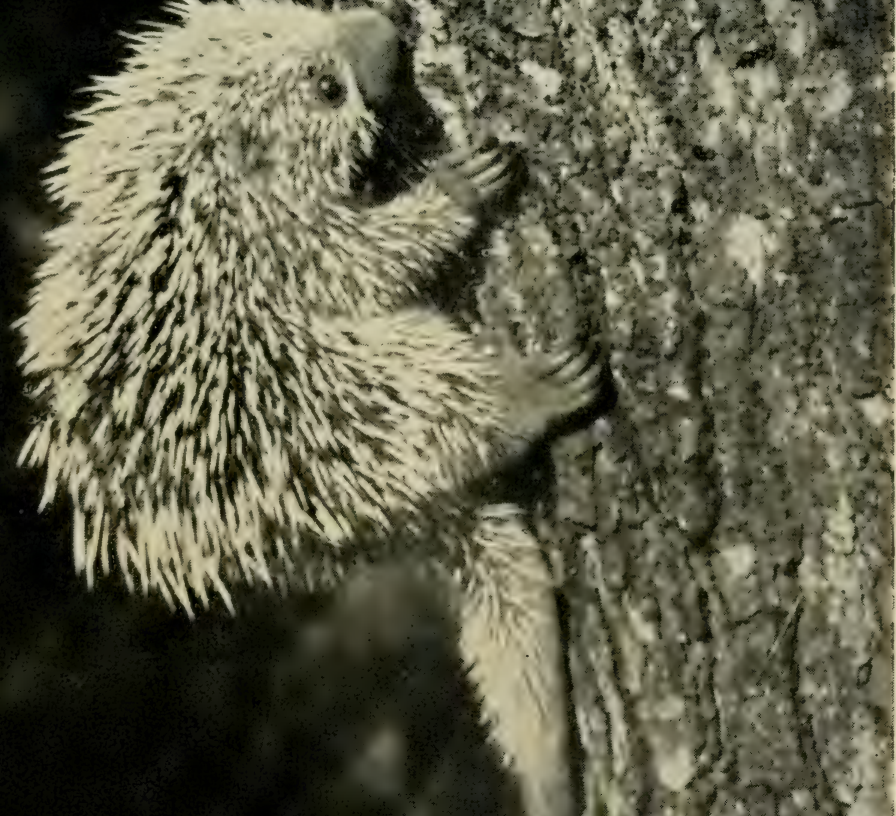

Brazilian Tree Porcupine

N. J. Smith 


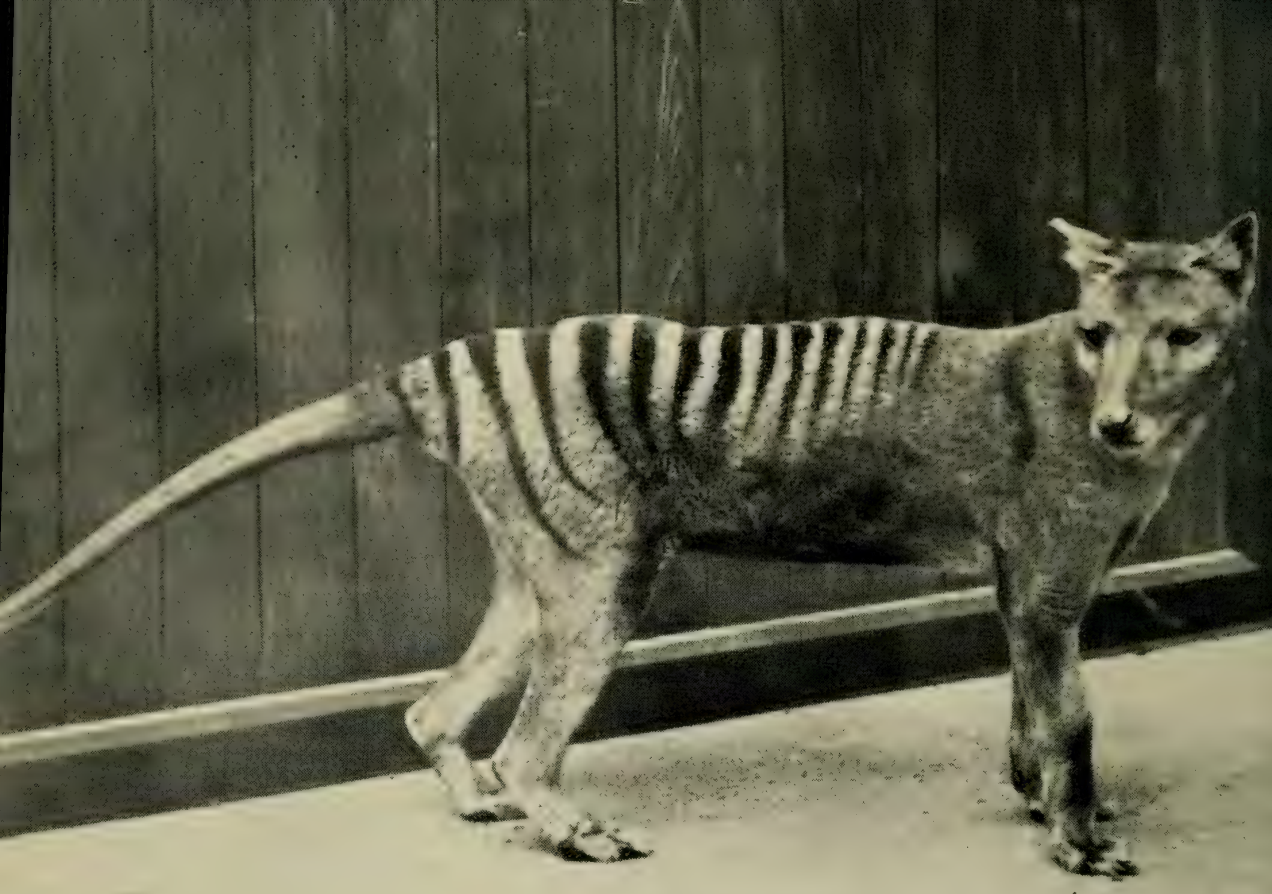

as

Thylacine, or Tasmanian Wolf

Hammerkop, or Hammerhead

F. W. Bond

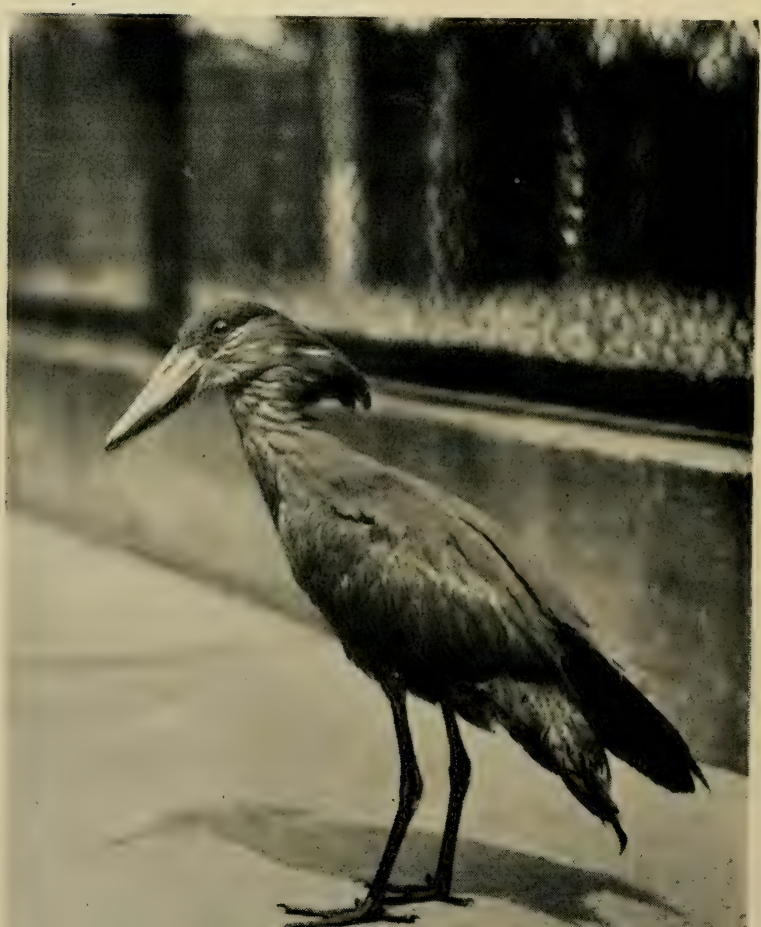




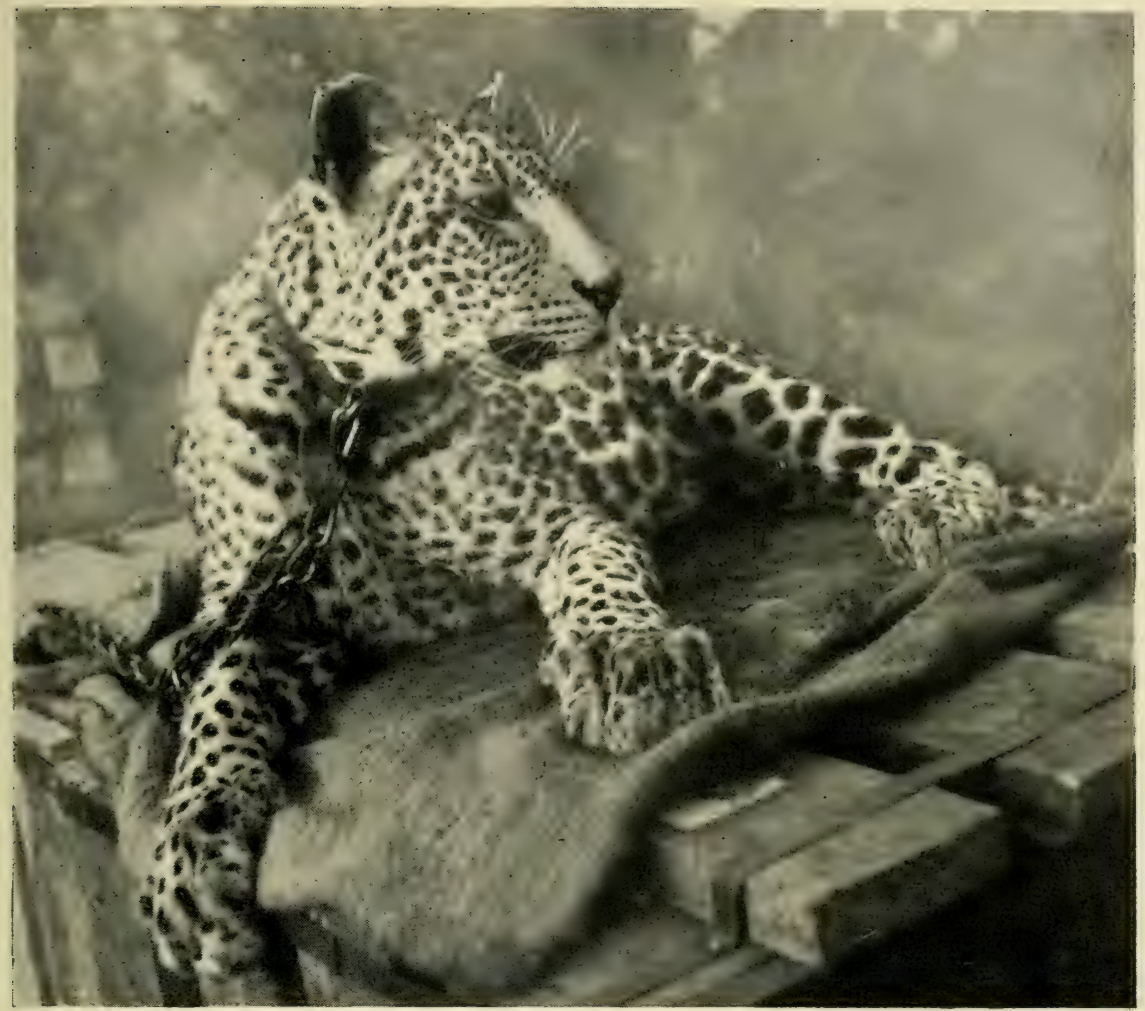

Uganda Leopard "Sandy"

C.S. Hebl

Black Rhinoceros, Kenya Colony

C. S. $H^{*} \cdot b b$

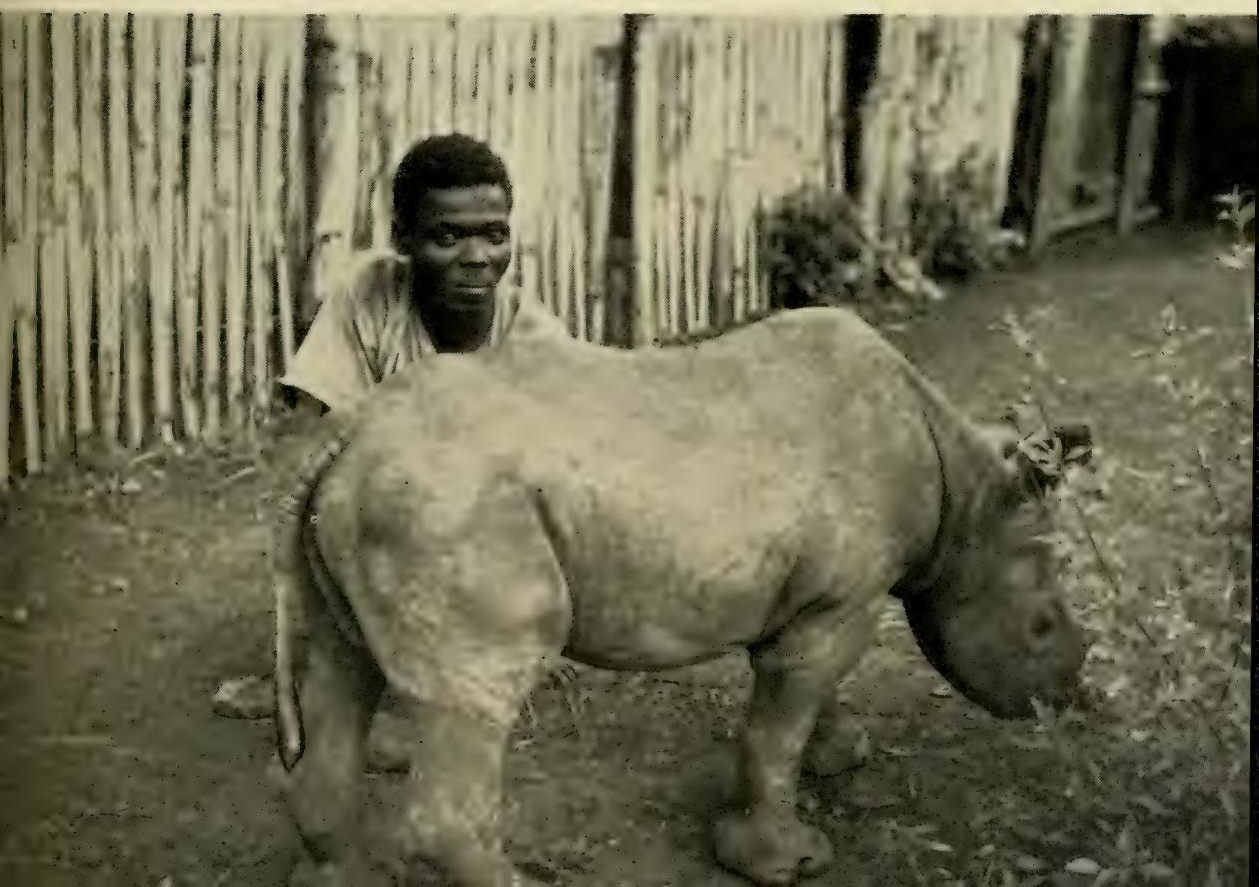




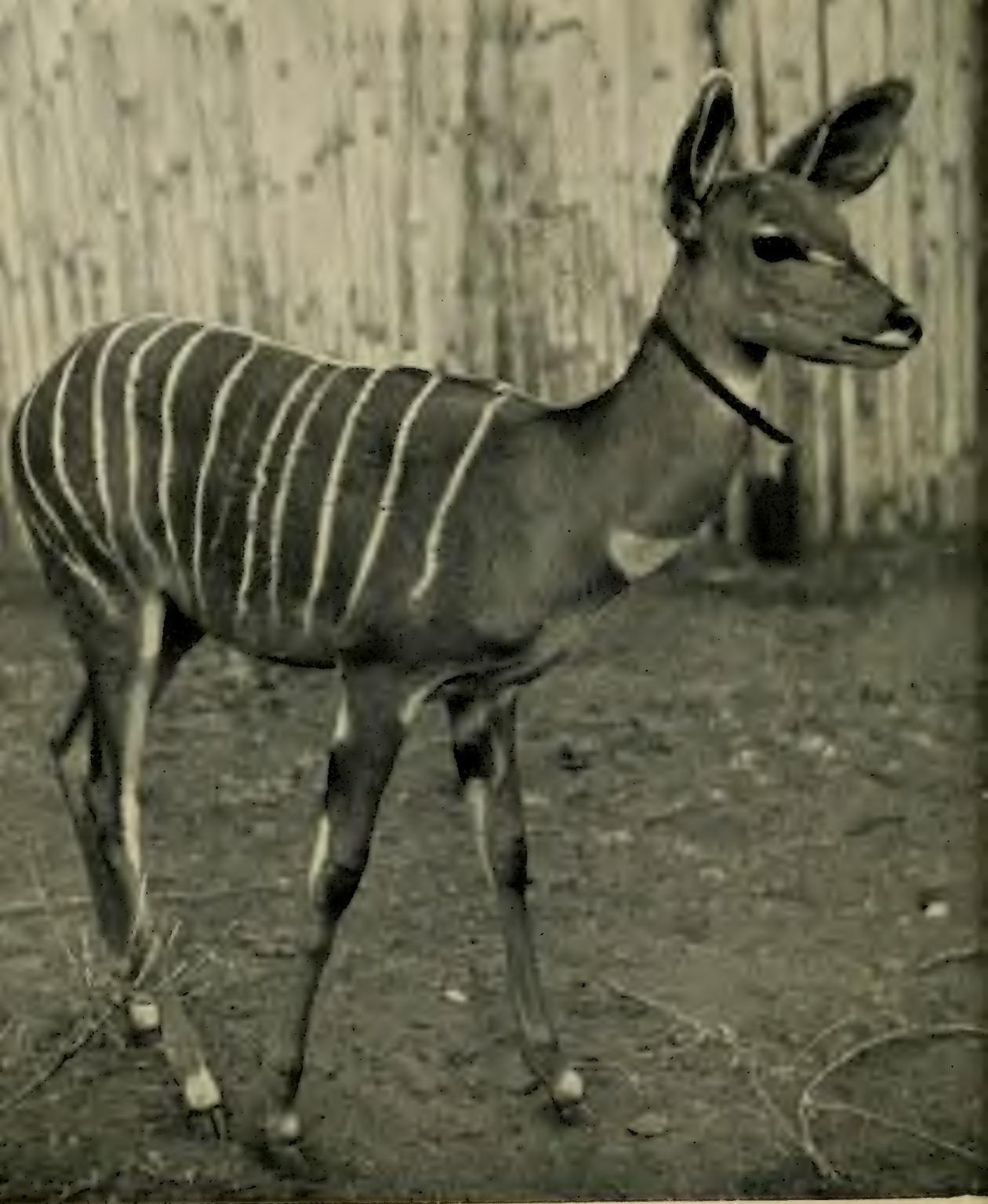

C. S. Webb

"Toto", young male Lesser Kudu, Kenya Colony 
mounds had been made, and these being grass-covered looked like two small hills jutting out of the swamps. They were burial grounds and when someone died a shallow grave was dug for the body, which was then covered and some of the deceased's personal belongings placed on top. These often included a plate so that food could be left at night for the departed one by the spirits who are supposed to succor the dead. To get to the mounds I had to wade a couple of miles, but although so far from the village, my movements were closely watched. I felt rather guilty about this as it is so easy to offend peoples whose lives are governed by superstitions and taboos, for the most trivial things are regarded as ill-omens.

When walking along the one village street I felt, at times, like the Pied Piper of Hamelin, for I was followed by the entire child population, who all wanted to look into my reflex camera. The adults showed no such interest and my missionary friend told me afterwards that they were scared of me. This was no surprise as I have had the same experience everywhere with primitive people. It is probably my unusual height and the fact that I show no fear of them. To this must be added my (to them) unusual profession, for the activities of a naturalist are something they cannot understand. Not only are the villages (according to local belief) surging with brigands, witches, and evil spirits at night, but the lake itself harbors a water-god who controls everything pertaining to the lake. No use complaining or changing the bait if you have had bad luck fishing-it is the will of the water-god. It is he who claims you if your canoe capsizes and who controls the level of the lake.

This mythical creature is a monster with seven heads, and goes under the name of Fananimpitoloha. There are also water-princesses, called Andriambavirano, who have very long hair which never gets wet, but their significance is obscure. Maybe they are the handmaidens to the monster.

After the departure of my friends from Ambatosoratra I was the sole occupant of the railway station, and at night exercised myself by walking up and down the station platform. The night noises were impressive, for the waters of the lake were at that 
season almost up to the line and ducks could be heard dibbling in the water, and the cries of the different species as they wheeled overhead was as thrilling as any music to me. In the stillness of the night sounds echo tremendously over water, and fantastic noises of groans, croaks, squawks and laughs issued from the reeds.

It was only after several weeks, when the lake began to subside, that the natives started bringing in waterfowls. To accommodate these I had converted a trench with fresh running water into a pool by damming, and had made low reed shelters for the birds to hide in when anyone appeared, to prevent their becoming alarmed. The whole was fenced round with wire netting, and when a newcomer arrived one of its wings was clipped and it was then put in the pen.

As the waters lowered and more and more natives got to hear that I was buying waterfowl, increasing numbers arrived with birds in baskets. It was always exciting going through them, for often there was a very mixed bag. The easiest to get were Hottentot Teal, which were brought in in numbers. They are minute and pretty but rather delicate until one knows their exact requirements. In lesser numbers were Meller's Duck-like a very large mallard-Red-billed Duck, Fulvous and White-faced Tree Ducks, Madagascar Pochard-a species confined to Lake Alaotra-and, more difficult to get, the White-backed Duck. The latter is a diving bird of the stiff-tail group and is most attractive.

The most interesting of the reed-dwellers was Allen's Porphyrio or Gallinule, a bird rather like a moorhen with its upper-parts olive-green, head black, and the underside dark purplish-blue. I cannot say for certain that I ever saw this pretty bird in the wild state and yet so many were brought to me that I had to refuse buying them. It is one of the skulking reed-dwellers easily trapped by natives, but which rarely shows itself outside of its natural retreats.

The ducks were fed largely on paddy, i.e., unhusked rice, and duckweed, which grew profusely on any stagnant pool and in ditches. Many of the waterfowl, and particularly the gallinules, relished the seeds of water-lilies, which I had to collect by canoe. When the water-lily flower dies the seed-pod sinks after a while, 
so many were brought up with the aid of a hooked stick by fishing for the long stem. There were two varieties in the lake-one white and the other a lovely blue. As a matter of interest I brought back a number of seeds of the latter, giving some to Kew Gardens and some to private people. I had taken every care to see that the right color was gathered, so was surprised to hear some years later that the seeds had all produced white flowers. After telling all concerned that the seeds were those of a beautiful blue variety my feelings can be imagined. However, many years later I read in a book on the flora of Madagascar by a French botanist that this particular water-lily is dimorphic-the situation in which it grows apparently affecting the color.

More difficult than the acquisition of waterfowl was getting material to make their traveling crates. For this I went to Ambatondrazaka - the nearest town-where I bought up numerous packing cases from the Chinese storekeepers. The problem arose of how to collect all these, which were scattered about in at least a dozen shops, and to get them to the station, which was the best part of a mile away. The simplest thing seemed to be to seek the advice of the Chef de District: he solved the difficulty there and then by calling out a number of prisoners in charge of a guard, who were instructed to follow me, drawing a large hand-cart.

The collection by now was considerable, and at no time have I had less trouble to get my livestock on to a train. On the appointed day an engine drawing a covered van was sent from Andréba-then the existing terminus-and drew up alongside my private platform where everything was stacked in readiness.

The Forestry Department had agreed to collect a number of mammals, and these were linked to the train at Moramanga on the way to the coast. This collection was far larger than I had expected and included many beautiful lemurs such as the large black-and-white Ruffed Lemurs, and several of the rufous phase of this animal. But most interesting to me were five aye-ayestwo true pairs and a baby.

The aye-aye is about the size of a large cat and has a long bushy tail, large eyes and big ears. It is nocturnal, and its odd appearance has given rise to some extraordinary superstitions. In fact the natives of eastern forests where the aye-aye lives are so scared 
of the animal that nothing will induce them to attempt to catch one. Although superficially it appears to have few, if any, affinities with the lemurs, dissection has proved this relationship; so in the aye-aye we see one of the finest examples in nature of an animal having modified itself to a particular mode of life.

The middle finger of each forehand is curiously slender, like a piece of wire, terminating with a curved claw. This is put to special use, for aye-ayes live largely on the wood-boring larvae of certain beetles. With their large sensitive ears they can hear the grubs at work in rotting wood, and having gnawed some of the wood away with their rodent-like incisors, the wiry finger is thrust into a grub-hole, hooking out the fat tasty larva with the claw.

To assist in keeping these animals fit on the boat, the Forestry Department had thoughtfully sent a supply of these larvae packed in chips of damp rotting wood. Next to beetle grubs they seem to favor raw eggs; these I gave daily to my specimens on board, and the mode of eating them was fascinating to watch. The animal holds the egg tightly in one hand, then bites a small hole in the top, and holding the egg close to its mouth it passes the wiry finger into the contents, then into the mouth with a flick; this is repeated continuously with great rapidity till the shell is empty.

Strangely enough ripe bananas were eaten in the same manner by flicking pieces into the mouth with its middle finger. The pair with the baby I took to the Jardin des Plantes in Paris and the other pair to London, and this is the only time these odd creatures have been brought to England since the First World War.

On our way round Madagascar we put into Nosy Bé on the west coast and there picked up another large collection that the local officials had been asked to get together. This included about twenty specimens of the Black Lemur-a species common in northwest Madagascar, and distinguished from other lemurs by the sexes being of different coloration. The females are rufous.

Lemurs, like many other mammals, have special adaptations for performing their toilet. In their case the lower incisors and canines are grouped together to form a comb, which protrudes from the lower jaw almost horizontally. These teeth are no longer employed in feeding, but are used solely for the purpose of comb- 
ing the fur, and consequently the upper incisors through lack of usage are small in some species and absent in others.

A further unique toilet arrangement in the lemurs is to be found in the feet. Whereas flat nails are found on all the fingers and four of the toes, the second toe on each foot is furnished with a pointed toilet claw for scratching. 


\section{Chapter Eight}

\section{PORTUGUESE EAST AFRICA (SOUTH)}

A FTER spending the following summer in England, I again took the overland route to Lourenço Marques in the southern part of Portuguese East Africa. This journey was via Pretoria and thence through the eastern Transvaal, passing the southern border of the Kruger National Park. This part of Portuguese East comes under the direct administration of Portugal through its Colonial Office, and not of a chartered company as was the case with the Mozambique Territory further north.

Lourenço Marques is an attractive city with fine buildings and tree-lined avenues. It has good hotels, golf, and a splendid beach, but its chief attraction to thousands of holiday-makers from the Union is, I think, that there are no restrictions against drinking, dancing, and gambling, or other forms of pleasure.

Inquiries led me to visit a place on the Umbeluzi River on the road from Lourenço Marques to the Transvaal, about thirty miles inland, and only twenty miles from the Swaziland border. Here I was fortunate in being able to stay with a young couple, a New Zealander and his Dutch wife, who were managing a dairy farm.

The Umbeluzi is a picturesque river which in the dry season is very narrow except for intermittent pools. The waters look inviting enough, but, as in most of the hotter parts of Africa, bathing is not a recognized pastime owing to the presence of crocodiles.

During my acquaintance with the Umbeluzi, stories concerning the activities of these creatures were rife as a number of natives, principally women, had been recently devoured when drawing water or washing clothes. Even my own native servant's brother 
was taken soon after my arrival. As with lions, such trouble is usually attributable to a few individual animals which become very cunning. The extraordinary thing, to a European, is the fatalistic manner in which natives accept these tragedies, but this is explained by the fact that when a man dies in the ordinary way his spirit is supposed to enter a crocodile, so it is not surprising that this animal is held sacred. The spirit it harbors controls the destiny of near relations, and so when a tragedy occurs it is considered to be the will of a departed ancestor.

One day I took my boy along the backwaters of the Umbeluzi trying to fish out some water-lily seeds which I required as food for some of my aquatic birds. After making slow progress with a long bamboo pole he calmly walked into the water up to his neck, and gathered all the pods I required, in spite of having lost his brother a short while before.

The long seasonal dry weather was broken by a storm, after which rain was plentiful. I awakened one morning to find that the Umbeluzi had overflowed its banks. The house I lived in overlooked a low-lying plain some six miles by three, all of which was now inundated and converted into a large shallow lake. As if by magic hundreds of waterfowl, herons and waders, etc., appeared on the scene overnight, and were busily engaged in mopping up the myriads of floating insects, mainly grasshoppers, that nature had so generously trapped. Every patch of floating vegetation, and even the smallest lump of debris, supported masses of ants, grasshoppers and other insects caught by the rapid flooding of such a large area. Small rodents were also much in evidence, some drowned and others clinging desperately to any floating material that offered support, but all doomed sooner or later to be devoured by the army of birds. It would be interesting to know what induces such a variety of bird-life from distant places to converge simultaneously overnight on a given point knowing that a sudden flood has arisen and that this will produce masses of trapped insects and other animal-life, whereas a permanent sheet of water in the same district will offer very little by comparison.

The scene from the adjacent hillside was breathtaking. The water glistening in the powerful sunlight was studded with Pygmy Geese, White-faced Tree Duck, and White-backed Duck 
skimming across it. The larger birds-storks, ibises and heronswere having a wonderful time gorging themselves while the opportunity offered. One of the most conspicuous and numerous birds, and one that I had not seen in the vicinity until the flood came, was the long-legged, rail-like jacana (described in a previous chapter). Its liquid call-notes echoing across the water added to the general din of the large assemblage of water-loving creatures.

There was a permanent pool covered with water-lilies and bordered by dense reed-beds in the center of the plain mentioned

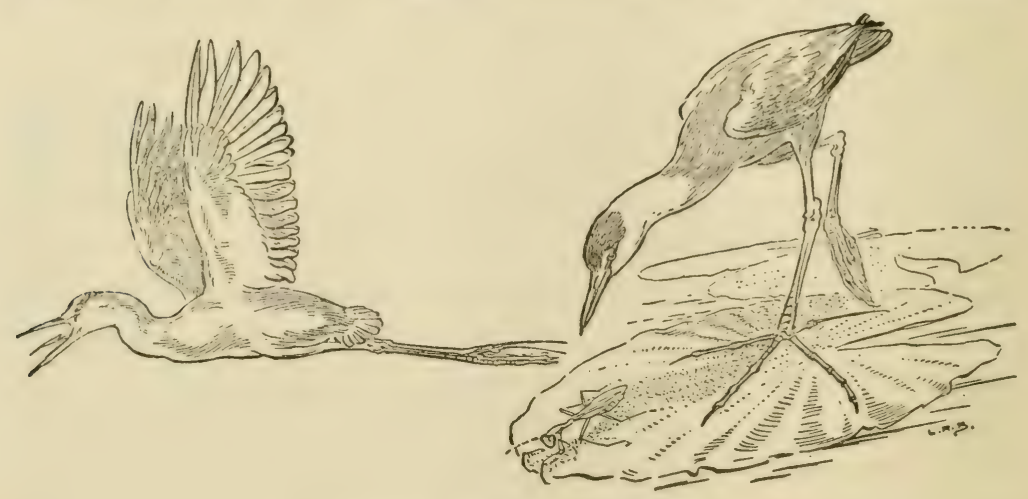

JACANA, OR LILY-TROTTER

above, which was unaffected by the dry season, but now that the rains had arrived this pool was in the middle of a lake and its deep fringe of reeds provided a natural retreat for crakes and rails, and the whole assemblage of waterfowl. On account of the water-lilies, jacanas also favored this spot, and by setting hanging nets in the long channel between the reeds I had no great difficulty in catching them.

To do this I was fortunate in being able to procure a large punt which, although being far too heavy and cumbersome for forcing one's way through the reed-beds without the greatest difficulty, was nevertheless the means of my obtaining many specimens that I could not possibly have collected otherwise.

The keeping of jacanas for the first two weeks after capture proved to be a difficult problem. Some specimens would remain in precisely the same position in their new roomy quarters as when first released from the hand. Thus it was not unusual to find one 
standing with one of its long legs forward and the other backwards, as if about to start a race, and for it to remain like this for hours, until moved bodily into another position. Their sphinx-like postures were not disturbed in the slightest by any noise, movement, or the introduction of every conceivable kind of natural food. Specimens that behaved in this way were no use persevering with and so they were liberated. Others were induced to begin feeding by placing their natural food-water-lily seeds and insects -in a shallow pan of water so that they could paddle through it. My difficulties were not at an end even when I had several birds apparently quite happy and feeding well, for some of them developed staggering fits. In this complaint the head was held back to such an extent that frequently the victim would roll over backwards. This was rather puzzling for I knew that it was through no fault in their diet, and I could find nothing that had any effect as a cure. The symptoms usually appeared within a few days of capture, but when I arrived at the London Zoo with three apparently perfect specimens, I was surprised a few days later to find that one had developed the same trouble, and it died quite suddenly. A post-mortem examination revealed nothing organically wrong, to the naked eye, so the blood was examined microscopically for parasites, and was found to contain filaria worms in great quantity. This solved the mystery of the previous cases of fits. These minute worms are introduced into the bloodstream by the bites of mosquitoes, and it is only natural that swamp-dwelling birds should be the most likely to be preyed on. It shows that many parasites are quite harmless to birds and mammals in their wild state, but the slightest falling off in condition, due to change of diet or temperature such as may occur in captivity, disturbs the delicate balance between the parasites and their host.

One day I caught a very young jacana in a floating cage-trap that I had set among the water-lilies in the hope of catching a Pygmy Goose. It had a most comical appearance as its legs and feet were even more out of proportion to the size of its body than in the adult birds, reminding me of a small boy wearing his father's boots. I liberated this bizarre specimen to see how it would thread its way across the water-lily leaves and other aquatic vegetation to the reed-beds, but to my surprise it instantly dived like 
a grebe and could be clearly seen under the water, making its way rapidly towards the reeds. I have never seen adult jacanas dive or swim, so I assume that this is a provision of nature for the protection of the young before they are fully feathered and have the power of flight.

I was very anxious to get a few specimens of the White-backed Duck and the Pygmy Goose, neither of which, at that time, had been seen in captivity in England. The latter is one of the smallest and prettiest of all waterfowl. Unfortunately my nets were not constructed for anything larger than a jacana, and more often than not a duck colliding with one would just bounce off without being caught.

My plan, on seeing some waterfowl on the pool, was to edge my way through the reeds, slowly approaching the deep water at the end opposite the nets, so that when I emerged the birds were on a straight and narrow stretch of water, hemmed in by reeds, between me and the nets. Then entering the long channel, I would propel my punt at great speed towards the birds, my hope being that they would keep low and skim along the water without rising over the tall reeds, and thus hit my nets. However, one learns more about birds' actions when trying to trap them than in any other way, and I soon found that Pygmy Geese can twist and alter course with an extraordinary facility. Several times, after having waited days for a favorable opportunity, I managed to institute a successful drive, only to see the birds suddenly swerve high over the nets when apparently about to collide. The Whitebacked Ducks, being heavy birds with a more clumsy flight, were unable to perform these antics, and I got a pair without much difficulty.

I shall never forget the capture of my first Pygmy Goose on this expedition. I had got as far as driving it into the hanging nets, but it was not properly in a pocket, and as it struggled I could see that it was only a matter of moments before it freed itself. Propelling the punt at a speed never attained before, I approached the nets, which were right in my path. The goose was nearly out and was about to take off when I dropped the pole and grabbed him in mid-air, but under the great weight and impetus of my bargelike craft the nets collapsed and enveloped me. However, I clung 
to my prize, too delighted to be worried by the fact that the whole affair would cost me hours of patient toil repairing and resetting the nets.

When on these excursions, I often used to hear the distinctive call of the Black Crake. This is a delightful bird with red legs, a yellow bill and black plumage, and like our moorhen, it frequently bobs its tail. Being fairly common, it is often heard but rarely seen, as it loves skulking in reed-beds but shuns open places. By setting a cage-trap with rotting vegetation on the floor to give it a natural appearance, I caught several specimens in the reeds by using maize-meal as bait. I have an idea that the birds entered the trap as much out of curiosity as for food, for although they will eat a certain amount of maize-meal, their natural diet is mainly insects and seeds. I had an unusual experience one day when I was sitting quietly in the punt setting a floating cage-trap. Looking up I saw a Black Crake timidly making his way over the water-lily leaves towards me. He was doing much clucking and tail-bobbing, indicating nervousness. I kept perfectly still and on he came, finally hopping on to the opposite end of the boat. His curiosity satisfied, he flew off and landed in the reeds-a brave effort considering the bird's natural shyness.

Snakes abounded on the wooded ridge surrounding the newlyformed lake; many, I suppose, had been driven there by the flood, and others were attracted by the army of frogs and the rodents driven fom their homes. As I was collecting anything likely to make an interesting zoo exhibit, these creatures provided me with plenty of excitement. Most of them, especially the Boomslangs and Green Mambas, were located in trees, and as these were thorny acacias it was no easy matter getting them out. The surest way of finding any snake in a tree was to go where a gathering of bulbuls were chattering excitedly in the branches. They are always the first to give vent to their alarm notes on seeing a snake, and this, in turn, attracts other birds, so that in the end there is usually a terrific hubbub coming from a host of different species, all wild with excitement.

The natives themselves were afraid of the snakes, but at least they were useful in locating them (aided by the birds), and letting me know their whereabouts. In spite of their fear, there was 
nothing they liked better than to watch me fish a large snake out of a tree, and often they would heave stones to get it to change position, so that I could more favorably operate my snake-stick. This was a contraption consisting of sections of bamboo fitting into one another like a fishing-rod, but much stouter. A thin strip of leather was fastened to the end of the rod, and then passed through a small hole a little over an inch from the end. To the loose end of this leather thong, a piece of cord as long as the pole was fixed. A loop of any desired length could be made by adjusting the leather thong between its fixed end and where it passed through the hole, and a tug on the cord immediately tightened the noose. All one had to do, thorns, leaves, and branches permitting, was to slip the noose over the snake's head, not bothering whether it was round his neck or body, and pull the string, keeping it taut. The snake was then pinned against the stick by the pressure of the thong, and could be hauled down. If he were caught near the neck, the operation of slipping him into a large sack was simple, as it was only necessary to close the sack tightly round the snake-stick, relax the tension on the cord, and so let the snake wriggle free. However, if caught in the middle, he was free to strike in all directions, thus making it too dangerous to get him into the sack; in such cases I used to walk home carrying the imprisoned snake on the pole, and then drop him straight into a traveling box specially provided with a lid on the upper side.

The fast-moving snakes are much more easily caught in trees than when on the ground. In the latter case, they travel at great speed through the grass and are difficult to follow, but in the trees they rely upon their protective coloration and remain fairly stationary. As their attention is glued on the person holding the snake-stick and not on the stick itself, there is little difficulty in slipping the noose over the snakes' heads.

Once I caught a snake in a most unusual manner. I had set a cage-trap, a home-made box-shaped affair made of wire netting with a drop-front, at the base of a wild fig-tree, hoping to catch an unusual squirrel I had seen there, but on visiting the trap found a rat had been caught. Being in a hurry to visit other traps and nets, I left him there and came back some hours later to reset the trap, but to my astonishment the rat had disappeared, and a snake 
had taken its place. This appeared at first to be a piece of magic, until I saw a bulge in the snake's stomach indicating that he had squeezed through the wire-netting, swallowed the rat, and was then unable to escape owing to the resultant bulge. Snakes were more plentiful here than in any place I had been, and once, when I was stooping making some fine adjustments to a spring-net trap, there was a sudden squealing only a few yards away. It was an intensely hot day- $-10^{\circ} \mathrm{F}$. in the shade-following a heavy downpour. The sun had come out with full force and had converted the place into a Turkish bath with steam rising from the bare wet soil around me. This condition suited the frogs, and it was one of these that was now squealing for dear life.

As I turned round I saw what I took to be a Green Mamba slithering at great speed towards the slow-moving frog, who knew before he was caught that he was doomed. The snake seized him by the rump, prior to the slow business of swallowing him, thus allowing the frog for a while to keep up his pitiful squealing. I had no snake-stick on that occasion, and was unable to find anything at hand suitable to pin the snake down, so he was able to escape; I did not allow my enthusiasm to take risks with a snake reputed to be one of the most venomous and aggressive of all the African reptiles. It was just another example of the terrific slaughter that goes on daily in the tropics through one animal preying on another.

I must say that I was happiest when punting. Tropical swamps have always fascinated me, as they attract a wealth of bird-life which is easy to observe. Another thing is that getting wet in tropical conditions is rather a joy. On one occasion when I was propelling the punt in professional style, my unusual height helping me to manipulate the long punt-pole with ease, a submerged stump stopped the boat dead and I fell overboard backwards. Such an experience would probably be fatal to me in the cold of a temperate zone, but here I thoroughly enjoyed it. The only thing about the swamp that displeased me was its leeches, so when wading I used to wear old shoes, and tuck my trousers inside my socks, thus defeating their attentions. These parasites are not dangerous to humans, though they make punctures in the skin that bleed freely after they have been removed. It is when they fasten 
on to creatures incapable of dislodging them that they become so loathsome. I have often seen them attached to the hind legs of cattle, where they remain and gradually distend with blood until they hang down like red sausages.

As far as dry land was concerned, one had to be very wary of certain areas in which minute red ticks swarmed in millions on the long grass. Sometimes my trousers became red with them, though individually they are only the size of a pin's head. They burrow into the flesh and, being so small, are difficult to find in certain parts of the anatomy. If not removed shortly after attaching themselves, nasty irritating spots which itched for days resulted, and when these were numerous the irritation was unbearable, sometimes giving rise to fever.

Having often, on previous expeditions, seen birds "mobbing" a snake, I got the idea of using a live one as a means of luring birds to my nets, so one day I suspended a specimen from a branch by a piece of cord. Its writhing soon attracted a few birds, but before things had really had time to get going the snake wriggled itself free, and not relishing the idea of juggling with a poisonous snake every time it got loose, I gave up the attempt. The experience, however, was not wasted, for on this expedition I applied the same principle in another way.

While at home I had managed to obtain a stuffed owl, complete with large yellow eyes. Birds will, of course, mob an owl in much the same way as they do a snake. Although doubtful whether a stuffed specimen would act like the real thing, I was determined to give it a trial. For this I chose a large tree with long spreading branches, and high up in the gaps between them I set a number of small flue nets. Next a springy sapling was secured, and the stuffed owl attached to it near one end. This springy stick was fixed so that it jutted out horizontally from the trunk, but lower down than the nets, as the tendency is for birds to gather in a circle above the object of curiosity, so that they are looking down on it. The owl was at the end of the stick away from the tree trunk, and to this end was fixed some black thread, which led to my hiding-place not far off. A gentle tug on the thread was sufficient to set the owl dancing up and down on its springy perch.

The main idea of all this was to catch some of the sunbirds 
which feed on the flowers of the high trees, and do not descend near the ground. These birds do not normally fly through the branches of trees, as their food is on the outside, so they are extremely difficult to catch in the ordinary way. It is perhaps as well for my reputation that I was in the wilds of Africa while carrying out this experiment, for I feel sure if anyone had seen me pulling a thread and causing a stuffed owl to perform strange antics on a stick, he would have had serious doubts as to my mental condition, especially as I could not help grinning when a few birds arrived and gazed on the restless yellow-eyed demon below with great alarm. Strange as it may seem, this "Heath Robinson" device was very successful and enticed quite a few rare sunbirds. However, they were not inclined to fly through the gaps where the nets were set, but merely hopped from one branch to another.

Unless a bird is going at speed, hanging nets will not function, as some force is required to form a pocket, also a net is easily detected if it is approached gradually. To remedy this state of affairs, I crept from my hiding-place and threw a fair-sized stone high into the air, so that in falling it crashed through the centre of the tree, causing all the birds to fly outwards through the gaps at full speed. I, of course, rushed to the tree and climbed it rapidly to find that quite an assortment of birds was caught, including three of those I specially wanted.

After that, this same stuffed owl performed signal service in many lands, but finally perished on the field of battle on another expedition. I was trying him out one morning, but was unable to get a start. This is always the most difficult part, for once a few birds arrive and begin chattering excitedly, the rest follow as a matter of course. As it was a very hot day, I went home for a drink and left the owl on a tree stump, but when I returned it had vanished. After a brief search I found a few tell-tale feathers, and following the trail, found my poor owl under a thick bush with his cottonwool innards hanging out. Evidently during my absence it had gathered an audience, and the pandemonium that ensued must have attracted a carnivorous animal, such as a mongoose, on the look-out for his dinner. The owl, being nearest to the ground and not being able to look after himself, was attacked and "killed" for the second time in his long and varied career. I 
would like to know what the animal thought about it when it sat down to eat its meal, to find that it had caught a freak of a bird without flesh, blood or bones.

Two of the most beautiful species of birds, and certainly the most difficult to establish of those I collected here, were a pair of Pygmy Kingfishers and some White-fronted Bee-eaters.

The kingfisher family is spread over most of the world and its numerous species comprise some of the most brilliantly colored birds in nature. The English name, however, is misleading. The Giant Kingfisher, or Laughing Jackass of Australia, for instance, devours almost any form of small animal life including birds, rodents, lizards and crabs, etc., and in Africa the majority of species live on insects-not fish. The Pygmy Kingfisher belongs to this group, and is not so difficult to accustom to an artificial diet as the purely fish-eating species. Its diminutive size and exquisite beauty never fail to make an impression when seen for the first time. It may often be seen sitting motionless on the tip of a dead branch, usually on a bush, watching for the movement of a grasshopper which, when detected, is immediately pounced upon, but in the heat of the day it loves to get into some cool spot where a clump of trees offers abundant shade. In such situations it was always getting caught in my "invisible" nets set for other birds, for it makes a swift direct flight, without caution, through dark gaps in the foliage.

Kingfishers, on account of their nervous disposition, are essentially aviary birds, and are, on the whole, not suitable for cage life. Apart from this, their full coloration is not revealed unless in flight. I rarely attempted to keep any except those taken straight from the nest, before they had any fear of man.

The bee-eater belongs to the same order as the kingfisher, but having entirely different feeding habits has developed certain features essential to its mode of life. One species inhabits southern Europe but most are inhabitants of the tropical and sub-tropical regions of the Old World.

Bee-eaters live mostly on winged insects and consequently "hawk" all their food in the air. For this they are well adapted, having long pointed wings and short legs, and what a joy it is to watch them performing their aerial acrobatics, twisting this way 
and that while chasing their prey! The most striking of all is the Carmine Bee-eater whose beauty and elegance leave one almost spellbound. I often watched them in Portuguese East Africa attending grazing cattle-at times perching on their backs. They have learned that cattle in long grass disturb grasshoppers that would otherwise be difficult to catch. A great proportion of these insects are of the flying kind and when disturbed travel ten yards or so and then flop down again, their protective coloring then rendering them invisible. It is during this short flight that the bee-eater takes off from the back of an ox or some adjacent branch, and swooping through the air, snaps up the grasshopper before it has time to drop into its grassy retreat.

On one occasion there was a grass fire raging and I saw a large assembly of Carmine Bee-eaters perched on bushes and other points of vantage near the advancing flames. The smoke and crackling of burning vegetation was a signal to them that a feast was at hand, and as the heat drove myriads of insects from their normally secure hiding-places, the bee-eaters swooped on them unmercifully.

I left Lourenço Marques with a large and varied collection of birds and snakes; many of the former were new to aviculture, including White-fronted Bee-eaters, Pygmy Kingfishers. Whiteshouldered Robin-chats, Southern Helmet Shrikes, Pygmy Geese, and Yellow-wattled Plovers, and the rest were exceedingly rare in collections. 


\section{Chapter Nine}

\section{BRITISH GUIANA (I)}

TN the winter of 1930-3I I set off for British Guiana by a Dutch 1 boat, calling en route at Madeira and Paramaribo, capital of Dutch Guiana. In making this trip I was influenced by my old friend Dr. Vevers, who had visited the Colony ten years previously to study tropical diseases.

He had described to me the hoatzins in the Canje Creek; the trumpeter birds, bell birds, macaws and parrots, of the jungles; the wonderful humming-birds; and the queer inhabitants of the great rivers. This was enough to rouse my curiosity, and the study of the bird-life from books and from skins in the British Museum determined me to see all these wonderful creatures in life.

As we neared the shores of Dutch Guiana, or Surinam, the sea became muddy-looking through the influence of the waters of the great rivers along the coast, particularly the Amazon and the Orinoco. This was my first introduction to South America and I was all agog as we entered the mouth of the Surinam River and steamed thirteen miles upstream through tropical scenery to Paramaribo.

As we stepped ashore we saw everything for the visitor-curiosity shops full of imported junk, and gaily painted cafés and estaminets with blaring gramophones and beseeching wenches. I made my way along the street until some vegetation hove in sight. The gardens of the poorer inhabitants resembled those one might see in Dar-es-Salaam, the Seychelles, the East Indies, or any other tropical place at coast level where there is a plentiful rainfall and high humidity. Coconuts, breadfruit, bananas, and plantains were the trees most in evidence, and in them were Blue, 
Palm and Silver-beaked Tanagers, the latter being especially showy with their crimson and black plumage. The most conspicuous bird was the Sulphury Tyrant, always making its presence known by its continuous loud call-notes which resemble a musical version of "Qu'est ce qu'il dit," hence the Colonial name Kiskadee which is now established throughout the Guianas. This bird is a flycatcher with shrike-like habits.

White-bellied Emerald Humming-birds flitted here and there, alternately chasing one another and hovering while sucking nectar from some flower. The more I watched these animated creatures the more they reminded me of dragon-flies-stationary at one moment and off like a flash the next. Their speed of acceleration from a stationary position is remarkable, and even more so their ability to fly backwards! Their wing-movements are much too fast (sixty to one hundred beats per second) to see what happens when they change from the forward to the backward movement, but it can be observed in any zoo when a humming-bird approaches its feeding bottle in flight, for after hovering and feeding for a while it usually backs away before flying off.

The midday temperature in Paramaribo was $100^{\circ} \mathrm{F}$. in the shade which, owing to the high humidity, was distinctly uncomfortable. Most of the passengers were weary and bored when we left that evening but to me the day had been one of adventure. The insect life alone-particularly the butterflies-was enough to make one gasp. By the time we steamed down the Surinam River, I was keyed up for exploration. My one desire was to get somewhere in the primitive forest away from the shackles of civilization.

The following day we reached Georgetown, the capital of British Guiana, some two hundred and fifteen miles to the northwest. I found it quite a delightful place with moderately good hotels, tree-lined streets, and delightful Botanical Gardens. Although only just on the edge of the town, the last was a splendid place for bird-life. The most impressive sight was before sundown when Snowy Egrets started to arrive to roost. They came from all directions, and by the time it was dusk their favorite roostingtrees were packed with thousands of snowy-white forms. With them were a small number of Tricolored Herons. As all these were about to settle down for the night, the night herons which 
roost in the same trees during the daytime set off for their feeding grounds in the coastal swamps. These birds are known locally as Blue Quaaks and have blue-gray plumage with a black cap-the male with elongated black and white nape feathers.

The manatees in the Botanical Gardens were the first I had seen and what impressed me most was their sluggishness and mode of feeding. There are several species-all entirely aquatic, frequenting rivers and estuaries of the warmer Atlantic countries. They are entirely vegetarian, living on seaweeds and fresh waterweeds, but here in the Botanical Gardens, besides a certain amount of natural vegetation growing in their ponds and dikes, they were living largely on lawn clippings. It was fascinating to watch them eating this floating grass; the upper lip of the manatee is split and furnished with bristles, and as the two portions are prehensile they are protruded and employed to grasp the vegetation, which is then sucked into the mouth. The female has one pair of teats on the breast and suckles her young like any other mammal; through this simple fact it has, like the dugong, given rise to the legendary mermaid, particularly as she is said partially to support her single young with her flippers while suckling.

There is little of interest in the environs of Georgetown, as the coastal belt is flat, denuded of trees, and given over largely to sugar growing.

The bulk of the interesting species of birds are found in the forests of the interior, access to which was then practical only by river. A notable exception is the Hoatzin-one of the avian curiosities of the world-which lives in a few widely separated localities bordering certain South American rivers.

One of the objects of my visit to British Guiana was to introduce some live specimens of this bird to England, as no one had before succeeded in transporting them alive out of their own country. I found Sir Edward Denham, the Governor of the Colony, sympathetic to the idea, and both he and his A.D.C., Lieutenant-Commander Rushbrooke, gave me every assistance.

The habitat of the hoatzin in British Guiana is along the Canje Creek and the Berbice River, not far from the border of Dutch Guiana. Having obtained permission to stay at the Government Rest-House at New Amsterdam on the right bank of the Berbice 
River, I set off by the coastal railway. The carriages were provided with mosquito-netting windows, and a few stations before reaching my destination it was forcibly brought home to me that these were not provided merely for ornamentation. Before the train had even come to a standstill at one station, mosquitoes swarmed in in hundreds through the open windows, settling immediately on ladies' legs and men's ankles, injecting their needle-like proboscises and sucking blood avidly. This was the first time I had met with swarms of diurnal mosquitoes, and their mode of attack was direct-none of them hovering while looking for a favorable feeding-place, as in the case of their nocturnal cousins. What could one do against this bloodthirsty army? The answer is "Precious little." The mosquito-proof windows were soon raised, but it was too late; the rest of the journey was spent in an ankle-slapping mosquito-squashing campaign.

Hoatzins are as fixed in their abode as rabbits in their burrows, and one can be directed to a colony with the same certainty of finding them as if being directed to a certain street in a town. Nevertheless, they are found in widely separated localities such as British Guiana, north Brazil, Colombia, Ecuador, Peru, and Bolivia.

The hoatzin is entirely a leaf-eater-the scientist would prefer to call it phyllophagous-and is dependent on two plants for its sustenance; the favorite is the Pimpler Thorn which grows along tidal creeks. Being a voracious feeder it spends much of its time cramming itself with the leaves of this tree, and it also utilizes the branches which hang over the water for nesting purposes. Its other food plant is the Giant Caladium which is common everywhere in the swamps.

The hoatzin's chief claim to fame lies in the fact that it is a link with the primitive lizard-tailed and toothed birds of the dim past in that the young, which are born naked, are furnished with wing-hooks on the extremities of the wing-bones known as the thumb and index finger. With the aid of these hooks and their feet the young can climb about the branches surrounding their nest. The necessity for this provision becomes evident as soon as one makes any attempt to take one of these queer creatures from the nest. It may climb a little way when danger is at hand, and 
then without hesitation plunge into the water below and disappear like a grebe. Somewhere it will be hiding and watching, and when all is clear this tiny naked soul will clamber out and regain the nest by the skilful use of its feet and wing-hooks. When hoatzins are sufficiently feathered to fly they never swim or dive, or, for that matter, descend to the water's edge. This provision in the juvenile is merely to save it from its natural enemies while incapable of flight. If never disturbed the young would not disclose this remarkable grebe-like adaptation to tide it over its nesting period.

In an attempt to transport the adult birds alive across the Atlantic the problem was to find a suitable substitute for their natural diet for the long voyage home.

The hoatzin is one of those sluggish creatures that are easy to approach but difficult to capture. The branches of the Pimpler Thorn will not bear a man's weight, and furthermore they hang over muddy creeks, which renders the setting of nets or traps in these situations almost impossible. To help solve this problem I enlisted the aid of the locals, who are mostly the descendants of African slaves, half-castes and Indians. To be ready for any sudden success, I purchased a number of packing cases from a local store and converted them into suitable travelling boxes for single hoatzins. The birds proved much more difficult to capture than I had anticipated, and to get them quickly I offered a high price. However, with the help of the Commissioner of Police, who was a great sportsman, some enthusiastic fellows were got together and they made an organized attack on the birds. I did not actually witness the performance, but was told that some men went along one side of the Pimpler Thorns in a boat while the rest proceeded on dry land on the other side of the line of bushes. Late one evening the gang arrived with five birds all covered with mud but uninjured. The captors were even more muddy than the caught, and one fellow had evidently done a lot of floundering about in the muddy creek to retrieve exhausted birds.

I got to work immediately and cleaned them up and by next morning the birds looked a fine lot. Their striking upcurled crests, permanently raised, gave them a warrior-like air, but for the first few days they gave off a strong musky odor. This smell seems to 
be the principal factor in their survival, for no one will eat them on account of it; in fact one of the local names for the hoatzin is "stinking Anna." If the bird had been considered a delicacy it would either have become extinct long ago or would have changed its habits.

The front of the hoatzins' cages I kept covered with cheesecloth, so that the birds got plenty of light and air but at the same time could not see out. This is an important precaution as a newly caught bird under these conditions will make no attempt to escape and therefore will not exhaust itself. In the safety and quietness of these boxes my birds quickly regained their normal appetites and fed greedily on caladium leaves which I gathered daily.

A few days later I left for Georgetown with my five hoatzins, three trumpeter birds, and a saki monkey.

I had already arranged to do the rest of my collecting in the region of Bartica, in those days a small town of one hundred inhabitants, one street and one church. It is on a spit of land at the junction of the Essequibo and the Mazaruni rivers, about forty miles from the sea. The trip there in the river steamer was uneventful except that the flat-bottomed craft designed for shallow rivers was out of its element in the roughish sea-waters between Georgetown and the mouth of the Essequibo. The Governor had given me permission to stay at the Penal Settlement opposite Bartica on the left bank of the Mazaruni near its confluence with the Essequibo. Here there was a comfortable and spacious resthouse for the use of Government officials visiting the district or on their way to or from the interior. There were no Europeans at the station at the time of my visit-the residents being a colored prison governor and his staff, a number of convicts serving long prison sentences, and a Negro and his wife who acted respectively as caretaker and cook for the rest-house.

Here was a penal settlement without any sort of enclosure. The whole place was really a large farm made by clearing a patch of virgin forest, and was largely self-supporting. The best feature was a herd of cows which supplied milk and butter. The settlement was surrounded by natural barriers more effective than any bars; on the one side there was a very wide river, and on the other 
three, virgin forest full of tidal swamps; any attempt at escape through this endless inhospitable jungle would have ended in disaster, and the prisoners knew it. Many of the more trusted ones were allowed to wander at will on their own without guards, doing their various jobs. One prisoner of African descent-named Joe-was allotted to me to assist in any way possible. He was a cheery fellow, hard-working and willing, and had another nine years to go before being freed. It seemed that he had merely clubbed his wife on the head for being unfaithful, an act which, among his forebears, would have been deemed a normal procedure, but the poor chap was now caught up in the meshes of a civilized legal code, and had to pay the consequences.

I soon made an aviary for my hoatzins, which had by now become fairly tame, and so all five were allowed to mix and take advantage of their flying space. It was Joe's job to go to the neighboring swamps and gather mucka-mucka (caladium) leaves daily for the birds.

I had left Georgetown without a personal servant, being unable to adjust myself to local values. In the local population of African descent there is a proportion who lounge around waiting to pounce on any visitor who has to accomplish something in a limited period. They can always produce documents to show that at one time or another they have attached themselves to some expedition, and at an interview will laud themselves to the skies. The salary demanded is always out of all proportion to the ability (if any) of the applicant, and if some figure is agreed upon, the unfortunate new arrival is asked to part with a considerable sum in advance, so that the newly employed person can purchase bush clothes, food, rum, medicine, etc., and settle all his debts, leave money behind for his wife and relations, and for a host of other reasons. I was impertinent enough to ask how anyone lived between the visits of various missions and expeditions to the country, and was told quite frankly that they reckoned to make enough when an opportunity occurred to tide them over the idle months. Giving money in advance to newly employed persons appears to be an established system where black labor is concerned in Guiana, particularly for those employed to go inland on some expedition such as belata collecting, gold prospecting, or 
seeking zoological specimens. The system has obvious disadvantages, for the fellows are then always in debt and are forever borrowing more, and if any turn out to be useless it means that the advance has been lost.

Bartica was populated with blacks, and there was every facility for producing anything in the way of food, but all my provisions, including fish and meat on ice, came up on the weekly river steamer from Georgetown. The coastal regions are populated largely by Indians (from India, not aboriginals), who are industrious people producing the bulk of the fruit, rice, and vegetables.

I soon became familiar with the forest adjacent to the penal settlement. The first encounter with these great forests gives one a slight feeling of awe rather like that experienced when entering a cathedral for the first time. The magnitude and splendor of it all seems beyond the powers of absorption by the human brain. Until one's eyes are trained there may seem little to see near the forest floor, and at first all life seems to be concentrated in the treetops, but these are at such a height and so closely knit into a single canopy that observation from the ground is well-nigh impossible. The first exciting moment came when one of the giants of the butterfly world-a Blue Morpho-flashed past me with a swift undulating flight, its metallic sky-blue wings shining like enamel as they occasionally caught the sun's rays. Their swift, almost bird-like flight renders them very difficult to catch in a net in the ordinary way, but they are easily enough trapped by the simple expedient of suspending peeled bananas, soaked in strong rum, from the boughs of forest trees. After these have been hanging for some time the butterflies get the smell of the rumcum-banana, and settle on the fruit, sucking the luscious juice. I used to inspect daily a line of these simple lures that I had put in the forest for a lepidopterist who had joined forces with me but was scared to venture into the forest. It was amazing how these doped butterflies clung to the banana, allowing one to slip a net gently upwards over them.

This morpho-hunting campaign had an amusing sequel. I used to carry the rum-soaked bananas around in a billy-can in the bottom of which there was always a little rum that had oozed 
out of the fruit. In a new field of operation far from my headquarters I had hung up a number of bananas by the usual method of suspending them singly on a string, and then, having a number left over, decided to leave the can in the forest for future operations. For safety I tied it to the tip of a spindly sapling branch, too high from the ground to be reached by vermin. Alas, when I returned the following day I found the can on the ground empty and licked clean! Who was the culprit? Like much of this forest the bed in this part was wet and muddy, and in one or two places I saw what I took to be the spoor of a coati (or coatimundi). This animal is a good climber, and he was evidently so smitten with the smell of this specially prepared sweetmeat that he had climbed up the trunk and along the thin branch, finally hanging on and dragging the can to earth. I had left six bananas soaked in the strong rum, and judging by the spoor the thief's steps were very unsteady as he made off!

It is well known that coatis have an extraordinarily keen sense of smell and also a liking for perfume, so no doubt the rum had the same attraction for this fellow as for the morphos. It is interesting to watch a captive coati that has been given some object, such as a piece of cloth, sprinkled with scent. He will become very excited and rub the cloth on his tail and then go to sleep with his now sweet-smelling appendage wrapped round his head.

"Experientia docet" is a saying that applies aptly to rambling on one's own in a tropical forest. One day, in an attempt to catch a trogon, I had to wade across a shallow swampy place, and it was some hours before I returned and reached the point where I had crossed an insignificant creek. At first I thought I had lost my sense of direction and hit on another swamp, for I was confronted with a wide and deep expanse of water. I then realized that the tidal waters of the Essequibo had spread their tentacles and had found their way up a large creek, then a smaller one, finally seeping through the low-lying parts of the forest bed. As I had been successful on my trogon hunt, I was anxious to get back quickly with my charge, now sitting quietly in a bag. Walking till nearly out of my depth, I held the much-prized trogon and a bag of nets at arm's-length above my head, then gently lay back and swam back-stroke with my feet till I gained the opposite bank. 
Much bedraggled, but with the trogon dry and undisturbed, I continued on my way.

I emerged from the forest, and as I made my way across the settlement clearing I passed a small hut that I had seen many times before. It was a low solidly built place, half sunk in the ground, encroached upon by grass, and apparently abandoned and forgotten. Prisoners had been engaged in cutting back the grass and other vegetation from this section of the plantation, and they had set fire to the dried clippings, some of which were around the door of the shed. When I was about two hundred and fifty yards away there was a nerve-shattering explosion, and on looking round I found that the structure had disappeared into space. The prison staff were mystified as well as terrified, for no one knew that the shed was an explosive dump. It eventually transpired that a large stock of dynamite had been kept there when the place was under construction, and the present staff knew nothing about it. Grass had grown through the space under the door and had become dry and so the advancing flames had crept through and set the whole lot off.

In creeping quietly through the forest I soon got to know the call of the trogons-a sound vaguely resembling the yelping cry of a puppy. There are many species in America-nearly all being confined to the tropical forests-and like the trogons of Africa and Asia, all are extremely beautiful. They are nowhere plentiful and are usually found singly or in pairs. My chances of catching any in the uppermost branches of the trees of the virgin forest, where they fed on berries, were, I thought, extremely slight, but following a trogon call one day I caught a glimpse of the bird as it appeared to settle on a tree trunk. On closer inspection I saw that it was clinging to a globular termites' nest attached to the trunk about thirty feet from the ground, and was hammering in woodpecker-like fashion, but more slowly, at a cavity in the nest.

Taking a hint from this, I found other trogons doing the same thing. This habit intrigued me as I was under the impression that the South American trogons were entirely frugivorous. I am unable to say whether they were eating the termites, but in each case the cavities were small and never enlarged sufficiently for a bird to enter, though I have read that the South American trogons 
nest in termites' nests. If this is so, it is not a constant habit, for I found the nest of the Green Trogon in a hollow at the top of a rotten tree stump only about eight feet high. The male of this species has the head and breast deep blue, the back metallic green, and the under parts orange-yellow. I captured this pair, and a pair of Black-throated Trogons that visited a termites' nest daily. These were smaller than the others, the male having the head and neck bright green, with orange-yellow underparts.

On the edge of the forest one day I stood watching some tanagers feeding in a ficus tree. A trogon arrived and from a neighboring tree made frequent darts at the small ficus fruit, snatching one at a time while still on the wing and then returning. This behavior seemed most peculiar. Why did it not sit on the branches of the ficus tree and have a good feed as the tanagers were doing? Just then there was a loud squawk and some fluttering on the tip of one of the lower branches. Rushing up I saw that a Palm Tanager was firmly held by a Green Sharp-nosed Tree Snake. The snake hung on determinedly to his prey and allowed me to seize him by the neck with one hand and the bird with the other. The latter I liberated and it flew off none the worse for its adventure, as the snake was non-venomous. These tree snakes have the instinct to go where birds are chattering and feeding and wait poised near the tip of a branch, their protective coloration rendering them almost invisible. Any small bird settling within reach is caught with the spring-like thrust of the snake's head and neck before it realizes what has happened. In this instance it seems that the trogon either suspected possible danger, or had actually seen the snake. Anyway, the latter with his lovely green coat and sharp-pointed snout made an interesting addition to my collection.

I have several times caught with my hands snakes in the act of swallowing their prey, usually frogs or rodents. They are then at a disadvantage, for the swallowing action is very slow, and they are also unable to disgorge quickly.

When Joe and I were walking through the swamps we disturbed a half-grown Capybara. This is the world's largest rodenthis body being much like that of a pig-who loves swampy places, where he feeds exclusively on lush vegetation. He is an excellent 
swimmer and diver and is much hunted for his flesh. The local name among the black colonials is Watras, which is a corruption of the name Water Haas (Water Hare), passed down by the Dutch colonists. More out of fun than anything else, I shouted to Joe, "Go chase him, man," and off he went. He was soon lost among the bushes growing in this boggy place. The capybara kept to the muddiest places for safety, but Joe, running like a rabbit and picking his way where the soil was firm, caught up with him and I heard a yell for assistance. When I had picked my way past numerous black muddy bog-holes, I found Joe floundering in a mud bath trying to hold the struggling capybara by the leg. I entered the fray, and there we struggled knee-deep in mud, staging our own version of "catch the greasy pig"-a game formerly reserved for country fairs. By the time we got the brute on dry land we looked a couple of fine specimens, and the mile trek home with our fat Watras put an end to any further exertions for that day.

It is noticeable that the male has a naked fleshy gland about the size of a halfpenny on his snout. If this is squeezed a milky musky-smelling secretion exudes from the pores. Such glands are regarded as of sexual significance and the odor given off may be to attract or excite the female, or simply to denote sex. They occur in different parts of the body in other mammals, for instance in certain primates, but the precise function of these secondary sex characters is obscure. Scent glands, as in the case of civets, palmcivets, genets, zorillas and skunks, may function mainly for defensive purposes, but in the peccaries - the wild pigs of South America -the glands seem to provide a means of maintaining contact with the herd. This gland is situated in the center of the lower back and occurs in both sexes. From this I have frequently seen a captive peccary eject a spray of malodorous fluid backwards for a distance of several feet.

There are two species of peccaries in British Guiana-the Collared and the White-lipped. Both go around in large herds and are much preyed upon by jaguars and man. As they wander through the forest nosing in the soil for roots and sniffing out fallen fruits, it is important that none stray too far from the herd, for it is the odd specimens that are preyed upon. When in num- 
bers, the vigilance of any one animal will warn the whole of approaching danger, but stray individuals are more easily caught off their guard.

It seems that the occasional functioning of the glands provides the necessary scent-trail to enable their large numbers to remain in close contact when progressing through thick jungle.

It is an interesting fact that all the ground-dwelling mammals of the coastal forests are excellent swimmers, though this is only natural seeing that the region is interspersed with wide rivers and numerous creeks and is subject to inundations. It is not an uncommon thing for a herd of peccaries, numbering several hundred, to attempt to swim across one of the jungle rivers, and as they may be half a mile or more wide, the crossing will be a long one. If it happens that an Indian is canoeing somewhere near the scene, or worse still, if the attempted crossing is in sight of an Indian village, a cry will go up and all and sundry will give chase, clubbing as many animals as possible before they are able to gain the safety of the opposite bank. They are, as is the most ferocious landmammal, quite defenceless while swimming, so are at the mercy of man. The Indians preserve the flesh by smoking it over a babracot, or wooden grid, which takes about forty-eight hours. The wood fire is kept going in one of their huts and it is the duty of one of the old women to get out of her hammock at odd times of the night to keep the fire burning.

Once I canoed along the edge of the Mazaruni River, nosing my way up small tree-canopied creeks looking for the King Humming-bird, and passed some Akawai Indians who had a halfgrown jaguar in their canoe. They had caught it that morning swimming in the Mazaruni, evidently by lassoing it. There was a rope round its neck, and its front legs were tied to its hind ones so that the beast could not struggle.

On another occasion an Indian brought me a Three-toed Sloth which he said he had found floating down the same river. With the native's usual fear of slow-moving animals, he brought me this creature on the end of a pole. The sloth was blown out so much that I took it to be gravid, but in a few days it got back to its normal size, so I assume that it had swallowed a lot of water which caused the leaves in its stomach to ferment. I have never 
heard of a sloth attempting to swim and feel that it almost certainly fell in the water in some way.

This species of sloth is smaller than the other species in British Guiana-the Two-toed-and is more specialized in its diet, living mainly on the leaves of the cecropia, or Umbrella Tree.

The sloth is a good example of the way the tree-dwelling mammals of South America have adapted themselves to a particular mode of life. Several species of monkeys, two species of ant-eaters, the tree-porcupines and the opossums, all have prehensile tails with which they can grip branches and use as a fifth limb. The sloth, on the other hand, has dispensed with his tail (all that remains is a rudimentary stump) and travels along branches upside down. His long legs, terminating in long hook-like claws, are specially adapted for this purpose, and are so constructed that it is impossible for him to walk in an upright position. This is no handicap, for his life is spent in the tree-tops, where he moves with ease from one to another seeking sustenance.

Although adapted for a purely arboreal existence there are times when the sloth finds himself compelled to progress along the ground. This he can do with difficulty, at a tortoise-like speed. In this situation his action is rather like that of a man lying on the ground, face downwards, going through the actions of the over-arm stroke in swimming. One forearm is stretched forward, then by leaning on that and pushing with his feet he drags the body along while the other forearm comes forward. Although the sloth can progress along branches only in an upside-down position, and usually feeds in this position, he normally sleeps upright clinging to a branch, his body doubled up so that his head rests between the forearms on his chest.

Among the special features of the sloth are his ability to go long periods without food; his hard and tough body, capable of sustaining injury with little or no apparent discomfort; ability to turn the hind feet through a wide angle to facilitate the grasping of branches; ability to turn the head round through $180^{\circ}$; the retarded passage of food through the intestinal tract (in experiments it has been found that foods, colored for identification, have taken up to seven weeks to pass right through the animal); and the retarded defecation (on average once a week). In the Three- 
toed species the neck vertebrae number nine instead of seven as in nearly all other mammals.

To fit in with his topsy-turvy condition, his hair hangs the opposite way to that of other mammals, thus allowing the rain to run off. Sloths have no incisor teeth and their molars are blackish in color and are lacking in enamel. This subjects the teeth to constant wear but to counteract this they continue to grow throughout life.
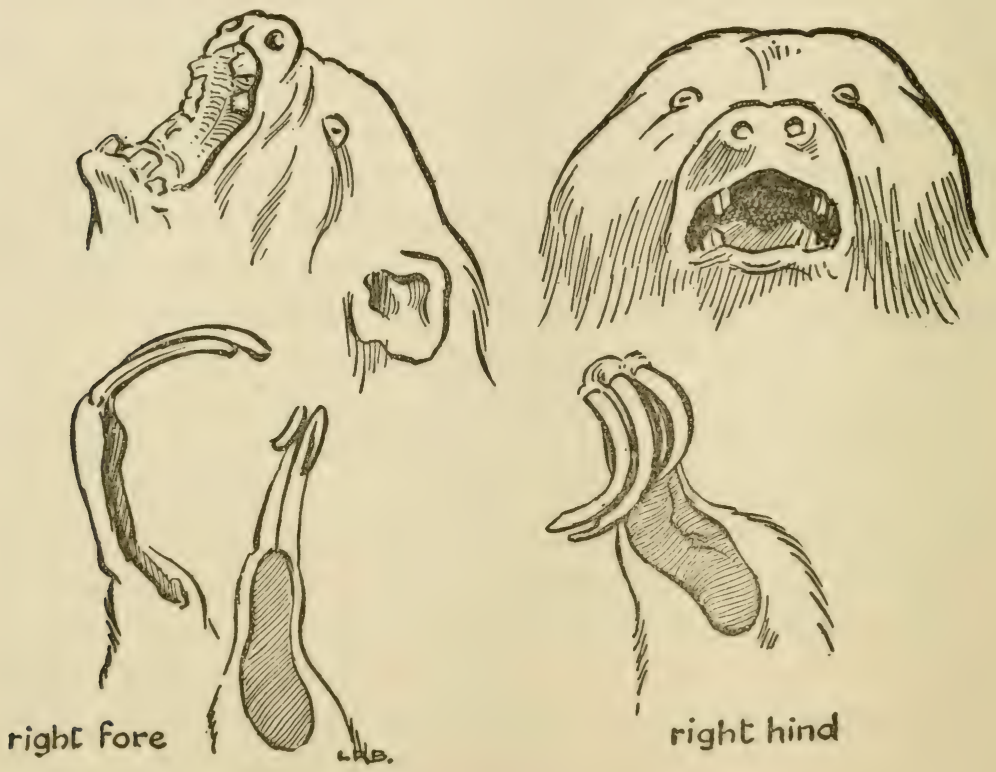

Two-TOED SLOTH

These animals seldom drink but do so occasionally with difficulty by climbing along a branch which hangs into the water. In the heat of the tropics I have several times seen captive sloths drinking and this was always a slow laborious business-one sucking away for fully half an hour before quenching its thirst.

All sloths have three toes on the hind feet, thus the names Three-toed and Two-toed are in reference to the front feet. The Three-toed Sloth is perfectly harmless but the larger Two-toed species is usually very aggressive until tamed and can give a nasty bite. The young, like those of most arboreal mammals that are 
not born in holes in trees, cling to the mother and are carried like this from the time of birth. The male Three-toed Sloth can be distinguished by a short-haired blackish patch on his back, whereas the sexes of the Two-toed species are indistinguishable, there not even being any visual signs of external sexual organs.

An American who came to visit my menagerie at the Settlement was very intrigued by the slow-motion chameleon-like movements of my sloths, which caused him to remark, "It's a wonder to me that they can get sufficient move-on to produce young." Nature is very versatile in her mode of reproduction, but the fact remains that the sloth's sluggishness is probably the main factor in its survival owing to primitive man's instinctive fear of slow-moving creatures.

To revert to swamp-dwelling mammals, the Brazilian Tapir is not uncommon throughout British Guiana in well-watered places, and has the distinction of being the largest local mammal. It belongs to the ungulates or hoofed animals, of which order there are only two other representatives in the country: deer and peccaries. With a body as big as a donkey's, though much shorter in the leg, it is a formidable creature in the wild, but becomes delightfully tame in captivity and then seems to enjoy human company. The adults are more or less uniformly dark brown in color, whereas the youngsters are beautifully spotted and striped up to the age of about ten months, when their markings slowly disappear. During this period they are most attractive. Their faces are indeed quaint on account of the flexible proboscis or snout, which seems to be forever on the move when the animals are feeding-waggling about in all directions. This proboscis can be protruded or retracted at will, and its usefulness is observed when the tapir-which is a great leaf-eater - is tearing leaves from plants and bushes. The snout is then seen to bend over and press on the leaves as they are being torn off by the teeth. The proboscis of the young when being suckled is conveniently retracted.

Tapirs were once widely distributed all over Europe, but are now confined to tropical America in the west and to Malaya and adjacent islands in the east. Although the adult animals of the two groups differ considerably from one another in coloration, the 
young have a marked resemblance-both being spotted and striped. In Guiana the tapir is much sought after by the aboriginal Indians for food, and its flesh is considered delicious.

In captivity tapirs should be treated like hippopotamuses and should have access to a pool. In this they will spend much of their time swimming, often diving out of sight for considerable periods.

Perhaps the most gorgeous bird in British Guiana is the Cockof-the-Rock. Although locally common it is restricted to a few localities where there are rocky ranges. People in Bartica said it was about twenty years since anyone had arrived there with one of these birds, and yet a week after my arrival an Indian who had come from the Upper Cuyuni, and who had been travelling for weeks down this river in his canoe, turned up at the Settlement with a magnificent male bird, which I purchased. He was a gorgeous orange-red color with a large compressed crest stretching from the bill to the nape. The crest is round and divides into two portions in front-one on each side of the bill.

The cock-of-the-rock gets its name from its nesting habits, as it plasters its nest on an overhanging rock-face like the crag martin, though this is not of mud but of fibrous vegetation held together by some gelatinous substance-possibly regurgitated food. They are gregarious and the males resort to dancing-grounds where a number come and perform regularly in the breeding season.

They have the reputation of being difficult to establish in captivity, especially the adults, but this one was perfectly tame and fed well, so had probably been in the hands of the Indian for some considerable time. His only call-note was a loud Quow!

Visitors to the Settlement were infrequent but one day the Governor of the Colony called for a few hours and was very interested in my collection especially the five hoatzins. These were perfectly at home in their aviary after several months in captivity, and were as fit as the day they were caught. I arranged for a supply of lettuce to be sent weekly by the river steamer and managed to grow some more, and these I chopped and mixed with the hoatzins' natural food. They soon came to like this new item of diet, which heartened me regarding the chances of transporting them 
on the high seas for three weeks with none of their natural food to fall back on.

Showing my queer assortment of charges to passers-by made an interesting diversion, as even residents of long standing are poorly acquainted with the animal-life of the Guiana forests. The Threetoed Sloths always attracted attention, especially as they had become accustomed to eating bananas and were now so tame that they would do their upside-down act by walking along a horizontal pole to a visitor and take fruit from his hands. So ingrained was the story about their bear-like hug that even Europeans were staggered to see me pick these sloths from their perches and nurse them like babies.

A visiting official, who evidently thought that his temporary escape from the world of officialdom should be made an occasion of celebration, became very much the worse for drink, and this might easily have meant the end of the rest-house and much of my collection. Although all the mammals and some of the larger birds were given the run of various sheds, the small birds and the cock-of-the-rock were kept in a box-room adjoining my bedroom where I could keep an eye on them. The furniture dated back to the days of the Dutch occupation, the beds were enormous, square and canopied, with huge carved bedposts. The oil lamps were the largest I have ever seen and their glass containers must have held gallons. It was one of these that nearly caused a tragedy. Just before dinner one night I was sitting downstairs talking to another of the visiting party when I heard a crash upstairs. Knowing that our friend was tipsy we took no notice of this, but suddenly there was a shout for the servant, who ran upstairs. I visualized a broken bottle of whiskey on the floor with the owner trying to mop it up. But such a commotion went on after the servant arrived that I tore up the stairs myself to see what had happened. When I arrived, I found the wooden floor of the reveler's bedroom covered in flames. He had dropped or knocked over the lamp! I shall never forget this half-dopey creature standing in the flames trying to stamp them out with his feet and staggering all over the place as he did so. The black servant was sweeping madly at the burning oil with his duster, but as fast as he put it out in one place, it flared up again. It was obviously useless to attempt to gain 
control by putting out the burning oil section by section, as the flames immediately re-ignited; something drastic had to be done quickly before the woodwork caught fire, so dashing through the flames to the bed and at the same time pushing the men on one side, I tore off the blanket and made two circular sweeps over the floor, which to my relief immediately obliterated the flames.

On another occasion I had to think and act with similar rapidity. When I was crossing a settlement clearing I heard a shout ahead and saw the herdsman beckoning wildly to me. It took only a split second to realize that a mad cow was tearing towards me. I have several times since had nasty experiences with native cattle, both with bulls and cows with calves. These creatures are often friendly enough with people they know, or at least with people of the same color as those who look after them, but very often native-tended cattle, especially cows with calves, have a rooted dislike of Europeans. This was my first experience of the sort and as I was in an open place and not near enough to any tree or shed to seek cover, my career as a collector might have ended there if my thoughts had become in any way confused. No use running from an animal whose speed is greater than your own if there is no cover handy, and in any case you will be facing the wrong way to do anything.

The cow was about forty yards away and coming at great speed. There was no time to dally, so I did the only thing that could give me a chance-I charged the cow! Going as hard as my legs have ever carried me, and never deviating from the line of the oncoming beast, I swerved like a rugby player as we were about to make contact, and tore on until I got to the safety of a tree. The cow was so bewildered at having missed me that when it brought itself to a standstill it just looked round and glared. By now the herdsman had come up, and he managed to drive the animal to its right quarters with the rest of the herd.

The bird-life of the lower forest stratum was distinctly scarce and most of it of somber plumage, for as I have indicated most of the brilliantly colored birds of these forests live their entire lives in the tree-tops. There are, of course, certain notable exceptions among the lower-level birds, such as the Wood-nymph Hum- 
ming-birds and certain species of manakins which are gorgeous. The only humming-birds to be met with with any degree of certainty at more or less ground level are the Wood-hermits, which are somber-plumaged birds with curved bills and long graduated tail feathers. These humming-birds are much more insectivorous than the rest of the family and spend much of their lives scanning the under sides of leaves in the forest undergrowth for spiders. Often as I was standing motionless, one of these birds would dart to within a few feet of my face to make a close inspection. Insects apart, the Hermit Humming-bird to my mind exhibits the finest example of motion-control in space of anything in the animal kingdom. It will approach one at full speed, stop and hover a few feet before one's eyes, then move vertically up and down the length of one's body as if to satisfy its curiosity (though perhaps to see if any spiders are clinging to one's person); then it will let in the clutch and disappear like a flash behind one's back to continue its inspection. A sudden flick of the arm will cause it to move like lightning, but not to panic. Usually it will just shoot through the air a few yards, hover awhile, and then make off in its own time. It can go through thick undergrowth at great speed and, like the rest of the family, can reverse as well as remain stationary or move vertically up and down.

To revert to the Wood-hermit Humming-birds. I remember a forestry officer telling me about an extraordinary communal gathering of a species called the Cayenne Wood-hermit. He found a number of these birds congregated together in a space of an acre or so in the heart of the forest. There was nothing to attract them in the way of food, but there they remained spread out evenly, sitting in the trees uttering their cricket-like call-notes and occasionally hunting for food, day after day and week after week. This is contrary to the general behavior of any humming-bird, and wood-hermits are normally seen only singly or in pairs.

I saw nothing of this curious happening but it remained in my mind, and if I may be allowed to jump ahead to my next expedition to British Guiana some seventeen years later, I can give an eye-witness account of this strange behavior exactly as it had been described to me.

On this second expedition I was staying inland along the Potaro 
River, which is a tributary of the Essequibo. It was the rainy season and practically all the humming-birds had disappeared. In desperation, I got hold of an English-speaking aboriginal Indian and offered a reward if he could show me any place where hummingbirds came to feed, or any place where it would be possible to catch them. He seemed confident, much to my surprise, for I had scoured the district. Two days later he informed me in his broken English that he had found some humming-birds, and it was arranged there and then to go to the place the following morning. The only information I could get was that it was "not far," which I knew from long experience with natives might mean anything from half a mile to a half a day's march.

The two of us set off along a forest trail in a fine rain and we had gone a little over two miles when the Indian stopped and said, "Humming-birds, massa." I could see nothing, but heard a host of high-pitched chirping noises which I took to be tree-frogs or crickets. I laughed at the man and asked him where the humming-birds were, thinking he must have misunderstood me all the time. Just then a wood-hermit flashed by me, which caused me to think again. Walking slowly in the direction of the center of noise, I saw a wood-hermit sitting on a dead twig, moving its tail up and down and incessantly uttering its high-pitched call-notes. In a moment it took wing, contacted another of its kind, and a chase went on round trees, over and under branches, then in a few seconds they parted, the first one alighting on the same twig as before. In about half an hour I was able to estimate that there were between thirty and forty birds in this small area, each with its favorite perching-place. They were all the same species-the Cayenne Wood-hermit.

Having been introduced to this humming-bird community, I went there day after day to make further observations. As I approached the same spot the distant chirping of the gathering could be heard, and every time they were there occupying their favorite perching-places. It was all rather mystifying. I set nets and caught several, though to catch any humming-bird in a hanging net is no easy matter. I set a number at about twenty feet from the ground between branches through which the birds flew when chasing one another. It seems to be the principal occupation 
of all humming-birds to spend much of their day chasing a rival. The latter never seems to be caught, and there is little or no actual fighting, but in this case, the fact of the birds pursuing one another blindly through gaps in the gloomy under-forest enabled me to catch them off guard. I doubt if any hermit would get caught when leading its normal solitary existence. It would be much too quick and wide awake for that. The birds I caught were killed by a storm when in the nets, and on sexing them I found them both to be cocks.

I would normally not try to catch this species as it is most difficult to keep in captivity on account of its mainly insectivorous diet. The usual humming-bird liquid food is quite unsuitable, and the four specimens I tried to establish all died in course of time. All these six that came into my hands were males. From this it is not possible to draw definite conclusions, but an explanation could be that the Cayenne Wood-hermit, instead of pairing in the usual way, has evolved the idea of special gathering-grounds for unpaired males, where they can indulge in community singing until some female with an urge is attracted by the racket and decides to choose a mate.

One of my most interesting captive birds was a sun-bittern which I used to let loose on the lawn daily, for the dual purpose of exercising itself and catching grasshoppers. This beautiful creature with long neck and beautifully mottled plumage of gray, brown, and gold, and also a certain amount of red, white, and black, is what might be described as a bird with a personality. It has no close relationship with anything else, but in the systematic list is conveniently placed near a few other equally difficult birds, all of which are referred to as aberrant cranes, though they show affinities also with bustards and rails.

For its size-that of a small pullet-it has more self-assurance than any other bird. It moves along slowly with measured step as if in the act of stalking, making a mournful high-pitched drawn-out whistle, while slowly swaying its body and making snakelike movements with its long neck. It takes a lot to disturb the bird's air of stately composure.

One day a dog, belonging to some visitors, spied my sun-bittern on the lawn and rushed at it. I expected to see the poor creature 
eaten alive, but then I did not know the peculiar ways of the sunbittern. Before the dog got too near to change his mind, the bird rushed forward to meet him with outstretched wings and somehow transformed himself into a most fearsome object, performing contortions with his neck and hissing like a snake. This scared the life out of the dog, who turned tail and ran.

I often stood close to this bird to watch him catch insects. $\mathrm{He}$ always behaved as though he was completely oblivious of my presence. His method of catching different insects was most illuminating, for he changed tactics according to the prey. To approach within striking distance of a tropical grasshopper in the heat of the day when it is most active and alert is quite a feat, especially in short grass. The sun-bittern knows all about this and never makes a direct assault. Instead he makes a number of halfcircles round the grasshopper with outstretched wings, the head always pointing to the prey and the neck waggling like a snake. The beak is slowly pushed nearer the insect as the bird gyrates, and when within easy striking distance a sudden and unexpected spring-like thrust puts an end to the hypnotized insect.

In catching flies the technique is quite different. The fly, unlike the grasshopper, is quite indifferent to approaching danger until it is within a few inches. So the sun-bittern has no difficulty in getting within striking distance, and he then stretches his neck slowly forward till the tip of the bill is only a few inches from the fly. There is then a pause, and it seems the bird's prominent red eyes distract the fly's attention so that it does not realize the proximity of the finely tipped bill, which viewed end-on looks flattish instead of long and pointed. After the pause there is a short sharp stab, and the fly invariably falls a victim to these tactics.

Collecting is a life of contrasts. On the lower crowded deck of the river steamer, on the first stage of the journey home, I had been busy tending my charges as we passed down the Essequibo River and then into the open sea on the way to Georgetown. On arrival there I was still juggling with a mass of foodstuffs and packing up everything prior to disembarkation; sweat was pouring from me and my clothes were suitable only for bush wear 
and the job I was doing. From my late simple life on the Settlement I was pulled up with a jerk as a tall figure immaculately attired in white stepped out of a gleaming car and informed me that I was invited to lunch with the Governor. This meant getting my menagerie into a safe shady place quickly and doing a quick change into something more suitable for the occasion.

The lunch at Government House was one of those amusing contrasts I was able to appreciate to the full, having had a good taste of the opposite extreme.

The trip home took me via Trinidad, where I had cabled for a further supply of lettuce for my hoatzins. These birds, which had never before been kept alive in captivity, were still perfectly fit when we sailed from Georgetown. As no other accommodation was available all my livestock was kept on deck, this being the usual procedure on the majority of boats. My only worry was how the hoatzins would stand the cold when nearing England, as the change in temperature on leaving the tropics can be unpleasantly rapid even in the summer months, and most birds dislike it.

The voyage went well until we reached the vicinity of the Azores, and then the weather worsened rapidly with a freezing cold head-wind blowing. The hoatzins, whose sole diet was leaves, were obviously affected more than anything else; I made strenuous efforts to get them put somewhere below decks. This request would, under the circumstances, have met with sympathetic consideration on most ships, but by an unfortunate coincidence this was the captain's first voyage on a passenger boat, and he was determined at all costs to do nothing wrong. He made great to-do about safeguarding the health of the passengers, though there are always odd places away from passengers' quarters. The result was that three of the hoatzins died of cold when only three days from England, the fourth arrived with a bad cold and died the following day, but the remaining one landed in perfect condition. He lived in the London Zoo for some months, and would probably have lasted longer if he had had the company of his own kind. Although this venture had a sad sequel, at least it gave me the satisfaction of being able to exhibit for the first time a living specimen of one of the world's most remarkable birds. It showed 
that under favorable circumstances hoatzins can be kept in captivity and even transported long distances. In these days of air travel the project would not be at all difficult provided the birds were treated correctly and accustomed to artificial food before shipment.

During the months that I kept hoatzins in British Guiana I was able to learn a lot about their habits. One of the most peculiar, for diurnal perching birds, was their habit of becoming active on bright moonlit nights. On such occasions they flew about a good deal and I often observed them feeding from their trough. During the day they spent much of their time on the ground, which is contrary to their recorded behavior at large. Another interesting thing about them was their almost entire absence of smell in captivity. This might be explained by the different diet, though much of the time they were fed on caladium leaves. I cannot say if it is possible for the odor to emanate from the oil duct, which may cease to function normally when the bird leads an unnatural existence. 


\section{Chapter Ten}

\section{KENYA (I)}

$\mathrm{O}$

$\mathrm{N}$ my first trip to Kenya I arrived at Mombasa on Christmas Eve, I932. I had previously called at the port but was not then greatly impressed, for its population, comprised mostly of Indians, Arabs, Goannese, and natives, with a very small percentage of Europeans, was too cosmopolitan to be of interest to me. Now that I had time to become familiar with the bird-life, the place took on a different air. But my objective was the far interior where I could seek out some of the numerous species confined to the highlands.

With this object in view, I took the train to Nairobi some three hundred thirty miles inland. It was rather disappointing that the only daily train left Mombasa late in the afternoon, so that all the low bush country was passed through at night. The country rises gradually on leaving the coast, and some two hundred eighty miles inland the train reaches an altitude of about five thousand feet. We awoke to find that the bush country had been left behind and we were now starting to cross the Kapiti and Athi Plains, an enormous stretch of open country where one can see for miles and miles, and which is (or was) a sanctuary for wild animals. It was an impressive sight and one never to be forgotten. On both sides of the line were vast herds of antelope, the commonest being kongoni, Thompson's and Grant's Gazelles, wildebeeste, also wild ostriches and Burchell's Zebra. Lions could be seen occasionally, but this was a matter of luck, and giraffes were plentiful on the coastal side of the plains, where there was plenty of bush for them to feed on. Of course, this type of country is of no great interest to one wishing to see tropical bird-life at its best, 
although I enjoyed seeing a crowd of vultures squabbling over the remains of some animal which the lions had left after having had their fill.

The clarity of the atmosphere at this altitude was extraordinary and Mount Kilimanjaro (19,700 feet) with its snow-capped peak could be seen distinctly at a distance of a hundred miles from the train; from the Aberdare Mountains, where I later did my collecting, it could be seen at about a hundred and eighty miles distant. After crossing the Athi Plains the line reaches Nairobi (5,500 feet), the capital of Kenya Colony, at their western extremity.

Here I got in touch with the Game Department and met Captain Ritchie, the Chief Warden, who did everything to help me. Some friends of his, Major and Mrs. Ward, from the Aberdare Mountains, were arriving the following day and he arranged to give me an introduction. I found them, as I did the majority of the Kenya settlers, most charming and hospitable. They agreed, there and then, for me to stay as long as I wished on their farm at eighty-five hundred feet, at the base of Kinangop Mountain. By their description of the place it seemed ideal, and having waited for them to return by car, I set off by train for Naivasha, the nearest station. This is the direction for Uganda and the line, on leaving Nairobi, rises rapidly to seven thousand feet to the Kenya Highlands, where nearly all the white settlers are situated, growing coffee and maize, etc., and ranching.

After a while one sees the great Rift Valley, a deep trough in the earth, formed in the days when Africa was dotted with active volcanoes and evidently caused by the shrinkage or collapse of the earth's crust for a very great distance. It can be traced for hundreds of miles, some parts being rather ill-defined owing to subsequent volcanic action. In some places the Rift Valley is bordered by escarpments with an almost sheer rise of a thousand feet and is upwards of twenty miles across. The country now becomes full of interest, as bird-life is much in evidence and shows considerable variation according to altitude. After following the edge of the escarpment for some distance the line descends to the Rift Valley by a tortuous course, and then reaches Lake Naivasha. From here I had to journey about twenty-five miles north to the 
Aberdare Mountains over roads which might be described as typically colonial.

Lake Naivasha was a beautiful sight and its shores were teeming with bird-life, the giant acacia trees affording a home for Blueeared Glossy Starlings and Superb Starlings, which were both exceedingly numerous. Red-billed Wood-hoopoes and Whitefronted Bee-eaters were also common here, but the only sunbird I saw close to the lake was Falkenstein's Buff-breasted, which is extremely beautiful with its shining blue upper parts and breast and light buff belly. On the water Red-knobbed Coots were in hundreds, while in the reeds and among the water-lilies the African Jacana or Lily-trotter and the Black Crake could be seen or heard. Waders were also fairly plentiful, being mostly migrant sandpipers from Europe, and the beautiful Blacksmith Plover was there sparingly; ducks were getting scarce, as within recent years there had been a boom in land sales round the edge of the lake, and houses were springing up everywhere, thus disturbing a delightful beauty spot which was once more or less a natural sanctuary. Shooting was rapidly becoming the order of the day.

The country between the lake and escarpment, some ten miles across and known as the Karati Bush, was more interesting, and after a good deal of exploring one could get glimpses of that charming bird the Purple Grenadier Waxbill, which belongs to the same genus as the Violet-eared Waxbill from South Africa, but is even more beautiful. These may sometimes be seen in semibare places in the bush, apparently pecking in the soil. There are no seeding grasses in such places, and probably never were, and it can only be concluded that they are eating minute wind-borne seeds, which are more easily found where the ground is bare.

In the tropics, where the hot air is constantly causing miniature whirlwinds, dust and small seeds and leaves, etc., are carried high into the skies, and in this way the small dust-like seeds of many weeds travel tremendous distances. This is particularly noticeable where a clearing has been made in the middle of a big forest, where under ordinary circumstances none of these weeds and plants can grow, but immediately there is sufficient air and light they spring up in a few days, although there may be no similar things growing within many miles. It has been recorded that, after 
fields have been cultivated and sown with grain, there has been an invasion of doves, which have been duly slaughtered. Later someone with knowledge has shown, by examining the stomachs, that they were not eating grain at all, but were devouring the wind-borne seeds of obnoxious weeds carried from fallow native lands many miles away. It is a great pity that some birds which are really of great economic value are persecuted because of our scanty knowledge of their feeding habits.

Interesting sunbirds to be found in the Karati Bush were the Kenya Highlands Scarlet-chested Sunbird, the Kenya Highlands Amethyst Sunbird, the Bronzy Sunbird, the Kenya Malachite Sunbird, and the Falkenstein's Sunbird already mentioned, all of which looked unbelievably beautiful in their natural surroundings.

Other birds that caught the eye were Long-tailed Rollers, the rare d'Arnaud's Barbet, and the beautiful little Red-fronted Tinker-barbet. In the bush there were still plenty of buffalo and that graceful antelope, the impala.

As one climbed the escarpment to the open highland plains $(8,000$ feet $)$ the air was noticeably cooler and invigorating. At that time this was a vast grazing ground for game, and great herds of Burchell's Zebra, kongoni, and Thompson's Gazelle wandered about with little fear of man. On occasions I saw a mixed herd of these animals, the numbers of which were so great that it was almost impossible to count them. One of the finest sights was a herd of sixty-four eland-the largest of the African antelopes and as big as any ox-the old bulls making a wonderful contrast to the females and calves.

Needless to say the most conspicuous form of bird-life on these plains was the ostrich, which was then quite plentiful.

The base of the forest-clad Aberdare Mountains is a very peculiar formation. Looking across the open country it seems for all the world like rolling plains, practically treeless, but there are all sorts of unseen wonders when you come to explore. The many streams which rise in the mountains flow through incredibly deep ravines, which are not visible at a distance. They are not formed by the action of water, but by the natural shrinkage of the earth's crust. Being thickly forested they are full of interest, and near the water in shady places there are wonderful ferns of all descriptions. 
To descend from the plains into one of these ravines is almost like going to another country as far as bird-life is concerned. Instead of seeing pipits, larks, whydahs and other plains-loving species, one comes across denizens of the jungle such as Hartlaub's Touracos, Narina Trogons, White-headed Wood-hoopoes, Whitestarred Bush-robins, and many bulbuls, zosterops and flycatchers.

There was one of these forest-clad gorges quite near the Wards' house, and the suddenness of the change of animal-life was amazing. After going fifty yards away from the typical highland grassland, one saw the beautiful black-and-white colobus monkeys in the trees with their long flowing hair harmonizing perfectly with the long tufts of usnea hanging from the boughs.

A good proportion of the trees were wild olives, which at a certain season are laden with berries. These olives are oily and very bitter to the taste but are relished by a number of birds, in fact many seem to feed on them exclusively when available. During my visit there was a sudden influx of Olive Pigeons and Masai Red-headed Parrots. The former are large, strikingly handsome birds and get their name not from their color but from their feeding-habits. The flavor of their flesh is said to be so affected during the olive season that it is too bitter to be edible. So used to eating olives are these birds that it is difficult to get them to take anything else when newly captured.

Wild olives are not as a rule ideal trees in which to set hanging nets; but there was one exception in the heart of this sunken forest. It was a very old specimen with gnarled and twisted trunk and wide-spreading branches. Through the crown of this I managed to set my long large-mesh net, which allowed most of the unwanted smaller fry to pass through without getting caught. My biggest headache was when trying to extricate a pair of Redheaded Parrots from it. This meant standing on a branch and employing both hands to try and disentangle the wings and legs from the net, and eventually get the bird out of the pocket formed by its impact. This is difficult enough in such a situation with any struggling bird, but with something that is capable of biting like a bulldog at every attempt to free it, one needs to be a tight-rope walker-cum-juggler.

As soon as the olive crop is thinned out to the extent that birds 
cannot gorge themselves easily, the parrots and pigeons disappear as quickly as they came, but not so the touracos. These are resident and continue to live on olives almost exclusively for a long period, even though they may be hard to find. The wild olive fruits are almost round and are swallowed whole by the touracos, and when the flesh is digested the stones are regurgitated and cast out. The parrots, however, ignore the fruit and crack open the stones for their kernels.

The mammals of the ravine forests are, apart from the monkeys, nearly all nocturnal. One of the things that impressed me most as a newcomer was the nocturnal serenade of the Tree Hyrax.

Lying peacefully in bed in a rondavel in the cool mountain air of the tropics, one may plainly hear the smallest sounds of insects or frogs; in fact if one is not used to Africa it is hard to believe that a cow mooing in the distance may be many miles away. Under these atmospheric conditions it is a bit of a shock to be awakened by a hyrax only a hundred yards or so from one's window suddenly shattering the tranquillity of the night by a long-drawn-out staccato call that might be likened to a donkey braying to the accompaniment of machine-gun fire. These curious animals, that look like a cross between a marmot and a guineapig, have as their nearest relations the elephant, so we are told by anatomists. They live in the crevices of rocks, or holes in trees in the gorges, and emerge at night to eat leaves and fruits. Their feet are not perfectly adapted for climbing though they are excellent for holding a surface; thus the Tree Hyrax will mount slanting trees, or those that are twisted and gnarled, with ease and is perfectly at home among the branches.

One of the most curious creatures of these high woodlands is the Crested Rat, which is the size of a guinea-pig with long fur on the body and tail. It has a habit of raising the fur on its back, thus making a distinct parting along each side of the body and exposing the white underfur, which contrasts vividly with its darker coat. It, also, lives in crevices in rocks in the wooded gorges, coming out at night to feed on a variety of vegetable matter. I snared several in such situations, but the first one I captured with my hands. One night I was walking along a track leading through the woods when I saw in the light of my torch 
this curious badger-like creature crossing my path. It seemed quite incapable of speed, and in fact this one made no attempt to escape from me but instead stood its ground and raised its fur.

In captivity a few weeks later this specimen gave birth to a single baby, which she reared. If this is the usual number of young it signifies that the Crested Rat has few or no natural enemies, for it has insufficient speed or the means of defense to protect itself, and yet the place abounds with servals, civets, genets and leopards. It does not emit a stinking odor like the striped zorilla that occurs in the same locality, so one might well ask how such an animal survives in Africa, where one thing is forever preying upon another.

A friend of mine, Raymond Hook, has suggested that it remains unmolested by predatory animals through its mimicry of the zorilla. Everything has a great respect for this animal, which drives away its enemies in the same manner as the skunk, and the Crested Rat does, in fact, adopt a similar attitude by arching up its fur when in danger, so this interesting explanation would appear to be reasonable.

One of the great attractions of this ravine was the trout-stocked stream that ran through it, for this occasionally provided me with a breakfast fit for the gods. A couple of hours' work in the keen morning air created a prodigious appetite, so that breakfast on a trout, with its delicate earthy flavor, straight from the stream, was surely something to put one on top of the world.

I had two willing coöperators in the persons of Johnny Nimmo and Geoffrey Ferrand, who lived on adjoining farms. One day we set off in Nimmo's car for Lake Elmenteita in the Rift Valley. This is a soda lake and is one of the homes of the beautiful Lesser Flamingo. Its waters are so strongly impregnated with soda that after wading in it a while one's legs become quite white with the chemical deposit; in the dry season, when the lake shrinks, its shores are as white as snow.

The sight of these flamingoes in their countless thousands is something impossible to describe. They are often so closely packed that, when disturbed, the outer ones often have to rise first before the inner ones can flap their wings. It is a mystery at first sight what such an army can live on, as there is nothing noticeable in 
the water and the lake is devoid of vegetation. A close inspection will reveal a very minute crustacean in the water, hardly larger than the larvae of mosquitoes, which is in myriads and is probably their main diet. These flamingoes are only half the size of the Greater Flamingo and belong to a different genus. In the latter species the upper mandible fits over the lower, whereas in the lesser flamingo it fits into the lower.

We had not much time to experiment in the capture of these birds, for it was a long car ride and I had to be back well before dark to see that my sunbirds had sufficient liquid food. It seemed so easy to trap a few specimens out of the many thousands, but then we had not as yet pitted our wits against those of the wily flamingo.

When we approached the lake the pink mass rose with a mighty roar of wings and made off for the other end. By pressing poles into the mud I set several long duck nets so that they jutted out from the shore some distance in the water, thinking that as the swarm came back following the shore line, some at least must get caught. All was ready and I concealed myself nearby while the other two drove the birds back. The nets might well have been red flags judging by the uncanny way the birds avoided them. Unfortunately, a slight breeze had sprung up which caused the nets to flutter, but even the sight of a thin sapling stuck in the water, where none had been before, was enough to make the flamingoes too wary for words. This move was a complete failure. I then tried setting a line of snares above water supported by thin sticks, thinking that at least a few individuals would be stupid enough to walk into them if driven slowly. My comrades had another walk of several miles, and back came the cloud of flamingoes. They settled in thousands near the snares, and by our appearing at odd points at some distance away the birds were slowly driven backwards and forwards past the snares; but each time they walked round them by going into deeper water, their eyes glued on the thin sticks projecting above water as if these were some new kind of aquatic predator and not to be trusted. Our efforts were completely frustrated as the winds got stronger and stronger, setting up currents which upset our efforts to snare the birds by the legs under water. This was one of those unsuc- 
cessful days when we returned home very tired with nothing in the bag.

No doubt the easiest way of getting such birds would be in the rainy season when the lakes are filled and the birds make their peculiar mud nests which jut out of the water. Then the youngsters could be got with ease.

The Lesser Flamingo has a curious distribution, being found in the soda lakes of East Africa, the salt lakes of western Madagascar, and in northwest India. So far as I know, no specimens have yet reached England alive.

Back in the Highlands I was fortunate to trace the sleeping quarters of a pair of the rather rare White-headed Wood-hoopoes in a small hole in a dead tree. These I captured as they came to roost. One could actually smell the hole when near the tree as the birds themselves give off a strong musky odor which remains in the sleeping chamber. There seems to be no explanation in literature as to how these birds, and others such as the Blue-necked Bee-eater, the hoatzin, etc., emit this odor. It is doubtful if it is due to food as many odorless birds have the same diet as those that smell. A probable explanation, as I have already mentioned, is that the secretion from the oil-gland is scented in the case of certain birds, presumably as a protective agent.

While I was there I heard a lot about the Nandi Bear. This is a mythical beast that has many champions among the local populace, in the same way that Scotland has its Loch Ness monster, Australia its Bunyip, and Madagascar its Fananimpitoloha. It is unfortunate that the Nandi Bear crosses people's paths only on misty days when it is impossible to obtain a perfect view. Those who believe in it do so with something of a fanaticism, and it is unwise to argue that in a country as settled as Kenya someone would have come across at least a piece of skin or some bones by now, if it really existed.

The Highlands plains are the home of a bird that has a very restricted range and is not found outside these limits. This is Jackson's Whydah, the male of which in the breeding season is mainly black with a long arched tail. Like the rest of the whydahs, he develops a showy plumage for the breeding season, then goes into eclipse and looks very much like the female. 
One of the great joys of this high grassland is to see the Jackson's Whydahs at breeding time; at odd points one will spot individual males displaying by leaping up from the ground while puffing out their feathers, holding their heads erect and dangling their legs. They have regular places for this dancing which are easily recognized by the neat round patch of short-cropped grass, whereas the surrounding grass may be two feet high or more. No one can say that these plains are monotonous with these animated black objects bobbing up above the level of the tall grass and disappearing again. A Jackson's Whydah lived for sixteen years in the London Zoo.

All too soon I reached a stage when my collection of birds was as much as I could cope with, and I returned home with a large variety of delicate insect-eating birds as well as nectar-feeders, fruit-eaters, and seed-eaters, nearly all of which were new to aviculture in England. 


\section{TANGANYIKA (I)}

THE great continent of Africa, with her wealth of bird-life, 1 many tribes with different customs and dialects, and vast sunbaked landscape, is certainly a land that calls one back once one has been steeped in her sunshine and peculiar ways of life. If continents were likened to animals, Africa would surely be the camel. She is tough and will stand a certain amount of human exploitation, but has a will of her own, and appears to wear a supercilious air as if mocking those who become too familiar or who think they have conquered her.

I find myself forever wanting to explore new territories, for much as I have seen during many years I still feel that there is something more exciting over the hill. Perhaps it was this insatiable desire for novelty and adventure in a strange land that led me to Tanganyika-that vast portion of Africa of which I was shamefully in complete ignorance. So in the winter of $1933-34$ I set off to satisfy a burning curiosity, and of course to collect birds.

With me came my friend, Captain Geoffrey Ferrand, whose only handicap in life was that he was six feet five and a half inches in height-half an inch taller than myself, and therefore had even more difficulty in passing through low doors and fitting into ships' bunks. Our previous meeting in the Kenya Highlands had so stimulated his interest in birds that he begged to join me on this expedition, to spend what he regarded as an ideal holiday.

I had set my heart on visiting the eastern Usambara Mountains in northeast Tanganyika, which lie between thirty and forty miles inland from the port of Tanga. They are clothed with evergreen 
forest, a remnant of the vast equatorial forests which once stretched right across Africa.

It was through the ornithological discoveries of $\mathrm{Mr}$. R. E. Moreau, of the Agricultural Research Station at Amani, that my attention was first drawn to this interesting area.

Our arrival at the Research Station caused a slight stir among the natives, who inquired if we belonged to a new race of giants. In accordance with their custom we were soon given native names: I was "Bwana Ndegi," i.e., the Bird Master, and Ferrand was "Bwana Nzige," the Locust Master. It was clear to everyone from the first day that my interest lay in the local bird-life, so my name was an obvious choice, but it so happened that our arrival coincided with a locust invasion, and this was instrumental in Ferrand's being dubbed Bwana Nzige. The swarm was huge and the locusts, as they settled, could be likened in numbers only to falling snow-flakes. I pointed out to Ferrand that it was a grand opportunity to catch quantities of locusts, dry them, and grind them up to make a basis for a mixture that would be ideal for any insectivorous birds we might capture. So while I was busy piecing together collapsible cages, he set to with a borrowed butterfly net, slashing in all directions and catching locusts by the hundred until he was exhausted. This one-day activity fastened to him a name that would have remained for the rest of his life had he become a permanent resident.

The Agricultural Research Station, started by the Germans in the early part of the century, was a fascinating place. Neat groves of a great variety of introduced trees ranging from cinchona to cedar, the latter filling the still morning air with perfume; experimental crops with an equally wide range from sorghum to sisal; and in the virgin forest, labels on many giants indicating their correct botanical names, were things to stimulate one's interest. Even more exciting were the laboratories themselves. Here were gathered together a number of specialists, each concerned with his particular job. In one section one could see a soil chemist analysing samples sent from as far afield as Nyasaland. His findings might reveal some chemical deficiency which would enable tea-growers to improve their soil and so produce good crops, where for some unknown reason they had always been disappointing. In another 
building the botanist could be seen surrounded by plants that he had gathered recently on an expedition, arranging and classifying them; but most intriguing to me was the laboratory where a fellow was testing the tensile strength of sisal fibers with a homemade "Heath Robinson" apparatus that worked splendidly. In front of this sat a trained native who gave each fiber an index number which, with its pedigree, was duly entered in a book, and to this was added the all-important breaking strain. Years of patient research with crops grown on the station have enabled those concerned to evolve varieties of sisal that grow quicker, give a greater yield, and produce stronger fibers, and so benefit, in no small measure, the important sisal-growing industry of the East African Territories.

The forest around Amani (3,00o feet) was luxurious and proved difficult for collecting live specimens as many of the interesting species were confined to the forest canopy, and even the capture of lower-level birds was an exhausting business owing to the humid heat and the steep slippery slopes of the forest bed.

The most conspicuous birds were the grotesque-looking Silverycheeked Hornbills-a black-and-white species somewhat larger than the Trumpeter Hornbill, which was also present in the district, but in much smaller numbers. These larger hornbills, known locally as Hondo-hondos, make their presence known not only by their incessant cries as they feed on berries in the tree-tops, but by the loud swishing noise of their wings when in flight.

In nature one is forever coming across creatures with unusual habits and here at Amani, besides the hornbills, the Palm Swifts provided a good example of the ingenuity or adaptiveness in the matter of nesting. These birds' nests are placed out of reach of most of their natural enemies, as they are always attached to the mid-rib of a leaf of the dracaena or other palm, according to locality. These leaves wave so violently in any breeze that it is evident that some unusual nesting-habits must have been evolved to survive such conditions. This is so, for the Palm Swift has solved the problem by laying one or two eggs and by sticking them with saliva to the nest. The latter has no depth at all and is merely a pad comprised of agglutinated saliva into which are woven feathers or fibers, and it is to the latter that the egg, or 
eggs, are fixed. When one has seen the contortions of the dracaena leaves in a strong breeze, one wonders how the parent bird sits, and even more how the young one manages to cling to the nestpad, as it must do very soon after hatching.

In spite of our difficulties we managed to get a fair collection in the immediate vicinity of Amani, comprising White-eared Barbets, Heuglin's and Red-capped Robin-chats, African and European Golden Orioles, Green-headed Orioles, Usambara Bluebilled Finches, Red-eyed Crimson-wings, and Kenya Crested Guinea-fowl. The latter is a forest-dwelling and extremely handsome bird, being delicately spotted and having a fine black crest and bright blue bare skin on the upper neck, which has the appearance of being in folds. So deceptive is this, that a number of passengers on the boat home asked me why I had tied blue ribbons round their necks!

The Blue-billed Finch is a pretty creature with its bright red fore-parts and large enamel-like bill, but there is little chance to admire its beauty until it is in the hand. It is a skulker and lives in the forest undergrowth. One occasionally gets a fleeting glimpse of what appears to be a dull bird as it flies away in the gloomy light of the forest, but it rarely alights in an open situation where one can obtain a good view of it. Its favorite food is the millet-like seeds of the curious Bamboo Grass (Olyra latifolia) that grows sparingly throughout the forest. The search for patches of this was a necessary preliminary to catching the birds: flue nets were then set in an adjacent gap in the undergrowth cut for the purpose. I reckoned these to be the most difficult birds to come by, as they did not appear to visit any particular spot regularly.

In order to get nearer the edge of the forest, where bird-life was more varied and easier to collect, we took advantage of the offer of an empty house at Sigi, a few miles east of Amani and at a much lower altitude.

This house had been vacant for some years and had fallen into disuse. The forest second growth had encroached upon it; in one room that had a cement floor there were large cracks which allowed a free passage for the smaller inhabitants of the jungle; and several panes of the leaded windows were missing, permitting a host of moths to enter at night, and also a number of bats to 
chew them up. In this delightful setting overlooking the Sigi River, Ferrand and I took up residence with a cook, houseboy and gramophone. A later acquisition was a ramshackle 30 h.p. box-body car which, when it was in the right mood, enabled us to go farther afield to hunt rare specimens.

On some nights, particularly before a storm, the moths came in in such numbers that we had to eat our soup as far as possible from the light of our hurricane lamps. As soon as any bats entered, the moths seemed to know instinctively that they had little chance of survival while on the wing, and straight away settled on the walls. It was interesting to watch the frustrated bats careering round the room and flicking at the moths with their wing-tips to try and make them take off, but they were not often successful. The wall-geckos benefited by these maneuvers, as the moths that stuck tight were easily caught by them, and any that escaped a gecko had to settle again immediately or it was snapped up by a bat. In the darkness the moths seemed to have more difficulty in detecting bats, for every morning we awoke to find moth wings all over the tops of our mosquito nets. Sometimes when I was awake I could hear the soft swish of a bat's wings, and later the sound of crunching as the creatures hung upsidedown on a beam above my head chewing the body of a moth and allowing the wings to float downwards.

Like me, Ferrand delighted in the antics of the bats and geckos as we sipped our "sundowners," but he took on an entirely different air whenever I emerged triumphantly from the room with the cracked floor dangling a snake from the end of my snakestick. A surprising number of these reptiles appeared in the house from time to time, usually when they were least expected, and it fell to my lot to shut the doors while the staff graciously disappeared, and chase the snake from behind all kinds of impedimenta until I could slip a noose somewhere round its neck or body.

We were often forcefully reminded that our abode was part of the jungle itself. Through many years of sleeping in strange places with the welfare of my menagerie always uppermost in my thoughts, I had learned to sleep so lightly that the faintest sound brought me instantly to full consciousness. One dark night I was 
awakened by a slight rattling of pots in the kitchen. This was an open-sided outhouse facing our bedroom. On a previous occasion I had been disturbed by the fluttering of my birds which were kept on the veranda, and on rushing out I had seen a wild cat trying to get at them. It made off at great speed. This time I was more prepared. Holding my electric torch to the level of my eyes, I pointed it through the window in the direction of the kitchen and switched on for a second only. There was an immediate flashback of two gleaming eyes. Ferrand was sleeping under the window so I had to wake him gently and whisper, "I'm going to fire"; raising a twelve-bore to the firing position, and grasping the torch and barrel with my left hand, I switched on again and fired instantly at the glaring eyes before they disappeared. The gun was only two feet above poor Ferrand's head, and being only half awake he had not the faintest idea what it was all about. He was visibly alarmed but regained his composure when I returned a few moments later with a really large male wild Black-footed Cat.

The most terrifying things to my mind are the Siafu, or marching ants. An army of these will arrive silently in the night, killing everything before it that is unable to escape. Strangely enough, captive birds seem to accept the inevitable without a struggle, so there is no warning disturbance or alarm call. Broody hens and puppies were victims at Amani, and once forty-two turkeys confined in a shed succumbed to their attack. It is not an uncommon thing for an employee and his wife to flee from their beds in the middle of the night and stay with a neighbor until a Siafu invasion has passed. These amazing creatures bite and hang on with the tenacity of a bulldog and are in such incredible numbers that even human beings find it safer to flee than to attempt to stem the tide.

In an aviary I had fifteen chameleons-some of them the very large Meller's Chameleon-and one morning I found them all overwhelmed and smothered so thickly with ants that not a portion of any could be seen. When I beat off the ants with a long stick, little more than the skeletons remained. The aviary was well provided with branches and bushes to act as perching places for the chameleons, so all must have been attacked at some height from the ground. The Siafu ants can smell out anything that is 
animal, and if it is unable to escape it will be overcome, no matter what situation it is in or how big it is. Often the eyes of an animal are eaten out long before its death. To safeguard my birds against them I had long trestle tables made to stand their traveling cages on, and each leg stood in a large tin partly filled with water on which was poured paraffin. This proved to be an effective barrier, but care had to be taken that not a single thing was leaning against the cages, and not even a blade of straw across one of the tins to act as a bridge, otherwise all one's precautions might be in vain.

Much of my time was taken up making excursions to the edge of the forest where I had located a few pairs of the beautiful seed-eaters called Peters' Spotted Waxbills. They frequent the thick scrub and seem always to pick up their food (mainly seeds) from the ground. They are skulking creatures preferring to feed under bushes or on their very edge where cover is close at hand. The only successful way of trapping them is to bait a number of places under bushes for a week or two until it is noticed that birds are coming there to feed. As they are not gregarious it is rarely that a patch is frequented by more than two pairs, so one has to operate over a fairly wide field. These waxbills, however, are exceedingly local and are rarely found except where the right type of scrub, interspersed with grass, is at hand. When one knows this, one can say almost for certain if any piece of territory harbors these beautiful but shy birds.

I found that several of my captive Peters' Spotted Waxbills were suffering from some eye trouble; strangely enough, those so affected were all hens. The symptom was a slight swelling in the inner corner of the eye, and usually both eyes were affected. So bad was one bird, which was moping and looked as if it was about to die, that I made a close examination and was quite mystified by the apparent swelling. Drastic action was called for, so by sharpening some tweezers I was able to grip the mysterious obstruction embedded deeply in the corner of the eye. I pulled gently, and to my horror out came a leech-like parasite about three-quarters of an inch long which moved in caterpillar-like fashion when released on a table. The bird seemed instantly relieved and quickly regained its normal health. I treated several 
birds in this way with the same good result, though sometimes it took several attempts to get the parasites out. If I failed to get a good hold at the first attempt it would completely disappear into the eye-socket and then I would have to wait and try again later when one end of the creature (I never knew which) was level with the eye. In only one bird did I fail to remove the offending parasite, as it never showed enough of itself for me to get a hold, and this specimen died as a result when I was homeward bound. With the bird dead I was able to plunge the tweezers deep into the eye-corner and pull out a really large specimen. None of my other seed-eating birds were troubled by these parasites, and neither were my Peters' Spotted Waxbills captured in Portuguese East Africa. In the wild state it is unusual for a parasite to be detrimental to its host, though the reverse is often the case when the host is living in unnatural conditions, such as in captivity.

It was not long before I had a wonderful lot of sunbirds-in all, nine species-most of which I captured myself, but one day a boy arrived bringing me some Scarlet-chested Sunbirds in a basket in perfect condition. This was most mystifying to me as the natives' usual method of capture in this district was crude, resulting in suffering, and I did everything I could to discourage it.

It was quite obvious that these sunbirds were not caught with lime or snares, and I knew the natives did not possess any means of netting them. What puzzled me most was that the birds were all freshly caught, otherwise some would be showing signs of lack of liquid food, which was not the case. It was always my experience that sunbirds are anything but easy to capture, and I have never caught a number at the same time.

When the native had gone, my cook-boy informed me that he had caught the sunbirds by using fermented coconut water. This is a sweet clear liquid which is very intoxicating, and it had been put into small vessels near the flowers where the birds fed. Having once tasted this delicious brew, the birds, it seemed, followed a good old Spanish custom, and did not think of departing until they were full up. By this time, unfortunately for the birds, they were decidedly under the influence of drink and were easily caught by the natives.

I had no means of checking this story but it seemed feasible 
enough and I was also told that a similar procedure was employed for beating up monkeys and baboons. When these became too troublesome in the natives' plantations, they conveniently placed coconut shells under the trees, but instead of filling them with the natural milk, they replaced this with their potent coconut "beer." When the animals had had their fill and had become a bit stupid, they were promptly chased by a crowd of natives, who attacked and killed them with sticks or bows and arrows, thereby teaching the rest a severe lesson.

I made one short trip to the western Usambaras, which rise to a height of seventy-five hundred feet. To get there meant motoring through the hot plains with miles of sisal plantations on all sides. This is a monotonous crop to look at, but being a succulent it survives where most other crops perish in times of droughtwhich are all too frequent in Tanganyika.

It was wonderful, on leaving the plains, to wind up and up the zigzag road to Lushoto and feel the air getting cooler and cooler. When the sun set at Lushoto the air became cold so rapidly that it was a comfort to sit in front of a log fire in the hotel lounge.

At this altitude I found the beautiful Golden-winged Sunbirds that I had first encountered in the Kenya Highlands, feeding on leonotis. In the forest I was fortunate in capturing a pair of White-starred Bush Robins-one of the smallest but most attractive of the African robin-chats-which have a conspicuous white spot above each eye in the otherwise blue-gray plumage of the head.

By the time I left the Usambaras for England I had some exceedingly fine birds in my collection. The sunbirds alone made a fine show and comprised the following species-Golden-winged, Lesser Bifasciated, Kenya Buff-breasted, East African Mariqua, Usambara Double-collared, Scarlet-chested, Mombasa Collared, Uluguru Violet-backed and Usambara Gray-chin Sunbirds. 


\section{Chapter Twelve}

\section{AUSTRALIA}

TN late November, 1934, I found myself making the dismal rail 1 journey from London to Tilbury, where I boarded the S.S. Mongolia for Australia.

My object in going to Australia was, of course, to collect rare birds, but I was also commissioned by the Zoological Society of London to bring back a number of mammals, such as Bennett's Wallabies, Tasmanian Devils, wombats, phalangers (opossums), Spiny Ant-eaters and, if possible a platypus, for the London and Whipsnade Zoos.

The first port-of-call after leaving Bombay was Fremantle, Western Australia, which gave me an opportunity to meet my eldest brother, whom I had not seen for twenty-one years. He had settled in Perth nearby, and now had three daughters aged from fourteen to eighteen years.

After a brief but delightful stay in Perth, I continued on my way to Melbourne. The morning of our arrival was hot and sunny, which is what one would expect in January in the southern hemisphere, and people were sitting in the shade in the lovely parks in their shirt-sleeves. In the streets, under a bright blue sky and in stifling heat, I found most people carrying overcoats. As the day wore on and the thermometer rose to over $100^{\circ} \mathrm{F}$. in the shade, $\mathrm{I}$ sat on a peculiar rack-rail tram and noticed many men boarding it carrying both jacket and greatcoat over their arms, and perspiring profusely. Within two hours a blustering wind from the south, bringing with it a cold blast from the antarctic, had settled upon the town, and as I returned to my hotel shivering and wiping dust 
from my eyes, there was only one consolation-the mystery of the overcoat was solved!

I found Melbourne a beautiful city, and in spite of its population of over a million people it seemed open and well provided with parks. The Botanical Gardens must be among the finest in the world, and a lovely spot in which to laze. The Zoo was interesting not only for its exhibits, but for the fact that the English sparrow seemed to have taken charge.

I made friends with many aviculturists who showed me things of interest in the surrounding country-the most memorable being some koala bears that were kept at liberty on an estate. However much one may look at pictures of these harmless, cuddlesome creatures, they will never convey the feeling that one gets on seeing them for the first time in life. Like the Giant Panda, or like a natural clown in a circus, they have a personality which endears them to one on sight. The koala is a slow-moving, tree-loving animal with large head and ears and a comical face, and is the origin of the teddy-bear toys. It is really an arboreal wombat that has become so highly specialized in its feeding requirements that it is almost impossible to transport it away from its native land. Its diet consists almost entirely of leaves of eucalyptus trees. These abound in Australia, but those of all but a few species are obnoxious to the koala. On this account it is difficult to keep in districts away from its natural haunts, for the same species of eucalyptus growing in a different soil will produce leaves disagreeable to the koala, and even under the right conditions it has to have freedom of choice, for the young leaves have toxic properties which are fatal. It is found only in eastern Australia.

The single young one, like those of all marsupials, is born in an undeveloped state and crawls like a caterpillar into the female's pouch, where it is nourished by muscular control from the teats until old enough to suckle of its own accord. When well developed it leaves the pouch and travels on its mother's back.

Another exciting experience was a visit to a well-wooded garden where the owner had trained dozens of honey-eaters of several different species to come, on hearing a whistle, to a bench on which he had scattered sugar. The sight of wild birds shooting 
out of tree-tops all over the place and racing to a common goal was delightful, to say the least.

Honey-eaters, like most nectar-feeding birds, are sprightly and intelligent creatures. It seems that whereas the small seed-eating birds, so numerously dotted over the globe, find their food easily and therefore require very little in the way of intellect, the nectarfeeders have to search for their food and are often compelled to shift from place to place wherever suitable trees and shrubs happen to be flowering.

The honey-eaters are less specialized in this respect than nectarfeeders, such as some of the sunbirds and humming-birds, for they consume a considerable proportion of insects as well as berries.

Not least enjoyable of my escorted tours was a trip to the Dandenong Hills to the east of Melbourne. In the wooded valleys deep with bracken and tree-ferns were many birds of interest, but my main idea was to hear a Lyre-bird. This, like the koala, is a creature of which Australians are justly proud.

The male in display has all the splendor of a bird-of-paradise, though the hen, like the female pheasant or peahen, looks dull by comparison with its mate. The beauty of the male lyre-bird is in its tail, but it is a shy bird and difficult to see in its secluded haunts. In spite of this he makes his presence felt by his almost unparalleled powers of mimicry-pouring out the call-notes of all the forest-dwelling birds of his locality, besides mechanical noises and the barking of dogs. He has also a wide range of liquid call-notes of his own. One of the most remarkable things about the bird is the strength of its legs and feet. It can leap almost vertically over eight feet without using its wings, and when scratching will turn up amazingly large pieces of rotting timber by grasping them with both feet and giving a tremendous jerk backwards.

On my visit to these hills I was delighted to hear a male going through his repertoire, though time was too short to hope to see one. I had to be content with seeing a female in captivity, which, however, was interesting if only to watch her scratching. Sometimes when using one leg for this purpose she would cross it over the other and continue to scratch.

Even though armed with letters from the London Zoo I saw that it was going to be exceedingly difficult to get anything out of Vic- 
toria or New South Wales owing to rigid protection laws, so after a few weeks' collecting on the mainland I went over to Tasmania, where the authorities were wholly sympathetic.

I took with me the few birds I had collected including honeyeaters, an Australian Bee-eater, and magpie-larks. The latter are black-and-white birds with lark-like habits, though related to the shrikes. Their local name of mud-lark is in allusion to their habit of building mud nests which are placed on the fork of a branch.

At the small zoo in Hobart there was a specimen of the thylacine or Tasmanian Wolf. It was particularly interesting to see a live specimen of this marsupial wolf as it was probably the last of its kind to be on exhibition. It was then extinct over all the settled areas of Tasmania, where it had been annihilated through being a menace to sheep and poultry, but its existence in the wild uninhabited country of the southwest was considered a probability.

More recently, after the last World War, expeditions have set out to find the thylacine but without success. However, although none were actually seen, it is considered certain that it does still exist because unmistakable tracks were found. As it is found on the mainland of Australia only in fossil form, it will be tragic if this unique creature disappears from its last stronghold.

The base of the thylacine's tail is greatly thickened and so seems to merge into the body. This appendage is also very rigid compared with that of most mammals and is never wagged. Its rather unhappy disposition is enhanced by the fact that it never gives vent to its feelings, and in fact appears to be as silent as the giraffe.

The mammals of Australia are of great interest as they are nearly all island forms belonging to families peculiar to the region. It is indeed strange that this part of the world should have produced so many marsupials. Unfortunately the great majority, with the exception of the kangaroos and wallabies, are nocturnal in their habits, and therefore do not make ideal exhibits for zoos.

By far the most extraordinary of the Australasian fauna are the two egg-laying mammals-the echidna, or Spiny Ant-eater, and the platypus-and both occur in Tasmania.

The platypus is quite common in the Tasmanian lakes, where it lives in burrows, the exits of which are usually near the water- 
line. In the evening it leaves its burrow in search of food, which is mainly earthworms, of which it will consume enormous quantities. It is an excellent swimmer and uses its duck-like bill very much as does a waterfowl. When not feeding in water the platypus likes to be in a dry warm place, and this, with its peculiar feeding habits, is one of the problems when trying to keep it in close confinement. An even greater problem is the animal's temperament. It has a low mentality-I should say almost reptilian-and in captivity will not tolerate any conditions or circumstances that are not entirely suited to it. In fact, it has the ability to die almost immediately when it decides that it has been completely frustrated. Naturally individuals vary in their adaptability to captive conditions, but the young are no easier than adults. Under semicaptive conditions such as in a pond in one's garden, a platypus will thrive, and such a specimen would obviously stand more chance of survival when introduced to a traveling box than a newly caught specimen.

The only success in the transportation of the platypus has been to America, in which case the collector constructed an elaborate and costly traveling cage with winding tunnels lined with rubber squeegees leading from the feeding tank to the sleeping box.

In these days of air travel the situation has changed entirely; for one thing, the problem of supplying live earthworms for anything up to six weeks during transit does not now arise.

In my own case, being on a short visit I had little time to experiment with these animals, especially as I was fully occupied with a large collection of other things. Anyway, I made a number of traveling boxes of simple construction, providing a tank and sleeping quarters, and some temporary boxes without a tank, so that the creatures would not get too wet the first night or two in their efforts to find a way out. Although quiet enough during the day, when nightfall approached the restless creatures would make stubborn efforts to scratch through the wooden boxes, and would die in doing this the first or second night. This is all the more remarkable for, as a rule, they are not very nervous and not at all upset when handled.

A later specimen I had was much more promising than the 
previous ones, and I tried keeping it in a box of dry hay until its feeding times at dusk and dawn, and then lifting it out and putting it into a shallow tank of water to feed on earthworms. When it had had enough of this I dried it in a towel and put it back in the sleeping box. I had slight hopes of this one surviving as it seemed quite contented, but the problem now was to find enough earthworms for the voyage home. It was hard enough to feed it from day to day with earthworms at hand, for I found that what I dug up in an hour the platypus would eat in a few minutes. Until then I never realized the magnitude of the problem. I approached various gardeners with the idea of buying worms in quantity from them, I advertised in the local press, and visited the local unemployment bureau offering to employ anyone at a reasonable wage to dig for worms, but without success. "Down under" it seems there is a code of honor which prevents even a down-andout from seeking the wily earthworm for monetary gain.

The platypus is certainly a specialized feeder, for with the idea of getting a satisfactory food supply for the voyage home I tried him with chopped scallops and many kinds of smaller shellfish, but he showed not the slightest interest. As he is reputed to eat a certain amount of fresh-water shrimps, I inquired among local fishermen for a supply of anything up to a hundredweight dried, but not a single shrimp came my way.

At last one man was found who was prepared to dig for worms. I was told that periodically he went off his head, so came to the conclusion that this must be one of his periods! Anyway he dug and dug and finally produced a quantity of worms which I estimated would last about a fortnight.

As it was getting near my time to leave for home on the Mongolia, which by now had done the round trip to England and back, I wrote to Adelaide and Fremantle to try to get an extra supply for the voyage, and also cabled Bombay, another port-of-call, in the hope of enrolling some of India's teeming millions to hunt for earthworms.

At this stage we will jump back to the day when this particular platypus was brought to me, for it was both eventful and painful and, to some people, probably of interest. 
I knew well enough that the male platypus has a spur-something like a cock's-near the heel on each hind leg which is connected to a poison gland. The spur carries a narrow channel through which the poison flows when ejected by muscular contraction, and this functions in much the same way as the hollow fangs in a venomous snake. Opinions differ as to the exact function of the spur, but the fact that it occurs only in the male has caused
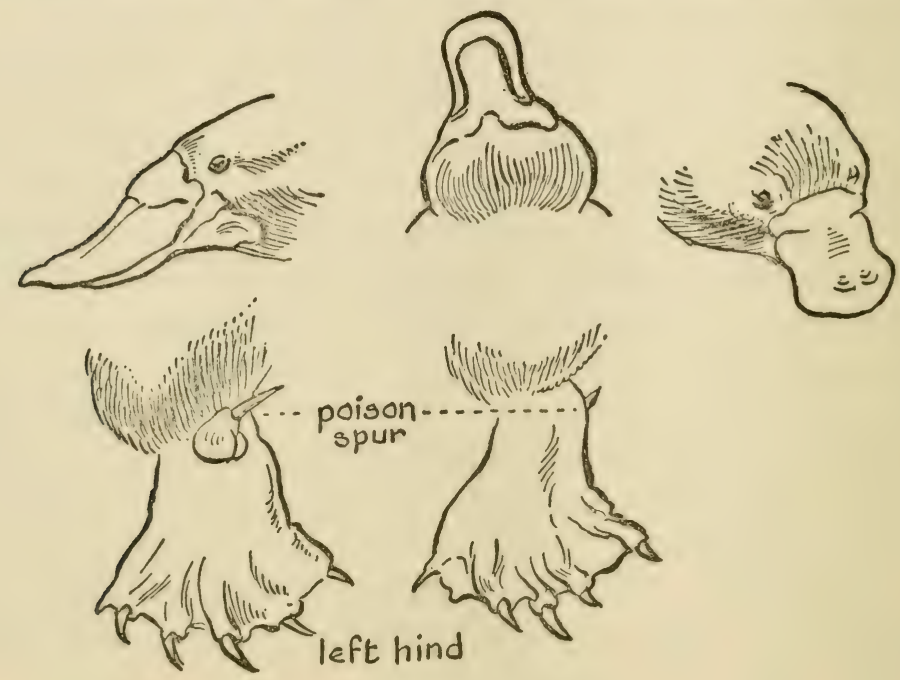

\section{Platypus}

some to attribute to it a secondary sexual significance. By others it is thought to be purely a defensive weapon brought into action only during the mating season.

I had already handled several males which were as docile as kittens, so I was slightly off guard when the fisherman who brought this one took it out of a box and handed it to me. In fairness I must say that he was wearing thick leather gauntlets and told me to beware of the spur. I took it from him gently with my bare hands but at this moment it struggled and in a flash thrust its spur deep into my left hand. There was immediate intense pain and my hand began to swell. The pain continued all night and by morning the whole of my arm up to the shoulder was badly swollen. By putting my hand at intervals in very hot water the 
pain gradually went, but the swelling remained. Inquiries by my host revealed the fact that no one locally knew the nature of the poison, so that no antidote could be given. There were stories of dogs that had died soon after having been stung, and of two humans many years previously, the first of whom died, and the second was in hospital for nine weeks and very nearly died. This was not particularly cheerful, but I was far too busy with my collection to think about it. With my left arm in a sling I went on with my work as usual, feeding all my charges and making traveling cases with one hand.

One or two of the local doctors took a morbid interest in me, mainly I think to take note of the symptoms and to see how long I would last. Apart from the second day, when my heart was beating feebly and I was advised to take some dope to avoid fainting, I cannot say that I was very upset except for the fact that my arm was completely out of action. All strength went out of my left hand and when the swelling had finally disappeared, which was about ten days after the accident, my hand was still paralysed and incapable of even turning a door-handle; but very slowly the strength returned. All I have as evidence is a faint scar about onethird of an inch long-a distinguishing mark of which I am mildly proud, for I am probably unique in this respect.

I learned afterwards that in experiments carried out on rabbits with platypus venom, anything in the nature of a large dose proved quickly fatal, the symptoms being similar to those caused by the bite of certain Australian snakes.

As far as the platypus in Australia goes, it has been stated that it is dangerous only during the mating season, i.e., June to September, and that at other times the secretion in the thigh gland is innocuous. However, my own experience was in late March.

The blood temperature of the platypus is said to be considerably lower than that of other mammals and to vary according to atmospheric temperature. This in itself reveals a reptilian characteristic, and one wonders what happens in the Tasmanian lakes which are sometimes frozen over in the winter. The platypus may then pass through a period of hibernation, as it normally feeds in water, staying under for not more than a minute, when it surfaces to chew its food. 
The other egg-laying mammal-the echidna-presents no great difficulty in captivity; in fact a simple diet of minced meat, milk, and raw egg is sufficient to maintain it in perfect health.

Owing to its sharp spines and its extraordinary ability to remain flat on the ground so that the spines are uppermost, it is an astonishingly difficult animal to pick up, short of doing so with a shovel. There is one trick, however, that never fails. If a stick is pressed hard against his ribs on one side of the body, the hind foot on the other side will be projected outwards just beyond the spines to act as a stop, and this can then be grabbed.

No other mammal has the ability to sink apparently out of sight into the ground like a submarine submerging. It never does this nose first but somehow scrapes the earth from under its body so that it slowly sinks and the earth gradually envelops it. This is accomplished much more quickly than one would imagine.

The echidna has the typical ant-eater's long thin snout with a mouth just large enough to allow the free movement of the long extensile tongue to which ants adhere when it is thrust in their midst. The in-and-out movement of the tongue, as in other anteaters, is very rapid. It seems to prefer small black ants, but doubtless eats other small insects.

Unlike the platypus, which deposits its eggs in a burrow, the echidna carries her single egg in her temporary abdominal pouch, where it is hatched and where the young one remains until too spiny to be comfortable to the mother. It is then left in a hidingplace and visited periodically to be fed.

It was for long a mystery how such an animal could get the egg into her pouch, but it has now been established that she lies on her back and doubles herself up so that the egg is laid either directly into the pouch or is helped into it by the aid of the animal's snout.

The length of life of these lowly creatures is considerable judging by one deposited in the London Zoo in 1912 by Lord Rothschild which lived until 1943, when it died of food poisoning!

I was struck by the prevalence of albinism in Tasmanian mammals. These freaks with their pink eyes are to me never as attractive as normal specimens, though many people seem to prefer 
anything that is out of the ordinary. One man maintained a number of albino Bennett's Wallabies in a semi-wild state on his farm and I was able to get a pair for London. I also got albinos of the Ring-tail and Brush-tail Opossums.

Three Tasmanian Devils came into my hands, and these, like the thylacine, are confined to the island. Although only the size of a badger and related to the Dasyures or Native Cats, the Tasmanian Devil is a particularly ferocious carnivore with a large head and powerful jaws. Mine were fairly tame, being young, but could not be kept together. At feeding time their whole character changed and it was then that the appropriateness of their name became evident; any attempt to introduce food into their cages without undue care would probably have meant the loss of a hand, for the mere smell of meat when they were hungry produced an unbelievable ferocity in these creatures.

When I left Hobart on the Mongolia, the fo'c'sle aft had been completely enclosed with canvas, converting it into a large marquee, and in this was housed my menagerie of devils, wallabies, opossums, echidnas, Fire-tailed Finches, honey-eaters, Spur-winged Plovers, Yellow-bellied Parrakeets, bee-eater, etc., and a platypus. At Melbourne considerable additions were made through the various contacts I had made on my way out. I was thus able to pick up more honey-eaters, Wonga-wonga Pigeons, Maned Geese, Australian Shelduck, Satin Bower-birds, Regent Bower-birds, catbirds, Banksian Cockatoos, and some delightful little Short-headed Flying Phalangers, and Long-necked Terrapins. The Flying Phalangers have large eyes and sleep in holes in trees during the daytime; they are, in fact, much like galagos in habits and general form except that they have a broad membrane connecting the hand with the ankle for gliding.

The bower-birds, to which the catbirds are related, extend throughout the Australasian region and New Guinea and are represented by a number of species. They are the artists of the bird world, seeming to possess some esthetic sense in the building and maintaining of their remarkable bowers. These are built by the cocks and have nothing to do with nesting, though they may be the center for display activities. However, the bowers are appar- 
ently maintained long past the breeding season, and in captivity odd males spend all their spare time constructing and altering them, so it is obvious that this activity is an urge not directly connected with breeding. The bowers are, in fact, used more as a playground than anything else. They are constructed on the ground of sticks, though the different species have totally different ideas as to the form they should take.

The most artistic of this strange group of birds is the Gardener Bower-bird of New Guinea. He constructs a hut-shaped bower that is open on one side and is composed largely of twigs as well as orchid stems, the whole being covered with moss. The ground facing the entrance to the bower is kept clear of fallen leaves and sticks and is decorated daily with fresh flowers and colorful fruits which are replaced when withered.

The Satin Bower-bird, which is fairly common throughout east and southeast Australia, is about the size of a jackdaw, the adult male having shiny purplish-blue plumage in contrast to the female and young male which have greenish plumage with speckled under parts. Both have wonderful light blue eyes, and it is strange that the male has a marked preference for this color when decorating the ground around the bower-choosing blue feathers, blue flowers, and, when obtainable, even pieces of blue cloth and blue glass. The bower itself is composed of a platform of twigs from which two parallel walls of sticks rise to a height of about a foot and are usually arched inwards to form a partly covered run-way.

Like the birds-of-paradise, the males take six or seven years to attain the full adult plumage, looking like females till their third or fourth year, then gradually producing more and more purple feathers. The Satin Bower-bird, besides his artistic accomplishments as a builder, is a wonderful mimic.

The catbirds, which get their name from their cat-like mewing call-notes, do not bother to construct bowers but clear a stretch of ground and strew it with leaves. These are invariably placed upside down and among them the catbird dances, tossing leaves in the air as he goes.

The Long-necked Terrapin is noted for its long rubber-like neck giving the creature the appearance of a snake emerging from a 
shell. The neck is incapable of being withdrawn as is the case with tortoises and most other terrapins, but is folded sideways under the carapace.

On the outward passage through Melbourne I had constructed six fairly large traveling boxes for snakes, and had arranged with Dr. Kellaway, head of the Medical Research Institute, to supply me with as many species as possible. These were snakes collected over a wide area of Australia and had been "milked" for their venom for the purpose of inoculating animals, from which antivenom serum was then prepared for use in snake-bite emergencies. They included the Brown, Tiger, Kangaroo, Black and Red-bellied Black; and Superb and Shaw's Death-adders. Besides these were a number of Blue-tongued Skinks and Stump-tailed Lizards.

At Adelaide I was given a Moloch Lizard, which, as its scientific name-Moloch horridus-implies, is a horrible thing to look at. It is mainly yellowish in color but is dotted with symmetrical reddish-brown patches, though on occasions it goes a dark uniform color, losing its ornamental spots. The most bizarre feature is its horn-like spines projecting outwards and backwards-one each side of the head. The rest of the body, legs, and tail are covered with conical spines resembling rose thorns, and the spaces between these are dotted with small tubercles, the whole giving this wholly inoffensive animal a most frightening aspect. It inhabits the dry treeless plains of south and western Australia and lives almost entirely on black ants; it is so specialized in this respect that it is hard to get it to take anything else.

A night or two before reaching Bombay I took the platypus from his sleeping box and put him in his feeding tank. He swam around with great vigor and mopped up his worms greedily. I usually limited him to half an hour of such activities, then dried him and he was put back in his private sleeping quarters.

On this particular evening I left him, to change hurriedly for dinner. A final glance showed that he was really enjoying himself, but on my return in under thirty minutes I found him stone dead! He had eaten all his food and had apparently wanted to return to his box, and this he was unable to do. He was frustrated, so he died. It was a great blow to me, though his body, which I put 
in cold storage, was greatly appreciated at home for anatomical purposes.

This sudden loss of the will to live reminds one of the behavior of the British shrews in captivity. They, too, can be apparently in good health and eating worms one minute, and will roll over dead the next, with no apparent sign beforehand of any decline. 


\section{Chapter Thirteen}

\section{FRENCH CAMEROONS}

VER in search of new hunting grounds, I was keen on seeing
something of the bird-life of the African equatorial forests. As these do not extend into East Africa I had little first-hand knowledge of the fauna of the center and the west. Much of this vast forest belt is too inaccessible to be convenient for collecting live specimens, so I had to choose the place with the greatest variety of bird-life in proximity to the west coast. After studying the birds of West Africa from books and from skins in the British Museum, and taking careful notes on distribution, I finally decided that the ideal place would be the French Cameroons.

I set off, going by way of Freetown, Takoradi, Accra and Lagos to Duala, the port of French Cameroons. At Lagos in Nigeria I had time to visit the native medicine market, which contained the weirdest assortment of "cures" I had ever seen. Dried hornbill heads were the most conspicuous, but there were also dried reptiles and the dried heads of monkeys and hawks. I imagine that some of these were charms or amulets rather than medicines. Among the live "cures" were Giant Land Snails, tortoises, chameleons and Electric Catfish. The chameleons were supposed to ward off evil spirits, and this is hardly surprising considering the dread all African tribes have of these queer slow-moving reptiles. Perhaps the unique swivel-eyes, which work independently, and their slothful manner of progression have inspired this awe.

The most amusing exhibit was a trio of Electric Catfish which were swimming in a petrol-can of water. The shock from these was supposed to cure all sorts of nervous disorders. Not suffering from these myself, I suggested to my lady friends from the boat 
that they might like to dip their hands in the water "just for fun"! "Quite harmless," I said reassuringly, but funking it myself. After much tittering and hesitation one summoned up enough courage to put her hand in the water, but immediately let out a loud scream. She was cured-if of nothing else-of her curiosity.

Electric Catfish in the wild state, it seems, have a partiality for predigested food, so what could be simpler; they just nose up alongside a friendly fish, the bigger the better, and switch on the current. This causes the poor fish to vomit-thus providing the catfish with his lunch.

The coastal climate of the Cameroons is hot and extremely humid, with heavy rainfall. However, Duala is a busy and very prosperous town, being the export center for the produce of the hinterland. This is naturally rich, yielding palm-nuts and palm-oil in tremendous quantity. Before the commencement of the r914I918 war the Germans ruled the whole of the Cameroons and started many palm-oil plantations. Then it was split up, and with typical generosity and lack of foresight the British handed over the most productive zone to the French, retaining the rest. In those days, of course, there was no shortage of fats and oils, and all that mattered was the entente cordiale.

Getting my luggage cleared at Duala was quite an experience, or rather I should say getting it from the customs sheds to the hotel. At the customs crowds of natives stood waiting to act as porters and were quite uncontrollable. I arranged with a lorry driver for him to take my luggage to the hotel, but having seen the forthcoming mêlée I told him that I was going to pay six boys only to put my baggage on the lorry. This idea he conveyed to the boys. The signal went and the battle was on; an avalanche of black humanity descended on my baggage. At least fifty madmen were fighting and pushing one another to get their hands to a piece of baggage. Each box was like a ball buried under a rugby scrum, and when each one was shot into the lorry, no one knew who had scored. At first, owing to the discomfort of the humid heat, I found this rather trying, but after a while, as the battle continued, I began to see the humor of it. As I climbed into the front seat beside the driver, the entire fifty surged round and demanded cadeau. Having already delegated this difficult part to 
the driver, he thrust sufficient money to pay six people into the hands of those nearest to him and then let in the clutch with a jerk. As we moved off a free fight was under way, but the driver assured me that this was the normal way of dealing with baggage in Duala!

Through the kindness of the manager of the United Africa Company, I was able to occupy a vacant house at Eseka on the very edge of the forest. Eseka is a small but important town about one hundred miles from Duala on the way to Yaounde, the capital. It is the principal center for the palm-oil and cocoa trade.

Before settling in at Eseka, I decided to visit Yaounde for a few days to see what the capital was like, and on my way there I caught my first glimpse of Pygmies-a few who had come through from South Cameroons. Yaounde did not impress me very much, being a straggling place with few decent buildings, and as there was no street lighting the vacant areas between the houses were gloomy and uninviting at night. Under these conditions, black ladies issued forth, especially in the vicinity of the hotel, each carrying a hurricane lamp. This served the double purpose of badge of office and beacon. Anyone seeking nocturnal recreation had only to make for the nearest lamp, for the bearers thereof all belonged to the same profession. This method of attracting would-be clients was certainly something new to me.

Having returned to the more healthy atmosphere of Eseka, I quickly organized things to start my collection. The first accomplishment was the finding of a houseboy and a cook. This was my introduction to pidgin English. With natives who knew French I found it much easier to converse in that language, but my two servants, being Gold Coast boys, could speak nothing but pidgin, so I was forced to murder my own language. Such expressions as "De massa 'e done come" = the white man has arrived; "De butter 'e done live" = there is no more butter; and "I'm no fit for catch 'em" = he is unable to do or get it, are rather bewildering when spoken rapidly with an unfamiliar intonation.

I spent the first week walking miles studying bird-life, and noting the haunts of the particular species I required.

There were two species of Black-capped Waxbills which were fairly numerous in the clearings around native huts, and I was 
keen to get a number as they are exquisite birds and had never been introduced alive to England. The marked similarity of the two species caused the natives to regard them as one and the same, the slight difference, in their view, denoting the sexes. To make it more confusing, both kinds were often to be seen in the same flock.

There was such an abundance of natural food in the way of grass-seed that they were not attracted by any form of bait, so I knew that trapping them on my own in that sticky heat was going to be a slow laborious business; but I hit on an idea to speed things up and allow me time to get on with something else. First of all I captured two of each species, and a few other small birds common in native plantations. Then I approached the local schoolmaster, asking him if he would announce in school that I would pay a reward for certain birds brought to me, alive and in an uninjured condition. I promised to show any boy the birds I had already captured so that he could see what I specially wanted. He not only fell in with this idea but brought the whole school along to my bird-room, where the boys filed past the cages, while I explained my requirements and impressed upon them that on no account must the birds be injured.

This idea worked much better than I had ever expected, as some of the more alert youngsters proved to be quite clever at trapping with their ingenious home-made traps. Besides the species asked for, they occasionally brought in something rare, so it was quite exciting examining the contents of their baskets when they arrived. Nearly all the boys spoke French fairly well as this was the official language of the schools; in fact it is the practice in all French possessions to change the native at an early age into a young Frenchman and to alienate him from the wilder elements of his own kind. The great objection to this idea seems to me to be that once a native learns to speak a European language, he will no longer do any manual labor. He immediately wants an office job, and is the first to exploit his own kind. Outside a French-speaking black gentleman's hut one may see the legend Ecrivain public, which means that he is prepared to act on behalf of the nonFrench-speaking fraternity in their affairs with the government over such matters as taxes, etc. This is a highly lucrative business, 
and illustrates the advantages of education. The ignorant client has no idea what the écrivain public has written on his behalfif indeed such a letter is ever sent off-and he may be told in reply that the government or police have demanded payment of 100 francs, failing which he will be put in prison. The écrivain may then wave a piece of paper under the boy's nose, which may be a jam-tin label, or it may bear the legend Corned Beef, but in any case, as the poor fellow cannot read, he is none the wiser and is frightened into parting with the money. In most British possessions officials have to learn the local language, so it is not the general policy to make every native an English-speaking citizen.

At the time of my visit there were some slight matrimonial complications among the natives owing to the system of levying a tax on both sexes. This meant that all the natives with unofficial wives promptly disowned them when taxes fell due. Thus thousands of natives returned to respectable bachelorhood annually until all taxes were paid.

I gradually built up one of the best collections I ever had, thanks largely to the schoolboys, though I had to trap nearly all the forestdwelling birds myself. The adult natives were of no assistance whatever. It is very noticeable among some tribes, especially in the very hot humid zones, that the youngsters are very bright, physically and mentally, until they reach adolescence, and then they change completely. This probably coincides with their cohabitation with the opposite sex.

I spent much time alone in the Cameroon forests climbing tall trees and setting nets. Birds that subsist on berries and fruits in the forest tree-tops are the hardest to get at. Hardly any trees have branches within fifty feet of the ground, which makes climbing difficult and hazardous, and every tree harbors colonies of biting ants which live in the crevices of the bark or in nests made among the leaves, according to species. These all viciously attack any intruder, and their bites can be very painful. They often defeated me by their incredible numbers. It can be well imagined that when one is clinging precariously to a tree trunk high above the earth, with no means of escape or defense, it is no joke to be attacked from all sides by swarms of furious ants. Their bites set up a violent irritation like prickly heat, and often fever, 
There are other snags in trying to trap rare tree-top birds. One is that the fruit- or berry-bearing trees may be so plentiful that it is sheer luck if these birds visit any particular tree. Secondly, having spent hours climbing a tree and arranging nets or traps, one has hardly descended to the ground before the common unwanted birds arrive in flocks and get caught immediately. Then begins the long climb up to release them and re-arrange the nets and reset the traps. This may go on and on until one is worn out with fatigue without catching anything worth while. If one is patient and persistent enough success usually comes in the end, though it may mean changing tactics or locality a number of times.

Of the many species of birds collected that had never been in captivity in Europe before, perhaps the most curious were some Black Hornbills. These are large arboreal birds with powerful voices. Their large bills are adorned with a cylindrical-shaped casque, which serves no purpose except that of ornamentation, and their throats are adorned with blue wattles. In flight their wings make a loud rushing noise like the sound of a distant train. Altogether they have a grotesque appearance which is accentuated by their short legs; nevertheless they are very intelligent and make the most amusing pets. Their huge clumsy-looking beaks are, in practice, very mobile and sensitive weapons. They are adepts at catching any food thrown to them, even if done so with some force, and they rarely miss if it is within their reach.

In walking through the forests, I frequently found it easier to follow the beds of shallow streams, wearing old shoes for the purpose. This was quicker, less tiring than scrambling through the undergrowth, and also served as a guide for the return home.

One of the familiar noises of these forests is the call of the Tinker-bird. The call is a monotonous tong, tong, tong, tong, which goes on all day. Tinker-birds are miniature barbets, and are usually black and yellow with white or yellow stripes on the head, according to species, and some have a moustachial streak which gives them a quaint appearance. They nest in small holes in trees or rotten stumps, and the entrance hole is no larger than one's middle finger.

Occasionally I got a glimpse of a dwarf kingfisher as it sped 


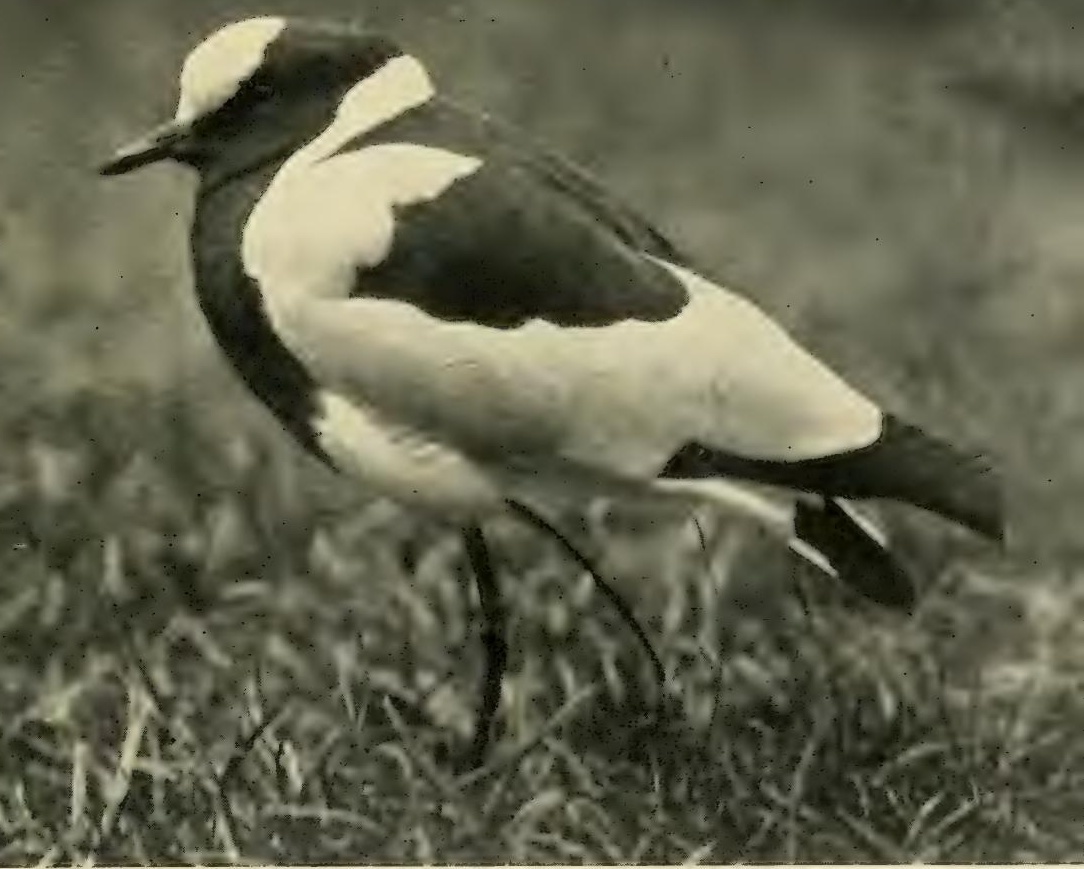

Blacksmith Plcver

Zoological Scciety of Londo

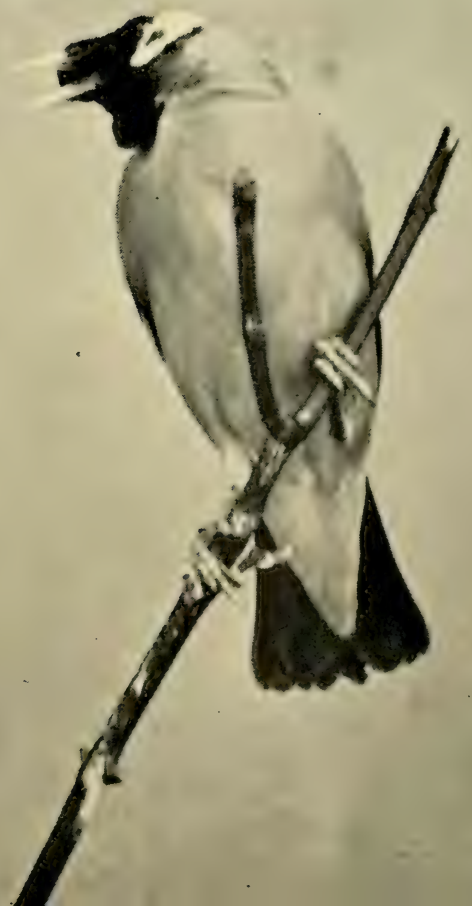

Male Wattled

Starling in breeding headdress 


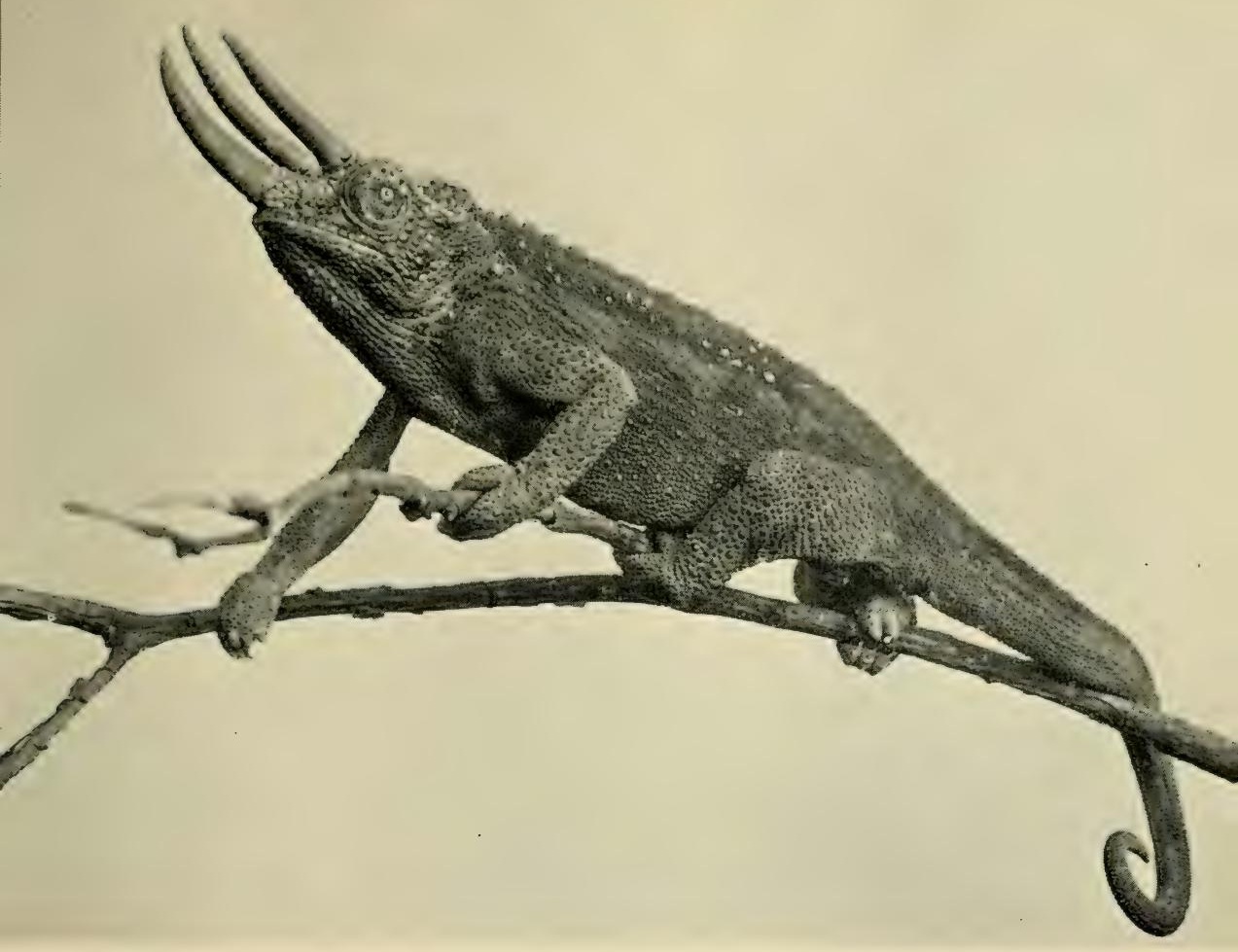

Jackson's Chamaeleon, Kenya Colony. A creature much feared by most African natives

Colobus Monkey with adopted Colobus baby, Kenya Highlands

C. S. Webb

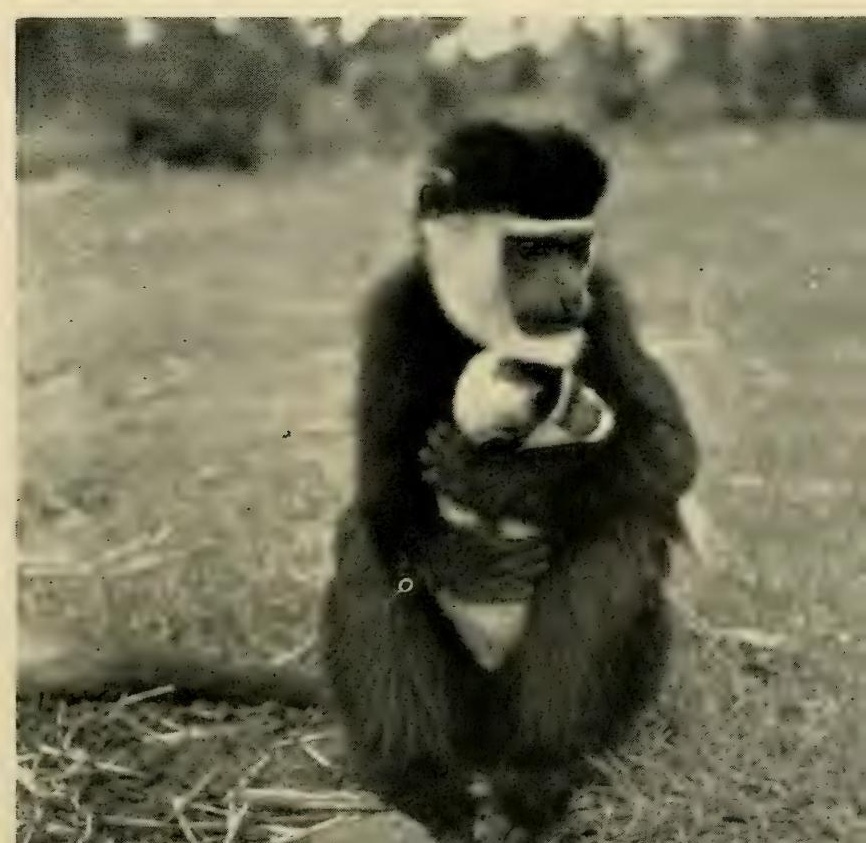


ent

ars on th:

$+\sin x^{+2}$

4.

4,53

$6+2: 20$

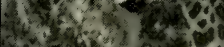

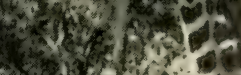

1.s. of

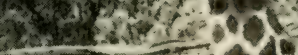

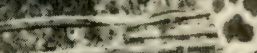

Sown

soras

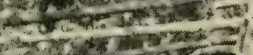

Tresnuthe

ar.

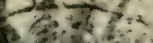
isy (5) a

$5,2 x+3$

$5+12{ }^{2}$ T.

\section{hio hat}

$p=4+80 \mathrm{x}$

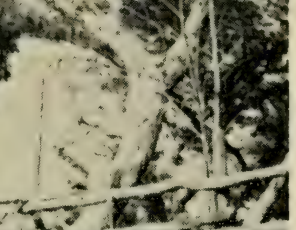
hos rases in $x^{2}$

"Girlie", female Baringo Giraffe, Kenya Colony

Raymond Hook with hybrid Grevy's Zebra x Arab mare. Latter in background. Nanyuki, Kenya Colony

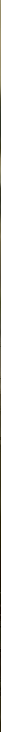




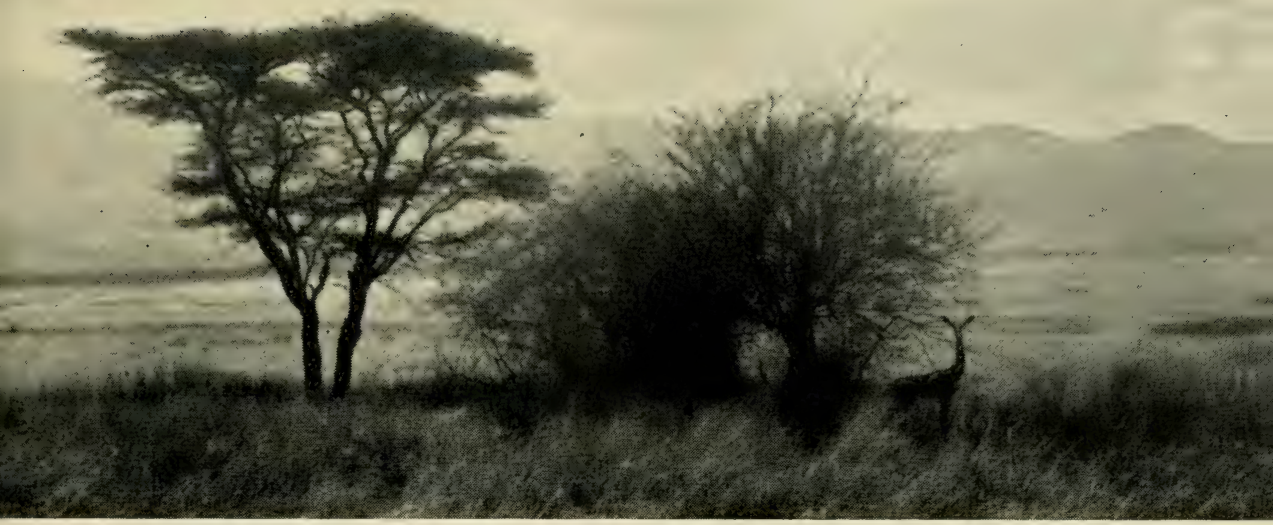

Gerenuk, or Giraffe-necked Antelope, Northern Kenya

Farewell to "Dicksi", Mombasa Harbour

Kenya Information Office

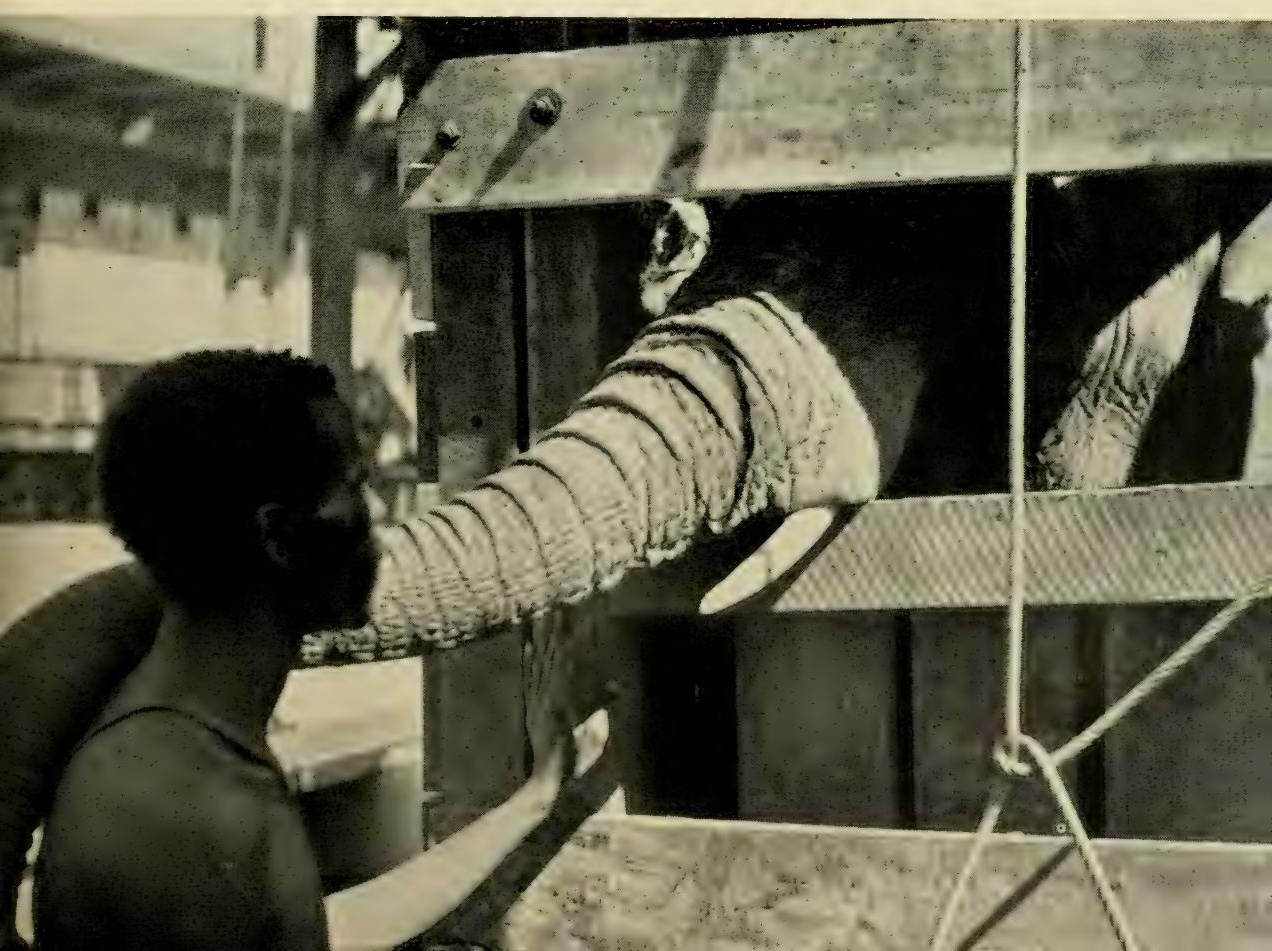




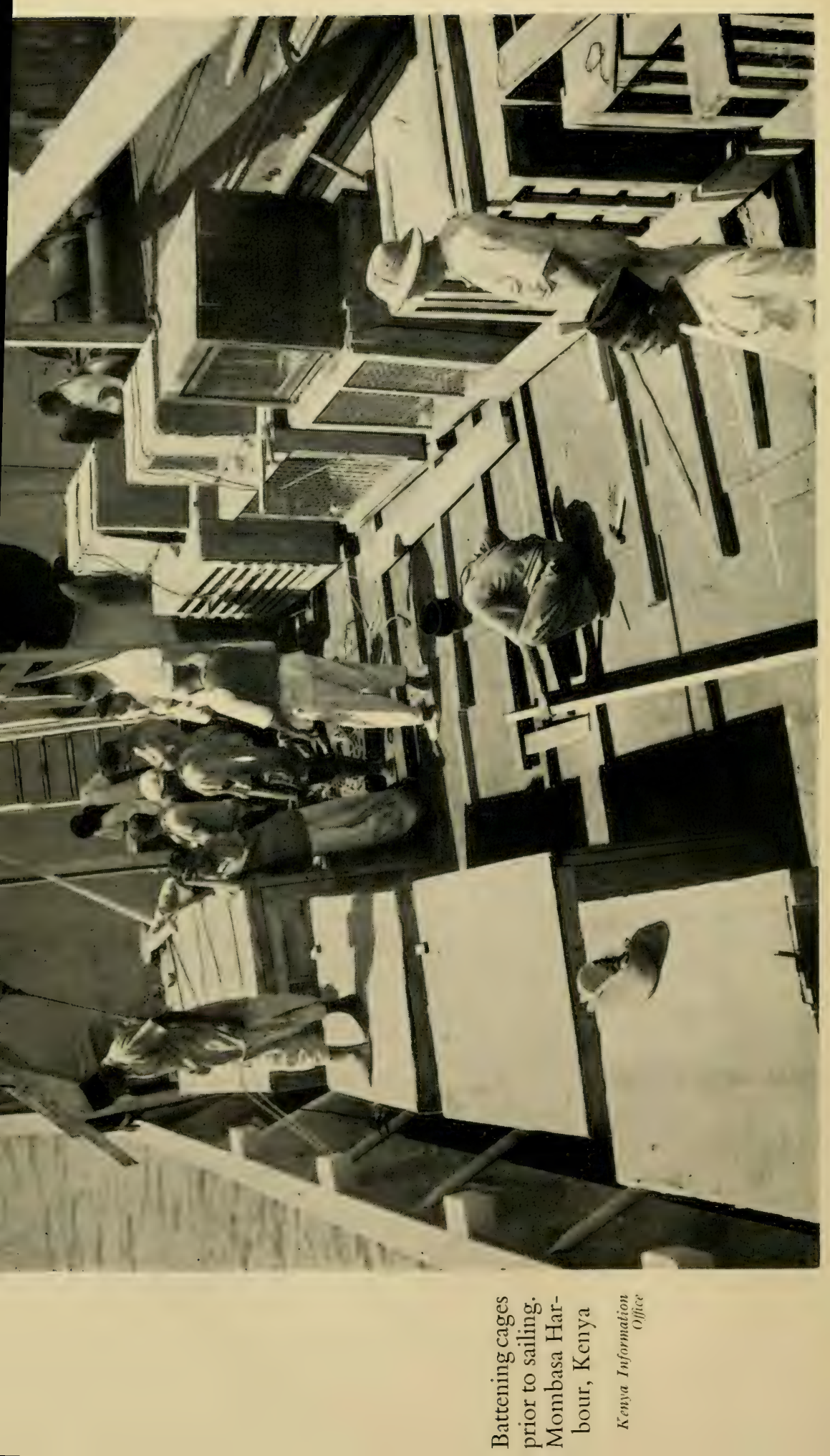


through the undergrowth. There are several species here-all being very minute and exquisite in color-and as they flit past the intense blue of the upper parts is most striking. Two of these species, although belonging to the kingfisher family, are frequently found far from water and never eat fish. They subsist mainly on grasshoppers and spiders, etc. In captivity they are diffcult, but will thrive on small pieces of meat and live meal-worms, though they are very nervous little birds even when reared from the nest. Like many other insect-eating birds, they cast up pellets of the undigested portion of their food.

At times there is something quite awesome about these vast equatorial forests, a feeling which is most acute, no doubt, when one is alone. The great height of the trees, the gloomy light, and occasionally the intense silence, combine to create an overbearing atmosphere. As one crawls along some animal track in a heavy damp atmosphere, one feels about the size of an ant and just as insignificant.

One of the more educated natives of Eseka begged me not to go into the forest alone. He said that once a European naturalist had disappeared near here, and that the bush people were very rough, so that it was foolish for the white man to go into the forests unaccompanied. He was evidently terrified of the dark creepy atmosphere of the jungle, but as he was a townsman I knew that much of his fear was due to fantastic stories and superstitions. Nevertheless, in view of his warning and being unarmed, I used quietly to conceal myself when I heard a number of natives coming towards me on a jungle path.

In going through tropical forests and elsewhere, making observations on the movements, feeding habits, and haunts of rare birds, silence is essential-there must be no talking. That is mainly why I prefer to go alone. I can stalk silently along in crêpe-soled shoes, and stop instantly when any movement would mean disturbing the interesting creature I have just spotted.

In the more open situations, weaver-birds were the commonest of the Cameroons avi-fauna, especially in the palm-growing districts. It is interesting to note how some birds have discovered that it is safer to live near human habitations than in wilder situations. 
In this way they avoid most, if not all, of their natural enemies. In the Cameroons the Black Weaver-birds build their pendant nests in trees right among the native huts. Almost every village is alive with them. It is a common sight to see a small tree festooned with their beautifully woven nests, the occupants taking no notice of the village life only a few yards away. I have never seen such active creatures as these weavers. Their nesting colonies are hives of industry the whole day long, and one gets the impression that they spend their entire lives weaving. It is a fascinating sight to see them one by one making a bee-line for a palm-nut tree. They settle on a frond, nip the edge of a palm leaf, then take off into the air; thus a long strip of leaf is torn off and the weaver sails through the air nestwards with a ribbon-like palm leaf trailing behind. At the nests tremendous chattering goes on while the birds hang upside down adjusting the latest piece of nesting material, and occasionally bobbing in and out of the nest to mold it into shape. Weaver-birds' nests are usually kidney-shaped with a hole at the bottom on one side. There is a ridge between the entrance hole and the nest cavity which prevents the eggs from falling out when the nest is swaying in a wind. Many are not used for breeding but are constructed by the cocks, either for the sheer joy of weaving or to serve as sleeping places.

There is another weaver-bird with similar habits called the V-marked Weaver. It is yellow with a black head, and like the foregoing, seems to realize the protection offered by choosing building sites right in the middle of a village.

In the Cameroons is found the world's largest frog. It is a monster, and goes under the scientific name of Rana goliath. One of my great desires was to get a few examples of this striking amphibian. Unfortunately it did not exist within many miles of my collecting base so I sent word to the local Chief to see if he could do something about it. He rolled up with his son and advisers, and with great solemnity I was presented with a fowl (years past the prime of life), some eggs (half of which turned out to be rotten), and a live tortoise. Guessing that a little whiskey would not be amiss on such an auspicious occasion, I poured out about a third of a tumbler for the Chief, who gulped the whole 
lot down neat. I soon found that he was a sort of human sponge where whiskey was concerned, and with some difficulty I eventually induced him to leave the house. He went away full of promises (and whiskey), saying that he would instruct all his people to search for Giant Frogs. One of his head men told me that to catch them the natives dammed up a small forest stream so that a fairly large deep pool was formed. A number of these were made in different parts of the forest and then left for any length of time, or sometimes permanently, until Giant Frogs had been attracted to them and made them their home. Then they were drained off, and a number of natives got into the shallow water and caught the frogs with baskets.

The Chief turned out to be a worthless old bounder, and it was obvious that his main idea was to get as much whiskey as possible out of me. His visits became more and more frequent, each time with trifling excuses as to why no one had brought any frogs, and each time asking me if I could spare him some whiskey. Finally I made it quite clear that until some Giant Frogs arrived there would be no more whiskey. This evidently spurred him into action, for about a week later three half-grown ones were brought in. Unfortunately they had been injured and soon died. Anyway it was a start. Later I got three more, one of which was full grown. It was a fine specimen, about a foot long, with tremendous power in its hind legs, and was very difficult to hold. I let it loose in an unfurnished spare room where it could jump quite easily from one end to the other and even over my head. I kept a large round shallow bath in the room which was filled with water and a lot of floating weed for the frogs to hide under. One day I was stooping down trying to find the big fellow, when he shot out from under the weed and hit me in the chest with such force that he knocked me flat on my back. Allowing for the fact that I was in a position to be easily overbalanced, this yet gives some indication of their strength. They are much sought after for food by the natives, who regard them as a great delicacy, so perhaps it is not surprising that I had difficulty in getting anyone to walk ten miles or more to bring me any-even for a good reward. Money means little or nothing to a bush native; a Giant Frog 
provides him with something to eat, which is all he wants, and as he cannot eat money, why should he walk twenty miles?

One of the dangers of the untrained eye is the concealed pits which are placed on forest tracks. These are dug fairly deep and are covered lightly with branches, then sticks and leaves, and are cleverly concealed in this way. In the bottom of the pit sharp wooden spikes are driven into the ground, point upwards, so that any unsuspecting bulky animal walking along the track at night treads on the flimsy pit-covering, which collapses, and is impaled on the spikes below. These pits are a nuisance to European hunters, and have been the cause of many accidents.

Being a specialist in the care of nectar-feeding birds, one of my great desires was to get a varied collection of the magnificent sunbirds of the Cameroons. But uppermost in my thoughts was the species aptly called the Superb Sunbird. This bird with its crown of metallic blue-green, its metallic green back, its throat and upper breast metallic violet, is a living gem. Even the natives, who clump the sunbirds in general under one name, recognize the outstanding brilliance of this species. They call it Njok Etong. It is one of those elusive denizens of the great forest that have no regular feeding places, but crop up here and there spasmodically. Occasionally one can be seen in some native plantation in, or bordering, the forest, where it seeks the nectar in the pawpaw and banana flowers. This diet is supplemented with insects and spiders. The females are inconspicuous birds of an olivaceous color.

The offer of a large reward failed to produce any Superb Sunbirds, although the schoolboys brought me several other species. However, I managed to get three males myself after finding a suitable place for catching them. These three represented many weeks of toil. The capture of these rare and elusive creatures put me on a high plane where the local boys were concerned, and they came to my bird-room to admire the Njok Etongs, and to inquire how I caught them. I pulled their legs unmercifully, referring to the inability of the entire local population to produce one, whereas I had caught three single-handed in my spare time. I gave them the impression that it was too easy for words, though actually, as with the trapping of almost any rare bird of the 
tropical jungle, my success was due, almost wholly, to close observation. After that it was merely a matter of common sense.

The abandoned native plantations in the forest produce a vegetation entirely different from that of the forest which envelops them. This is brought into being by wind-borne seeds, and is called second growth. It is composed of bushes and small trees which are bound together by creepers of all descriptions, forming an impenetrable mass. Some of these bear thorns and others have knife-edged grass-like blades which cut one to pieces. It would need at least the weight of an elephant to penetrate this tangled mass, and even boys armed with cutlasses make little impression on it. They may hack away until they are exhausted and the result is a small tunnel a few yards long. The bird-life in this second growth is quite distinct from that of the forest. Some of its inhabitants are skulkers which live near the ground, and rarely, if ever, show themselves in open places. One of these is the Blue-shouldered Robin-chat, which is a magnificent bird. It was weeks before I got my first glimpse of one of these most secretive creatures, though I knew of their existence by hearing their soft call-notes late in the day. Determined to find one, I crawled along an animal track frequented mainly by wild pigs. It was like crawling through a tunnel only two feet high, as the vegetation was dense beyond belief. I went along this for some distance like a snake, and then came to a part that was more lofty which enabled me to sit upright. Keeping quite still I waited patiently, and after a while was rewarded by seeing a Blue-shouldered Robin-chat hop on to the track only a few yards away, obviously looking for insects. I soon realized that this track was its favorite feeding place, and as robinchats are usually in pairs, I concluded that its mate was not far off. Returning with a spring-net trap, I crawled along the tunnel again and set it on the ground baited with a live meal-worm. When I returned a little later the robin-chat was caught, and the next day I caught his mate.

Once while crawling on my belly through a similar secondgrowth tunnel, a startling noise ahead brought me to a halt; it might have been a child being murdered, but the noise was constant and of steady volume. After listening to this uncanny noise 
for a few moments I was able to ascertain that it was not a large volume of sound coming from a distance, as I at first thought, but a lesser volume quite close to me. I went nearer and I suddenly seemed to be on top of it. It must be a small mammal, I thought, but then what mammal, and why was the cry so continuous and from the same spot? It intrigued me more and more as I crawled to within a few feet of the sound, but could see nothing. Determined to find it, I wriggled through the wall of vegetation bordering the track, and there saw, within two feet of my nose, a long tree-snake swallowing a tree-frog. The poor frog was very much alive, and was being slowly devoured rump first, hence the frantic squealing. I tried to grab the snake with my hands but the density of the undergrowth prevented me from acting quickly, and after my first attempt it slithered off at great speed with the frog's pitiful cries still disturbing the peace of the second growth.

The children of Eseka possessed real live toys which caused them endless amusement. With these they used to play at "aeroplanes." The same "toys" formed part of my collection and proved so irresistible that when I got home to the Zoo with them many otherwise serious-minded, staid gentlemen took up the same game - that is, when not in company of underlings. To play the game, all that is needed is one Goliath Beetle and some cotton or string. This beetle is a gaily colored fellow of enormous size and with hard "horns." In flights the buzzing of the wings is quite formidable. The cotton (or string) is attached to the horns and the beetle is then cast into the air. When the string pulls tight, he flies round and round in circles making a noise like a miniature aeroplane, until he gets fed up with it and flops to the ground. This is, of course, a seasonal game, as during its full life-cycle of one year this insect, like most of the Coleoptera, enjoys only a short period in the beetle stage.

Although my residence was secluded and on the very edge of the forest, it was but one hundred yards from the railway station and two hundred yards from the local market. This latter was the gathering ground for many hundreds of women who came daily to sell palm-nuts and exchange the proceeds for something they particularly required. They wore raffia skirts and were bare 
to the waist, and displayed their figures to advantage as they walked along carrying their wares in baskets on their heads. It is surprising how quickly one becomes inured to such an array of naked flesh, but no one with an eye could fail to remark how much more beautiful a native girl is in this simple attire than in the sloppy get-up planted on their more sophisticated sisters by well-meaning Europeans.

As time went on and I became known farther and farther afield, more and more children, and even women, arrived with baskets of birds, and so some rare and interesting species came into my hands that I could never have captured myself during a limited period. Included in these were several species of Malimbus Weavers, which are denizens of the forest. They are insect-eating weavers feeding solely in the trees, and have black and red in the plumage. That the red is an ancestral character is shown by the fact that even the young have this coloration-a most unusual thing in birds.

The most beautiful seed-eating bird brought to me was one with an enormously thick bill known as the Black-bellied Seed-cracker. Certainly its bill was powerful enough to crack almost any seed, judging by the facility with which it drew blood when being handled. Its head and neck were crimson and shone like silk; its breast was also of this color but not shiny, and the rest of the plumage black.

Speaking of powerful bills reminds me also of a Fiery-breasted or Gladiator Bush-shrike that was brought in. He lives in the forest undergrowth and with his cruel beak, terminating in a pronounced sharp-pointed hook, he catches all sorts of insects such as beetles, grasshoppers and frogs.

Besides getting the largest species of sunbird-the Superb-I was fortunate in capturing one specimen of the Tiny Sunbird, which is the smallest of the African species. It so resembles one of the common kinds that I had to examine these carefully before liberating surplus specimens, and in the end was delighted to get this one, which was the first ever kept in captivity.

The rarest and most beautiful of the small seed-eating birds were some I captured myself. These were tiny birds mainly green 
in color with black breasts spotted white, and known as twinspots. They are usually in pairs and were most difficult to come by. I got a glimpse of one or two in a palm-nut grove that was overrun with long grass and bushes. Here these shy birds had all the protective covering they like, while searching on the ground for fallen grass seed. Fortunately they had a passion for my millet, so I baited patches in secluded spots, and those that I found were being visited I continued to bait daily for weeks. More and more birds found these desirable food-centers, and then I placed a homemade wire-netting trap, constructed on the principle of a fish-trap, over the bait. So keen were the birds on the millet by now that they entered the funnel-shaped entrance of the trap without hesitation, and were unable to find their way out. In this way I was able to capture over twenty of a species that has always been an extreme rarity in collections.

Certain birds have learned to feed on the outer oily husk of the palm-nut to such an extent that this food now seems an essential part of their diet in the wild state. This is a yellowish fleshy substance, mingled with fibers, that surrounds the actual nut, and which in turn is encased in a thin shiny skin. From this outer flesh palm-oil is produced, and from the nut, palm-kernels which are used for margarine, etc. The nuts are packed so tightly in bunches that they are hard to dislodge except when very ripe, and then they turn yellow and drop. It is the dropped nuts on which birds and rodents come to feed.

By using these as a lure I caught a variety of Negro-finches, which are normally insect-eating birds but have a passion for the oily palm-nut pulp. A most surprising development in this line is that the West African Harrier Hawk now feeds largely on this diet, which he supplements with more natural food-young birds, especially nesting weavers. Even more strange is that a fish-eating bird-the Vulturine Fish Eagle-has also taken to palm-nuts, at least in the French Cameroons.

With what was probably my best collection so far, I was at last due to leave, and even as my menagerie was being stowed in a special covered van waiting in the siding, a woman thrust some baskets containing Black Hornbills in my hand. This created a 
problem. As the train made its way to the steamy heat of Duala I not only had to feed all my seed-eaters, insect-eaters, fruit-eaters, meat-eaters, and nectar-feeders, but now I was confronted with a lot of squabbling hornbills trying to hammer one another's heads open with their enormous bills. I had put them temporarily in boxes in which others of their kind were caged singly, but this would not work, so I returned the newcomers to their baskets and quickly scrounged some boxes when I reached Duala, where I sat up half the night converting these into traveling crates. 


\section{Chapter Fourteen}

\section{MADAGASCAR (II)}

HAVING gained valuable experience on my first expedition $\Pi$ to Madagascar I was anxious to return to do even better. My eldest brother, who had spent twenty years in western Australia, had returned to England with his family about this time, and his eldest daughter Delys, then aged nineteen, was very keen to accompany me. It was certainly a grand way of providing an outlet for her adventurous spirit and an opportunity for seeing an out-of-the-way part of the world.

Our arrival in Madagascar early in 1935 coincided with the flowering season of many orchids, and on our way by train through the eastern rain-forests we saw numbers of Angraecum superbum and A. sesquipedale in bloom. The former has greenishwhite flowers about four inches across, and the latter ivory-white blooms averaging six inches with a spur about a foot long. It is strange that Madagascar is so rich in its variety of epiphytic orchids as compared with the African mainland. A great many, such as the Angraecums, have no pseudo-bulbs, and are therefore difficult to transport unless established on pieces of bark.

Our destination was again Lake Alaotra as I had been commissioned to get another collection of waterfowl. My former collecting base-the station at Ambatosoratra-was now in full operation and was occupied by station staff.

Whilst making arrangements for somewhere to settle down, we stayed at Ambatondrazaka, some miles south of the lake, this being the only place at that time supporting an hotel. Most of the houses here were two-storied and were made of unburned red brick. The hotel proprietor was a colored man whose chocolate- 
colored daughter, named Maria, had a Bandro (reed-lemur). Although allowed to run loose, it used to sleep most of the day in a room, but in the afternoon about the time for Maria to return home from school the bandro was very much awake, perched on the window-sill of her bedroom, waiting and watching. When she was close enough to be recognizable, this intelligent little animal hopped down the stairs to greet her, and then followed a great fussing while the bandro clung to her breast. No one else mattered in the slightest, for Maria, it seemed, was mother and father to this delightful little orphan.

By good fortune we were able to stay on the mission station belonging to the London Missionary Society at Imerimandroso, a Malagasy town at the northeast end of the lake. This was a great help to us as the L.M.S. missionary, Mr. Williams, was fluent in the Malagasy language and was able to spread our requirements to all the lakeside villages through his native pastors.

Profiting from previous experience I decided to keep my waterfowl quite dry, and so converted a large fowl run into a suitable aviary for ducks. To make it secluded I had the place enclosed with a close-fitting papyrus reed fence, and the sleeping shed bedded deeply with rice straw. The feeding troughs were made long but only two inches wide so that the birds were unable to get into them and wet their plumage. As soon as the straw became at all damp it was replaced with clean dry straw. It seems ridiculous to keep waterfowl dry but in point of fact this is the only way to insure that newly captured birds-especially delicate species-survive. In close confinement wild ducks quickly lose the oiliness in their feathers, which then become damp, and this is fatal. On my first expedition I used traveling crates with barred fronts so that the ducks had to put their heads through the bars to feed and drink. Rice straw was put on the floors of the boxes, but owing to the large amount of water consumed, and the consequent wateriness of the droppings, the straw became quickly soiled and had to be changed twice daily. This entailed a lot of work because of the numbers involved, and was never wholly satisfactory because the birds' feathers inevitably became damp.

On this second expedition I made a new type of traveling box with a false bottom of small-mesh wire netting so that all drop- 
pings passed through into a metal tray, leaving the birds perfectly dry, and with this type of cage straw was unnecessary. By carrying out this idea we successfully kept numbers of such delicate birds as Pygmy Geese and Hottentot Teal without loss. To feed the former, I took a two-hundred-pound sack of Indian millet with me to Madagascar as they relish small seeds of this type, which are unobtainable locally. They will not thrive on paddy.

The Pygmy Goose, or perhaps African Cotton Teal is a better name as it is not really a goose, is smaller than our English teal and is one of the prettiest of all waterfowl. Even the Antsihanaka tribe recognize this, judging by their name for it-vorontsara, i.e., handsome bird. It has the upper side glossy green; forehead, facepatches and under side, white; crown glossy greenish-black; and flanks chestnut.

When a consignment like this is landed after a long voyage, great care has to be exercised in introducing the birds to water. One might think on a fine day how nice it would be to let them all out on one's private lake or pond for exercise. This would be disastrous, for the birds would swim out, become water-logged and drown. They must be kept in sunny places with shallow pans to get into, and when thoroughly wet the water taken away so that they quickly dry again in the sun. More and more time can gradually be given for bathing until the natural oiliness comes back to the feathers.

Staying at the mission proved of immense value to me, for it meant that I was able to leave Delys in safety to look after the collection while I went off for a few days to the forest some twelve miles to the east. The evergreen forest belt runs north and south for the greater part of the length of Madagascar and varies from ten to twenty miles wide. It is mostly on the first range of hills inland from the sea and catches all the rain-bearing clouds brought in by the southeast trade winds. Rainfall is plentiful and rivers and streams are everywhere. By contrast, on the west side of Madagascar the rainfall is spasmodic and there is a long dry season, and under these climatic conditions an entirely different vegetation with mostly deciduous trees has evolved.

It is the forests that harbor most of the lemurs, and in the particular section that I visited I found Ruffed Lemurs very plentiful, 
their amazing cries-even of a single animal-sounding much like a dog-fight.

The wailing cry of the indris I often heard: this creature and the aye-aye are two of Madagascar's most interesting mammals. Both are $f a d y$, in local parlance, which means that their capture, dead or alive, is taboo. The indris is the largest of all the lemurs, progresses in an upright position, and is almost tailless. It is mainly velvety-black on the upper parts, with a curious triangular white or yellowish-white patch on the lower back. I once stalked in thick forest an isolated specimen that was making his customary sad wail-a sound that carries an amazing distance-and found him seated on the ground. He soon spotted me and made off, not by making for the tree-tops as would a monkey or one of the true lemurs, and not along the ground as would a baboon, but by leaping from trunk to trunk below the level of the branches in the manner of a tree-kangaroo.

According to Malagasy tradition, long ago a native woman was guilty of unfaithfulness and for her indiscretion was changed into a lemur. It was only natural that she should be larger than the other lemurs, have practically no tail and walk upright-in fact she became the first indris. It follows that she took her customs with her, and so even today the indris is supposed to practice midwifery, and when one is about to have a baby her friends gather round and massage her with certain leaves. When born the baby is subjected to a test to see if it is lucky-formerly a common practice among the Malagasy themselves-and is thrown from a tree-top into the air. If it manages to cling to a branch on descending it is lucky, but if it fails it is considered unlucky and better out of the way.

In the eastern forest I came across many native lemur traps, although, theroetically, these animals are strictly protected. In favorable places narrow channels are cut through the forest so that any lemurs traveling across them are unable to do so by the usual method of springing from branch to branch. The true forest-dwelling lemurs do not like descending to the ground if they can avoid it, and so advantage is taken of this by placing here and there a long pole horizontally between the trees about five feet from the ground so that it bridges the gap. In the center of this is fixed a native 
trap consisting of a string noose attached to a bent sapling which, when the trigger is touched, flies up, causing the noose to be pulled tightly round the lemur's neck and dangling him in the air. This would hang an ordinary mammal, but the lemur, being four-handed, clings to the pole and waits till the trapper releases him. His usual end is the pot.

If by accident an indris or aye-aye is caught, it is smeared with some special concoction which is supposed to counteract evil influences and the animal is then given its freedom. Can one wonder that one rarely sees such creatures outside their native haunts? I believe to this day no indris has ever been brought alive to England.

My trip to the forest was my first introduction to traveling by palanquin, known in Malagasy as filanjana, which is the usual method of transport for all Europeans in districts where there is no motor transport. The filanjana is a chair, with an arm- and foot-rest, supported by two parallel poles, and is carried by four natives - two in front and two behind-each with one end of a pole on his shoulder. Four more are in attendance and every few hundred yards the teams change over while still on the march. Two or more porters carry one's camping outfit, food, etc., in the Chinese fashion by fixing more or less equal loads on the two ends of a bamboo pole, which is carried on the shoulder. The method of procedure to obtain bourjanes, as the porters are called, is to approach the local Chef de Canton, informing him of one's requirements and the date. He will then instruct one of his henchmen to go to some small village or villages and collect the required number of men. These have no alternative but to turn up when required unless too ill to move. The traveler must pay them the rate fixed by the government plus a fixed rice ration. It is an interesting reflection on civilization that the individuals that comprise a town important enough to support a Chef de Canton are apparently considered beyond the stage of engaging in the menial tasks of a bourjane, and of course once a native speaks French he is exempt, by some unwritten law, from ever again performing any sort of manual labor. The villager, by contrast, is regarded as belonging to a lower order.

For those interested in diet and the importance of having this 
correctly balanced, it will come as a blow to learn that these people, who may be quite unused to carrying heavy loads, who may be old or sick and frail-looking, and who feed almost exclusively on rice, will pick up a forty-pound load and march all day with it, whereas the average scientifically nourished European would have the greatest difficulty in walking the same distance empty-handed.

On my first trip by filanjana I felt quite sorry for the men carrying me up steep hills in the heat of the day, so I invariably got out and walked-a thing that seasoned Europeans of the country never do. On most subsequent marches, however long, I have dispensed with the bearers altogether and have gone on foot, accompanying the porters. In tropical heat I thought I was doing well to march fifteen to twenty miles a day, but was always amazed at the stamina of the native porter, who carries a load that would defeat me after a quarter of a mile.

Speaking of balanced diets, the Malagasy, being of Eastern origin, are mostly rice-eaters, though in some districts they live largely on maize and cassava, whereas the coastal peoples of the dry south and southeast live almost entirely on fish. In the towns and the fertile districts of the east and west coasts the diet is much more varied.

My entry into the eastern forests brought me in contact with the Betsimisaraka tribe, who inhabit a considerable portion of eastern Madagascar from the coast to the western limits of the rain-forests. Although the coastal villages are, on the whole, moderately clean, all the small hamlets that I came across in the forests were filthy. In spite of the fact that space is unlimited and that the only building material they need-such as poles, grass, and reeds-cost nothing, they build tiny one-roomed huts almost touching one another. This is another of the native customs governed by superstition and custom.

A space about eight feet square serves as a living-room, bedroom, and storeroom for their rice, etc., and at one end of the hut there is an open fireplace but no chimney. The smoke finds its way out through the low thatched roof or the door. On the filthy floor the children squat with their elders, with a multitude of flies sucking the moisture from their mouths and eyes, and in odd 
corners broody hens sit complacently on their eggs while scraggy dogs wait hungrily outside for scrapings from the rice-pots. Rats and mice are outnumbered only by fleas and other vermin. In these sordid surroundings the forest-dwelling Betsimisaraka ekes out his miserable existence with apparently no desire for anything better.

On the whole the Malagasy people prefer living in open places where the forest has been destroyed and so where there is grassland for their cattle, which are more or less sacred. Even the forest-dwelling tribes incline to living on the edge of the forest or in very large clearings. There are two reasons for this. Firstly the primitive forest is an awe-inspiring place to the average native, especially at night, for then all sorts of beings (albeit mythical) are on the move. These have special names and are usually malformed or grotesque in shape and are all of evil intent. Secondly, the wild pig makes life exceedingly difficult in any forest village, for at night he emerges from his secluded retreat and plunders the natives' crops, doing tremendous damage. This could easily be prevented by fencing, but the natives, anything but industrious, have not even the enterprise to safeguard their own food. An easier method for them, but less effective, is to rely on their mangy half-starved dogs to keep the wild pigs away. Unless the cultivations are in the immediate vicinity of a village this is of little avail, for dogs have a great respect for the lambo, as the Malagasy call it, and will not readily attack it unless in a big troop.

The dogs serve another important function. They keep away the numerous brigands, witches, demons, and ghouls that haunt the Malagasy mind, and so enable him to sleep in peace. The poor $\mathrm{dog}$, in return for this service, is entirely neglected. He is never petted or fed. Whenever I threw food-scraps out of my hut there was an unbelievable scramble of dogs and fowls to the spot with such speed that the opposing forces invariably collided, but soon spread out again, when the most powerful dog snapped wildly at everything, getting all the food for himself. It was noticeable that every village supported one well-fed dog, for he, being the master, terrified the rest whenever rice-scraps were heaved out of someone's door.

To me it seems a pity that so much effort and money go into 
teaching godliness to people whose superstitious beliefs are so deep-rooted as to be ineradicable, whereas the advantages of cleanliness and of kindness to animals are ignored. How much more would be achicved, and what an incalculable amount of suffering would be avoided, if these two latter virtues came into the forefront of the picture! There seems to be some misguidance of sentiment where the inhabitants of a village have been taught to gather together to sing hymns, yet where the starving dogs will follow one into the bush and, driven by hunger, await the chance of devouring human excrement.

Betsimisaraka myths are not confined to strange creatures that wander at large at night-they even extend to snakes. There is an arboreal species (Ithycyphus) that is reputed to wait in the branches overhanging forest paths; when a bullock or some wild animal passes underneath, it stiffens itself, then drops, using its tail as a spear and piercing the animal to the heart-with what purpose I was never able to ascertain.

Besides boa constrictors and Sganzin's Tree Boas I was able to collect a number of the handsome Sharp-nosed Snakes, which are fairly large and dangerous-looking though not at all aggressive. They are nevertheless back-fanged and therefore mildly venomous. It is generally stated that Madagascar is devoid of venomous snakes, but it is more correct to say that it possesses no dangerous snakes. The only thing in the whole country that man has cause to fear is the crocodile, which is particularly numerous in the warm waters of the west-coast rivers.

Among our large and varied collection we had a few specimens of the Tailless Tenrec, or tandraka, as it is known to all the natives. This is the largest of the tenrecs-a family that comprises a variety of forms, some spiny and hedgehor-like, down to the smooth-haired animals that resemble shrews. The Tailless Tenrec is a thick-set creature about the size of a small rabbit and is furnished with longish spines on the head and upper back which graduate into stiff hairs on the lower back. It lives mainly on earthworms, and towards the beginning of the dry season becomes very fat in readiness for hibernation, which usually commences in May. At this period it is considered a great delicacy by the natives, who hunt it with trained dogs. It comes out of hibernation when 
the rains commence, usually in November or December in the higher parts of the island. It is probably the most prolific mammal on earth, having anything from twelve to twenty-two young ones at a time. ${ }^{1}$ In captivity a diet of raw meat suffices to maintain it in good health, though its appetite varies considerably. At times during the voyage home ours were most voracious, while at others they seemed to be in a semi-torpid state and refused food for days at a stretch. Unaccustomed changes in climatic conditions may have accounted partly for this, but not wholly so, as some specimens ate nothing during spells of warm weather similar to conditions in their natural home.

In the London Zoo they continued to show a reptilian trait in their spasmodic desire for food.

In collecting in places like Madagascar one can never tell how much one has been hampered by local superstition. Apart from some innocent action which may give offence and therefore be the cause of non-co-operation, one has to contend with the legends concerning the animals themselves. I could never make up my mind whether the difficulty in getting White-backed Ducks was due to their scarcity or difficulty in trapping, or to a native belief. It seems that when the White-backed Duck breeds, the female sits so tightly on its eggs that it allows itself to be picked up. This has given rise to the legend that this species lays such large eggs as to cause it to faint and remain helpless. Native women thus refuse to eat it in case it is the cause of their having difficulty in childbirth.

We left Madagascar with a large collection comprising Pygmy Geese, Hottentot Teal, Madagascar Pochard, Meller's Duck, White-backed Duck and Red-billed Duck; Allen's and Greenbacked Gallinules; Cuvier's Rails; Madagascar Bee-eater; partridges, button quail and white-eyes; and various sunbirds, Foudia Finches, tenrecs, and various snakes and chameleons.

On the way home we called at the island of Anjouan (Johanna), one of the Comoro group, and I got ashore through the surging swell with difficulty in a small boat. My objective was the Anjouan

\footnotetext{
${ }^{1}$ Prof. H. Blüntschli records finding thirty-two well-developed embryos in a specimen he dissected.
} 
Sunbird-a species confined to this island-and I had only an hour in which to operate.

Unfortunately I was followed by a crowd of curious youths, but in the main square I spotted a clump of hibiscus bushes in bloom. The fact of stopping and watching these bushes increased the curiosity of my followers, but I was determined to see it through, much as I dislike performing in public. In a few minutes an Anjouan Sunbird arrived and I watched its movements closely. There was one very prominent bloom which received a lot of attention from the sunbird. I decided to try my hand at that one, though the number of adjacent blooms greatly reduced my chances of success. I quickly limed a small twig and inserted it into a cut at the base of the flower petiole in such a position that the bird would almost certainly perch on it to feed. I stood back while the crowd increased.

A male sunbird soon arrived and spent much time feeding from the flowers on every side of the bush except the right one, but finally worked nearer and nearer to the chosen flower. Such moments are always exciting. At last he settled on the prepared twig. Sunbirds are so adept at getting off that I was dashing towards it at the moment of its settling. If the bird escaped when I was but a few feet away, I visualized the crowd roaring with laughter. By a split second, for the bird was nearly off, I avoided any such loss of face, and having cleaned my prize and put him safely in a covered box, I hurriedly made my way back to the ship. This is the only Anjouan Sunbird that has ever been exported alive from its island home. 


\section{Chapter Fifteen}

\section{INDIA}

7 HE winter of 1935 was approaching and something in the I air told me it was time to be off. Thank heaven fate had decreed that I was to be collector-free to go anywhere that fancy led me. Why not the Himalayas? Here were forests, scenery, lovely birds, tea plantations and distant snows. What more could one wish for? Delys needed no coaxing; she could hardly wait to set forth.

Setting off on such an expedition sounds easy enough, but when visiting a stretch of country such as the Himalayan foothills, which stretch right across the Indian continent, it is a problem to know which locality is likely to prove the most suitable. Our choice fell on the Darjeeling area in the foothills of the great mountains, and more or less due north of Calcutta.

Traveling from Bombay, where we disembarked, across the hot dusty interior of India to Calcutta was certainly an experience, though anything but a pleasant one. Bodies, baggage, clothes, and seats became so dust-covered as to be almost unrecognizable. At various stations a sweeper would scuttle in and sweep out piles of dust while passengers took refuge on the platform, but this was just a formality which really added little or nothing to one's comfort. It was, of course, before the advent of the air-conditioned, dust-proof coaches that passengers enjoy at the present day.

Calcutta with its heat and teeming population, all seemingly bent on ejecting betel-stained spittle on to the pavements and anyone who got in the way, did not appeal to me very much, but at least the Alipore Zoo was nearby and this helped us to while away the time while we made inquiries and arrangements for the trip 
north. One of the most interesting birds in the Zoo was a solitary Pink-headed Duck, a peculiar long-necked species with a chocolate-brown body and rosy-pink head and neck. Formerly these birds were found in the vicinity of the Ganges and Brahmaputra Rivers wherever there were small ponds surrounded by plenty of cover in the way of long grass or reeds, but they are now almost extinct, or occur only in remote inaccessible places.

It was here that I met Herbert Fooks, who was the Hon. Secretary of the Zoo. He was very keen on wild-life-birds in particular - and had a fund of knowledge concerning almost anything Indian. His stories of a pair of Pygmy Hippos that were in the Alipore Zoo are worth quoting. I had come across many instances of animals changing their feeding habits under captive or semicaptive conditions-for instance, wolves eating ice-cream, otters bread, and llamas paper bags-but who ever heard of a hippo eating monkeys? That is Fooks's story.

"A pair of Pgymy Hippos, purchased from the London Zoo, were introduced to an enclosure in the Alipore Zoo that was originally intended for chimps and orangs. This consisted of a circular moat about ten feet wide enclosing an island about eighteen yards in diameter, on which was a raised shelter (for the apes). As the hippos spent most of the day in the moat showing only the tops of their heads, they were considered a dull show, and so to liven things up about twenty rhesus monkeys were put on the island. The experiment at first sight seemed a great success as the food given to the hippos were shared by the monkeys, and vice versa. It was not until several months had elapsed that it was noticed that the monkey population seemed to be decreasing. I was now on the alert and discovered that monkeys were definitely disappearing, and later witnessed, on two occasions, the female hippos snatch at and catch an unsuspecting monkey while they were feeding together. I then watched the hippos' food and found that very little of it was eaten.

"The female at about this time became very bad-tempered and savagely attacked the male, who had to be separated from her. As I couldn't afford to feed them on monkeys, I decided to turn them into a larger lake of about five acres in area. For some days they were not seen nor did they come ashore for food, but they 
eventually did come in for their vegetables. Meanwhile, they began to catch and eat swans, Bar-headed Geese, and anything else they could catch. The public hardly, if ever, caught a glimpse of them, and the swans were more attractive, so the Pygmy Hippos had to be caged on the lake side. Here the female finally killed the male and I can only suggest that the cause was that she had been cut off from her meat diet."

About a pair of ordinary hippos that had been in the Alipore Zoo for about thirty to thirty-five years Mr. Fooks told this rather gruesome story:

"The old male, many years ago, was taught by his keeper to open his mouth for minutes on end while visitors admired his teeth. From this trick the keeper advanced to something more thrilling, and for one rupee put his head into the hippo's mouth. One day the inevitable happened and the keeper was killed.

"Some twenty years later, when I was Secretary, tragedy again overtook us. I was in Calcutta at the time in my timber office, when about 3:15 p.m. the 'phone rang. It was the Superintendent of the Zoo asking me to come at once. The hippo had killed a girl! Most unfortunately this was one of the Hindu poojah days and there were at least twenty thousand visitors. Needless to say, the possibilities of complication were enormous, as unless I could do something quickly the relations of the dead girl would increase every minute. I therefore 'phoned the police and asked for a small detachment to form a cordon, and also told the Superintendent to procure the longest rope he could and to cordon off the hippo pool, allowing no one in until I said so.

"On my arrival, after inspecting the enclosure, I found that the girl had been pulled in, picked up by the small of the back and systematically smashed against the walls of the cage until her entrails gushed out. Part of these were eaten by the hippo, and the balance taken by kites and crows which flew up into the surrounding Casuarina trees with them. A truly horrible business.

"Inquiries showed that this is what had taken place. The girl together with several others of her caste (gipsy) were throwing bunches of grass to the animal, but she, probably to show off, put her arm under the three strands of wire topping the wall, intending to put the grass in the hippo's mouth, which he was holding 
open in his accustomed way. The hippo closed his jaws over both grass and hand and pulled her in. Her screams and the yells of the crowd must have excited him, and he turned on the girl and killed her against the wall. When I arrived he was quite placid but was shut up in an inner compartment.

"I think it quite possible that hippos in their natural state are partially carnivorous and in captivity could probably be induced to eat meat and fish."

Eventually we managed to arrange to stay at a Forestry Station at Siliguri, some twenty-five miles north of Jalpaiguri, the terminus of the broad-gaged railway. Here we had to transfer to the light-gage railway that passes through the Siliguri forests, then winds its way up and up to Darjeeling (7,000 feet).

The country round Siliguri was studded with forest-covered hills that stood out like buttresses in the plains, with the enormous land mass towering far to the north.

Through the winding valleys of these hills a beautiful small river-the upper reaches of the Mahananda-with its wide sandy bed, threaded its way, and this was the home of many Spotted Forktails. These birds have black-and-white plumage and a deeply forked tail, and resemble large wagtails in appearance and habits, but really belong to the thrush tribe. It is a pretty sight to see them strutting over sand and stones and through shallow water, suddenly speeding up to peck at some small insect, and incessantly bobbing their tails. When put to flight they utter a plaintive call but rarely fly more than a short distance to settle again in the river-bed, and if driven more than a certain distance from their favorite haunt they will invariably double back to it. I saw them only where forest was bordering mountain streams.

One of the first things to make my heart beat faster was the sight of a Blue-necked Bee-eater-a veritable monster of the family, having an overall length of fourteen inches. This bird has a large head and lengthy throat hackles of ultramarine blue, but is otherwise mainly green. There was a pair perched on the tips of the highest branches of a forest giant, from where they occasionally darted into the air to catch a winged insect, only to return to bang it a few times on the branch prior to swallowing it. How 
could one begin to trap such creatures that never remained for long on any particular tree and always chose the very top of a high one?

As I stood watching them in their tree-top world, I realized the futility of making any assault on them in such a situation; but all birds have to roost and I wondered where-perhaps in a hole in a bank along the river near which they were now perched. The idea spurred me on. With their tree-top habits it was not difficult to locate them, and this I did later in the day when the sun was setting. I sat quietly in the river-bed and watched. The twilight was short, and soon the bee-eaters made off to another tree a quarter of a mile away along the river. I caught up with them and watched again. At this point the river was skirted by a thickly forested steep hill, and to a tall tree on this the bee-eaters flew. It was now getting rapidly darker and the birds suddenly plunged into the foliage out of sight for the night. Two things I had discovered: that they roosted in the forest, and almost certainly in a particular place. The following evening I took up my position at this point, in a spot where I could watch the birds' movements on leaving the tall trees where I had last seen them. To me this was all very exciting. The birds arrived according to schedule, but then there was an awful suspense during which time the undergrowth became rapidly enveloped in the twilight gloom. At last the birds flew down to a point I could not clearly see and disappeared, apparently into the bowels of the earth.

I left it at that and threaded my way through the forest undergrowth to the river-bed and I then began the long walk home, well satisfied with the way things were going.

The following day I returned and searched the spot where the bee-eaters had disappeared into the undergrowth; it was not long before I found a well-used hole running steeply into the earth and just about large enough to admit one of these birds. The campaign was drawing to its logical conclusion, and the evening shadows found me closeted in a thicket overlooking the hole. I hurriedly covered this with a special net, for time was short. However, before I had finished I had to use my electric torch as the net had to be pegged down and so arranged that on leaving the hole the bird would get well clear of it before contacting the net. 
When this was finally arranged it was pitch-dark and I felt happier when I had got back to the river-bed, where at least I could walk with ease and see ahead of me with my torch. As every morning revealed the footprints of a tiger along this sandy track and, as usual, I had no gun, the escapade had its exciting side.

Next morning I was up at 4 A.M. and set out for the bee-eaters' sleeping quarters in order to arrive there by daybreak. I seemed to be waiting an age before anything happened. I suppose early rising on the part of forest-dwelling bee-eaters would serve no purpose as there would be few of their favorite insects around until sunrise.

At last one of the pair scuttled out of the hole and while he, in a bewildered fashion, was busy trying to find a way through the net, I shot out of my hiding-place and caught him. His mate must have heard me thumping over the ground for it was fully a quarter of an hour before she emerged and met the same fate. What impressed me most about these birds was their great size, their curious neck hackles, and their slight musky odor.

In the deep gorges of the forested hillsides, where the music of the water rushing wildly over boulders drowns the call of the forest-dwelling birds, one is almost sure to find the Himalayan Whistling Thrush-a massive bird, about a food in length and thrush-like in form, though, unlike the true thrushes, its young are not spotted. It is a striking bird of blue-black plumage which looks bright blue in certain lights owing to the metallic blue tips to the feathers. Its whistling call-notes are quite pleasant but have a certain harsh penetrating quality that makes them heard above the roar of the torrents. It is almost wholly terrestrial, living on aquatic insects and snails. Seeing it in its native haunts gives one the impression that it is a wild independent creature, quite unlike most of the purely forest-dwelling birds that often band together in parties. This spirit manifests itself in captivity, for if the Whistling Thrush is mixed up with birds smaller than himself he often reveals himself as a bloody murderer.

Most of the interesting birds in the forest of the Himalayan foothills are strictly arboreal, and those I remember best at Siliguri were Scarlet Minivets, Silver-eared Mesias, Chestnut-bellied Nuthatches, Racket-tailed Drongos, Blue-throated Barbets and various 
flycatchers. In the undergrowth I occasionally saw, and frequently heard, Red Jungle Fowl-the cocks with their quaint short crow making known their whereabouts. The most conspicuous birds of the forest bed were the laughing thrushes and true thrushes, and in the more thickly wooded parts the Magpie-robin or Dayal Bird.

The season was rather too far advanced for collecting at the lowest levels, for it was daily getting hotter and birds were already beginning to move to higher levels.

In order to seek a new collecting base at a higher altitude I took the small-gage railway to Ghum, near Darjeeling, taking my bicycle with me. At eight thousand feet the air here was distinctly icy compared with that of the lower foothills, and a certain amount of snow lay on the ground. The sleet made cycling unpleasant, but this cleared and I was soon in bright sunshine again. I was able to watch for birds, going slowly along the winding and beautifully graduated road with my brake on, for during the ride back of nearly forty miles, when I descended over seven thousand feet, I never once had to pedal.

Inquiries led me to a vacant bungalow on the edge of some good forest near Mahanadi (5,00o feet), and in this the owners kindly consented to my staying for a couple of months. The air was much more invigorating here and the nights quite cold.

We set off on the journey with a considerable menagerie, and an old cook we had brought with us from Calcutta and a locally recruited houseboy. It takes a while for one to adjust oneself to the servant code in India. As a European, it was of little import whether I was scrubbing cages, climbing trees, doing carpentry, or meeting the Governor-General, but the humble Indian servant lives in a shallow social stratum that keeps him within annoyingly narrow limits. Thus if a houseboy trips over himself and scatters the curry and rice in all directions on the floor, a special man-the sweeper-is sent for. If he, in turn, happens to have had a heart attack or has disappeared for no reason whatsoever, the dish will repose peacefully until a new sweeper has been recruited. The cook cannot wait at table, the houseboy cannot sweep, and so on. Therefore every respectable person in India has a minimum of five servants.

Our cook was passable at his profession, but being old the 
change of altitude and temperature did not agree with him. In the steamy heat of Calcutta, where he had spent the whole of his life, his numerous endoparasites lived in harmony with their host, but now the delicate balance was upset, and he complained of being unwell. In a wave of self-pity he wrote to his family, telling them of his ailments. To his surprise his wife and other relations arrived out of the blue a few days later, though he was actively engaged in cooking and probably only had a slight attack of malaria, for which I was treating him with quinine. However, the arrival of the family could only portend one thing-it was akin to reading the last sacraments. The psychological effect was almost immediate. By noon he complained of illness and said to me, while holding his stomach, "God plenty trouble is giving." He retired to bed in his hut closely attended by the family, and our own cooking that night was left to Delys. About 9 P.M. one of the family burst into the bungalow in a panic saying that the old man was dying. I went immediately to see him and found the family encircling the prostrate figure, screaming like lunatics and shaking the old man violently. This was presumably to keep him awake so that his soul could not leave his body. The situation called for firm handling regardless of custom, so I chased the lot outside.

It was evident that he had a temperature and was slightly delirious-a state brought on largely by the treatment and the ignorance of his own relations. To soothe his tormented mind I gave him a good tot of whiskey and some more quinine, and forbade anyone to interfere with his sleep.

To my astonishment he entered the house the following morning, serving tea at the usual hour-6 A.M.-apparently quite well. But this was too good to last. His relations showed no desire to leave, and their presence was too much for him: he sickened again. Not having the time, or facilities, to cope with such a situation indefinitely, I arranged for him to go to the hospital at Kurseong, where he was accompanied by his relatives, who thrust themselves on him on every possible occasion, the effect of which, it seemed, was one of hopelessness from the cook's point of view. Their presence must mean that the end was near. It was, for within a few days he passed away. This was sad, for he was a likable 
fellow, and it gave us an uneasy feeling when we pondered the uncanny influences brought about by ingrained customs, beliefs, and fears.

Some of India's finest teas are produced around Mahanadi, and in odd moments it was a joy to look over these well-kept tea gardens and to see the inner workings of the factories. The employees are mainly Lepchas and Bhutias and differ considerably in temperament from the peoples of the plains. It was a particularly refreshing contrast to see the smiling girls working in the tea gardens with apparently much more freedom than their sisters in the lowlands.

It was noticeable at Mahanadi that birds were still making their way to higher altitudes to breed. At one period the forest was thickly populated with Gray-winged Ouzels, but a week or two later all had disappeared. One of the most conspicuous birds in the more open situations was the Verditer Flycatcher, which looks a real gem as it darts about in the brilliant sunshine hawking insects. Blue, in fact, seemed to be the predominant color in many birds, including several species of flycatchers, nuthatches, and rock-thrushes. In the flycatchers are included the niltavas, which are among the prettiest of India's smaller birds. I was fortunate in trapping two Greater Niltavas in a spring net-trap, but this necessitated a climb of about one thousand feet as there were none near our base. The male is a gorgeous creature with a mixture of dark blue, violet blue, and cobalt blue.

The Rufous-bellied Niltava was more common and was not very difficult to come by. Although this is a smaller species it is equally handsome, having red underparts and an upper surface mainly of bright shining blue.

Among the birds from higher altitudes I collected a number of Ixulus and Yuhinas. These are small birds of rather dull plumage but have a great attractiveness on account of their sprightly ways, reminding one very much of zosterops. They move through the tree-tops in small flocks, searching everywhere for small insects and consuming a certain amount of berries.

One of the most interesting of the nectar-feeders in our collection was the Great Indian Spider-hunter. Its rather dull plumage of olive yellow streaked with black is offset by its rather con- 
spicuous yellow eyes and by its sprightly appearance. It uses its curved bill, which is about an inch and a half long, effectively to catch spiders and insects, and to probe its favorite flowers-those of the plantain tree.

So far, everything was progressing smoothly. Delys took advantage of the hospitality of various planters and their wives, and went off occasionally to visit beauty spots by car, and to see the Himalayan snows from Darjeeling.

Our corrugated-iron-roofed bungalow was situated in a bend on a hillside which was particularly steep. It was easy, in fact too easy, to descend a thousand feet through the forest without realizing it until one had to make the journey back.

After a long day of climbing in the invigorating mountain air, sleep was always welcome. This was usually undisturbed, but one night something of a gale arose, unknown to me until a sudden mighty gust sweeping round the bend in the hillside hit the bungalow with great force. I awoke suddenly to a noise I am never likely to hear again, and at the same time a shower of brickdust and mortar fell on my face. When I had recovered from the shock I jumped up and saw the stars shining above me, and realized that half the bungalow roof had disappeared in one piece. Delys was fortunately in the right half, but the birds, which were quartered in a closed-in part of the veranda, had a nasty shock, though none were injured. They were all in stout wooden traveling boxes which I found covered with bricks and mortar. The gust had hit the open veranda, thus finding a purchase under that part of the roof, and had lifted it up bodily, taking with it the rest of the roof and veranda supports that were embedded in cement, all in one. Part of the thunderous noise was all this crashing to earth, and fortunately it was just clear of the inner wall where I was sleeping.

Time was ripe for our return to England as we planned to get home in June. Various people helped us to add to our collection in Calcutta, and through the Calcutta Zoo we collected three pandas that we had ordered on our way out. These are found at various altitudes in the Himalayas, but are commonest between eight and ten thousand feet. They remind one somewhat of rac- 
coons in general form, size, and in their banded tails, but have thicker fur. Although classed as carnivores, their diet in the wilds is probably mainly vegetarian, and judging by the difficulty in feeding newly captured specimens, they are almost certainly specialized in this part of their diet, which is supplemented with animal food in the form of eggs, insects, and probably young birds. In captivity they will lap up a mixture of raw eggs and milk from the start but will touch little else for weeks. They are forestdwelling animals, mainly nocturnal, and sleep during the day in trees. Being used to a cool rarefied atmosphere they undoubtedly feel the heat, and in a place like Calcutta great care has to be taken to keep them in a cool shady spot where there is a breeze, otherwise they show signs of distress. I was worried about the hot train journey across India to Bombay, so arranged for numerous large blocks of ice to be put round their boxes in the van.

Our return journey was much more of a headache than anything we had experienced while collecting. We had ordered a closed van to be attached to the mail train. This was agreed upon, but it had never occurred to any official that the menagerie would require any air, light, or attendance during the long train journey. Having loaded up everything, the officials concerned forbade me to travel in the van and insisted that it be shut, bolted, and sealed. This meant that the van was in almost total darkness. A tremendous argument ensued, and I was placed in a difficult position, for transference to a goods train would have meant a slow journey with much shunting and no facilities for eating and sleeping.

In the end it was agreed that I should be allowed to enter the van at certain stations to feed the birds and give them some light. At the first big station after several hours' travel I managed to have the seals broken and to enter the van.

Feeding was a long job with masses of insectivorous and nectarfeeding birds all caged singly. Before I had half finished I was asked to leave the van as the train was due to leave. This I refused to do and went on feeding the birds. More and more officials arrived and the argument became increasingly heated.

My line was that the railway had accepted this livestock, the nature of which was disclosed at the time, and therefore they must allow facilities for feeding. I offered to ride in the van and look 
after everything en route, but this was refused. Under regulation number so-and-so, oblique stroke something else, the van doors had to be shut and sealed before the train could start. This was just too bad. I was there to look after my birds and I told them what they could do with their regulations. In the end the police arrived. I was holding up the train, and they threatened to remove me or detach the van, but I was near the end and most of the birds had all had a good feed and a drink. I wasted a few more precious minutes puttings things away, and saying all the time that I was just coming, in order to make sure that all the nectarfeeders had had something, as they are the first to feel the effects of hunger.

Finally I descended among an irate crowd of officials and the doors were shut and sealed while I raced up the platform to my compartment. There were hundreds of heads hanging out of windows leering at the man who had the audacity to hold up the mail train for thirty minutes.

The eleven-hundred-mile rail journey was the means of cutting a few miles off the homeward trip, but was so worrying that I began to wish I had embarked on a steamer at Calcutta and made the longer sea voyage home via Ceylon. Fate, however, probably had a finger in the pie, for Delys struck up a friendship with one of the passengers, whom she married two years later. 


\section{Chapter Sixteen}

\section{GOLD COAST}

$\mathrm{A}^{\mathrm{T}}$ the end of $1936 \mathrm{I}$ visited the Gold Coast, with my niece, A with the idea of collecting some of the gems of the birdlife of the forest and savanna regions. As in the Cameroons the country is divided into three natural zones-forest, savanna or park-like country, and semi-arid. The latter was too far from a rail-head for collecting live specimens without entailing tremendous expense and trouble in transportation, so, much to my regret, I was unable to include this in the itinerary. On arrival at the port of Takoradi I was impressed by the entire absence of hotelsa state of affairs that applied to the whole of the Gold Coast. In many cases, however, permission could be obtained to stay at the Government Rest-House at Sekondi, which was very pleasantly situated.

As our destination was Ashanti we remained on the coast only long enough to make certain arrangements, purchase stores, and select suitable servants for the interior. The latter we did on local advice as we had been informed that it was much easier to obtain servants on the coast. We therefore informed the Commissioner of Police of our requirements, and presently numbers of applicants arrived armed with all-important documents.

It was a custom (or rule) that every boy should produce a statement by his previous employer when applying for work. These testimonials, if this is the correct word, made interesting reading. Some were couched in such flowery terms that I suspected they were written by some educated dark-skinned gentleman who made this his profession. Others were very noncommittal and amounted to saying "Find out for yourself what he is 
like"- but the best was pithy and brief. It read: This boy, Joseph, was in my employ for three weeks. He says he is a cook.

Choosing a houseboy and a cook from this assortment was indeed like a shot in the dark. Our final choice fell on two boys of different tribes as we thought this would circumvent any collusion. The cook was of the Hausa tribe and the houseboy a Twi. All complete we set off for the capital.

The rail route to Kumasi through forest, resembling somewhat that of the French Cameroons, was very hot and uncomfortable and after a while became rather monotonous. In an endeavor to keep cool I traveled with the electric fan switched full on and as a result spent two days in Kumasi Hospital suffering from muscular rheumatism. This was not as boring as it might have been for I was able to get an occasional glimpse of the local birdlife, and was highly amused one day at a little comedy acted by a party of Pied Crows. They had gathered together in the shade of a small tree, near the window of my room, when there was a sudden commotion and I noticed that they had treed a large lizard. Two of the crows were chasing it among the branches and the rest had spaced themselves evenly on the ground below watching the proceedings intently, knowing full well that sooner or later the lizard would have to jump for its life. They frequently changed position according to the movements of the prey overhead and after several minutes of this comic procedure the lizard was cornered and was compelled to jump. There was an immediate scrimmage of crows on the ground and one emerged with the lizard in its beak and flew off, with the others in hot pursuit.

From Kumasi we went about thirty-five miles north by road to the outskirts of Mampong-a native town in the forest. Actually most of the virgin forest in Ashanti had disappeared owing to the extensive growing of cacao by the natives. It happened that just prior to our visit the price of cocoa rose so suddenly that the natives were getting far more money than their limited requirements necessitated, which made them rather independent and unhelpful.

As in all cacao-growing countries the climate is very hot and humid, and any exertion in the Gold Coast forest is sufficient to 
make one perspire freely and to quickly bring on a feeling of exhaustion. Changing into something dry was my chief form of recreation, but it meant only a few minutes' comfort.

Our first captures were some Gray-headed Negro-finches, an Allied Hornbill, a Black-and-white Casqued Hornbill-a large quaint-looking species which had only quite recently been recorded as far west as the Gold Coast-and some Red-headed Parrots-a species which is rare in captivity. But trapping was exceedingly difficult and bird-life comparatively scarce.

Soon after our arrival here I suddenly developed a temperature and became almost delirious. The local District Commissioner 'phoned the doctor at Kumasi, who motored out and gave me an injection. This was my first real dose of malaria since I started collecting and it was certainly a knockout. I was much weakened but eventually went on with the job.

My chief interest here, as in the Cameroons, was the forestdwelling species of sunbirds. These included the exquisite Superb Sunbird and the Buff-throated Sunbird. The latter was new to me and being very distinctly marked I was keen to add a few specimens to my collection. It has a forehead of metallic green, a dark brown back, throat buff, and the rest of the under side chestnut. At certain seasons the forest species feed exclusively on the blooms of Bombax or Silk Cotton Trees, which grow to a great height and have branchless trunks studded with thorny protuberances. I came across one immense tree with an unusually fine crop of flowers that had attracted a host of sunbirds, which from the ground looked like a swarm of bees busily at work. Unfortunately bombax trees flower before the leaves form, so there is not enough shade for the setting of nets in them; but this is not the only difficulty. The tree, just mentioned, seemed so difficult and dangerous to climb that I offered a substantial reward to some forest-dwelling natives if they would go up and fix a rope to the first branch, so that I could climb it more easily myself, but they refused to make the attempt. Not to be outdone, I got a native blacksmith to make a number of iron spikes, but the driving of these into the trunk was infinitely more difficult than I had imagined. The humid heat of the Gold Coast is trying enough at 
any time, but when one is performing a task requiring considerable physical exertion, it is almost overpowering.

The tree was far too big round to get a hold, so as I ascended I had to grip an iron peg that had already been driven in, while knocking in another above my head. My hands were wet with perspiration, so I felt anything but secure, especially as I had to lean back considerably to use the hammer effectively. It was very exhausting and nerve-racking, and it took me a whole day to complete the job.

During this effort I was attacked by swarms of biting black ants which seemed to resent the vibration caused by the hammering. In an infuriated state they emerged from the crevices in the bark, inflicting painful bites all over my arms and legs, and their overwhelming numbers caused me many times to descend rapidly. When I eventually reached the first branch my arms were bleeding from scratches and were covered with swellings looking like a heat rash, caused by bites.

In the branches I was greeted by a swarm of large red ants, no less vicious than their black friends below. They make their nests among the leaves and resent anything in the nature of an intrusion by a human being.

After several ascents the ants became less troublesome, so I was able to get on with the job of catching sunbirds. Not being able to use nets, I had to resort to bird-lime. Sunbirds have an uncanny way of detecting anything of an adhesive nature, and if by chance one should settle on a stick of lime, it shows great intelligence in dealing with the situation. It seems to know by instinct that, although its feet are stuck, it is no use flapping its wings or it will overbalance and then they too will become stuck. Keeping its wings closed it turns over and hangs upside down, trusting that its own weight will gradually pull it from the bird-lime, which it does if the latter is not very strong.

To catch them, then, by this means the limed twigs must be small and inconspicuous, and must be easily detached from the tree as soon as the bird touches one. I found that the ribs of certain fern leaves were ideal for this purpose, being quite strong but hardly thicker than grass stems. These were broken into lengths 
of about three inches, with the lime thinly and evenly applied, leaving about an inch untouched at one end for easy handling. To set them, a small cut had to be made with a penknife in the twig on which a flower was growing, and then the non-sticky end of the prepared fern-rib inserted into this so that it jutted out at a convenient angle for a bird to sit on when about to feed from a flower. This had to be done so that the incision was deep enough to hold the limed twig in position, but also so that any movement on it would cause it to become detached. A number were set alongside the most inviting-looking flowers, and then I awaited developments below.

The sunbirds soon flocked back to the tree and it was not long before one came floating gently down to earth, having perched on a prepared twig and dislodged it. In this way I successfully obtained species of sunbirds never before seen in captivity. The relief of not having to climb the tree again was even greater than the satisfaction of at last getting something that had proved so difficult.

In the same district we were also successful in getting a pair of the quaint-looking White-crested Hornbills-birds unlike any other hornbills, with their white crests looking like bonnets, and their very long graduated tail-feathers. They appear to be more insectivorous than any other species inhabiting the forest.

Owls were not uncommon and a pair of Fraser's Eagle-owls was obtained. These fascinating birds with their lovely large brown eyes and their soft barred plumage are very handsome and become very tame, making charming intelligent pets. Equally beautiful, though small by comparison, was a pair of West African Wood Owls, with large black eyes and reddish-brown plumage, spotted with white. An owl could often be located in the daytime when it was roosting, if it had been seen by an inquisitive bulbul, for the latter would set up a chattering alarm-note which would quickly bring more bulbuls to the scene. As the chattering increased, other birds, especially sunbirds, would arrive to see the cause of the commotion. Eventually the owl would resent this unwanted attention and fly off seeking a quieter spot, but usually followed by bulbuls, so if the owl only flew a short distance the mobbing would start afresh. 
In Ashanti the Twi natives have a legend concerning this unfriendly relationship between bulbuls and owls-the native name is the same for both except that a suffix is added for that of the bulbul. The legend runs: "In early times there was a bulbul who, being a hard-working fellow and careful with his money, accumulated more wealth than he could conveniently manage, so he looked round to find someone capable of looking after his hardearned savings. His choice fell on an owl, who was not only wise but was also big and strong. The owl agreed to take care of the money, but some time later when the bulbul required some of it, the owl made the excuse that he had none with him because he had hidden it away. Again and again the bulbul tried to get his money, but each time the owl made fresh excuses and finally admitted that he had squandered it all. This so incensed the bulbur that he told all his friends, who gathered together and mobbed the owl furiously. So, from that day, owls have always been afraid to come out in daylight, or if any dare do so they are immediately chased by bulbuls, who have never forgotten or forgiven a gross injustice to one of their forefathers."

Hawks were quite plentiful at Mampong, the most conspicuous being the African Harrier. These long-legged hawks, with bare yellow skin on the face, were often seen clinging to clumps of parasitic plants on the high trees, apparently searching for foodperhaps young birds or small arboreal mammals. Here, as in the Cameroons, they are also fond of palm-nuts. Another peculiarity is their flexibly jointed legs, which bend partly forward as well as backward. I obtained a fine specimen, which was fed for a time on palm-nuts and flesh and then on the latter only. It appeared to be perfectly healthy on a carnivorous diet, but there is no doubt about their fondness for palm-nuts when at large, for these harriers are found only in districts where palm-nuts flourish. This, of course, applies only to the forest race.

A rather rare hawk which I obtained was the African Little Sparrow-hawk. This, as its name implies, is very diminutive, but is nevertheless very handsome, with black head, slaty-black upper parts, whitish breast and chestnut flanks. Like all sparrow-hawks these birds are exceedingly quick, have incredibly sharp claws, and are adept at catching birds. Few aviculturists nowadays are 
interested in smaller hawks, but apart from this I dislike catching them as they invariably badly damage the nets with their powerful legs and claws, which necessitates hours of tedious labor repairing them. It is also a tricky business trying to disentangle a sparrow-hawk from a net, as, to avoid a painful experience, it is essential to catch the bird by the legs (avoiding the claws), and to retain one's hold until he is free.

In the Gold Coast the native children are very clever at locating the breeding-places of squirrels by watching their movements. A lot of material, such as leaves, is carried into a hole high up in a tree just before the young are due to be born, so when this activity is noted it follows that there will shortly be an increase to the squirrel family. When this nest-making ceases the natives wait for some days and then occasionally climb up to the hole. If they can hear any young ones making a noise, as they nearly always do when their mother is absent, they enlarge the hole with an ax and get the babies out. Several were brought to us so young that they still had their eyes closed. Some were Gambian Tree Squirrels and others White-striped Squirrels. My niece hand-reared them with tinned milk administered by means of a small bottle with a lip to it, normally used for feeding sunbirds and humming-birds. I never realized the intelligence of squirrels until I witnessed the amazing antics of these hand-reared specimens.

From the start they were given their full liberty and at an early age used to follow us about wherever we went. They seemed to get great joy out of hiding under things. One specialized in crawling under our bedclothes and another used to crawl up and down inside my trouser legs as soon as I sat down, peeping out every now and then to ascertain the whereabouts of his mates. When they were full grown they used to make excursions into the neighboring trees, but had an uncanny knack of appearing when our meals were served, and would then run all over us cadging tit-bits.

At the first sign of dawn they would visit us in turn, running over the mosquito nets of our beds, trying to get in. When they were allowed to enter they always greeted us by crawling over our faces, then, after playing hide-and-seek for a while under the bed- 
clothes, they would go out to the trees and forage for food, and bask in the early-morning sunshine.

The one drawback to the Gambian Tree Squirrels was that they could never be trusted with birds, and I had two killed before I realized that these squirrels, when the opportunity occurred, were carnivorous. In fact they reminded me rather of mongooses in habits and appearance, the tail being rather thin and straight and never arched in the typical squirrel fashion. In diet they are practically omnivorous and are especially fond of eating brains out of a dead bird. After I reached England one climbed up to a sparrow's nest, and though it was attacked viciously by the cock sparrow it took out the eggs one by one and ate them.

When one thinks of a the abundance of these squirrels in the Gold Coast it makes one wonder how the smaller birds survive. Only those species with protective nesting habits, such as tinkerbirds and barbets, etc., which nest in small holes in trees, or species large enough to protect their eggs and young, can be immune from the depredations of these creatures.

One day we invited the sisters from the local convent to tea and we were seated comfortably on the lawn in front of the rest-house. Having quenched our thirst we produced the highlight of the entertainment-the squirrels. They performed their usual amusing antics, running all over us and cadging food-much to the delight of the sisters. At a moment when I was slightly off my guard the side-striped specimen, named Nutty, who loved disappearing up my trouser leg, was on his way to explore new fields. He was approaching one of the sisters at good speed, and had just arrived at her feet, when I took a headlong dive in time to catch him as he was about to ascend into the unknown!

The Gold Coast forest contains many other arboreal mammals, but as some of these are nocturnal they are seldom seen. One such is the beautiful Demidoff's Galago-a large-eyed lemuroid with a body only four inches long and a tail nearly twice this length. It is the smallest of the family and the most delicate in captivity. In tropical forests, where the trees are a great height and often festooned with great clusters of epiphytes in the upper branches, the chances of seeing some small mammal curled up asleep are 
indeed slight, but in the case of the galago they are nil, for it usually chooses a hole in a tree to retire to during daylight. To locate such rare animals in a vast forest one must resort to other means.

My experience here was somewhat similar to the one I had in Portuguese East Africa where I located Garnett's Galagos by observing the feeding places of Trumpeter Hornbills. Here in the Gold Coast forest I had noted the croaking call of the touracosan unmistakable sound which carries a long distance-coming from the same direction every morning. Wondering if there was some fruit-bearing tree that was the attraction, I set out to find the spot. This took two mornings, as on the first occasion I got about half-way there when calling ceased. I knew that it would be too difficult to find one tree hemmed in by a sea of others-all looking more or less the same-without some further guide. On the second morning I took my post at the half-way mark, and was able to get a new bearing by renewed croaking on the part of the touracos. When I got near, the common bulbuls could be heard in numbers, so I knew that I was approaching one of the forest trees that bear an enormous quantity of small fruits-attractive alike to mammals and birds, and the center of great activity while the fruit lasts.

It was, in fact, a tree laden with large bunches of fruit resembling damsons. The usual run of forest fruit is dry, tough and insipid, but here was something really fleshy and juicy. My guess was that if there were any Demidoff's Galagos in the vicinity they would certainly visit this tree.

To climb it with a cage-trap was the next problem, but being fairly fertile with "Heath Robinson" ideas I solved the problem without difficulty. The trap, of course, had to be set as it was getting dark, otherwise the bulbuls would have got caught, so arriving on the spot about half an hour before sunset I arranged an attractive display of ripe bananas and pawpaw-the latter sliced to expose the luscious flesh-in my trap. The next essential was a ball of string. This commodity was fixed to each corner of the cage-trap, the four pieces being tied together so that the cage could be lifted without tilting. To the joining place of the four corner strings I fixed one end of the ball of string. The ball itself 
I put in the back pocket of my trousers, then fastened the button. This allowed both arms free, and as I climbed up and up the tree the string gave out behind me so that when I reached the upper branches all I had to do was to haul up the trap. I could fill a book with my failures, but this was a success. The following morning I was delighted to find the trap off and a Demidoff's Galago sitting quietly inside. Next night his mate obliged also by going into the trap.

Another nocturnal lemuroid animal I captured was a Bosman's Potto. Although related to the galagos this animal is as sluggish as the galagos are active. It seems that nature has evolved two
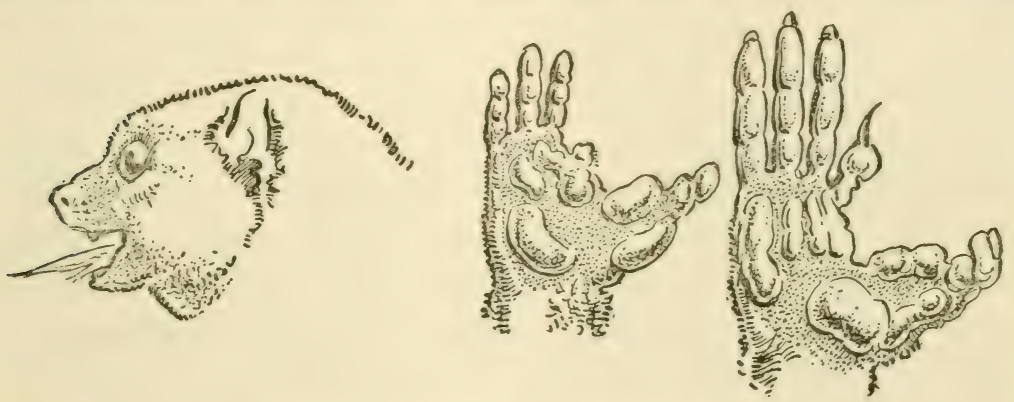

Potro-showing hand and foot

means of survival-speed and slowness. Between these extremes the chances of survival are small. It is a strange fact that all slowmoving animals such as the potto, the sloth, and the chameleon are feared by the very creatures that might ordinarily bring about their extinction; this applies particularly to man. An African or a Madagascar native will almost pass out with fright if a European playfully tries to put a chameleon on his person, although the creature is quite harmless.

The slow-moving potto, according to the West African native, is also a demon and can perform terrifying feats of strength with its arms although it is only as big as a guinea-pig.

The legend goes that if this creature once gets hold of anyone the only means of escape is by chopping off its arms. This deep-rooted belief is not confined to the Gold Coast; it is prevalent among the natives of the Congo and the Cameroons. In the latter territory the natives substantiate their story by saying that the withered 
arms of pottos have been found still adhering to the necks of monkeys brought down by their arrows. Nevertheless the potto's grip is nothing to worry about, though he can give one quite a nasty bite. He is characterized by a very short tail and rudimentary index fingers on the forehands. As in the lemurs one toe on each foot is furnished with a long tapering nail, instead of the normal short rounded one, which is used for toilet purposes.

One day at Mampong some natives brought me several small weird-looking animals with blackened faces. On close inspection I saw that they were Bushy-tailed Dormice-normally beautiful fluffy creatures-but these had been captured by putting dried grass and leaves in a hole in a tree where they were sleeping, and setting fire to it. The fumes and heat had driven them out and the natives had no difficulty in catching the poor half-dazed and badly burned creatures. These people are terribly cruel and think nothing of inflicting the most diabolical torture on animals. Fortunately, beyond singed whiskers and blistered toes, these specimens were not as badly burned as at first it seemed and most of them eventually made a complete recovery. To discourage the boys we sent them off without payment and threatened to thrash anyone attempting to trap anything more by these methods.

This dormouse, the larger of the two West African species, has much the same habits as the galagos, feeding on fruit and insects, and sleeping in holes in trees-sometimes quite a number together.

About fifty miles north of Kumasi the forest gives way to savanna country which becomes drier and drier as one proceeds northward, until the semi-arid belt with its stunted thorn-bush growth is reached. It might be imagined that any tropical forest would be a paradise for birds, but it is in the drier regions that they are most plentiful. To be sure of seeing an abundance of bird-life, both in variety and numbers, it is only necessary to visit a stream or river, with its usual fringing luxurious vegetation, running through some dry region.

In seeking such a spot I went northward from Mampong through the savanna country, and found that, as it was the end of the dry season, the usual annual fires had swept the country, leaving it quite barren. The charred leafless trees and the ground 
covered with the ashes of burned grasses and shrubs presented a picture of complete desolation. There were hundreds of square miles of this eyesore and one wondered what could have happened to all the bird-life.

At the River Pru, about one hundred and twenty miles north of Kumasi, a real oasis came into view. The trees and bushes bordering the water, being of a totally different kind-mainly evergreens-and not being interspersed with dried grasses, had entirely escaped the fire. This offered a natural sanctuary to all the birds of the surrounding countryside, and I have never gazed on such an animated scene. Thousands of weaver-birds were twittering in the trees and large flocks of them were bathing in shallow water. Mixed up with these were whydahs, Orange-cheeked Waxbills, Bar-breasted Firefinches, and Cordon-bleus in great numbers, and other birds such as Spectacled and Fairy Flycatchers, Coppery and Beautiful Sunbirds, and many species of kingfishers, etc., were plentiful. The natural beauty of the river, combined with such a dazzling display of bird-life in the bright tropical sunlight, presented a picture almost impossible to describe.

This appeared to be the ideal place for collecting, although I was well aware that living in the proximity of the river would have serious drawbacks, such as being exposed to the attacks of the dreaded tsetse flies and mosquitoes. The natives themselves prefer to make their villages as much as two miles or more from a river and carry their water this distance, rather than tolerate the blood-sucking tsetse flies-carriers of sleeping-sickness.

The only available place that we could occupy was the Government Rest-House at Prang-some two miles from the river-so having made arrangements with the local District Commissioner to occupy this for a while, I prepared for the trip, which we decided to make at night, for by day our delicate birds would require feeding, and in a lorry there would be little light and too much vibration.

A fortnight later we set off in a native lorry and trailer over some of the bumpiest roads in creation. On this vehicle were stacked not only our personal luggage, menagerie, and bird-foods, etc., but also three native servants, their paraphernalia, and the 
two natives in charge of the lorry. Cooking utensils and buckets, etc., were tied on with string, and the din as we thundered along was terrific.

Arrived at Prang, our first project was to get some quarters built near the river, for we had decided to risk the dangers of dwelling where insect pests were most numerous. To offset this we would be able to enjoy the beautiful river scenery and be right among the bird-life and so save constant journeyings to and fro, which in the heat of the Gold Coast was in itself a big consideration.

Fortunately the native Chief of the district was very friendly and helpful, and having learned our requirements he immediately ordered about a hundred natives to begin building grass huts to house us, our servants, and the birds. With two natives beating tom-toms furiously to spur the others on, the huts sprang up like mushrooms. Every native had an appointed task and while huts were being erected some natives were cutting grass, others poles, and a few making string from the inner bark of trees for binding the thatch, and some of the old men, well experienced at the job, were making grass mats for the walls.

As the huts neared completion the rhythmic music from the tom-toms became faster and louder until, when the last piece of thatch was laid, the drummers were in a frenzy. They had done their job and had spurred their otherwise lethargic fellow-tribesmen into action in a big way. There was a sudden relaxation and the assembly made its way back to resume normal village life, while we moved into our riverside bungalow, where all was now tranquil.

Our squirrels were soon liberated and thoroughly approved of the new quarters, especially the thatch, into which they tunnelled and used as a snug sleeping place. Nippy, one of the Gambian Tree Squirrels, soon established himself as the villain of the trio and was always in mischief. It is extraordinary how individual squirrels vary in temperament. Nippy was a likable fellow but was never really fond of being handled and became bad-tempered if corrected when doing something naughty, which was frequent. His best effort, I think, was when he discovered that Delys's face cream was not only good for the face but even better for the stomach. We found him sitting by the jar, clucking loudly, 
his face plastered with cream, devouring this new-found delicacy with much gusto.

A few days after my first journey through the savanna country the first heavy rain of the season fell and the charred stumps of trees soon burst into a wonderful green, and from the ash-covered soil a profusion of plants sprang up in an incredibly short space of time. It was as if the whole countryside had been suddenly thrust from winter into spring. Although all this was very pleasing to the eye it only meant extra work for me, as many of the birds left the riverside foliage and returned to their savanna haunts. If I had come to the district a few weeks earlier it would have saved me miles of trudging, especially when trapping sunbirds. There were some lovely species here not found in the forest zone, such as the Coppery, the Splendid, the Beautiful, and the Senegal Scarletbreasted Sunbird-all exquisite birds with metallic plumage. Specimens of all these were obtained, but the Splendid Sunbirds, which rival in beauty the Superb Sunbird of the forest, were by far the hardest to trap. They were rather uncommon and showed a preference for feeding on the flowers of the higher savanna trees rather than on the flowering shrubs of the riverside. I have always regarded sunbirds as the quickest of all birds in detecting anything in the nature of traps, nets or bird-lime, and these Splendid Sunbirds were certainly no exception. They were so elusive that after many weeks of tree-climbing I managed to get only three specimens.

One day I visited a tall wild fig-tree, frequented by a variety of birds, to inspect a cage-trap, when I noticed a Gambian Tree Squirrel feeding on the figs. I had to climb the tree to take a Glossy Starling from the trap, and so wondered what line of action the squirrel would take in view of the fact that there were no adjoining trees. My own idea was that he would let me get half-way up the tree and then sidetrack me and scuttle down the trunk to earth, but I was wrong. As I reached the lower branches his concern was obvious as he scampered hither and thither near the top, then suddenly he ran to the tip of one of the longest branches and leapt into space. As he sailed to the ground I could see his legs and tail stretched to the utmost to act as resistance and so break the fall. He hit the hard ground with a thump and there was a momentary 
pause which, to me, in view of the height from which he had jumped, could only mean death or serious injury, but the thought had hardly crossed my mind when he was up and off in a flash, none the worse for his crash-landing.

In a much higher tree I once cornered a lizard and he too jumped from near the top. He was a large Agama Lizard and, like the squirrel, spread his arms and legs as he descended, but considering his weight he seemed to go down remarkably slowly and I have an idea that this ballooning effect was created by inflating himself with air. No sooner had he hit the ground than he scuttled off as fast as his legs would carry him.

To add to our three arboreal squirrels, a native brought in two baby Ground Squirrels. These live in burrows like rabbits and never climb, and consequently have numerous enemies, including the native. Ours were hand-reared from the blind stage by Delys and became delightfully tame, but were always pathetically nervous. They had an instinctive fear that any sudden noise indicated enemy action, so if either of us appeared suddenly round a corner of the huts, the squirrels panicked until realizing that we were their friends and protectors, and not mongooses or hawks.

Our stock of hand-reared pets was increased by the acquisition of some baby Cane Rats, known in West Africa as Cutting-grass. They become delightfully tame when captured young. They are rather stocky animals with fat wire-haired bodies, short legs, and broad flat faces. They live on green food and on roots, and in fact somewhat resemble young pigs in habits and shape. They are water-loving creatures and ours delighted in having their daily bath in a large pan of water. Cane Rats are hunted extensively by the natives, as they are not only meaty, but are considered very tasty. It was a common sight to see natives working along the river's edge with their dogs, searching through the thick clumps of reeds and thick vegetation, where these animals seek shelter from the heat of the day.

One of my most exciting moments was when I got my first glimpse of a Standard-wing Nightjar near the banks of the River Pru.

It was dusk and suddenly a fair-sized bird that appeared to be 
chased by two smaller birds flashed in front of me, and settled on the ground. When it rose again, to hawk insects, I realized what it was. In the breeding season the male bird of this species develops a long bare shaft-like plume in each wing in place of an ordinary flight-feather, at the end of which is a feathery vane. This in all is about eighteen inches long, so when the bird is in flight the rush of air causes the vanes, which trail well behind, to twist and turn. The effect is enhanced by the fact that the bird itself is always wheeling while catching insects. As the shaft cannot be seen at a distance, it gives the bird the appearance of being pursued.

One of the most distressing sights we saw while in our riverside bungalow was that of fowls being transported along the nearby road. Almost daily a native lorry passed on its way from the northern territories to Kumasi, carrying merchandise and baggage. On this sat numerous native passengers, and wherever there was space on top, or even tied to the sides or back of the lorry, were baskets of fowls on their way to the capital to be sold. The baskets were made of widely spaced cane and offered no protection whatever from the relentless sun. The birds were invariably badly overcrowded and were obviously in great distress.

Throughout Africa fowls, as kept by the natives, have a somewhat wretched existence. In the first place they are never fed, so they are forced to find their own living in the way of insects, seeds, etc. When a native decides to sell a few fowls, he may walk all day in the tropical sun with the birds tied by the legs, hanging head downwards and fastened to a stave by which he carries them. On arrival at a village the helpless creatures are put on the ground in a bunch, and there they stay until the owner has satisfied his own hunger and thirst and is ready to move on; no thought is ever given to the plight of the luckless birds.

To facilitate the trapping of birds in the riverside foliage I hired a native canoe which enabled me to set nets in the overhanging creepers and branches. Many of these creepers formed natural archways through which Malachite, Pygmy and Shining Blue Kingfishers could be seen darting to and fro, making a most delightful scene. Being particularly keen on getting that gem of a 
bird, the Shining Blue Kingfisher, I searched the banks of the river in my canoe for likely nesting holes and was lucky to find one frequented by a pair. Unfortunately the breeding season had commenced just prior to our departure so I was compelled to make a chance excavation in the hope of finding young.

Lifting the nose of the canoe on to the bottom of the steep bank I mounted the slope and began tunneling with a cutlass. The heat from the sun was terrific as it shone on my back and progress was slow owing to roots. The hole kept caving in, and to follow it and to find out if I was nearing the nest chamber I had to scoop out the fallen earth with my hands. Suddenly I realized that I had reached the nest as the hole became wider. The exciting moment had arrived, but as I cleared away the last bit of earth prior to feeling for the young, I touched something and instinctively withdrew my hand like a flash. After widening the hole with the cutlass (and not using my hands) I peered in and saw the coils of a snake. The only reason he had not attacked me was, I presume, because he was coiled up in a tiny space and had no room to strike. I now perspired more freely than ever, but the primary duty of a collector is to collect, so pulling out a net from my bag, which I always carried, I laid it over the hole. I then cut a flexible stick and, pushing this through the meshes of the net, gave the snake a prod. At first he merely hissed but after some more determined prodding he shot out full of rage into the net. While he was trying to find a way through this I pinned him down with the stick and quickly transferred him to a bag. I was surprised and somewhat alarmed at his size and realized what a lucky escape I had had, for he was none other than a Black-and-yellow Cobra-a species that is very venomous. It is probable that he had eaten the young kingfishers I was hoping to get.

It was only when I had got him safely in the bag that I realized that my canoe had disappeared. This was serious, as I was on the wrong side of the river with my snake and paraphernalia. In the excitement I had failed to notice that the current had taken my canoe downstream, so my only course was to swim after it, which I did fully dressed.

The heat was so intense here that I think that most of the snakes 
were crepuscular or nocturnal; I frequently saw their sloughed skins in bushes bordering the river but rarely saw a snake. No doubt many of the disused kingfisher holes were regularly used by them during the heat of the day.

The riverside vegetation, sometimes referred to as gallery forest, contained some interesting robin-chats and a very curious bird known as the Oriole Babbler. The English name for this is not a very fitting one, for, except that the Oriole Babbler has yellow and green in its plumage, it has little resemblance to any oriole and is even less like a typical babbler. It is not gregarious and therefore does not indulge in community babbling, but it has a variety of calls, the usual one being a whistle up and down the scale uttered in a quick lively manner. Other notes reminded me very much of those of certain bush-shrikes. The markings are rather unusual, for the head is black, with each feather laced with silver, while the upper parts are olive green and the under parts yellow, with a black breast-band.

One day while trying to capture one of these rare birds I caught five weaver-birds that had flown into one of my nets in a creeper overhanging the water. Not requiring anything so common I released them while standing in the canoe, but the last one, in its eagerness to escape, dashed down a bit too low, struck the water, and started flapping its wings rapidly in an endeavor to reach the shore. A second later there was a big splash but no further sign of the weaver-bird-a large fish had taken the luckless creature.

I noticed that frogs were plentiful where the river widened out and was shallow, and from these places the croaking at night was tremendous, but along the deeper water there was an ominous silence. This alone, I think, indicated the presence of many carnivorous fish.

One day the Hausa Chief again arrived to see how we were getting on. A tall man, looking very dignified in his native robes, he addressed me in his own tongue-Hausa. One of his followers translated this into Twi, and another finally put it into English. The result, I fear, was merely an outline of what had been said by the Chief, and not a correct version at that. It ran: "The Chief says that as he hasn't seen you since the last time he saw you, he has 
come to see you again"! I made a suitable reply of welcome, but what it was like by the time it reached the Chief, I shudder to think.

He was very interested in our menagerie and asked if I caught my cobra by magic! When he left he asked if we would care to attend a native dance. We accepted, and a few days later the affair was arranged in our honor. The afternoon was hot and the bare ground where the dance was held was dry and dusty. The dancers were mainly women and the dance consisted of a rather monotonous shuffling of feet, which made the dust fly and the air even more oppressive. The sound of tom-toms to a native are as the pipes to a Scot, stirring the emotions and warding off fatigue. The dancing was continuous and as time went on the drummers were swept away by the soul-stirring rhythm of their own music. Sweat streamed down their faces as they thumped away with an everincreasing tempo. After an hour of this we had had enough, and in any case our family of pets was needing attention, so we thanked the Chief and returned to our grass huts, but judging by the distant sound of tom-toms the dancing continued well into the night.

Every afternoon in February a large flock of Carmine Bee-eaters arrived in the vicinity of the river and remained there for several hours, performing aerial acrobatics while catching flying insects; they often swooped down to the water, just touching it with their bills-presumably to catch flies, as I have never known bee-eaters to drink. They certainly do not in captivity.

I have rarely seen any birds more attractive either in color or in flight than Carmine Bee-eaters. They are clothed in a garment of pale blue and red on the back, with a rosy-red breast and blue-andblack head. They are also among the largest of the African beeeaters and have the central tail-feathers about seven inches long. In the dry season when grass fires are sweeping the country these birds are attracted long distances by the sight of the rising smoke, for they know that where there is a fire, there is a feast. Having captured a grasshopper, they usually make for somewhere to perch so that they can bang it hard with a sideways swing of the bill to insure killing it. This habit is continued in captivity even with artificial food, and they rarely eat a piece of meat without "killing" 
it first on the perch. Bee-eaters and kingfishers, and I suppose all other birds that tunnel into banks, run equally well backwards or forwards-a trait brought about, no doubt, by necessity.

One evening Moses the houseboy came running to my hut in a panic and threw himself on the ground, writhing like a snake and groaning. It transpired that he had been stung on the big toe by a scorpion. I lanced the wound immediately, but in spite of a liberal dose of neat whiskey given to soothe his nerves, he howled like a child. It must have been very painful, but I think fear had as much to do with his behavior as the actual sting, for there was no swelling. After being taken to his hut he kept up such a continuous wail that I took him some more whiskey and found him in a frantic state. Sweat was streaming from his body, and he was shouting and sobbing and grasping his legs and body as if suffering agonies. This was kept up for half the night, but to my surprise he arrived with the tea at the usual hour (6 A.M.) the following morning, and by then was perfectly normal. One never knows quite how much native beliefs and superstitions enter into such happenings, although I know full well that a scorpion's sting is very unpleasant.

The only exciting episode that happened to me, unless one includes the capture of the Black-and-yellow Cobra, was one day when I was bathing alone. Usually Delys accompanied me, as she loved swimming and was adept at the crawl, which she had learnt on the bathing beaches of Western Australia. We had often seen natives bathing about a mile downstream but had noticed that it was always a communal affair-practically the whole village of both sexes going in at once. They bathed where it was shallow and made a lot of noise. The significance of this did not enter our heads at the time, and as I had occasionally seen fishermen dive into the deep water to disentangle their nets from submerged branches, I never suspected that crocodiles ever frequented this small river. We had been bathing for a month or more when there was a storm in the distant hills which caused the river to rise considerably, and the water was now murky instead of clear.

On the day in question I went to the river where my canoe was tied to the bank. After stripping I walked to the far end of the 
craft and dived in. Never having previously thought of any possible danger, I cannot explain why I suspected the presence of a crocodile the moment I hit the water. On rising I looked around and to my horror saw the eyes of one on the same level as my own and less than twenty yards away, and the brute was moving rapidly towards me. I shot out of the water like a leaping tarpon and gained the top of the bank before looking round, and there the croc was only a few yards from the canoe with just the top of his head above water. Snatching my clothes I retired to a safe distance, resolved never to go bathing again in the River Pru.

Crocodiles have endless patience and this fellow hung around for weeks, guided no doubt by some instinct that told him that sooner or later someone would enter the water at the same spot.

The wisdom of engaging boys from different tribes became evident as time went on at our riverside camp. The novelty of living miles away from their home towns had worn off and a certain amount of friction had arisen between Moses and Lucas the cook. The latter, being a Hausa, was now among his own people and we suspected that he had started a racket, especially as our tins of milk, flour, and sugar were disappearing at an alarming rate. We called Moses and accused him of stealing our provisions, realizing full well that Lucas was probably the culprit. Moses became very heated and took advantage of the opportunity to split on one not of his own tribe. "Massa," he said, "Lucas 'e done go cook cake for woman." Apparently he had been supplying the said woman from the village, and her various relations, for weeks past with luxuries from our limited supplies.

We then put Lucas on the mat and he accused Moses of stealing all kinds of stores, from cutlery to clothing. Finally we had them both in front of us together, and the ensuing tirades hurled at each other in pidgin English were so laughable that for the moment we forgot all about the pilfering. After making accusations against each other concerning incidents dating back almost to the day they were employed, they became so heated that we had to part them. After all the hot air had blown over, they resumed normal working relations, but to teach them a lesson we made an estimate of our losses and docked the amount off their wages-an action which they accepted philosophically. 
One of the greatest problems in the Northern Territory was getting a daily supply of flesh for my hawks, owls, and kingfishers. In Prang the natives killed a beast only once or twice a week for local consumption, and in that climate meat would not remain fresh for twenty-four hours, so in between times I had to purchase the skinny native fowls. It took several of these bony creatures to satisfy our carnivorous birds for one day, and as often as not even fowls were not procurable. On many occasions my houseboy spent hours cycling round to native villages trying to purchase domestic pigeons for bird food. When his efforts were unsuccessful I had to get busy trying to catch common birds with my nets. Even the feeding of our insectivorous birds was a bit of a worry for, although we had plenty of dried flies, ants' eggs, and biscuit meal, it was very difficult to get a constant supply of eggs, the latter when hard-boiled being, of course, a very necessary ingredient. As there were no Europeans living in the district there was no demand for new-laid eggs, and those that were brought to the local market were usually from outlying villages where they might have been accumulating for any period up to a month before being deemed sufficient to merit the long journey to market to sell them. On an average nine eggs out of every dozen were rotten and this even applied to the eggs presented to us by the local Chief. For our fruit-eating birds, bananas had to be brought from the forest zone about a hundred miles away. In spite of these and many other difficulties we got together a fine collection, including tinker-birds, barbets, robin-chats, Golden Orioles, sunbirds, starlings, flycatchers, Oriole Babblers, kingfishers, eagle-owls, owlets, hawks, touracos, etc., and a number of small mammals.

In the Northern Territory I had to do all my own trapping and making of traveling cages, while Delys did most of the feeding, and as the collection grew and grew our duties became increasingly strenuous. Weakened by a recurrence of a very bad dose of malaria that I had at Mampong in the forest zone, I felt that I had reached the limit of endurance when the time came for us to leave on the I20-mile journey to Kumasi. My niece, who had withstood the effects of roughing it in a hot, humid, enervating climate with indifferent food and too much hard work, had the misfortune to develop an attack of malaria on the day that we were leav- 
ing for the railhead. With a temperature of $104^{\circ} \mathrm{F}$. she had to travel all night on a lorry over terribly bumpy roads. During this nightmare we encountered a very bad storm, which blew a large tree across the road; it took twenty natives with cutlasses, working in the light of our headlamps, nearly an hour to clear away the trunk and masses of branches.

After one day's respite at Kumasi we caught the train to the coast and Delys had to be carried to the train from the hospital. Once aboard the ship for home we soon forgot all the hardships and rejoiced to think that we were able to introduce quite a number of new species to England. 


\section{Chapter Seventeen}

\section{ECUADOR}

TN the winter of $1937-38$ I went to Ecuador-again with Delys1 in search of some of the delightful birds confined to the Andes, which were little known to aviculturists in Europe. I believe that, prior to my visit, Walter Goodfellow was the only Englishman to go to Ecuador to make a collection of live birds from the Andean region, and that was in 1914 .

Away from the towns and railways, traveling conditions had undergone no great change since his day, and to get to any of the forested regions of the western or eastern Andes it was still necessary to go on foot or by horse along the same old narrow trails that had been in use for generations.

When we disembarked at Guayaquil, the principal port of Ecuador, we were pleasantly surprised to find such a clean, wellbuilt town, with parks, promenades, and attractive buildings. It stands alongside the River Guyas about thirty miles from its mouth. A noticeable feature of the place is its climate, which is pleasantly cool considering the latitude-only about $3^{\circ}$ south. This is due to the cool Humboldt current which flows along these shores from the Antarctic, and which has had such a tremendous influence on the marine animal-life of the west coast. This in turn has affected the economy of the adjacent maritime countries, for the cool waters produce favorable breeding conditions for millions of fish, which not only sustain the population, but attract vast flocks of fish-eating birds which produce the valuable guano deposits on the coasts and islands of Chile and Peru. Penguins, normally residents of the cold Antarctic and sub-Antarctic, are 
found as far north as the Galapagos Islands, which lie three hundred miles due east of Ecuador right on the equator.

Guayaquil is unusual, if not unique, in that it boasts of a railway station with no railway. The building, ticket office, and luggage office are there, but passengers find that after settling the usual formalities they board a ferry which takes them over the river to the waiting train. Our destination was Quito the capital, three hundred miles away by rail and lying at an altitude of nearly ninety-five hundred feet. The line for the first fifty miles traverses the flat coastal belt, then winds its way up the western slopes of the Andes to a height of twelve thousand feet, after which it descends to the plateau in which Quito is situated.

The Andes cross Ecuador from north to south, leaving only a narrow strip of flat country between them and the Pacific, and every kind of climate exists from desert, tropical (humid), subtropical (humid and dry), temperate (humid and dry), to the alpine regions of the great mountains which are perpetually covered with snow. In this respect Ecuador can boast of the fact that it has snow on the equator. This extraordinary variety of climate with its corresponding types of vegetation make this part of the New World the most prolific in bird-life, and its inaccessibility to the ordinary traveler rather adds to the excitement of exploring the numerous mountains and valleys where bird-life is extremely local.

The Andes, on account of their great height, create a natural division in the animal-life, and so we find about four hundred species and sub-species of birds in eastern Ecuador that are not found on the western side, and nearly two hundred in the west that do not occur in the east. The very size of some of the families is sufficient to indicate a number of distinct zones: there are, for instance, $\mathrm{I} 32$ species and $\mathrm{I} 6$ sub-species of humming-birds (many more than in the whole of Brazil); but this enormous total is beaten by the tyrants, which number 142 species and 18 subspecies. Altogether there are 1,357 species and 15I sub-species of birds in Eucador, in an area less than that of Germany!

Quito is a delightful place with a temperature averaging $60^{\circ} \mathrm{F}$. We were immediately struck by the smartness of the Spanish women and Delys had a grand time exploring the shops, especially 
the milliners', who would make up a hat to any design quickly and cheaply. In the leading hotel there was a sort of fashion parade daily from II A.M. till lunch-time, when all the smart people assembled in the lounge for coffee and aperitifs. We soon got to know some of the best Ecuadorian families and found them charming and hospitable. The same rigid code as in other Spanish countries regarding señoritas prevailed here, and if Delys went to the cinema with an Ecuadorian girl in broad daylight there were always relations sitting a few seats behind them.

At that time the rate of exchange was so much in our favor that Ecuador was probably the cheapest country in the world to live in, and it attracted a number of English and Americans who had decided to make it their home. Apart from the low cost of living, the clear and invigorating air of the Andes, the mountain scenery, good food and wine in lovely restaurants where one dined to the strains of tango music, all combined to make the capital a place of charm.

We decided, first of all, to visit a small village called Santo Domingo de los Colorados at the foot of the western Andes, which is famous for its Indians and also rich in bird-life-being in the humid tropical zone. We were able to go about eighty miles by car from Quito, but then we had to resort to mules for three days. I was horrified when I saw that the bigger of the riding mulesthe one allotted to me-was saddled with a Mexican-style wooden saddle. This was as hard as a rock, and not having ridden for two years, my anatomy was the worse for wear after the first day when we spent nearly thirteen hours in the saddle. We were accompanied by a muleteer and four pack-animals, his remarks to the mules providing an education in baser Spanish!

This being the rainy season, it poured down nearly all the way and the narrow trail was in a terrible state. It was very rocky in some parts, and in others so boggy that the mules sank to their bellies in the mud. One seemed to be completely hemmed in by the mountains all the time, but the trail wound its way through the valleys, following the river on its tortuous course to the open plains. Waterfalls hundreds of feet high were a frequent sight and at short intervals streams were rushing wildly from the mountains 
into the rivers. Often these streams tore their way through deep gorges which were spanned by rudely made narrow bridges consisting of a few poles laid horizontally and covered with earth. In some cases they were made of bamboo, and in the heavy rains it is not an uncommon thing for the earth to get washed through the crevices between the poles so that the mules' feet sometimes go clean through the bridge.

My niece had a hairbreadth escape crossing one of these gorges on a bridge that was only three feet wide, with no sides. Her mule put its foot in a hole and fell flat on its stomach; as it struggled wildly to regain its feet it seemed inevitable that it must go over the side into the raging torrent below. Fortunately it righted itself safely and Delys managed somehow to keep on the mule's back, otherwise it would have been a disastrous affair.

The grandeur of the scenery surpassed anything that I had seen in the Himalayas previously, and acted as some compensation for the rough going and for the discomfort of being wet through to the skin. We were so late one day in reaching a hut along the trail where we intended staying the night that it was pitch dark before we reached our destination, so we just had to rely on the senses of our mules to guide us to safety. It was rather an awesome business crossing the narrow bamboo bridges without being able to see anything, and with the sound of water rushing far below.

Our pack-mules were laden with provisions, blankets and birdcages, and the transportation of the latter along the narrow forested trails was a problem because the mules constantly tried to pass one another, with the result that the loads jutting out from their sides were subjected to heavy crashes. The same thing happened when a mule passed too near to a tree. It was not uncommon, also, for them to fall over when sliding down the sides of slippery boulders or when wading torrents studded with large rocks and holes.

One small rest-house on our way was fully occupied by passing muleteers, so the proprietor drove some pigs and fowls out of a small shed, swept it out, and said we could spend the night there. We had no option and in any case were only too glad to get out of the rain and find some dry clothes.

Santo Domingo is noted for its nearly extinct tribe of Indians, 
who plaster their bodies all over, and even their hair, with a bright red paste made from the seeds of the achiote tree. They are very shy and only a few speak broken Spanish, so conversing with them is difficult. They were once a fine race physically and morally, but these attributes as well as their very existence are jeopardized through contact with the Ecuadorian degenerates now living in their midst.

Unfortunately it rained hard every day that we were at Santo Domingo and the surrounding country was reduced to a bog, otherwise I might have received some assistance from the local Indians. I was particularly keen on getting a live specimen of the Umbrella Bird, known locally as the pajaro toro (bull bird) on account of its bellowing call-notes. This bird is one of the curiosities of the animal kingdom with its bushy crest and feathered wattle, over a foot long, hanging down from the neck. An Indian hunter told me that this appendage is inflated when the bird is calling.

In the plantations and second growth tanagers were plentiful, especially the Yellow-backed Tanager and the migrant Scarlet Tanager. The males of the former were the most conspicuous birds of the region, and in flight looked very handsome with their yellow backs contrasting with the velvety black of the rest of the plumage.

In spite of the rain and mud I managed to trap a number of interesting specimens by setting nets in the trees, though this was rendered somewhat hazardous by the wet and slippery nature of the branches. Two of the nicest birds that I got at Santo Domingo were a pair of Coroneted Manakins, which looked like very diminutive cocks-of-the-rock. The most handsome tanagers were a pair known as the Greenish Blue.

I saw on rare occasions a rather pretty bird, which had an orange bill and black-and-white striped head. It is closely related to the saltators, but does not appear to have a satisfactory English name. I believe that it was referred to formerly as the Orangebilled Tanager, but it is now classed as a Pectoral Sparrow. I managed to secure only one, which was quite a handsome bird and not a bit sparrow-like in its habits. A very distinct tanager, and one of the most beautiful-the Western Swallow Fruit-eater-was 
occasionally seen in the clearings where berries were plentiful. It has a wide gape like that of the cotinga, and the males are a shining turquoise-blue with the forehead, throat and sides of the face black. The female is quite unlike the male but is nevertheless very beautiful, with brilliant green plumage.

A pair of Sclater's Orange-headed Tanagers were also obtained. They are very striking, with their orange plumage contrasting with a black face, wings and tail.

Many other attractive birds were seen in the forest around Santo Domingo, including several barbets. The New World barbets are not well known in England, but some that I saw were exceedingly handsome, especially Bourcier's Barbet, which is a gorgeous bird with a mixture of green, scarlet, silvery white and yellow in its plumage. Swainson's Toucans were also seen, and we were fortunate in obtaining a pair of young ones which were ridiculously tame and made most amusing pets. They are rare in captivity.

The everlasting rain and mud and the filthy conditions under which we were living made us give a sigh of relief when we set off again on our mules for Quito. The return journey was even worse than the outward one as the heavy rains were continuous, and we had to climb over eight thousand feet.

We could not obtain any porters, so our bird-cages had to be strapped to the mules; the journey was rather a nightmare, with the animals frequently falling into mud holes and crashing into trees. All the birds survived the first two days, but the last one was too much for some of them. I never attempted to carry birds again by mules, and wherever I went I took porters with me.

Our next trip was to Lloa, a small Spanish village to the southwest of Mount Pichincha, situated at an elevation of eleven thousand feet. While we were searching the surrounding country for some sort of hut to stay in and to use as our headquarters while collecting, we were offered the use of the local school, as there was no other accommodation available in the village. Fortunately the children were on holiday, though this did not mean that we were without company. Ecuador is noted for its fleas, but I never experienced anything like the massed attack by the inmates of that schoolroom. Luckily we did not have to put up with that ordeal 
for long, as we got the loan of a charcoal-burner's hut about four hundred feet above Lloa on a steep hill overlooking the valley and facing Mount Pichincha.

Apropos of fleas, a botanist friend who had traveled in Peru, where the railway reaches a height of over fifteen thousand feet, once told me he could tell more or less when the train had reached around twelve thousand feet as the fleas, unable to stand the altitude, all "popped." Either the Ecuadorian fleas were of stronger stock or we were not quite high enough at Lloa, for there was unfortunately no inclination on the part of the fleas to pop until pressed incredibly tightly between the fingers.

At eleven thousand five hundred feet we were in the temperate zone and the countryside was frequently enveloped in a cold mist. The nights were particularly cold and anything less like the tropical conditions usually met with on the equator it would be difficult to imagine. In this region humming-birds were particularly plentiful, and it was an extraordinary sight to look out of the hut at daybreak when one's limbs were stiff with cold to see numbers of the fragile-looking Thornbill Humming-birds flitting round the flowers through the cold gray mist in the most animated manner. Other humming-birds common at this altitude were Bouquet's Puff-legs, and a charming sight they were with their white "powder-puffs" displayed prominently on the legs. It is a common belief that humming-birds are attracted only to red flowers, but in this region nearly all the different species were feeding on white blossoms.

After much searching I came across a Sword-billed Hummingbird, a bird which I was particularly anxious to capture owing to its very unusual proportions. The beak is considerably longer than the body, and it feeds almost entirely on the trumpet-shaped flowers of the scarlet brugmansia. These blooms are about the same length or a little longer than the bird's beak, and it seems that the Swordbill has evolved a bill (and tongue) sufficiently long to enable it to feed quite easily from its favorite food-plant. During six weeks of strenuous mountaineering I captured five of these rare birds, but was unable to find a suitable artificial diet for their sustenance. The usual proprietary infants' food mixed with condensed milk 
and honey and glucose, such as is a recognized diet for hummingbirds in general, acted like a poison to these specialized feeders, and after having a good feed they looked miserably ill and I liberated them. I kept one for three weeks by completely changing the diet and was hopeful of solving the problem, but by that time the Sword-bills had completely disappeared as the brugmansia had finished flowering. Evidently they had gone to another district where, owing to different climatic conditions, these bushes were late in blooming. By changing about it seems that they can find their favorite food for most of the year. There is evidently something different about the nectar of the brugmansia flowers for I never experienced any difficulty with artificial food for any other humming-birds.

While here I was very interested in torpidity in humming-birds. At night at this altitude, when the temperature drops to around freezing point, these birds become torpid-a condition somewhat akin to that of a hibernating mammal, except that in the case of the humming-bird it endures merely for the night. As with reptiles, the temperature of the blood falls in keeping with that of the surrounding atmosphere, and respiration almost ceases. In this state a humming-bird can be picked up and has the appearance of being on the verge of death. Its tiny body feels frozen though it may give a feeble squeak when it is touched. Warmth will quickly revive it, but what is most astonishing is that this torpidity in humming-birds is something rhythmic, for on the coldest mornings when it is still freezing they come out of their torpidity at daybreak, so this is really a provision of nature to defeat the effects of cold nights. The lowering of the blood temperature means that less nourishment is required and so the bird survives until the morning, when it can get sustenance in the form of nectar. Humming-birds in captivity go torpid very easily at the slightest lowering of temperature if they are not a hundred per cent fit, and then they have to be revived artificially.

It is interesting that the only other birds in which torpidity has been observed are swifts, nightjars and colies (mousebirds), all of which show some relationship to the humming-bird. Once when I was in Natal I caught four colies and put them in an aviary. There 


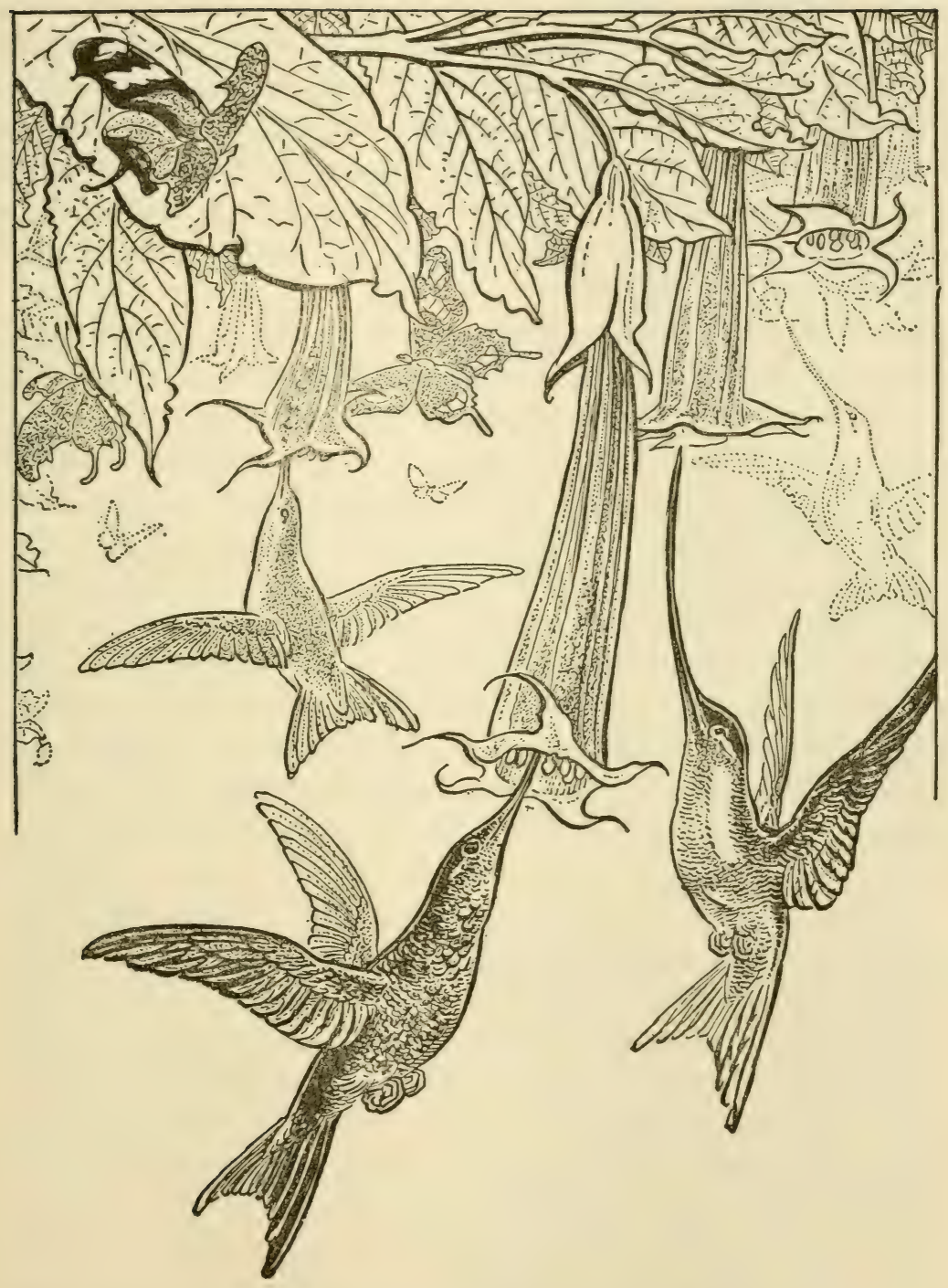

Sword-billed Humming-birds Feeding on Brugmansia 
was a frost that night, and in the morning I found all four clinging to the wire netting, where they had slept, apparently dead. They were frozen stiff and were quite lifeless. I threw them onto a rubbish heap and left them. An hour or so later, when the warm morning sun began to shine on them, I happened to pass and saw one moving and showing signs of life, so I put all four in a small box-cage where they caught the full force of the sun's rays, and in a short while they were as lively as crickets. I took them back to the aviary, opened the cage door and out they flew as though nothing had ever happened.

The Andes in Ecuador consist of two parallel chains of mountains with wide valleys between, in which the bulk of the population lives. A few miles east of the capital civilization, as such, comes to an end. Ecuadorian territory on the eastern side of the Andes is little known, except to the aboriginal Indians.

In an attempt to find a region untampered by man I made the journey to Papallacta-an Indian village situated at eleven thousand five hundred feet in the eastern Andes-leaving my collection of birds in charge of my niece in Quito. This trip into the unknown was an exciting one for me, though I was not happy about leaving Delys on her own. To reduce my absence to the shortest possible time, I engaged a half-caste Indian blowgunner to accompany me, whose duty it was to get live hummingbirds.

It is fascinating to watch one of these fellows at work. The blowgun is six feet or more long and is like the glorified pea-shooter of olden days. It is merely the stem of some kind of cane or plant with a hollow pithy center. This is split lengthwise and the pith removed; the two halves are then replaced, bound round spirally with a thin flexible ribbon-like cane over which is plastered some wild rubber latex of a kind that is resinous and sets hard like pitch. Thus the barrel is sheathed with a solid case preventing it from warping and keeping it perfectly straight. The great art of using such a weapon is to be able to roll pellets exactly the right size, for it follows if these are too big they will jam, and if too small will allow a certain amount of air to escape, resulting in a loss of force. A special sort of black clay with the texture of 
plasticine is used for the purpose, and the operator rolls one pellet at a time in his fingers, which only takes a few moments, and this he transfers to his mouth. With the tongue he pushes the pellet into the end of the barrel. Experience is necessary when aiming at a bird for the operator is not looking directly along the barrel as with an ordinary gun, and allowance has to be made for this. With a mighty puff the pellet is propelled through the shaft-its length giving it force and accuracy.

I have often seen a blow-gunner bring down a hovering humming-bird at a range of thirty feet. If the bird is struck it falls down winded and he rushes up and puts it into a porous cloth bag, and in most cases the bird recovers in less than a minute, and is perfectly normal. Usually the gunner puts several pellets at once into his mouth so that in the event of a miss he can quickly insert another with his tongue, and have another shot. As there is no noise, a missed bird is not disturbed or scared. When seeking humming-birds the gunner always tries to locate some flowering bushes or trees where the birds congregate to feed, and then stands still at a convenient range to pot at them while they are hovering in front of the flowers. A layman using one of these instruments will find that the pellet will trickle gently out of the end of the blow-gun and fall to earth a few feet away, but these experts, through constant practice since youth, have developed tremendous lung-power, and so produce a force equivalent to that of a powerful air-gun.

I set off by car from Quito and descended to the Tumbaco Valley (about 8,500 feet) and here got my first glimpse of the Giant Humming-bird, which looked quite enormous on the wing. What it has in bulk it lacks in beauty for it is one of the dullest, although the largest, of the family. Having crossed this wide valley, I picked up the muleteer complete with riding-mules, packmules and stores, and also the blow-gunner, who had gone on ahead, and then we started the long climb up to the Guamani Pass ( I 4,500 feet). As we proceeded by easy stages it became colder and colder until I felt that I could no longer sit on a mule's back, so I tried walking for a change. I soon discovered that walking up a stiff incline at fourteen thousand feet, in competition with 
mules that were used to high altitudes, was no joke and in a few minutes I was gasping for breath. This was more unpleasant than being half frozen so I quickly resumed my seat. In this treeless alpine zone, known as the paramo, there was precious little birdlife-the only two living things that I saw being a Black-rumped and a Red-rumped Ground-tyrant. As I sat almost frozen to the saddle I marvelled to think that here and even higher in the mountains lived a humming-bird, the Hill Star, and that it should choose such a bleak zone to live in permanently, rather than descend to the warmth of the lower levels.

Having reached the highest point of the pass, we crossed a sort of no-man's-land with some of the wildest scenery imaginable. It was quite thrilling to think that I was passing over one of nature's greatest barriers and that I would soon be in a very different floral and faunal zone. The excitement grew when I saw a few small streams running eastward instead of to the west. These soon became torrents rushing wildly down, and I thought of their long course to the headwaters of the Amazon and then thousands of miles through Brazil to the Atlantic, in contrast to the rivers of the western Andes, which have a very short course to the Pacific coast.

As we were leaving the paramo and passing into the forest zone at about thirteen thousand feet the first bird I saw was the Scarletbellied Tanager; then came some humming-birds and more tanagers. At twelve thousand five hundred feet we passed the dark cold-looking waters of Lake Papallacta, where I saw a few Andean Teal. We then descended to Papallacta-a village surrounded by mountains dominated by the picturesque and mighty Mount Antisana (r9,335 feet). At Papallacta and the higher regions round about, the forest trees are stunted and gnarled and their branches festooned with mosses and epiphytic orchids. Papallacta is one of the most beautiful places I have seen, but the climate, although warm in the daytime, was incredibly cold at night. I was fortunate in being able to stay in the substantial residence of the local Jefe Politico, which was far more comfortable than any of the Indians' huts. The latter were very picturesque with their long thatched roofs reaching almost to the ground, 
but the insides were dark and wonderful breeding-places for vermin.

My blow-gun man soon came in with an assortment of marvelous humming-birds, including a Temminck's Sapphire-wing, which reminded one of an enormous butterfly, with its shining deep blue wings and silent flight. The body was metallic green and the total length six and three-quarter inches. Another species of humming-bird, the Shining Sunbeam, was very common around Papallacta and was interesting to me because of the iridescent plumage, showing only when viewed from behind. Normally the back is a velvety blackish-brown but viewed from behind it lights up into purplish-crimson, with a coppery hue on the lower back and metallic green on the rump.

One of the most gorgeous species-the Comte de Paris Humming-bird-was locally common, and it had an affinity for some crimson tubular flowers with yellow tips. These grew in great clusters but only in a few spots, and it was here that I found the Comtes de Paris plentiful, though elsewhere none were to be seen. The coloring of these birds was rather extraordinary, the head being velvety black, the forehead metallic green, the under parts shining green, with a metallic blue throat, the secondaries buff, making a conspicuous patch in the wing, and the upper parts brownish-black glossed with green. They are medium-sized birds with long straight bills, and in captivity they seem to have a constant fear of one another. When I had several together in a large cage they were too busy watching every movement to seize an occasion to take a few sips of nectar from one of the feedingbottles. I never once saw anything in the nature of an attack, but they all seemed to live in constant anticipation of one, and it was only necessary for one bird to hover to cause the rest to dive into corners on the floor, with their hearts beating rapidly as if the enemy were about to drop bombs. They were so stupid in this respect that I was forced to cage them singly.

While at Papallacta a trader showed me five shrunken human heads he was offering for sale. He had got them, so he said, from the River Napo district some distance to the southeast. They were perfect examples showing no distortion of the features, yet no 
larger than an orange. I was told that the procedure in shrinking a head is to make an incision up the back and then carefully remove the skull. The lips are fastened, and the eye-sockets and skull incision sewn up, then the skin is plunged into boiling water to which an astringent has been added. After some hours considerable shrinkage takes place, but of course the skin is shapeless. When removed from the water, hot round stones are put in the skin and these are kept moving by rotation. Thus slow drying and further evaporation sets in, and the head-hunter himself has to mold the face into shape while it is hardening but is still pliable. When the process is complete the skin is tough like leather, but how closely the head resembles its owner in life has never been ascertained. However, the result is remarkable, for the life-like miniature has tightly closed eyes with long upcurling lashes, and hair as long and as soft as in life.

One of the heads I saw was of an old lady of about sixty years, with gray hair; there were also three men of various ages, and a boy of probably ten years with fresh complexion and lovely features.

The Ecuadorian government had recently brought in a law imposing heavy fines and imprisonment on vendors of these heads. This was to put a stop to the growing traffic in these curios with tourists and collectors.

Scarlet-bellied Tanagers were common here, and I was able to capture all I wanted by setting nets in the trees where they fed. I occasionally saw a few Orange-bellied Tanagers-a species very similar in size and appearance to the foregoing, but with the scarlet parts orange. Another most striking tanager that I saw near Papallacta was Vassor's Tanager; I saw a small flock of these one day at close quarters, and the brilliance of their shining silky blue plumage was almost startling.

The return journey to Quito was by no means a picnic as the birds had to be carried by porters. Crossing the paramo we were subjected to a fierce freezing wind, and so the cages had to be wrapped up tightly in sacks. It was a relief to descend to the warmer levels again, both for our own comfort and the safety of the birds. 
On reaching Quito I found that Delys had kept the menagerie in fine fettle in spite of the fact that many of the birds were difficult to cater for. Her main worry had been warding off wouldbe suitors, who pursued her with customary Latin ardor. A pretty blonde always attracts attention in countries where the women are predominantly brunette, and I think some of her proposalsmade within a few minutes of her being introduced to someonewere merely expressions of admiration. Ecuadorian politeness, in any case, can quite easily lead one "up the garden"; for instance, if on entering a house one expresses admiration for an ornament, picture, or even the grand piano, the courteous reply is "It's yours"!

Our stay in Quito coincided with the annual water fête. This is grand fun if you are not one of the uninitiated. Having business to do that day, I left the hotel and gaily strutted down one of the main thoroughfares in the crisp and sunny morning air, but was brought sharply to my senses by receiving a large jug of water showered on me from above. Most of the buildings have verandas on the first floor jutting over the pavements, and these are the danger spots on fête day. Later on things warmed up, or cooled off, according to whether one remained wet or dry, and every veranda and window was occupied with tittering people waiting to hurl water at passers-by. Street vendors sold paper bags of water, which were bought readily by youths, who slung them at pedestrians on the opposite side of the street. The residents either stayed indoors and indulged in water-heaving, or donned old clothes and ventured forth to take what was coming.

To escape the battle I took a taxi through the storm-center, but this did not save me. Ardent bag-throwers dashed at the taxi and heaved water-bombs through the window and in the driver's face.

Another harmless form of sport was on the occasion of the Presidential elections, which seemed to take the place of football or rugby in other lands as an outlet for people's feelings. I saw mounted police charging down back streets firing revolvers in all directions. When I inquired the following day from the hotel proprietor how many people had been killed, he looked at me in a 
bewildered manner and assured me that no one was ever hurt on such occasions-merely a trifle excited!

Around Quito the ubiquitous eucalyptus tree is very much in evidence and these are a great attraction to humming-birds, especially the Violet-ear and the Trainbearer. This was another instance of humming-birds feeding on white flowers. In many of the gardens in Quito Violet-ears and Trainbearers can be seen flitting about all day long, the latter being particularly fascinating to watch as they dart through the air like arrows.

It is remarkable how most of the Andean humming-birds remain at certain altitudes, in some cases within narrow limits. It would be difficult to say if this is brought about by the influence of climate or vegetation, or both. Nearly all the mountain humming-birds have favorite food-plants, but the plant-life is influenced by different climatic conditions. Who can say, for instance, whether the Hill Star, which lives at thirteen to fourteen thousand feet, confines itself to such a frigid zone on account of the climate or its favorite food-plants which grow at such altitudes?

The Hill Star Humming-birds are among the wonders of the bird world, for it is amazing that such small creatures, which rely mainly on nectar for their sustenance, should choose the cold windswept paramo region of Mount Pichincha (15,918 feet) and Mount Chimborazo (20,498 feet). On the latter mountain Hill Stars are found within five hundred feet of the snow-line. So isolated are these birds in their alpine retreats that the two mountains, although quite close together, have produced two distinct races. The capture of both these alive was a very uncomfortable and laborious business and the expense entailed was out of all proportion to the prizes gained. Strange to say, these birds were not affected in the slightest by the tropical heat when taken down to the coast.

Our last trip was to Chiriboga on the River Saloya. This was on the western slopes of the Andes, at five thousand feet, in a region thickly forested and very precipitous-in fact too precipitous to be an ideal collecting ground. A road had been newly constructed 
following the course of the Rio Saloya; this is a sporting course in the rainy season, for the road, being cut out of loose earth on the precipitous slopes rising from the river, is apt to give way under the weight of a car. This actually happened only three days before we went along there, and the car and its occupants came to rest a thousand feet below. Normally the roots of tree, bushes, and grasses hold the soil together, but once the vegetation has been cleared the torrential rains cause erosion.

The main idea of coming to this part was to make an effort to capture the Red Cock-of-the-rock. This magnificent bird even outclasses in splendor its eastern relative, which is well known in captivity. The former has blood-red plumage, with the wings and tail black and the secondaries silver gray. The crest is also much broader than that of its relative.

On this occasion we took all our birds with us and, having gone as far as we could by lorry, we proceeded on foot with fifteen porters along a narrow path through dense jungle. The going was bad, for the path was blocked with the stumps of fallen trees; swamps and slippery rocks were met with alternately, and numerous small rapids had to be forded. Finally, after marching for six hours, we had to cross the Rio Saloya. This, like all the mountain rivers, is a raging torrent, especially in the rainy season. The only "bridge" was a long slimy tree trunk stretching from the bank to a pile of stranded driftwood in the middle of the river, and another long trunk from there to the opposite bank. We managed to get all the birds over safely but some of our stores, which were left behind owing to an insufficiency of porters, remained on the wrong side of the river for a week. The reason for this was that our crossing of the river coincided with the commencement of a terrific storm; owing to the mountainous nature of the country the river rose rapidly, and with a roar we saw our "bridge" and its supporting pile of tree trunks washed away in the mad torrent. While another bridge was being constructed, our sole diet consisted of rice and potatoes.

We began by capturing several Blue Sylph Humming-birds, one of the most beautiful of the whole family, and conspicuous chiefly on account its long blue graduated tail-feathers with metallic 
edgings. They are extremely temperamental, and while they are becoming used to captivity behave more or less like sulky children. Sometimes they feign death, and while doing so will occasionally open one eye to see if anyone is about. If they think all is clear, they get up and fly around in the normal manner, but if someone is in view the eye is closed immediately and the "dying" position is resumed. They are also very finical about their food, and once they have become accustomed to feeding out of a particular type of vessel, nothing will induce them to feed from any other. This is very curious, for they will get as far as tasting the fluid, but the fact that it is not in the familiar pot seems to put them off completely and they will die of starvation rather than give in. I was thankful that all humming-birds were not such a trial as these though, generally speaking, the mountain species are much more difficult to establish than those of the low country. Other beautiful humming-birds that we added to the collection in this region were the White-booted Racket-tail-a very diminutive species-and the Hill Angel; we also captured a pair of the very quaint-looking Toucan-like Barbets, which are rare and rather local.

Unfortunately heavy rain continued to fall and we had great difficulty in reaching the region where it was known that the cocks-of-the-rock lived. In the dry season they can be found in numbers in certain spots where the males have dancing-grounds, and so normally the trapping of them would have presented no great difficulty. But we discovered that they give up their dancing displays during the rain and disperse throughout the forest. We saw and heard odd specimens, but the drenching vegetation and swollen rivers were such a handicap that we had to abandon the idea, with regret. After my departure I heard that they all returned to their old haunts once the dry season had set in.

One day I was fascinated to see a Torrent Duck feeding in the river. This bird is shaped like a cormorant, with a thin body and legs set far back. Its powers of swimming in a raging torrent have to be seen to be believed; in fact the bird is more like a fish in this respect. The one I watched was sitting on a fallen tree trunk, the bulk of which was jammed fast in shallow water, but with one end jutting out into the fast-flowing current. The bird kept diving 
off into the swirling mass, completely disappearing for a while, then suddenly breaking surface and leaping on to the tree trunk as the water rushed madly past. After a while I thought that I would go closer to see if he would take flight, but not a bit of it: he sought refuge in the foaming angry waters dashing themselves against boulders and rocks on their way to the sea. He had dived in upstream and I rushed up to see where he would surface, but never saw the bird again. There was no fringing vegetation to obscure the view, so he must have threaded his way a considerable distance up the river, dodging numerous rocks, before rounding a bend out of view.

Ecuador is a most interesting country for the ornithologist, but to anyone wishing to accomplish a certain task in a limited time it can be most exasperating. The Ecuadorian country folk have little sense of responsibility, and even less of time. They cannot and will not understand why anything should be done on a certain day, if it can possibly be left over to some future date. Consequently, arranging for transport in the way of porters or mules was a business calculated to try one's temper to the utmost, for usually all the arrangements misfired. The people concerned seemed most surprised if asked why they had failed to turn up, as if we were being very unreasonable.

My luck was not of the best in Ecuador, and I had a series of rather disappointing adventures, but the final episode capped everything. This occurred when the collection was being transported from Quito to the coast. It was a two-day journey by rail, with a halt for the night at the half-way station. After I had paid an enormous sum for a truck to be attached to the passenger train, and made all the arrangements with the heads of the railway departments for the journey, someone detached the truck and attached it to a goods train in the middle of the night, when we were sleeping at the halt. I awoke at 5 A.M. to find that my birds had gone. My feelings can be imagined, as nectar-feeders cannot live long without food. I had to dash around getting heads-ofdepartments out of bed, and some were most annoyed, but through threatening to hold them responsible for the whole affair if there 
were any casualties, I finally induced them to let us have a motor rail-trolley to chase the goods train. The latter had had about five hours' start by the time we got away, but the driver went all out, taking dangerous curves at great speed, and we overtook the train at II A.M.

When we boarded it we expected to see all the humming-birds dead, but the van, having had the doors locked, was fairly dark inside, which had the effect of keeping the humming-birds less active. However, the whole lot had gone torpid, which they do very easily when weak, and had to be revived by alternate warming and pushing their opened beaks into the sweetened mixture, then tilting their heads back so that a drop or two of liquid would run down their necks. The warming process is best done by opening one's shirt front and dropping the bodies inside so that they remain next to the skin above the belt. After some minutes one feels a movement and then some buzzing as a revived specimen tries to fly around inside the shirt. $\mathrm{He}$ is then removed, fed and replaced, and when his flight is strong and prolonged it is safe to put him back in his cage after a final feed, where he will now be able to look after himself.

After Delys and I had worked furiously for an hour, we had revived practically the whole lot. By this time, of course, we were chugging along in the slow-going goods train, and instead of reaching Guayaquil in the daylight by the mail train, we found ourselves abandoned in the goods depot at midnight with no ferry to transport us and our birds across to an hotel.

We were two tired, bedraggled specimens when we finally arrived, and as tending the menagerie was a whole-time job for both of us, we had little chance to recover. This was a painful experience after months of hard work in difficult mountain country.

Our boat on its way north from Chile was late in reaching Guayaquil, so altogether we had over a week's stay. We were not sorry for this as it gave us a chance to recuperate and collect some more specimens. The best things we got were some Swainson's Toucans-lovely tame creatures with enormous red and yellow bills - and a grison-an animal related to the martens, with light 
gray upper parts and dark brown under parts-in this respect resembling the ratels or honey badgers. The general rule in the coloration of mammals is that the upper parts are the darker.

I managed to find time to visit the fish-market daily, getting every kind of queer fish-both estuarine and marine-to put in alcohol for the British Museum. I told the fishermen not to throw anything back in the sea even if it were deemed to be too small and uninteresting for human consumption, so altogether I got an amazing assortment. I had taken out a special preserving tank for these fish and managed to fill it. 


\section{Chapter Eighteen}

\section{TANGANYIKA (II)}

A $\mathrm{S}$ the autumn of 1938 advanced and the first icy blast of longer, our thoughts turned to lands of sunshine, and Delys and I decided to go south as soon as possible. This time it was to be Tanganyika; not the mountainous northeast where I had been before, but the rather flat central district on the line that runs from the port of Dar-es-Salaam right across Tanganyika to the lake of the same name.

We took a German boat for cheapness, as we found that by catching one at Genoa and travelling there via Germany we were entitled to pay the fare in travelers' marks, thus effecting a great saving. This was at a time when it was not only a crime to be a Jew in Germany, but was equally degrading for a full-blooded German to be married to one. We had such an unfortunate on board. He was a German of good stock and was, to all intents and purposes, driven out of his country because of his marriage; the poor fellow was now on his way to Tanganyika to try his luck at farming. The strain of it all was too much for him and he drank to excess, so the captain had him quartered in the isolation hospital where he was guarded and forbidden to have any more drink. This was also too much for him. At nine o'clock one night he burst through the hospital door and jumped overboard. A self-illuminating life-buoy was thrown into the sea, and the blast of the ship's sirens brought all hands on deck. The ship began a circular turn which seemed incredibly slow, and in fact took twenty minutes to reach the lighted buoy. In the meantime a 
scratch crew composed of the baker, barman, waiters and others was being let down in a lifeboat, when something went wrong with the pulley, causing the boat to drop at one end so that it hung vertically by a single rope. By some miracle all the crew managed to cling on while the boat was righted-an operation which took fully ten minutes. When all was well and the liner had brought itself to a standstill, the lifeboat took off in an unconvincing style, but they had gone less than thirty yards when the crew found the German apparently none the worse for wear. Evidently the shock of the cold water had brought him to his senses and made him change his outlook.

When the man was brought to the gangway, which had been let down in readiness, he was met by the ship's hefty butcher, who rough-handled him as if he were a side of beef. With a mighty heave he threw him on his back and carried him up the gangway and then dumped him on the deck. With aid he was able to walk back to the hospital, but it was noticeable through all this that the ship's doctor kept well out of sight. Most of the passengers were British and were quite stirred by this dramatic episode, not least by the launching of the lifeboat, which would have been serious under different circumstances. Other episodes during the course of the voyage made us quite relieved when we reached Dar-es-Salaam and could leave the boat for good.

Our destination was Saranda, a stop on the central railway a few stations west of Dodoma and over three hundred miles from the coast. We had heard of a farmhouse that was vacant and had obtained permission to stay there.

Saranda itself was composed of only a few corrugated-iron shacks centered in rather flat, dry thorn-scrub country. Without delay we were able to arrange with an Indian to transport us by lorry to the farmhouse, which was in rather an outlandish spot some fifteen miles south of the railway.

After the usual preliminaries of finding a cook and a houseboy, we made ourselves fairly comfortable, then got down to the business of exploring the countryside and becoming familiar with the local bird-life. This was interesting, for I saw a number of birds such as Chestnut Sparrows, Silverbills, Social Weavers and Black- 
bellied Sunbirds that frequent the sub-desert region of northern Kenya and spread through the rather narrow corridor of dry scrub which runs southward to the east of Mount Kilimanjaro, then fanning out into the dry central region of Tanganyika.

I was mainly interested in capturing some Purple Grenadier Waxbills, undoubtedly the prettiest and most elegant of the waxbill family, and one of the few in which the sexes differ in plumage-the male having the head cinnamon brown, the rest of the upper parts dark brown, and the under parts purplishblue, while the female has the under parts cinnamon spotted with white. They are skulking birds and have very similar habits to Peters' Spotted Waxbills, feeding largely under or near bushes in scrub country. I found them sparsely distributed and mine were captured with difficulty after baiting places with millet in suitable situations.

The bird-collecting proceeded smoothly but we found it difficult to get stores without some sort of conveyance, so I inquired about the possibility of hiring a car. Eventually I heard of one that had been more or less abandoned at a mission station some miles away. The terms of hire were agreed upon, but it was doubtful if the ancient and dust-covered relic would ever proceed under its own steam. The first thing was to get it out of its shed and give it a spring cleaning and a general overhaul. This was not as easy as it seemed, for as soon as the boys, delegated to help me, started to move the vehicle, out flew a swarm of angry hornets which scattered everybody in all directions.

It took a couple of days to clean the old bus, mend tires, and get the engine to function, by which time I wondered whether it was all worth while, for I foresaw a lot of trouble once we took the road. The fuel suction system may have functioned in its youth, but it was now suffering from senile decay and had to be abandoned in favor of a gravity tank. One mudguard was missing, which was one of the best features of the car, for the other was so loose that it made a shocking clatter when we finally set off on a typical colonial earth road.

Our first outing was to Kilimatinde-a small town to the south of the line with a mission station-to replenish stores. 
As we thundered along the dry sun-baked track the cloud of dust we raised could have been seen for miles. Indeed it was. As we approached the township we saw a newly erected archway in our path bearing the legend Welcome. This was not all, for an expectant crowd of natives and Indians lined the road. Those nearest rushed toward the car and started waving, eagerly trying to get a glimpse of us. As if in response to this surprising welcome, the mudguard flapped more violently than ever. Having driven through the curious throng, most of whom, I must admit, looked very bewildered, I drew up at the Mission and heard that the Governor of Tanganyika was due to arrive at that moment by car. No wonder there were looks of bewilderment when the crowd, who had been waiting impatiently in the heat and had become excited at the sight of our tell-tale dust cloud appearing over the horizon, found that instead of the stately automobile flying the Governor's ensign that the occasion demanded, a museum piece with a flapping wing had stolen the show!

The natives of central Tanganyika are of the Gogo tribe and are called the Wagogo. They do not readily assimilate European ideas and so are dubbed as primitive or backward people by those who think that our mode of life is a model for all and should be thrust upon everybody, ignoring the fact that the way of life of uncivilized tribes has been evolved through thousands of years and may therefore be the one most suited to their requirements.

A missionary at a trade school frankly admitted that most of his teaching was waste of effort. He quoted the example of boys who learned to make tables and chairs, etc., and who, on returning to their native huts, never made any attempt to produce these things and so make themselves more comfortable. Such teaching is only of value (to their employers) if they get a job in a town. But here they will be away from all the deep-rooted tribal customs and superstitions that make the uncivilized natives far more moral than the enlightened races who seek to reform them, and they will quickly become enamored of the sordid ways of life which engulf all who are without the necessary self-disciplinary training to withstand them.

One of the most interesting animals in this scrub-country was 
Kirk's Dik-dik. This is a tiny antelope, not much bigger than a hare, with a flexible snout that its owner waggles in the same way as the tapir and the shrew. Parturition takes place at a very definite season and this coincided with our stay. The Wagogo brought us several of these newly born dik-diks but we were unable to cope with more than one, which Delys hand-reared from the bottle.

The more one has to do with animals, the more one realizes how individual they are in character. This dik-dik, which we christened with the obvious name of Dick, turned out to be one of the most delightful and intelligent creatures I have ever possessed. From the day of his arrival he always went out to the nearest bushes to relieve himself, and quickly learned to accompany us on walks or to stay in the house, whichever was demanded of him. After a few weeks a clap of the hands was sufficient to indicate to Dick that we were willing to play his favorite game. This was a form of hide-and-seek that he indulged in with great gusto and skill. He would start off by dashing behind a bush, then peeping round the corner to see if we were giving chase. When he saw that the game was really on he would play all sorts of tricks to put us off the scent. His favorite one was to run round the back of the house with one of us in hot pursuit, only to find that Dick had disappeared-not behind a bush but through the kitchen door, thence out of the front of the house to the bush from which he originally started.

While I was on the veranda making traveling boxes, Dick would entertain me with a display of acrobatics by dashing along the veranda at full speed, then turning round in mid-air and careering back again, his frail legs looking as if they would break if he stumbled. He was our constant companion at mealtimes and was never in the slightest degree a nuisance. Unfortunately he contracted diarrhea, which was probably brought about by eating wood shavings where I was working, some of which were paintcoated. In spite of all our efforts he got weaker and weaker and it was pathetic to see him struggle to his knees to go outside rather than foul our home, but we saved him the trouble by carrying him. 
This brave little soul, with such a lovable character, succumbed after a few days, and his passing was like that of a human friend. Delys was in tears and insisted on making a neat little grave, an action which, with my wider knowledge of Africa, I knew would be futile, but on such occasions it is as well to give sentiment full rein. The following morning the grave was emptya predator of the African night in the form of a hyena or jackal having undone in one swoop our efforts to express affection for a departed friend.

The native cattle were always of interest, not because of their special breed but because of the Red-billed Oxpeckers they attracted. These birds are related to starlings but progress in woodpecker-like fashion as they run all over the bodies of certain mammals, particularly rhinos, buffaloes, and cattle, searching for ticks, blood-sucking flies, and apparently scurf. This is a perfect example of a bird becoming so specialized that it is now wholly dependent upon mammals for its existence. Most people favor these birds on account of the great number of parasites they consume, but some maintain that they do a lot of harm, especially to packanimals with abrasions, by pecking at the wounds to get blood and small pieces of flesh and so prevent them from healing.

It is amazing that those mammals that suffer, without demur, the attendance of oxpeckers, no matter on which part of the body they cling, are quite intolerant of flies.

I caught a pair of these curious birds which were nesting under the eaves of an outhouse, but they refused all forms of live insect food. I tried forcibly feeding them for a while on raw bloody liver, but they never showed any inclination to feed voluntarily. If I could have introduced this food on the back of a cow, no doubt it would have been gobbled down at great speed, but in a traveling cage it ceased to have any significance. The only hope of establishing birds of this nature is to get them from the nest before they have developed rigid habits.

The natives here brought me a number of Fischer's Lovebirds: I soon discovered their attitude to one another when not separated into tree pairs is certainly not one of love. Every morning I found one or more killed through having its scalp bitten into, or some 
lamed through having their toes bitten off, so I refused any more and kept only a few pairs separately caged.

As a change from our bush existence we moved to the vicinity of Dodoma, where we were kindly offered accommodation by a mission society.

One of my most vivid memories of this place was an attempt to capture some Amethyst Starlings that came to feed on the fruit of some very tall fig-trees bordering the river which, at the time of our visit, was a dry sandy watercourse. This bird is a beautiful creature-the male having its upper parts and breast metallic violet, with white under parts. The female is quite different, having a thrush-like appearance-brown above with streaked under parts. The immature males are like the hens, and it is hard to know if one has true pairs, for it has often happened in captivity that an apparent hen has changed into the male plumage after several years. The immature males seem variable in this respect - some getting their adult plumage the first year and others after three or four years.

In order to have everything ready for the early morning visit of these starlings, I climbed one of the largest fig-trees late one afternoon and spent more than an hour in the tree-top setting nets between the branches. The following morning about an hour after sunrise I returned hopefully to see the result of my labors. On looking up I cursed when I saw that the nets were clustered with Straw-colored Fruit Bats that had got in during the night. There were seventeen in all and I now had a tiring worthless job in front of me. Fruit Bats become inextricably entangled in flue nets-the long membranous wings and wing-hooks being the source of the trouble.

Any attempt at freeing these while the bat is alive means a danger of being bitten. Even when I had safeguarded against this I was unable to free many specimens, so was reluctantly compelled to hit them on the head and cut off their wings, for they were then easy to extricate. Some had babies and it was interesting to see the young one clinging to its mother's body-apparently carried in this fashion without hindrance when the mother is in flight. A Fruit Bat that has been in a net for some time manages 
somehow to bunch together all the slack netting by using its winghooks as crochet-hooks, and having done this it decides to bite a hole through the bunch. The result is that when the animal is liberated and the net straightened out, one finds a hole as big as a football.

Many of my nets were thus put out of action until I got back to England and had time to repair them. 


\section{Chapter Nineteen}

\section{MADAGASCAR (III)}

TN the summer of 1939 I decided to make a quick trip alone to 1 Madagascar and so complete two expeditions in a single yeara thing I had never done before. The underlying motive for this sacrifice of my usual summer holiday in England was shortage of cash.

It was a sad day when I bade Delys good-by in London, for the thought of voyaging alone after making five collecting trips in her cheerful company was depressing, to say the least, though not so bad as it would have been could I have foreseen the future. Little did I know that shortly war was to be declared and that I would be compelled to stay in Madagascar for six long years, during two and a half years of this time completely cut off from the outside world with no money and no news of my relatives.

Events moved swiftly when I arrived in the Great Island. I had been asked to look for two rare rodents for the British Museum. One of these, the Madagascar Gerbil-a mouse-like rodent with long ears, long hind feet, and a long tufted tail-was not represented in the Museum, and was then known only by the type specimen in Paris. The other was the Madagascar Giant Rat, of which the Museum possessed only one specimen (preserved in alcohol), and which was thought to be extinct, as nothing had been heard of it for over fifty years.

As I had planned to do a lightning trip, cramming into a couple of months the collection of waterfowl at Lake Alaotra and of various mammals, birds, and reptiles from the eastern forests, there was not a day to lose. My return passage had been booked by the Dutch Line to Durban, and from there to England by a Union 
Castle steamer, and arrangements made for accommodation of the livestock, so as to get me back before the advent of winter.

In Tananarive, the capital, my first concern was to find out the quickest and most convenient way of getting to the west coast forest that lies between the Tsiribihina and Morondava Rivers, this being the type locality of the Giant Rat. I was told that the only way to get there and back, short of wasting weeks in waiting, was to hire a car, which would also facilitate my explorations.

This was soon arranged and I came to terms with a local garage proprietor to supply me with an American car and native driver, at so much a kilometer.

Madagascar, owing to its mountainous nature and great size, and also its language problems, can be rather overwhelming to the new arrival. It takes time to become familiar with the geography of the place, and with the ways and means of getting to the forests, which for the most part are difficult of access, but fortunately I was able to profit by the valuable experience gained during two previous visits to the island.

Formerly the whole of Madagascar was covered with forest, except for the extreme south and southwest, where for a long period the arid conditions have permitted only a scrub-like vegetation to flourish. Forest destruction has gone on for centuries and is continuing to the extent that much of the fauna seems doomed to an early extinction. The native method of cultivation, annual grass fires, and commercial exploitation are responsible for the destruction of large tracts of primitive forest in which the indigenous mammals abide. Most of these have specialized requirements and do not favor second growth, savanna or prairie.

Unfortunately, owing to special conditions prevailing in Madagascar, a forest once destroyed has little or no chance of reëstablishing itself.

The country in the east and center is extremely hilly and could be aptly termed chaotic. This region, commonly called the central plateau, comprises a vast area of grassland between the eastern and western escarpments and is situated at an altitude of from three thousand to six thousand feet. It is dominated by numerous peaks, parts of which have a distinctly melancholy aspect which gives the impression sometimes that one is getting a close-up view 
of the moon. Before it was deforested it was inhabited by some queer creatures which are known today only by their sub-fossil remains, and of which, perhaps, the most remarkable were the Giant Lemurs.

After lunch one day the hired car arrived at the Grand Hotel, Tananarive, and when the traveling boxes containing provisions and kit, and a camp bed, had been arranged, we set off south for Antsirabe to spend the night. From here it was a good day's run, taking the road to the west, through Miandrivazo to Belo-surTsiribihina-a small west-coast town supporting an hotel and a convenient base for excursions to the forest I wished to explore.

At Belo I soon discovered that a Catholic priest, when driving through the forest at night, had sometimes seen a Giant Rat cross the road. He said it was well known to the Sakalava natives, living in the forest villages south of Belo, under the name of Voalavo Voutsotse. It was encouraging to get apparently authentic news, so soon after my arrival, of an animal thought to be extinct. However, there remained the problem of catching an obviously rare forest-dwelling creature with nocturnal habits.

My first piece of good fortune was being able to borrow a shotgun from one of the local missionaries. With this I planned to shoot through the open windscreen any Giant Rats that might cross our path while cruising along the forest road at night in the car. It was at best a wild gamble, but if it came off it would save me weeks of hunting and setting traps in the forest undergrowth.

The Tsiribihina River is wide near its mouth and Belo is situated on the north bank, whereas the habitat of the Giant Rat is some twelve miles to the south. This meant resorting to the laboriously slow ferry-a rather primitive raft-like construction supported by three large dugout canoes, which was propelled by punt poles in shallow water and paddles in deep. The crossing was considerably lengthened as the difficult terrain had necessitated the approaches on opposite banks being constructed on a diagonal course. Added to this, the ferry-boat was usually on the opposite side, or had just left, when one arrived at the river, so an allowance of nearly an hour was often necessary for the crossing.

We set off one night after an early dinner to get across by night- 
fall, for after that the ferry boys would most likely have been unavailable.

It was a typical west-coast balmy evening as we made our way along the road that runs southward to Morondava, and for me adventure was in the air. We arrived at the Sakalava village of Beroboka about half an hour after nightfall; just beyond this the road entered the forest-a mere fragment of its former extent of over fifty miles from the Tsiribihina to the Morondava River.

I asked my French-speaking native driver to stop at Beroboka and inquire for the village Chief. My driver knew the Sakalava country and spoke the language fluently, so I was able to employ him to translate the Chief's remarks into French.

My efforts to find out something useful about the Giant Rat were in vain, for I soon discovered that the Malagasy, on the whole, are very suspicious of strangers and will often go out of their way to give wrong information, even on matters of little consequence.

The Chief admitted the existence of the Giant Rat in the nearby forest, but said that at this time of the year (the dry season) it remained underground and did not appear until the rains came. Although my knowledge of the animal was nil I guessed this latter part of the information to be humbug, and so with some impatience I told the driver to thank the Chief and tell him that I thought he was mad. And with that we drove on.

In a few moments we were in the forest, so different in its aspect from the rain-forest of the east with its trees festooned with epiphytes. Here most of the trees had shed their leaves, their branches were devoid of mosses, ferns, and orchids, and the outstanding feature was the magnificent array of baobab trees that flanked the highway.

Within ten minutes of leaving the Sakalava village Chief, who had stressed the subterranean habits of the Giant Rat, our headlights caught some object in the distance and by the side of the road, which looked like a rabbit. Unfortunately, in the excitement my driver accelerated instead of going cautiously, so that when wc passed the animal we were doing around fifty miles per hour, ane as the road was merely a hard earth track we were bumping too much for me to get a shot. We sped by the ceature as it leapt into 
the undergrowth, and I plainly saw that it was indeed a fine specimen of the Giant Rat. Furious at having missed a golden opportunity, I gave the driver a lecture on the importance of slowing down to a moderate speed in the event of our seeing another rat, for I was determined not to miss another chance.

As we drove on a dreadful feeling of disappointment came over me when nothing more materialized. I felt that I should probably return to England to report that I had seen a Madagascar Giant Rat but was unable to obtain one, and who would believe me?

After about eight miles the forest became patchy with much second growth and open spaces, so I knew that it was useless to proceed any farther. I decided to wait awhile before returning over the same beat, to give any Giant Rats time to move around.

As we had the whole night in front of us, we coasted slowly at about twenty-five miles an hour when trying the next run. On and on we went with all sorts of nocturnal insects hitting me in the face as I sat behind the open windscreen with fixed gaze, and gun at the ready.

When within about half a mile of the scene of our first excitement, I caught a glimpse of something ahead and told the driver to reduce speed; this time I got in a shot as the animal was leaving the road. We stopped, and seizing my electric torch I ran back; after a short search in the fringing vegetation of the forest I found a Giant Rat lying dead. It was about the size of a small rabbit.

Now that success had come so soon in what I had at first thought to be a vain quest for an extinct animal, I could hardly believe it. I was in such high spirits that the idea of staying up all night became an exciting adventure rather than a painful duty. After some hot coffee from my large vacuum flask, some light refreshment and a chat, we hit the trail again.

After about two hours' coasting up and down the road with occasional halts, I bowled over my second specimen stone dead in the road, but after that we drew a blank. Toward 3 A.M. we were both weary and dozed in the car, awaiting the ferry back to Belo at daybreak.

After breakfast at the hotel I got some sleep, then rose for an early lunch so as to have time to prepare the two precious speci- 
mens before setting out again. I was not in the habit of doing field work for museums, so the task of skinning, preserving and stuffing took much longer than I had anticipated.

However, we were able to stick to our timetable of the previous night and were again rewarded, but this time with a single specimen-the only one we saw. Anyway, I counted this as excellent progress and decided to continue the good work. The third night was a blank, but on the fourth night I obtained my fourth specimen.

After the first outing I took my camp bed and mosquito net with me for comfort, as dozing in the car was not only unrestful but became torture on account of the bloodthirsty mosquitoes. I had already arranged with the Chief of the village near the ferry to let me use a spare hut, and to this I retired and had a good sleep around midnight. Sleeping in any hut that has been frequented by natives, or their fowls or dogs, in a west-coast village is a great mistake, but I did not realize this until several days later when my toes began to itch. Then I became painfully aware that they were harboring a number of jigger fleas that had burrowed their way under the skin to lay their eggs. I made no attempt to remove them myself, for unless this is done cleanly, festering sores arise which are slow in healing. Instead, I gave a needle to my driver who, like most natives where jiggers abound, was an expert at extricating them with only a tiny puncture of the skin.

After a few days' respite at Belo we bade farewell to the genial hotel proprietor, once more crossed the ferry, and were then able to view the scene of our rat-hunting escapades in daylight, which gave me an opportunity to take some photographs.

After spending the night at Morondava - a west-coast town and provincial headquarters-we made our way back eastwards by the Morondava-Ambositra road which runs parallel to the AntsirabeBelo road by which we came, about fifty miles to its south.

I took this route, which passed near the hill-top village and ancient fort of Midongy-de-l'Ouest, in an attempt to fulfil the second half of my mission, namely to obtain some specimens of the Madagascar Gerbil. History tells us that Monsieur Bastard, the French naturalist, discovered a small rodent, new to science, about 
three days' march north of Ihosy on the path to Midongy-del'Ouest. It received the scientific name of Macrotarsomys bastardi in honor of its discoverer.

It would have meant a long detour to the Bara town of Ihosy had I proceeded on foot northward to the type locality of this small rodent, so I decided for convenience to do some exploring from the northern end of the native path that links Midongy with Ihosy, a distance of about one hundred miles. Midongy lies a few miles south of the east-west route and is accessible by one route only. At the end of this one finds oneself in a quaint village perched many hundred feet above the surrounding country with precipitous rocky buttresses on three sides. It supports a small garrison of soldiers, a Norwegian Mission, a Chef de Canton, and a gite d'étape or rest-house, more sumptuous than most, having all the necessary furniture to make one feel comfortable.

After two days at Midongy, all was ready for the departure south. Leaving my driver behind, I set off by palanquin with the usual eight bearers and two more carrying baggage. Seeing that the rate of pay, fixed by government, was then only the equivalent of sixpence a day per person, plus rice, it seemed a very cheap form of travel, in spite of being limited to fifteen to twenty miles a day. Indeed it was, so long as one was on the move, but in collecting off the beaten track one may spend weeks using the various villages as headquarters when one's bearers are doing nothing, and this may easily treble the cost of transport.

We left by the road zig-zagging rapidly downhill and then took the palanquin path that bends round the base of the great rocky massif that supports Midongy. After some hours we were well clear of this and began alternately rising to the crest of a hill and then descending to the valley below.

The first night I spent in a village gitte d'étape and soon learned that but for an occasional visit from the missionary at Midongy, it was rare for these people to see a white man. It was uneventful except that my sleep was disturbed so much by fleas that I was quite thankful to be up and off at daybreak.

On the second day's march I spent much of the time walking some distance on one side of the track looking for rodent holes as I went, and I also got my bearers to inquire at any hamlet we 
passed about the existence of a tufted-tailed mouse, but not a shred of evidence was forthcoming.

That night I decided to sleep on the outskirts of the village at which we had halted, setting up my camp bed and mosquito net under a small tree. At dusk the village Chief and some of the elders approached saying that it was dangerous to sleep away from the village as there were numerous brigands wandering round at night. Knowing full well that this was based on superstitious fears, I replied that I had slaughtered hundreds of brigands during my travels and that I had no fear of them whatsoever. What really worried me was fleas! At this they seemed incredulous and wondered if I had fully understood what they were driving at. My remarks about fleas must have caused some bewilderment, for the Malagasy is introduced to these parasites within a few moments of birth and is never without them. After a lot of repetition on both sides the deputation departed. The long day in the sun had made me so tired that immediately after a dinner consisting mainly of rice I turned into bed. As I lay under the bright moon a gentle breeze soon fanned me into a healthy sleep with no visitations from bloodthirsty parasites.

In the vicinity of the Mangoky River I continued the search for Macrotarsomys for several days, using native villages as my headquarters. In this region the natives seldom see a European and my arrival created great interest. They gathered round daily to watch me eat and shave, and the unfamiliar sight of flame being produced without the agency of wood when I set my primus stove going never ceased to mystify these simple people.

No evidence as to the whereabouts of Macrotarsomys was forthcoming, the only rodents in this region being rattus and mus, which were common around the native lands. Crossing the Mangoky River, where crocodiles were much in evidence on the sand-banks, I continued to search for some days and then proceeded south through the uninhabited country separating the Mangoky and Mananantanana Rivers. This is a distance of over twenty miles. We still had no luck, so after making a thorough search in the plains near the latter river I made the three-day journey back to Midongy.

This result was disappointing, though I had enjoyed the experi- 
ence and consoled myself with the knowledge that the Giant Rat specimens had made the round trip well worth while.

As I was about to leave for Tananarive via Ambositra, I was told that a native had a captive Verreaux's Sifaka, so I called on him with the idea of getting it. Unfortunately the animal was missing and he explained that it was free to wander at will and that it spent the daytime in the trees-here all introduced eucalyptus-and returned to his hut at night to sleep. He said he might be able to get it in the afternoon when it came to the hut to take a piece of banana. Much as I wanted to get on my way, I delayed my departure till the afternoon on the off chance.

Sifakas, of which there are two species and many races, are lemurs which belong to the same family as the indris, and progress in an upright position. Unlike the true lemurs, they subsist mainly on leaves, flowers, and bark, with perhaps a small quantity of wild fruits. An interesting feature of the sifakas is that within natural barriers such as rivers there are very distinct races with varying color patterns ranging from almost wholly white to wholly black, and some with chestnut markings. In this variability and in their diet they may be said to be the Madagascar counterpart of the African Colobus Monkeys.

The tame Verreaux's Sifaka, which originally came from the Morondava district, was late in returning to his master's hut, but I eventually got it and was pleased that I had waited as it was a most interesting creature.

We set off much too late to reach Tananarive, so spent the night at Ambositra. Here I heard that war clouds were gathering and that certain people were already on the verge of panic, suspecting every foreigner to be engaged in spy activities.

On reaching Tananarive I made immediate arrangements to go to Lake Alaotra to begin collecting waterfowl. I had already despatched a great pile of packing-cases, dismantled into sections, to the lake ready for making into suitably sized travelling boxes for waterfowl.

I notified the London Missionary Society missionary at Imerimandroso on the lakeside, with whom I had arranged to stay, that I was arriving on a certain date. But before this came to pass I 
heard Chamberlain's solemn declaration over the radio that war had been declared.

To one who had been through the 1914-I9I8 war the news was staggering: to think that all the previous suffering was in vain and the whole sordid business of war had to be gone through again!

It was useless to start collecting anything alive for there would be no means of shipping it home, and in any case it would not be wanted in time of war. I cancelled my trip to the lake and presented the sifaka, which had been allowed the freedom of my hotel bedroom, to the small local zoo. The only other acquisition -a Greater Vasa Parrot-I gave to one of the hotel staff.

The declaration of war put me in an awkward predicament for I had only enough funds to last a few months, especially if I stayed in an hotel. There was a lot of optimistic gossip going around to the effect that the war could not possibly last more than six months as all large cities would be destroyed by bombing.

I decided to await events and to do some exploring in the wilds, where I could live for next to nothing. So I set off on another hunt for Macrotarsomys and this time made Ihosy my startingpoint. This is about three hundred and eighty-five miles from Tananarive and is on the main route to the south, served by a weekly bus service called the Transud. The journey takes three days, one by train to Antsirabe and thence two days by bus.

On arrival I engaged three porters and then set out on foot to the north in order to traverse the southern portion of the country I had omitted to explore previously.

To the east of the River Ihosy there is a valley some six miles wide bordered by a range of hills, and along this valley we proceeded more or less parallel to the river. The territory is less difficult than that farther north, there being wide stretches of flattish country separating definite chains of hills, instead of a disorderly mass of hills and ravines.

Inquiries were made at native villages en route in the hope of getting some information about Macrotarsomys, but without avail. This was not without its amusing side, and I remember the Chief 
of one large village summoning the entire population, who squatted solemnly on the ground while he gave a long discourse on the object of my visit and a vivid description of the beast I was trying to track down. A tremendous discussion followed and it seemed that everyone was talking at once, but the outcome of it all was that no such animal had ever been seen in the district. This, of course, did not deter me from carrying out my plans, so I searched the plains systematically until we were some twenty-five miles north of Ihosy. As there was still nothing forthcoming I moved farther to the west to explore the range of high hills, and in order to be as near as possible I camped at the hamlet of Ambararatra, about four miles distant.

One of the chief difficulties in exploring Madagascar is that the native porters hate to sleep away from a village. So great is their belief in spirits, witches, brigands, and the like, that without the feeling of security afforded by a hut they become quite terrified. They are very superstitious and have numbers of taboos.

There is no doubt that my daily excursions to the hills, which I took alone, caused some uneasiness among the natives, for as soon as I had departed they used to squat on the outskirts of the village and watch me out of sight, and there they would sit for hours until I came into view again.

The Bara people use these secluded hills as burial grounds. The tombs are situated sometimes miles apart, on any prominent point where there happen to be enough large stones with which to construct them. These are piled up in brick-like formation. Sometimes natural cavities under large boulders of rock, sealed up with stones, serve the same purpose, but in most of these the skeleton is disclosed through subsidence caused by heavy rain.

As I never once encountered any natives on these hills it is probably taboo for them to visit such places except during burial ceremonies. I felt very much alone in these eerie surroundings and not too comfortable at the thought that, in the minds of the natives, I was doubtless disturbing the spirits of their forefathers and would thus be blamed for any sickness or other misfortune befalling any of the local inhabitants.

These grass-covered hills with their rocks, loose stones, and occasional huge boulders, remind one of the kopjes so typical of 
South Africa. Here and there are outcrops of flat rock projecting only slightly above the surrounding surface, and the fissures in these provide a home for many kinds of peculiar rock plants and small bushes.

While searching among the latter I found some small berries which had been gnawed. This gave me the first clue to the existence of a small rodent in this region, and I lost no time in setting traps. At dawn the following day I set off on the six-mile jaunt to see what luck was in store. By this time I had walked several hundred miles in search of Macrotarsomys and was beginning to regard it in the light of something legendary, so it came almost as a shock when I caught a small rodent corresponding in every way with the detailed description I had long since memorized.

Encouraged by this, I explored similar situations over a wide area, but no further traces were found. However, a number of traps were set on the off-chance of catching something, and I tried again for several nights where the first specimen was caught, in the hope that a mate would be forthcoming, but without success. After that we proceeded farther north, where the search was continued in the same range of hills, at first with no success; but then on an isolated kopje about thirty miles north of Ihosy I came across further indications of rodents among the rock vegetation. This led to the discovery of a small hole under a rock which was found to contain a single Macrotarsomys. On the same hill two more holes were discovered which also contained solitary specimens.

With the capture of a total of four specimens, my success came to an end.

The extreme rarity of these rodents, and the fact that those which I trapped were all leading a solitary existence, was rather mystifying, especially as I had expected to find them living in the plains.

After more than three weeks of continuous mountaineering I returned to Ihosy and thence to Tananarive.

The British Museum was keen on getting any material in the way of small nocturnal mammals, particularly the rodents and insectivores which were poorly represented in their collections, so I 
decided to try my hand in the eastern forest at Perinet (3,000 feet). Fortunately, through the Forestry Department I was able to get the loan of a comfortable wooden shack right in the heart of the forest, which was ideally situated for collecting.

The most widely spread indigenous rodent is the Tufted-tailed Rat, which is a purely forest-dwelling creature with squirrellike habits. It is about the size of the common brown rat, but has a soft sleek coat and very long tail which, as its name implies, is tufted at the end.

This was one of the first creatures I caught, and with beginner's luck I trapped a couple of the elusive Mole-like Tenrecs-a creature with mainly subterranean habits, about which little was known. Better still I caught a Pygmy Tenrec (Microgale melanorrachis) that was new to science. It had a distinct black dorsal stripe, unlike any of the previously described Microgale.

Trapping the small nocturnal mammals of the Madagascar forests is much more difficult than one would imagine. In the first place there is little evidence of their existence, and tracking them down calls for great patience and careful search. Furthermore, the common Brown Rat (Rattus norvegicus) and a race of the common Black Rat (Rattus $r$. frugivorus) have been introduced, probably through the agency of rat-infested ships, and have multiplied at an alarming rate. The eastern forests are now swarming with them, even in the most isolated regions where the precipitous nature of the country is unfavorable to human habitation. These foreigners, well able to adapt themselves to any new conditions, are extremely prolific, and unlike the native rats have large broods all the year round. Their savage instincts are no doubt responsible for the rapid diminution of the indigenous species.

In setting traps for the Tufted-tailed Rats, I estimated that they were outnumbered by about twelve to one by the imported species. This meant that the latter not only got caught in traps set for other things, but even when I was fortunate enough to catch something rare I frequently found it partly eaten by one of these pests.

As far as the Tufted-tailed Rats were concerned I circumvented this by setting my traps, attached to pieces of cord, on branches, so that the action of its going off, and of the rat doing its dying kick, dislodged the trap, thus suspending it with the captive safely 
in mid-air. I also employed several home-made cage-traps consisting mainly of wire netting in which any captive specimen could not be harmed.

The insectivores, known collectively as tenrecs, are, with the exception of the Spiny Tenrecs, most difficult creatures to collect. They live almost entirely on live insects and are not attracted to bait. Any form of animal food put on a trap is immediately covered with ants and is then unattractive. The capture of the smaller Shrew-like Tenrecs is, more often than not, quite accidental. They live invariably in the most precipitous parts of the forest where there are projecting roots and narrow shelves to run along, but most of their food is undoubtedly gained under these numerous roots.

Once a native who was clearing some bush on a slope near his hut in the forest to plant taro, dug up two live Pygmy Tenrecs out of the ground, and brought them to me, but in years I only caught two in traps.

One of the most enjoyable aspects of this first long stay in the evergreen forests was observing the bird-life. Almost daily I saw specimens of the Scaly Ground Roller and Pitta-like Ground Roller, both gorgeous birds, which, as the name of one suggests. are much like the pittas in habits and appearance.

A further example of the peculiarity of Madagascar bird-life is provided by the philepittas, which are strictly arboreal, while their relatives-the pittas of Africa and the Far East-are all terrestrial. Of the two species of philepittas, the one inhabiting the eastern forests is called the Velvet Pitta. I first noticed these exquisite birds in a tree that was laden with small berries, and found that they arrived about the same time every afternoon to feed. Being anxious to see what a live philepitta looked like at close quarters, I set a flue net in the tree, and within half an hour captured two males. The plumage of these is velvety black contrasting with a splash of yellow at the bend of the wing; and another striking feature is the bright blue fleshy carbuncle above each eye. In all there is a very marked resemblance to the Wattled Birds-of-paradise (Paradigalla) of New Guinea. The female is very dull by comparison, being more or less olive green all over with the under parts splashed with yellow. 
It is very doubtful if a philepitta had ever been captured alive, but under the circumstances there was no point in keeping them, so I gave them their freedom.

One of the most conspicuous birds of the forest was the Blue Coua, a bird closely related to the coucals but resembling the touracos of Africa in size and form. Like the coucals it lives almost entirely on insects and other forms of animal-life.

The most exciting creature I got glimpses of was the curious rail-like bird called the Roatelo (Mesoenas). Its relationship was for a long time in doubt and it has been placed with the passerine and the gallinaceous birds, but the study of its anatomy has proved it to be an aberrant crane-showing affinities with the so-called sun-bitterns of South America and the kagu of New Caledonia.

Although apparently flightless the roatelo makes its nest of twigs above ground on a low fork of a tree, which is reached in some cases by climbing up a sloping trunk, and in others by hopping from branch to branch.

Like most, if not all, terrestrial forest-dwelling birds, the Mesoenas has highly developed senses of hearing and sight, and like the true pittas may be common without being seen. On the few occasions when I spotted Mesoenas I was sitting quite still on a log. Even so it was obvious that the bird suspected my presence, for it alternately ran rapidly and then remained motionless, its colors so harmonizing with the background that it was exceedingly difficult to see when stationary.

The eastern forests are very rich in orchids, many of the branches of the larger trees being festooned with them. At Perinet during my visit the most conspicuous (being in flower) was Angraecum germinyanum. These have but two leaves and no pseudo-bulbs, and are attached to the leafy outer branches of evergreen trees, so that when not displaying their white waxy flowers they are very difficult to spot.

After six weeks of Perinet I returned to Tananarive, but as there seemed to be a stalemate on the so-called battlefront, with no inkling as to when the war would really start, let alone end, I decided to make another visit to the eastern forest, this time farther north, to the east of Lake Alaotra. 
At the end of this trip I began seriously to think of leaving for home as the war was taking no decisive course. At this point the German onslaught developed and shortly afterwards we heard the staggering news of the overrunning of Belgium, the defeat of the Allied armies in northern France, and the decision of the French Government to capitulate.

The French in Madagascar were visibly grieved at the thought of their beloved mother country being brought under the subjection of their hereditary enemies, and their immediate reaction was to continue the fight. In a few days the local press in Tananarive published telegrams sent by ex-servicemen's associations and patriots from all over the country, all to the same effect: to fight on; and such headlines as Nous continuerons la lutte jusqu'à la victoire finale were blazoned across the front pages.

The Governor-General and the army shared in the surge of patriotism, and at this point it needed only the presence of a British General or other British emissary to give some backing and encouragement for the whole island to have remained on the side of the Allies; whereby the entire costly chain of unsavory events might have been avoided. As it was, nothing was done. While the man in the street was giving vent to outbursts of patriotism, the Governor-General was beginning to receive instructions from the Vichy Government as to the line he must follow. This put him in a quandary, and with no backing from the mainland he calmly relinquished his post without opposition to a new Governor-General, who arrived by air.

Thus the island of Madagascar became a German satellite at a distance of five thousand miles from the homeland, right under the nose of a British Dominion.

All funds from the Allied countries were immediately cut, and so I was left with sufficient money to carry on for a few months only.

There was a rumor that British subjects would not be allowed to leave the island except by special permission, but I was determined to make the attempt, particularly as there was still contact by boat with neutral countries such as Portuguese East Africa.

With this in view I approached the British Consul in Tana- 
narive, who informed me that he was not in touch with the new Governor-General and therefore did not know what the position was regarding British subjects. I suggested that it was his duty to find out, but he insisted that I should make direct application to the Governor-General.

With no alternative I wrote to him asking permission to leave the country. In doing so I explained that I had come to Madagascar on a zoological mission by permission of the Ministry of Colonies in Paris, and that I had only limited funds which would shortly be exhausted, and I would then not even be in a position to pay my fare.

In his reply he said that he regretted that, under the existing circumstances, he was unable to grant me permission to leave the island.

I thereupon approached the British Consul once again, who informed me that communications with the British Government were cut, and that he could not help me in any way.

I was thus a prisoner of war at large, with the disadvantage that I was obliged somehow to keep myself.

The position, at least, was clarified, and I was determined not to waste time and money by staying in Tananarive. It was cheaper and much more interesting to do some exploring, so with plenty of time on my hands I set off again for Ihosy to do some further researches on Macrotarsomys - the Madagascar Gerbil. Although having obtained a few odd specimens, I felt that the information I had gathered about the animal was very meager and that I had only found the fringe of its real habitat.

Two days' march from Ihosy brought me to the scene of my former hunting ground, but this time I pushed on for about another six miles and settled in the Bara village of Atáratra. From there I set out daily to the distant range of hills in the east. During the first fortnight I captured three more specimens of Macrotarsomys, found to be inhabiting similar situations to those caught previously. By this time I had worked out the whole range of hills to the most northerly point where it merges into the plains, and judging by the result obtained it seemed that Macrotarsomys must be on the verge of extinction, for I had thoroughly inspected every likely dwelling-place. Up to the present there was 
not the slightest sign of these rodents in the plains, but I had a feeling that the specimens captured in the hills were merely stragglers so I continued the search farther to the north. Here the hard laterite soil studded with termite hills gave way to one of a more sandy nature and in this I at last found Macrotarsomys dwelling in the plains. Their holes dotted about here and there between tufts of grass were not uncommon, although not easy to find.

As some of my previous specimens had been slightly damaged in traps by ants, I was keen on catching some alive and uninjured, but did not find it easy to lure them into a cage-trap; in the plains they live almost exclusively on the stems of grasses and their seeds and are not particularly attracted to baits such as the roots of cassava and sweet potato.

When I was fortunate enough to capture a few alive, the Bara natives were very curious and gathered round to make close inspection. I told them that they could make a lot of money without effort by simply catching a few of these "mice." This caused considerable amusement as they were unable to see why this mouse should be valuable while the ordinary mouse, which was plentiful in their huts and easier to catch, should be scoffed at. To them all small rodents were the same. However, a couple of days later an old native woman, with the pert look of a conjurer about to produce a rabbit from a hat, came to me clutching a piece of rag from which she produced three Macrotarsomys! Unfortunately they were damaged and the hair had started slipping, but in order not to discourage the old woman and the many onlookers, I made her a present of a few francs and at the same time stressed the importance of bringing specimens which were freshly caught and uninjured.

This set things going, and the next evening some natives arrived with a few live specimens in a gourd. With difficulty I emptied them out through the tiny hole in the top and found that there were six Macrotarsomys.

Asked how they managed to get so many at once, they said that they had spent all day digging them out of their holes. They were so pleased with their reward that from then on Macrotar. somys were brought alive to me much faster than I could skin 
and prepare them, and after a few days I stopped buying any more. Some I kept alive in captivity for a while and these became quite tame; in fact only a few days after capture they allowed themselves to be handled like domesticated white mice.

The Macrotarsomys in this region, although not uncommon, are very local, which is probably accounted for by the nature of the soil. The few specimens collected in the hills were obviously stragglers driven there in the dry season by the grass fires which sweep the plains and leave large areas quite bare. They are not very prolific and seem to have rather a definite breeding season, which is probably the rainy season when food is plentiful. My specimens were caught in the dry season, and out of the whole lot only one was found to contain young (these numbered two only), and only one was immature.

I was not sorry when the time came to make the two-day journey of thirty-five miles back to Ihosy. Under the best conditions the skinning of small mammals can be somewhat tedious, but in the semi-darkness of a small native hut with flies swarming all over the carcass, and with no table or chair, it is an ordeal. Quite apart from this, a long stay in a Malagasy village is not exactly a joy, as fruit and green vegetables are unobtainable, and after a while one is reduced to living on sweet potatoes and rice. Worst of all is the lack of sleep at night because of the ceaseless activities of vermin.

While at Ihosy, I decided to visit the southern part of the eastern forest to see how the small mammals there compared with those farther north. This necessitated a journey to Ivohibe, about fiftyfive miles to the east, which is a picturesque town on the border of the Bara country, and dominated by the impressive Ivohibe Mountain (7,00o feet).

After a delay of a few days while getting supplies and some suitable porters I set off on foot to a village sixteen miles to the east; after a long climb we crossed the foothills of Ivohibe Mountain and entered the country inhabited by the Tanala tribe. It is very seldom that such places are visited by Europeans and my arrival aroused a good deal of curiosity.

The Chief made a speech of welcome and presented me with a 
chicken and some rice, and put the best hut at my disposal, which is a customary procedure in many parts of Madagascar. In my reply to his speech of welcome I asked if the Tanala fleas were fine healthy specimens, and he solemnly assured me that they were plentiful and as good as any in the land!

The forest here was decidedly patchy as the bulk of it had been destroyed by the natives to make way for their cattle.

The Tanala people appeared to have little knowledge of the small mammals inhabiting their forests, for my inquiries brought forth the information that they contained nothing different from those inhabiting their villages, namely the common rats.

It is true that the imported rats are as plentiful here as they are in the Perinet district about two hundred and eighty miles to the north, but I also trapped a number of Tufted-tailed Rats, Nesogale and Oryzoryctes. In this district the skins of the former are extraordinarily fragile, in texture resembling wet blotting-paper. Skinning them required great patience as the slightest pull caused a tear, and when sewing them up even the insertion of the needle and the tying of the cotton had the same annoying effect.

Owing to the proximity of the Ivohibe Mountain, the rainfall here was heavy; the undergrowth of the forest was always dripping wet, and clouds often descended low to clothe everything in mist. Mosses and lichens festooned the trees and a wonderful variety of ferns issued from the crevices of rocks on the slopes of the steep ravines. The mountain torrents maintained a ceaseless roar as they crashed against the huge boulders strewn in their path, and sent columns of spray high into the air.

After tolerating these conditions for a fortnight, during which time my clothes were never dry, I decided to go to the west side of the mountain where the rainfall was less heavy. In spite of this, the leeches were much more abundant here and greatly hampered us in our work. My porters, who used to assist me daily in the search for rodent holes, were unable to proceed more than a few yards at a time without being compelled to stop and scrape dozens of leeches off their bare legs with their long-bladed knives. After a while, in spite of constant vigil, their legs would be streaming with blood. Almost every plant, leaf and blade of grass supported 
a number of these bloodthirsty parasites, all waiting to attach themselves to any warm-blooded animal that happened to pass by. In view of the fact that cattle rarely wander into this forest, and that the natives themselves make occasional visits only for wood, it seems that millions of these leeches must pass their lives away without ever having the opportunity of tasting blood.

Here, as elsewhere in Madagascar, I came up against a number of curious customs, beliefs, and superstitions.

While staying in one village about a mile from the forest I hung up some wet clothes on the railings of a cattle kraal, this being the only place available. In a few moments there was a great commotion among the villagers and I was told that it was fady (taboo) to hang clothing on the kraal as it would bring all kinds of misfortune. There was also some taboo in connection with the gathering of firewood. In a district where the rainfall is very heavy one would expect the people to keep a reserve of wood under cover, but the custom was to make a daily excursion to the forest, no matter what the weather, to collect only sufficient wet sticks for their immediate requirements. Thus these people spend their lives blowing and blowing in an effort to kindle the smoldering wood under their cooking pots, in huts full of dense smoke which cannot seep away except through the door or holes in the thatch. Tears stream from their eyes, but no amount of this misery will ever induce them to keep a reserve of dry wood. It is difficult to get to the bottom of such rigid customs, as the natives are very reticent to strangers on subjects pertaining to everyday life, especially as these are invariably linked with superstition.

The more I saw of the different Malagasy tribes the more it became evident that, where they remain intact as a native community and have not come directly under European influence, all their customs are against any form of progress. Superstitious beliefs take the place of religion; there is no ambition or greed; no one has any possessions other than simple necessities such as cooking pots. This is life in its simplest form-a naturally evolved communism, with no directing force other than superstition, and therefore no written laws, and no one delegated to keep law and order.

It is difficult for the European to understand the outlook of 
people who have from time immemorial led a stable communal. existence at the lowest possible level, giving nothing and expecting nothing. He fails to see why the spending of vast sums of money in trying to change them to his way of life brings no response of gratitude but rather suspicion and distrust.

An educated Malagasy once told me of a significant native proverb-"If the tree went on growing, the rats would eat the skies." He explained that, to primitive people, the skies are the beginning and end of life. From them come the sun and the rain, and they harbor the spirits of their ancestors. The growing tree refers to what we consider progress. It is interesting from the European angle that the evolution of time, which has brought about the tribal system, has ingrained into primitive peoples the fact that while they remain primitive the tribe will remain indestructible but that progress will mean its ultimate disintegration. This is all too evident where tribal barriers have vanished and intermarriage has changed the peoples into a mongrel community.

From the high mountain forests of the Ihosy district I went some eighty miles to the east to visit the low-lying coastal forests. On the way one descends the steep escarpment to the coastal plains where the picturesque Traveler's Palm is a feature of the landscape. I reached the coast at the pleasant town of Farafangana, about three hundred miles south of the port of Tamatave. There is no hotel, so my few days' stay was not much of a change from life in the bush as I had to do my own catering.

From Farafangana I went twenty miles south to the village of Manombo, where the inhabitants are of the Antaifasy tribe. The forest here is very luxuriant and is only four miles from the sea. Here again superstition ruled the roost. I asked why, in view of the proximity of the sea, there was no fish available, and was told that on a certain date (determined by a phase of the moon) there would be plenty of fish, and that it would be dangerous to fish before this time. It was evident that there were fixed lucky and unlucky periods for fishing, and that no one dare make the attempt when custom decreed that it was taboo.

The native fishing craft are outrigger canoes which are very safe 
unless the fishermen are caught without warning in a very rough sea, which may happen from time to time. Any such disaster due to the elements, which we should look upon merely as bad luck is, in the eyes of the Malagasy, brought about by some evil influence. Hence the origin of lucky days, whether it be for fishing, hunting wild boar, or even planting rice.

During the fishless period at Manombo the weather was perfect and the sea calm, but not a single craft put out. After a fortnight of this the great day arrived, and almost the entire population made its way rejoicing to the sea, with thoughts of the coming evening when they would all be feasting on fish. But someone must have offended the ancestral spirits. A gale sprang up and the sea became violently rough so that fishing was out of the question. It was late afternoon when the dejected-looking crowd returned without a single fish. So much for lucky days!

Rather disappointingly my collecting here brought forth no new discoveries, but enabled me to get a good series of the small mammals I had collected elsewhere in the eastern forests, thus throwing light on their distribution and local variation.

Madagascar has some interesting mongooses, and in this locality the Graceful Mongoose was not uncommon. It is not popular with the natives as they say that it takes great toll of their chickens. They trap them occasionally in snares set on foothpaths leading from the forest, along which the mongooses love to run at night in preference to threading their way through coarse tufts of grass. When setting snares for these animals in the forest, the Antaifasy make a small fire of sticks and leaves nearby. They maintain that any mongoose smelling the ashes will come to investigate, as it will think that travelers have halted there in order to cook a meal, and may have left behind some scraps of food. This is a pretty story and is an example of the many simple native beliefs, passed on from father to son, in which there is no substance in fact.

It occurred to me that in all probability the western forests would produce some interesting material if a systematic search were carried out. The fact that so little was known about the Giant Rat was a sure indication that little had been done on that 
side of the island to carry out a survey of the nocturnal mammals. I had no illusions as to the difficulties of getting there. It became more and more evident that having one's own car is the only satisfactory way of exploring Madagascar. In this case I had to rely on whatever transport was available on different parts of the route.

The journey, which took a fortnight, was more tiring than I had ever imagined owing to numerous breakdowns and punctures. Once when we were about a hundred miles from any town, one of the back wheels of our lorry fell to pieces, leaving the body resting in the road. With characteristic lack of foresight the driver had forgotten to bring a spare wheel. Eventually I managed to get another lorry, but as we were nearing Morondava the driver, by going too fast, lost control and we crashed into the forest at full speed. Fortunately no one was killed although some of the native passengers were badly knocked about.

On the route across the central plateau there is no hotel, and no provision whatsoever is made for European travelers. I had to sleep in the back of the lorry on top of sacks of merchandise and machinery. After the heat and dust coupled with the lack of food and water, it was a great relief to be comfortably installed in the hotel at Morondava.

Here I had the good fortune to meet the owner of a timber concession at Beroboka, the village near which I had previously collected specimens of the Giant Rat, and as his house in the forest was temporarily vacant he put it at my disposal. I was very glad of the opportunity to reside in the heart of this forest in order to explore it thoroughly, and so after a few days in Morondava I made the forty-mile trip north to take up my new abode.

This deciduous forest is a great contrast to the evergreen rainforests of the east. In it there are practically no epiphytes or any other vegetation that favors moist or shady conditions. Leeches are also absent, but this blessing is more than counterbalanced by the lack of shade in the dry season, and by the bloodthirsty diurnal mosquitoes.

I made a systematic search for small rodents and my first impression, as I trudged mile after mile through this flat forest carpeted with dead leaves, was that I should be extremely unlikely 
to find anything, so different was it from the eastern forests in which rodents choose the most precipitous places to live.

With no hills, valleys, rivers or other geographical features to guide one, exploring alone in this coastal forest is not without risk and is a test for one's sense of direction. Another problem in such a place is to locate traps again after setting them at widely separated points far from any path.

The first thing that aroused my curiosity was a freshly made mound of earth about the size of a mole-hill. No hole was visible, but by probing one was discovered leading off from the edge of the mound.

I had no idea what the occupant would be, but guessed that it was some kind of burrowing insectivore.

Having set a small trap at the entrance of the hole, I returned the following morning at daybreak to see the result, and to my surprise found that I had caught a Madagascar Gerbil. No one had ever suspected that this rodent was an inhabitant of the deciduous forests. Even before taking any measurements, I could see that it was larger than any of my specimens from the plains, and it has since been classified as a new race. Unfortunately the skin was completely ruined by red ants.

After continuous search I found a few more mounds similar to the one described, and in each case the entrance to the hole had been filled in. A few more Macrotarsomys were captured but all were ruined by red ants.

Soon I found that it was a waste of time to catch anything in a break-back trap in this forest, for almost immediately after capture these ants would appear in thousands out of the earth as if by magic, and in a very short time would eat away the skin and flesh.

I tried to circumvent this first of all by visiting the traps at night in the hope of finding freshly caught specimens before any damage had been done, but I soon gave this up as I found that I was tiring myself unduly without getting any useful results. Instead, I relied on a couple of home-made cage-traps that I had brought with me.

It became more and more difficult to locate fresh specimens, and 
I had to search farther and farther afield. In the course of a month I managed to get eleven specimens-all in perfect conditionwhich I thought quite satisfactory considering their rarity.

These forest-dwelling gerbils are very local. There are many square miles of forest without a trace of them, and they are to be found only where the soil is of a light sandy nature, and where the undergrowth is in thick clumps. This applies equally to the Giant Rat, and I had the experience of finding a hole, newly dug by the latter, only a few yards from one occupied by Macrotarsomys. These represent the largest and smallest of the Malagasy rodents, and the least known.

The habit of filling in its hole after entering, which is so cleverly done that no trace of it can be seen, is a provision on the part of the gerbil to protect itself from snakes, which abound in the west coast forest. It is purely a local adaptation to defeat its natural enemies. In regions where snakes are scarce the holes are left open.

As all my previous specimens of the Giant Rat were slightly damaged by being shot with a twelve-bore gun, I offered the Sakalava natives a good reward to bring me some alive. For some weeks the natives said they were unable to locate any holes, but then they brought me a young one only a few days old, with its eyes still unopened. They said they had spent all day in digging out the burrow and that finally the adults escaped. This may have been so or they may have eaten them, which I think is more probable. However, about a week later they brought me a true pair and a young one, all alive. Again the natives related the same story about the difficulty of digging out the burrow, which they said was deep and long and wound between a labyrinth of roots. As they arrived with their quarry well after dark, I do not doubt that their task occupied the whole day. The few burrows that I saw were not unlike those of a rabbit.

Like many other Malagasy mammals, Giant Rats are very docile. I kept this pair for a day in a basket, where they remained without any attempt to escape, and allowed themselves to be stroked without any sign of fear. While doing this they put their ears flat on their backs, reminding me more than ever of a tame 
rabbit. But for the war, I would have kept them alive and taken them home to England with the idea of trying to breed them.

In a tropical forest, where there is little shade for six months of the year, it is not surprising to find that nearly all the mammals are nocturnal. The forest between Morondava and Belo is particularly rich in nocturnal lemurs, three of which-the Weasel Lemur, the Fork-crowned Lemur and the Fat-tailed Lemurare quite common. There is also a fourth-the Pygmy or Mouse Lemur.

By day most of these creatures sleep in holes in baobab trees, which provide ideal shelter in a forest where it is otherwise scarce. The baobabs in this district, known as Grandidier's Baobab, are enormous, and as the wood is soft and spongy, excavations are easily made by birds and mammals alike. They offer protection for owls, parrots, nocturnal lemurs and even bats.

The Fat-tailed Lemur, known to the Sakalava as kely behoy, is a curious beast. Although only about seven inches long in the head and body, its tail is sometimes an inch and a half in diameter at the base, and is a reservoir of fat. The amount of fat varies greatly in individual specimens, and is considered to be a reserve to help the animal tide over the long dry season when food is scarce. This seems a likely explanation, although in October, towards the end of the dry period, their tails are still enormously fat. I was unable to obtain any evidence that the Fat-tailed Lemur hibernates, as has often been stated. The specimens brought to me were lively enough and were always eager for food. Moreover, I saw them at large at night, with the aid of a hunting-lamp, in the height of the winter season.

It is difficult to learn much of the habits of nocturnal lemurs. I kept the above-mentioned four species in captivity for a while, but was unable to note anything of particular interest except that the Weasel Lemur is less nocturnal than the others and is probably partly crepuscular in its wild state.

As a result of my activities in the hot coastal belts of the east and west, under somewhat primitive conditions, I contracted malaria on my journey back to the plateau. Being bumped about 
for hours on end in a lorry along hot dusty roads, and then having to do all one's own catering, is not the sort of thing one would normally choose to do while in a feverish condition, but to accomplish anything in Madagascar it is necessary to regard such trials in a light-hearted manner.

In I94I, apart from the scarcity of motor transport due to petrol shortages and lack of spare parts, travel in the island, especially for foreigners, became an ordeal because of the political situation. The newspapers maintained a flow of anti-British propaganda, and many officials and civilians who were formerly friendly towards British subjects became aloof or openly hostile, either through conviction or through fear of the consequences of being otherwise.

In this unpleasant atmosphere I went to Tulear in the southwest, little knowing that in the coastal regions the police were in a state of nerves owing to the supposed imminence of a British attack. At the time of my visit, there were no English people in Tulear, so my arrival caused a slight sensation. I was questioned at great length by the police, and all my movements were watched.

Apart from this, the shops were empty, and so the supplies most needed for a long stay in the bush, such as tinned milk, tinned vegetables, and dried fruits, etc., were unobtainable. Also I had received no money from England for over twelve months owing to restrictions in force.

My idea of going to the southwest was to try to discover something further of the distribution of Macrotarsomys. Having found it in one dry forest of the west, I thought it probable that it might extend to all the deciduous forests of the west and southwest.

At this time Tulear was far more accessible than most places on the west as it was linked with Tananarive by a weekly motorbus service. It had the additional advantage of being over two hundred and fifty miles from my previous collecting places in the west, with several intervening natural barriers in the way of large rivers, thus offering an interesting locality in which to study distribution, and variation brought about by isolation over a long period. 
The dwarf xerophilous vegetation, which is a feature of this part of the country, extends about twenty miles inland from Tulear and continues at varying width for hundreds of miles from the southwest, right through the south to the southeast corner of Madagascar. It must be of very distant origin judging by the way everything has adapted itself so perfectly to the arid conditions. In fact, this region is the botanist's paradise with its great wealth of endemic species.

It was here that the giant æpyornis, the extinct ostrich-like bird, formerly roamed, and fragments of its enormous eggs are not uncommon.

The dry conditions are caused not so much by drought, i.e., lack of seasonal rains, as by the extreme porousness of the soil to a great depth. Thus during the six months' dry season the ground becomes so desiccated that any flora not adapted to such conditions cannot possibly survive.

From Tulear, my first objective was a village on the Onilahy River in the country occupied by the Masikoro-a sub-tribe of the Sakalava.

I got word of a lorry that was going to Tongobory and would thus be able to drop me off at the desired spot. It so happened that my exit from Tulear was at half an hour's notice, and I left with no servants or bearers. This unorthodox behavior in the European mode of travel, I learned later, roused greater suspicion than ever in the minds of the local police.

I descended alone at the village of Ambohimavelo, planting my kit on the roadside, and, after contacting the village Chief, settled down in a grass hut, thankful to be away from native detectives peeping at me from behind trees.

The luxuriant vegetation along the banks of the Onilahy River contrasts greatly with that of the surrounding country where the dry stony earth is covered with thick sub-desert scrub. Much of the latter is composed of dwarf trees from six to ten feet in height, intermixed with bushes and lianas which are aphilous or provided with only minute foliage. I spent a week in this arid region but the only mammals located were Telfair's Tenrec and a Pygmy Lemur. Considering the vast extent of this type of vegetation and 
its age, it is rather surprising that no rodent has adapted itself to such conditions.

After my brief and unproductive stay here I left the Onilahy River with four bearers and went northwards in search of forest. Two of the bearers were carrying water, as the country to be traversed was absolutely dry. After a twenty-mile march through scrub and over rock we reached a village of about two hundred inhabitants. Their nearest water was the Onilahy River!

The village was filthy, and as the only place available for me to sleep in was a dirty hovel about six feet square, I decided to go on in spite of being hot and tired. Just before nightfall we reached a small native settlement near the main Tulear-Ihosy road, about twenty-six miles from Tulear. This was quite a pleasant spot, and at least there was a nice hut to stay in.

It was amazing to find people with their herds of cattle and goats, as well as pigs, fowls and dogs, living so far from water. There is enough rich soil in certain shallow depressions between the stony hills to support these people with such crops as cassava, maize, and sweet potatoes, which thrive in the rainy season. At such times water can be obtained when it is not actually running by digging in the water-courses, but as soon as the dry season commences it is unobtainable owing to the porous nature of the soil. From then on, for at least six months, the natives have to rely mainly on the roots of a wild yam (Dioscorea) for their moisture. This plant has adapted itself to tide over long periods of drought by conserving an enormous amount of fluid in its roots in times of rain. The tubers are white, and average about eighteen inches long by six inches in diameter, and are as juicy as any watermelon. They are more or less tasteless, but are supposed to possess medicinal properties beneficial to the kidneys. I must say that during my stay of over a month in the district, during which time I had very little water but consumed large quantities of Dioscorea roots, I felt extremely fit, in spite of limited facilities for washing.

In this locality the vegetation is a link between the sub-desert scrub and deciduous forest. The trees are from ten to twenty feet high with a dense, almost impenetrable undergrowth of scrub. 
The conditions seemed well suited to Macrotarsomys, but to carry out the extensive search that would be necessary to locate it was indeed a problem. In such vegetation one has only to proceed a few yards from a path to be lost in a maze of creepers and thornbearing bushes, with no protection whatsoever from the burning sun.

During the first week's scramble, when I lost most of my clothes and not a little skin and blood, I found nothing but one or two old mounds of earth that had the appearance of having been made by Macrotarsomys, which made me determined to carry on the search whatever the difficulties. I was rewarded by finding a used hole which I knew at once to be that of a Macrotarsomys. I trapped the occupant without difficulty, and continuous search in the same vicinity revealed the presence of more.

Eventually I found that in these scrub-forests Macrotarsomys is very local, and that for some unapparent reason there are vast areas where it does not exist at all. In the course of three weeks I caught twenty specimens, all within a space of less than a square mile.

I would have liked to continue my researches at a spot about ten miles to the east where a patch of forest contained sifakas, Macrotarsomys, and mongooses, but it was too far from any habitations and water, and the natives would not accompany me as they were too concerned about sleeping quarters. I expect the real reason was their fear of brigands, who, according to them, abound in this wild region.

Here, as elsewhere, the natives' huts, although of simple construction, conformed to a pattern, and it is interesting that each native tribe or sub-tribe in Madagascar and Africa builds a particular kind of hut which is as uniform within the tribe as nest construction is in different species of birds, mammals, and insects.

At the settlement of Andranohilany, meaning "Where there was formerly water," I saw several native huts being constructed. The sole materials used were poles, sticks, grass, and inner bark as string. The floor space of the huts was about nine feet by six, and only in the center were they high enough for the occupants to stand upright. 
In a way it seemed ludicrous that anyone should choose to live under such cramped conditions when unlimited material was close at hand and restrictions on building space were non-existent. Furthermore the huts were barely three feet apart, so that every word uttered in one could be plainly heard in the next. There was no privacy of any kind. The native never talks in a whisper but rather in a loud voice. Nothing is hidden from neighbors or children, consequently there is no secret gossip, and no mysteries for the young about the facts of life.

What was at first incomprehensible to me was now becoming quite clear. Everywhere I went I saw more and more the deep significance of "If the tree went on growing ...." and it seemed that I had reached the stage where, although a civilized human being, I was beginning to see civilization from the viewpoint of primitive man.

While I was enjoying the tranquillity of bush-life in this district my peace of mind was disturbed by a visit from the Tulear police. The party consisted of the Commissioner of Police, another European police officer, and two native police. The former were armed with revolvers and the latter carried handcuffs. The Commissioner, a short tubby man with a red face, confronted me as I returned from the bush with the overnight catch. Standing on an anthill to discount my advantage in height, he threw out his chest and informed me at some length that one of his native detectives had seen me, or a bearer, carrying through the bush a folding apparatus resembling a periscope. He then asked for an explanation and demanded to see the apparatus in question.

When he had finished his exposition, I ruffled him badly by replying, "Comment, Monsieur?" With his face considerably redder he started all over again. At the end of the second attempt I replied, "Je ne comprends pas, Monsieur," which, by the look on his face, caused him to almost burst into flames. He thereupon demanded to see my baggage, saying that he was compelled under the circumstances to carry out a search.

This was done with great thoroughness and discourtesy. My kit boxes were emptied and the contents thrown on the floor of the 
hut. Supplies such as potatoes were also scattered over the floor. The periscope seemed to be forgotten in the desire to find some incriminating evidence in my notebooks. Even my French dictionary was examined page by page and held up to the light, presumably to discover any invisible writing.

This comic opera lasted about two hours, after which the Commissioner reluctantly decided to leave, without any grounds for arresting what he was convinced was English spy No. I!

After his departure it dawned on me that the folding apparatus in canvas, which he had sketched on paper and alleged to be a periscope, was none other than my lightweight, metal-rodded camp bed, but as it was now assembled for sleeping, it did not occur to me at the time that this could have been the cause of all the trouble. I had thought it wise not to ask to what purpose he thought I might put a periscope in the bush, forty-two kilometers from the sea.

Many of the town-dwelling natives began to be afraid to have any dealings with me, and the climax came when the driver of a lorry refused to take me back to Tulear for fear of getting into trouble with the police. Managing to borrow an old bicycle from a native, I was compelled to make the twenty-six-mile journey by night, without lights or brakes.

Much of the bush in the coastal region north and south of Tulear I would have liked to explore, but the journey overland on foot through uninhabited waterless jungle was too difficult, and the more comfortable way of going by native coastal schooner would have caused too much suspicion at that period, so I gave up the idea and returned to the capital.

Shortly afterwards a new decree was issued forbidding foreigners to travel from one district to another without special permission, which put an end to my collecting.

The English missionaries were extremely kind and it was solely through their hospitality that I was able to live in the capital, but I soon became tired of doing nothing useful, and I longed to get to the Androy country in the extreme dry south.

With doubts in my mind, I wrote to the Governor-General asking permission to travel to the town of Ambovombe, a distance 
of over six hundred miles, explaining the object of my mission. This request was refused, and I found myself confined indefinitely to Tananarive and its administrative area.

If I could have continued my calling I should have remained a harmless law-abiding internee. But when one is loafing around the capital of a country, anything can happen-and it did. A bird whispered to me that a British attack had been planned. Would I give my services? Being a patriotic British subject I had no alternative. 


\section{Chapter Twenty}

\section{MADAGASCAR (III)-contd.}

$\mathrm{T}^{\mathrm{T}}$ was exciting to think that soon we might once again be 1 linked up with the outside world. While waiting, I thought it better to continue my researches, though I was told to be available when wanted. Fortunately there is a small patch of forest about thirty miles to the east of Tananarive which was included in the administrative zone and this enabled me to do some more collecting without the necessity for permits.

After about a week, when I was thoroughly enjoying the lovely setting and tranquillity of La Mandraka, I received a telegram in French wishing me "Many happy returns of the day." This was in April, 1942. There was nothing to arouse suspicion here, except that my birthday is in December.

I packed my traps and caught the next train to the capital as I knew the British attack was imminent.

A few days later I found myself crouching in the back of a car at midnight on the start of a 250-mile journey to the west coast. The Tananarive outpost guards were successfully avoided, and we arrived at Majunga without suspicion, as it was the home of the owner of the car. Here we remained in hiding in a house for two days. This had its comic side, for whenever French visitors came to the place we slid out of the back door and hid in the bush until we were called.

At last the great the day, or rather night, arrived. Our worldly possessions we had left behind in Tananarive, and we were now reduced to what we could carry in the way of clothing, etc., on our backs. My only worry was my valuable collection of skins, which I thought might be lost. 
According to schedule, we set off to a point some twenty miles to the north of Majunga, the last four or five miles being on foot through dense bush.

We reached the sea an hour before sunset and waited anxiously under cover. At dusk we eagerly scanned the horizon, and at last saw the faint outline of a small boat, but this was soon lost in the darkness as there was no moon. While we were waiting we flashed a code sign in the direction of the ship with an electric torch.

At last the dark hull of a ship could be seen slowly nosing its way towards us, and a few minutes later the crew launched a small craft and put ashore. Our moment of liberation had arrived. We leapt aboard, and were soon on the coaster being greeted by the crew. The evening was lovely as we steamed north in a calm sea. It was hard to realize that we were free, and clear of the enemy camp.

The British attack was not due for some days, so we whiled away the time on an uninhabited island. The attack was planned against the fortress of Diego Suarez-the northern tip of the island. It has a natural deep land-locked harbor large enough to accommodate a whole navy. The French had concentrated on making this impregnable, to the neglect of the rest of the island. At any time the British could have sailed into the ports of Tamatave and Majunga without serious opposition, and quickly captured the whole island without a fight. Diego Suarez could then have been bombed into submission.

The great moment came, and we carried out the job assigned to us. The British convoy arrived on a dark night, and the coastal batteries in Courrier Bay were taken by surprise without opposition. As the troops advanced towards the fortress, opposition became stiffer than expected. Field guns and Senegalese troops barred the way, and instead of taking the place by shock tactics as planned, there was fighting for some days before the French capitulated. I had the stirring experience of landing in an invasion barge and seeing some of the fighting.

Although the strong fortified area of Diego Suarez was soon taken, its capture had not gone exactly to plan. The High Command thought, and rightly so, that the information they had re- 
ceived about the defenses of Diego Suarez was wholly inaccurate. To me this was not surprising, knowing the source from which the information came.

The navigation of the whole convoy of something like forty-six ships into the shoal-studded Courrier Bay on a dark night was a brilliant feat, and it was exciting to be on the small boat that gave the navigators their final bearings. The French had considered such a landing by night impossible, and were therefore taken completely by surprise. Our Command had thought that once we had overcome these coastal defenses the rest would be a walkover, and that the whole operation would be completed in a day. The main defenses were against a frontal attack, whereas this maneuver was by the back door.

The unexpected resistance caused the High Command to waver. After the fall of Diego the possibility of proceeding in two convoys, one to the port of Majunga on the west coast and the other to the port of Tamatave on the east, to capture the rest of the island, had been considered.

At this juncture nothing could have been more simple, but the High Command was apprehensive and thought that a bigger and more highly organized effort was necessary to capture the major portion of the island, which was, in effect, defenseless. We know what this cost in time, but the cost in money and wastage of manpower was incalculable.

The delay played right into the hands of the Vichy Government and therefore the Germans, and no time was wasted on their part in working out defensive delaying tactics, so that when the next attack came the capture of the rest of the island ( $\mathrm{I}, 000$ miles long) would be a long and costly business for the Allies.

Six months later I found myself in a large convoy making its way to Majunga. Another headed for Tamatave.

There was not much real fighting but there was plenty of scope for the delaying tactics demanded by Vichy. Bridges were blown up, but this caused little delay. What was far more serious was that where a single road passed through miles of inundated rice- 
fields, the avenues of trees were felled so that the way was completely blocked, with no possibility of making a detour. Thus the campaign lingered on with hordes of administrative types filling the towns. One got the impression that for every soldier in the field, there must be at least a hundred doing base jobs.

My own absence from the island had never caused concern among the authorities in Tananarive, as it was taken for granted that I was collecting in a certain piece of forest. Indeed, the day before I left the capital I had made it known that that was where I was going.

Shortly after reaching Majunga in the second attack, I offered my services to the Supplies and Transport Unit. This gave me the opportunity of doing something useful in the way of helping to organize supplies in a region wholly disorganized and unfavorable to cope with such heavy demands. The difficulties were increased by the fact that the local Malagasy had fled in terror at the time of the invasion, and so their coöperation was missed.

When Tananarive was captured, I was whisked off there in a fighter plane in a convoy carrying mainly generals and their staff, and soon linked up with old friends again in an entirely different atmosphere from that when I left.

Base Headquarters sprang up like mushrooms and staff cars filled the streets. There was an atmosphere of gaiety; hotels and bars did a roaring trade after the period of doldrums during the blockade; dances were held, and the formerly Vichy-minded community jumped over the fence, and a good time was had by all-especially the womenfolk.

Perhaps the least happy about all this were the English missionaries. Madagascar was under British influence long before the island was conquered by the French in 1895 . Schools and churches for the Malagasy were built by English missions as long as a hundred years ago, and through their efforts the island is still predominantly Protestant. In and around Tananarive alone there are over three hundred Protestant churches, all supported by British missions.

In the 1880's there was even an English newspaper called the Madagascar Times. Thus the Malagasy in general, and the old 
Hova nobility and their descendants in particular, had come to look upon the British as a superior race.

When troops of any nationality arrive in a foreign land, away from the restrictive influence of the social conventions of their own country, they are apt to go haywire and have fun. Madagascar was no exception, and so the almost mythical idea that had arisen through the years as to the gentlemanliness, the culture and fine ideals of the English people was rudely shattered.

When everything was in full swing and army supplies were no longer a problem, I was engaged by the Royal Engineers as timber-buyer. It had been decided to maintain a big garrison at Diego Suarez and to build extra barracks and other quarters, for which large quantities of timber were urgently required. So I had the assignment of getting all the timber I could in the way of planks and quarterings from the timber cutters operating in the eastern forests, railing truckloads to Tananarive, getting the timber to the quayside, and making all arrangements for the shipment to Diego Suarez. This kept me busy, and from time to time I had to write reports for the High Command on the timber situation in Madagascar.

This went on for some months and then there was one wonderful interlude when I was asked to accompany a captain of the Royal Engineers as interpreter and guide on a road reconnaissance. By now it had been decided to evacuate most of the troops to Diego Suarez and hand back the running of the rest of the island to the French. Shipping was short, so the High Command wanted to find out if the formidable array of army vehicles could make the journey of 500 miles by road instead of by sea.

Ferries, fords, and hundreds of small bridges had to be inspected over a distance of some four hundred miles. As it was the commencement of the dry season, the road was not yet fit for any vehicular traffic, and we had a strenuous time with the aid of local villagers making diversions round the bog-holes and filling swampy places with branches, so that our one-ton lorry could pass. Finally we were compelled to resort to palanquins, and altogether spent a week traveling by this means.

Back in the capital life was never dull. One day I was busy in my hotel bedroom, which I used as an office, when a great com- 
motion shook the very foundations of the hotel. It was evident that a female's wrath had been roused, for a most formidable fracas was under way in the adjoining room, and needless to say the guests and staff were curious to know what it was all about. It was really all the woman's fault. She, a French lady, had told her husband that she was visiting friends to have tea, but she foolishly forgot her sun-glasses. When about five minutes away from the hotel she remembered them, and went back. The husband had lost no time, for when his wife returned he was in bed with the black femme de chambre. To make matters worse, he was extremely deaf and in his excitement had omitted to lock the door. The first he knew of his spouse's return was a crack on the back of the head with her sunshade; then the poor man and the servant were beaten up to the accompaniment of the wild outbursts of a female mad with rage.

It was all a storm in a teacup. The following day the couple turned up for meals as usual, she looking intensely pleased with herself and he with a badly bruised face.

Another more serious affair concerned the jealousies of youth. It happened after a dance in the night-club that was under the hotel in which I was staying. It seems that a French youth visited the place with a beautiful French girl to whom he was deeply attached. As so often happens, an unattached male asked her to dance and she accepted. The outcome was that when the couple left and ascended the stairway to the street, the offended French lad drew a revolver and shot his lady love dead, and then shot himself. This occurred just under my window.

Having shipped enough timber to carry out all the projects in Diego Suarez, I was sent to Nairobi to a conference with the East African Timber Control, and flew over in a military plane. It was arranged that two officials should visit Madagascar to weigh the possibilities of exporting timber for military use. This was required for various purposes in the Middle East, and sleepers of the hardest wood were required for India.

All this time I had chosen to remain a civilian, as in that status I could mingle with generals and troopers alike, which suited me admirably.

Some weeks after my return, my friends in the Timber Control 
arranged their visit and I went to Diego by plane to meet them. They were highly delighted with the visit, though they fully realized the difficulties of getting timber out of the hilly eastern forests where the rain made the going extremely heavy. Much of the timber had to be cut on the spot by hand-saw and carried out by porters as there was no means of getting it to a saw-mill. It was decided to give the scheme a trial, and I received the highsounding title of Madagascar Representative of the East African Timber Control.

Early in 1944 the changes in the war had made it less imperative to get timber from Madagascar and the project was dropped.

I was told that if I cared to go to Kenya a staff appointment would be found for me, which would have been fine from the purely money-making angle, but as I was more interested in collecting I declined the offer. So in June of that year, after eighteen months' employment with the British Army of Occupation, I found an opportunity of doing the trip I had long had in mind. This was to the Androy country in the extreme south, a wild sub-desert region populated by nomads. Even under the most favorable climatic conditions it is somewhat desert-like owing to the porousness of the earth and to the prevailing southeasterly winds, but it is very fertile, and if the seasonal rains arrive the Antandroy natives have no difficulty in producing enough food to live on. At the time of my arrival, however, there had been no rain for three years, and the sight was an unforgettable one.

At the principal town of Ambovombe everyone was in an emaciated condition and the death roll was heavy, especially among the old people and children, who were, in the main, abandoned to their fate. Ambovombe means the "Place of many wells," and fortunately these still carried water.

Shortly afterwards, owing to the efforts of the local District Commissioner, the Government made a free distribution of maize and cassava brought from the well-watered districts of the southeast. The appearance of the people underwent a remarkable change in a short time and many thousands were saved from a pitiful death. 
The Antandroy are an independent and restless race. They loathe any form of comfort, as they do clothes, and as long as they continue to expose their bodies to the sun they will doubtless remain the most perfect specimens, physically, of all the Malagasy tribes.

Under the existing conditions, with the whole country suffering from lack of food and water, I could see that collecting mammals was going to be very difficult.

Inquiries elicited the information that Lake Anongy-a saltwater lake, some thirty miles to the east of Ambovombe-offered many advantages for collecting as there is a perennial fresh-water stream entering the lake, and it is surrounded by a wealth of xerophilous vegetation long since disappeared from the plains of Ambovombe.

It was one and a half day's march to the lake on a path that ran parallel to the sea, about seven miles inland. I had two Antandroy porters with me to carry my baggage. On the way we passed through a sandy belt studded with low bushes, many of which were festooned with the shells of land snails. This was the work of a spider (Olios) that makes use of these shells to lay its eggs in and to harbor the young. For safety the shells are hauled up and fixed to branches.

The spider selects a shell under a bush, cleans it out, then climbs the bush to a point immediately over the shell, and lowers itself on to it by a web. Having securely attached the latter to the spiral of the shell, it runs up the web to the branch and hauls the shell up, making it fast so that the aperture is facing downwards. Over this the female weaves a protective cover of web and lays her eggs inside, where the young hatch in safety.

Lake Anongy is one of the quaintest places I have seen. The locality is dotted with low stony kopjes which favor the growth of that extraordinary tree the didieria, known as Fantsilotra to the natives. Its long branches closely studded with thorns and minute leaves, waving in the breeze like the tentacles of an octopus, give a bizarre appearance to the landscape. The effect is particularly eerie on moonlit nights. These and several species of euphorbias predominate in the sub-desert scrub, which here reaches its 
easterly limit. A few miles to the east the vegetation is affected by the humid conditions of the east coast and there is a rapid transition to the evergreen vegetation of the eastern rain-forests.

I stayed in the village of Antsovelo, close to Lake Anongy, the sole inhabitants being two old men; the rest had migrated to the east where food was more plentiful. Sea fish, which abound in the lake, were the sole means of subsistence of the two men except when a native traveler carrying cassava passed by, in which case they were able to effect an exchange.

At the south end of the lake there is a bar of sand dividing it from the sea, but the two are sometimes linked in times of heavy rain as several watercourses bring down the flood waters from the mountains to the northeast, causing the lake to swell considerably.

As I expected, I found the Madagascar Gerbil around Lake Anongy, but it is very scarce and local. Strangely enough, I never encountered a single specimen in the didieria-euphorbia scrubbut only in a more luxuriant vegetation some miles to the northeast. This is in the nature of a gallery forest and borders dry watercourses where the subterranean water supply is near the surface. Here a common evergreen tree bears a large round nutlike fruit which, in July, appears to be the principal food of the gerbil. Many of these trees are hollow and are the home of the pretty nocturnal Weasel Lemur.

In this locality they have a curious habit which appears to be unique in the lemur family. Whenever they hear a passer-by their curiosity is aroused to such an extent that they seem to be unable to resist exposing themselves in order to see what is going on. One morning, during a walk through a gallery forest bordering a dry watercourse, I saw five of these fluffy creatures peeping at me from holes in trees. Sometimes merely the face is shown but at others they come right outside their hiding-places. In either case they remain stationary as if paralysed and allow themselves to be prodded with a stick. The trunks of these hollow trees are very short and the holes are thus rarely more than ten feet from the ground, and often only four or five. If left undisturbed the lemur will remain with its head projecting from a hole until the passer- 
by is out of sight, then, its curiosity satisfied, it retreats and continues its slumber. It is one of the few mammals that is unafraid of man, an indication that it has been little persecuted.

After a few weeks at Lake Anongy I left on foot for Bevilany, about sixteen miles to the northeast. Only a few days were spent here while exploring the countryside for a suitable collecting ground.

In the mountains a few miles to the east of Bevilany there is a rapid transition from sub-desert scrub to evergreen rain-forest, and in some places one can pass in a few yards from one type to the other. The only way to explore these mountains is to dwell on the spot, so with little difficulty some natives were induced to build me a hut from Traveler's Palm leaves in a valley beside a fresh-water stream. The building operation occupied only three days. I found myself quartered in delightful surroundings with evergreen foliage on one side and succulents on the other. Nearby was an outcrop of rock covered with the most curious rock-plants.

About fifteen yards away my two Antandroy native servants had erected a hut for themselves. Being nomads they had no qualms about staying away from a village, and the more primitive the conditions the happier they seemed to be. The month spent here under a clear blue sky was heavenly.

This transitional zone yielded some interesting natural history forms, and I was able to record the Madagascar Gerbil at the eastern limit of its range, which is right on the edge of the rainforest.

Thus in all I had obtained about ninety specimens of Macrotarsomys stretching over a distance of more than six hundred miles through all the scrub-forests from the extreme southeast, through the south and southwest, and through the western deciduous forests as far north as Belo. Prior to this nothing was known about this particular animal, and instead of being a plains-dweller as was previously supposed, it turned out to be an inhabitant of the sub-desert scrub of the south and southwest, and of the deciduous forests of the west. In the few places where it is found in the plains it is in localities where deciduous forest formerly 
existed, and the animal has managed to adapt itself to changed conditions.

After a month of bliss in my palm-leaf hut I returned to Ambovombe and thence to Tsihombe, about forty miles farther west. This district is even more arid than the eastern side of the Androy country, the vegetation being very stunted in growth. The landscape is dominated by a few dwarf baobabs, some only twelve to fourteen feet high, the rest being made up of low bushes -leafless in the dry season-and some stunted euphorbias.

In this district there are several large depressions, now dry, which according to native legend formerly formed a chain of lakes in which hippopotamuses abounded. This was not so long ago, for many of the older Antandroy maintain that their grandfathers spoke of these animals in the live state. The story goes that the Manombovo River at that time had no outlet to the sea, but terminated in a series of lakes. After a big storm the flood waters of the river made an outlet to the sea, and so the lake dried up, causing the death of all the hippopotamuses. Now one frequently comes across their sub-fossil remains in these depressions.

The river never flows in the dry season, and during my visit the Antandroy women were getting water from holes dug quite four feet deep in the sandy river-bed.

The extinct giant aepyornis formerly roamed this district and I was shown a perfect egg showing no signs of age. It weighed eighteen pounds!

Going from the extreme south to Tananarive, a distance of over six hundred miles, one can observe what we call the progress of the human race. At the southern end are the nomadic Antandroy, contemptuously called pagans by most Europeans, with healthy bodies and a ready smile; then as we advance north we come to the Baras, who are not nomadic and who have not been greatly influenced by civilization except in the few towns; then come the Betsileos, who are very christianized and have lost most of their old tribal customs; and finally in Tananarive the Hovas, formerly the ruling tribe, who hold high administrative posts and wear morning jackets and striped trousers to work. These people 
are adept at exploiting the less educated Malagasy and have become highly money-conscious, ready to take part in any racket. Their bodies are sun-starved through wearing too many clothes and a large percentage are consumptive.

Immediately after my return to the capital I decided to visit a region entirely different from the one I had just left, and set out for Maroantsetra at the north end of Antongil Bay on the northeast coast. This necessitated a journey by rail to the port of Tamatave and then over two hundred miles by coastal road. As this had not been completed at the time of my visit I was compelled to do three days on foot. My stay in Maroantsetra was made delightful by the hospitality of Monsieur and Madame Tinayre, who allowed me to use their house as my headquarters.

The coastal scenery of the northeast is magnificent, and the climate and vegetation are so different from that of the south that it is difficult to believe one is still on the same island. I had come straight from a region where there had been practically no rain for three years to one where it rains almost every day, and where the minimum annual rainfall is around 160 inches.

I made several excursions to the forests around Maroantsetra, staying with woodcutters and living in native villages. In all, this occupied about eight weeks, during which time I got a most interesting collection of the small nocturnal mammals. The biggest surprise was finding the Mole-like Tenrec, which had never been reported from near the coast.

At the end of Antongil Bay lies the uninhabited island of Mangabe, about four miles from Maroantsetra. The Tinayres took me there by motorboat for a picnic and I was so enamored of the place that I got permission from the District Commissioner to stay there for a month. From the local jail I was allotted one Malagasy prisoner to accompany me and to do the daily chores. He was my sole companion.

Mangabe Island, which is about three miles long, is of volcanic origin and rises to a thousand feet. It is covered with primitive forest and its precipitous slopes are scored with numerous narrow gorges down which streams find their way over the many bould- 
ers to the sea. The sea-bed is of coral and as the water is crystal clear the myriads of tropical fish of all colors can be easily observed. A small waterfall of pure cold water a few yards from a beautiful red gravel beach made this an ideal bathing place, as I was able to have a cold fresh-water shower a few yards from the warm sea.

Variegated and White-fronted Lemurs were common, though it is possible that they were introduced. It was interesting to find Spiny Tenrecs and Mole-like Tenrecs on the island and also a shrew (Suncus). When not hunting for these elusive nocturnal creatures, I spent much of my time sea-bathing and canoeing. The brightly colored fish in a setting of fantastically colorful coral beds, added to the indescribable beauty of the island itself, and the distant views of the mainland mountains, made life here seem like a South Sea Island tale come true. Never before had I lived in such a dreamland.

Back on the mainland once more my island companion resumed his prison life, while I made my way to some hills northeast of Maroantsetra. The intervening country is traversed by rivers and creeks which are linked by swamps, and I was thus able to make the whole trip by canoe, passing through channels bordered by the impressive Typhonodorum, a giant of the arum family which reaches a height of ten feet. The floating vegetation, in the way of water-lilies, etc., made these swamps an ideal abode for waterfowl, especially Pygmy Geese and jacanas, which were both very plentiful.

Early in I945 I returned to the capital, and not long after we heard the news of the German surrender.

I wasted no time in getting in touch with Dr. Vevers, the Superintendent of the London Zoo, who wrote asking if I could go to Kenya to collect an elephant on my way home, and anything else I thought would be useful to the Zoo, which was by now much depleted of stock.

At last the opportunity came, and I left with the valuable museum specimens that I had collected at odd times over a period of nearly six years. 
In spite of the hardships, I had become greatly attached to Madagascar, and left it with mixed feelings. I had stayed in the villages of eight tribes and many sub-tribes, living the same simple life as the natives, and felt in the end that I would be quite happy to spend the rest of my days in a land of such beauty and interest. 


\section{Chapter Twenty-one}

\section{KENYA (II)}

T HAD been given a free hand to collect whatever I thought 1 suitable for restocking the Zoo and in this I found the people of Kenya helpful beyond words. The press made an appeal on my behalf, the radio station broadcast my requirements, and the military authorities notified the troops that I was prepared to accept any pet animals, either as gifts or by purchase: this latter after an order had appeared stating that they would not be allowed to take their pets home. From this source I procured a cheetah and four Ring-tailed Lemurs that had been brought back from Madagascar. Settlers responded by presenting me with all sorts of things from Bush Babies and Tree Hyraxes to a buffalo and an eland.

The greatest difficulty was the construction of the necessary traveling crates, as materials such as nails, hinges, screws, etc., were in short supply and obtainable only by permit.

Much of the cage construction was guesswork, as I had often to visualize the size of certain animals by their owner's brief or vague description. This was of little import in the case of small mammals, but when a letter arrived asking if I would care to accept a cow eland, a lot of head-scratching took place before I had finished designing a suitable crate.

The settler in question solved the problem of transporting this crate from his nearest station to the farm and back, a distance of twelve miles each way, by driving the eland to the station and crating it there. This will give an idea of the tameness of the animal, and was in fact typical of most of the creatures in my collection, as they had nearly all been hand-reared. 
One of the best gifts was from the Yellow Fever Research Station at Entebbe, Uganda, owner of a collection of rare monkeys it no longer required. These had been collected over a wide area and were a valuable acquisition.

The full list of presentations by a number of people gives an indication of the generous response to my appeal: one wart-hog, one eland, one buffalo, one bush pig, one leopard, one cheetah, one black serval, one Brown Lemur, two Thick-tailed Galagos, one Sacred Baboon, one East African Olive Baboon, two Johnston's Vervet Monkeys, one Abyssinian Vervet, one Uganda Vervet, one Lonnberg's Monkey, one Stuhlmann's Monkey, three Uganda White-nosed Monkeys, two L'Hoest's Monkeys, two Crawshay's Tree Hyraxes, three puff adders, one Andrew Smith's Green Mamba, one boomslang and four Sharp-snouted Snakes.

The rest of the collection, which was purchased, was made up as follows: one elephant (Dicksi), one Baringo Giraffe (Girlie), one wart-hog, one oryx, one Thompson's Gazelle, one Hinde's Duiker, one steinbok, one lion (Straw), three leopards, one cheetah, two impala, one genet, one ditto (black), four Ringtailed Lemurs, two Thick-tailed Galagos, two Augur Buzzards, one puff adder and one python.

There were quite a few characters among this lot, the most notable being Straw the lion, Dicksi the elephant, Bully the buffalo, and Tommy the Thompson's Gazelle. Strangely enough the last was the first of its kind to reach the London Zoo, although it is the commonest gazelle in East Africa.

Straw had spent most of his life running around the house and estate of his owner, the late Cleland Scott, who was famed for his fearlessness with lions; but Straw was now too big-not for Scott but for his visitors. I must say that my introduction to the animal was exciting in the extreme. At that moment, I am thankful to say, he was not sharing the settee with visitors, but was shut up in an enclosure. Cleland Scott took me to this, and to show me how docile a full-grown lion can be, he entered. Straw was delighted, so much so that he bounded on Scott and knocked him flat on his back, which I understood afterwards was a customary form of greeting. I began to get a little apprehensive when Straw sat lengthwise on his owner's prostrate body and chewed playfully 
at his head, Scott meanwhile trying to push the animal off without success. After a few moments of this horse-play, which looked most frightening to me, I saw blood trickling from his head. I feared I was witnessing a man being actually eaten alive, and looked round quickly to see what I could grab to stave the maneater off. Luckily Straw decided at that moment that the greeting had lasted long enough, and suddenly jumped up, allowing Scott to get to his feet. To my utter astonishment he merely smacked Straw on the rump to show that there was no ill-feeling, and held out a hand that was bleeding, which Straw licked. He then walked calmly out as if nothing had happened. Subsequently Straw did the same thing again when no one was present, and sat on Scott for so long that some of his ribs caved in and he had to go to the hospital.

Such incidents as this never intimidated him in the slightest degree. On a subsequent trip when one of his lions was brought to Nairobi station to link up with the rest of the menagerie, I noticed a nail protruding inside the crate, and without hesitation Scott got a hammer and slid into the crate while I lifted the sliding door. As he lay on his back bashing at the nail above him, the lion licked his face and sat on him, but otherwise took it all as a matter of course.

Dicksi the elephant, then aged five years, had come into the hands of Major Sharpe of Ngobit as a baby and was brought up as one of the family. Major Sharpe is renowned as a landscape gardener and his home near Thomson's Falls is a delight. What was formerly swamp and bush has been converted into a gardener's dreamland with a large pond, trickling streams and rustic bridges, in a setting of the most beautiful aquatic plants. How Dicksi fitted into all this I cannot imagine, for Sharpe loved his garden, and was no less devoted to his pet.

Sharpe's stories about Dicksi's upbringing are delightful, one of the most amusing concerning an occasion when someone wagered Sharpe that he could not entice Dicksi upstairs to his bedroom.

This he did easily enough, but the prospect of returning down a steep stairway did not appeal to Dicksi in the slightest. Elephants were hardly constructed for this purpose anyway. She lost her nerve after trying unsuccessfully to get through the bedroom 
window, and with the result that she relieved herself in every way possible. As she became more and more upset at efforts to get her downstairs, she made more and bigger deposits in the bedroom, until Sharpe wondered if there was any limit to what an elephant can hold.

Finally she was enticed down the first step by her owner offering her some special dish, which was an opportunity for the helpers behind to give a shove; this resulted in an avalanche of flesh down the staircase with Sharpe and Dicksi finishing up together in a heap-fortunately with no bones broken.

Dicksi was always a lovable character and was particularly gentle with children, whom she carried around without protest. The ever-increasing problem of giving a rapidly growing elephant the freedom of the house and grounds must have been disquieting at times, although the attachment one can have for such an animal will often over-ride other considerations. It must have been with mixed feelings that Major Sharpe had to say farewell to his beloved pet, but presumably he realized that there must come a time when the elephant, like the lion, is out of place in the home if one is to lead a normal life.

Dicksi was transferred to Gilbert Sauvage's farm near Nairobi, accompanied by the boy who had tended her almost since birth. Here she was allowed to wander at large but always with the boy in close attendance. Most of my collection was kept here pending such time as I could arrange for a suitable boat to carry it home. Sauvage himself was an animal trapper and supplied me with Girlie, the Baringo Giraffe, the first to reach England after the war and now a proud mother at Whipsnade Park.

The black serval-a melanistic variety of the common servalwas a fine-looking beast that showed no signs of being friendly. He came from the western end of the Mau Escarpment, which has a greater rainfall than the rest of Kenya. Altitude and humidity appear to be conducive to melanism, for here it is common among the genets and galagos. For some distance around Sotik the Kikuyu Galago is represented by a black variety to the total exclusion of the typical form which occurs in the neighboring country at a lower and drier altitude.

One day an emissary from the Kabaka, King of the Buganda, 
arrived from Uganda bearing a tame leopard named "Sandy." He was a lovely beast and allowed me to take him for walks, though he regarded my feet as something to pounce on and maul. On Sauvage's farm his chain was attached to a long length of fencing wire with a ring free to run along it, and so Sandy was able to sprint with unexpected suddenness from his kennela privilege he took advantage of to catch most of Sauvage's unsuspecting fowls when they came within range.

When the time came to entrain the whole collection at Nairobi station thousands of natives assembled in the goods yard jabbering excitedly as they clambered over trucks to get a close-up view of all the animals. I had already enlisted the aid of the police, but even they were helpless to cope with such a crowd. It was fortunate that Major Sharpe had agreed that his elephant boy should accompany me to the coast, for his presence did a lot to pacify Dicksi.

As the tugs pulled the City of Calcutta from the quayside at Mombasa, the elephant boy burst into tears as he saw his "baby" slowly slipping forever from his sight. The two had formed a deep attachment and had been constant companions for five years. Dicksi was no less affected by the parting and I realized that an effort must be made to befriend her or she would fret and refuse to eat.

That night as we steamed up the coast of East Africa my legs were so tired that I could hardly stand. Only those who have experienced the work and anxiety of transporting a large collection of animals by rail, shipping them and stowing them to the best advantage, getting tons of foodstuffs, from frozen meats to bananas and sugar cane, suitably stored, and meanwhile feeding and watering everything, can begin to realize what it all means. I had remained up all night on the way to the coast and had been on the go non-stop since 5 A.M. the previous day, but Dicksi had to be comforted, so I stood by her for hours far into the night, talking softly to her and stroking her head until the shock of leaving land and her guardian had to some extent worn off. It was I A.M. when I retired but I was back again at 5:30 A.M., talking to and patting Dicksi at intervals while feeding the other animals. This perseverance and sympathy had its reward, for 
Dicksi was a most sensitive and responsive creature. In a few days she formed an attachment for me which was almost pathetic. As long as I was in sight she was happy but when I left the deck to go for a meal she became boisterously restless and tried to get out of her crate to follow me, and when I returned she always greeted me with tremendous trumpetings. After a while she realized that even I needed food and sleep and could not remain on deck every minute of the day, and so she became less fretful. Quite a lot of my time was taken up in chopping up the young sugar-cane stalks of which three tons had been shipped, but only a little could be given at a time as she refused to eat a quantity of any one thing. This meant tempting her with a variety of things such as maize, bread, apples, carrots, potatoes, cabbages, hay, which had to be done very sparingly to avoid wastage.

Bully the buffalo presented no great problem except when I tried to muck him out. This he took as a signal for a game. The rake or fork, or whatever I was using, would be frivolously tossed into the air if he could get his horns to it, and so frisky was he that I feel sure he would have delighted in tossing me overboard -all in good fun, of course. Bully was really the tamest creature imaginable, but he was always seeking an outlet for his high spirits.

The City of Calcutta was a fast cargo ship with a speed of seventeen knots, which meant that we should be home considerably quicker than if I had caught the fastest passenger boat. The only snag was that we were bound for Liverpool, which meant probably a cold passage through the Irish Sea, and all the trouble, delay, and expense of getting the collection by rail to London.

At Aden I cabled the London Zoo asking if, in view of valuable cargo and risk involved by going to Liverpool so late in the season, it would be possible to get the boat diverted to a southern port. This caused much mirth among the officers, most of whom hailed from London. At that time ships were still under war-time control and could be diverted to any port, wherever the cargo was most needed. At Port Said it was my turn to smile, for the captain received orders to proceed to the Port of London. At that time, thanks to Dr. Vevers, the Zoo had many loyal friends.

We arrived at Port Said at the beginning of the migratory sea- 
son and so the common quail was on offer by the hundred. These were kept alive in shallow crates and were sold at nine shillings a dozen. After crossing the Mediterranean Sea the quail arrive on the sandy Egyptian coastline exhausted. For a while they have little energy for flight, so run inland seeking cover and food. It was then that thousands of quail found themselves trapped under cunningly placed nets, and the annual slaughter used to be terrific, though it has to some extent been brought under control in recent years.

I bought three dozen of these quail-giving them one by one, freshly killed, to the smaller carnivores, i.e., servals, genets, and the caracal. After feeding exclusively for some weeks on beef this came as a welcome change of food for these creatures, for fresh blood, bones, and entrails all play an important part in maintaining them in perfect condition. In most cases the entire quail was eaten, even legs, beak and feathers, the consumption of the last indicating how necessary it is for the smaller carnivores to have roughage in the way of fur or feather.

We passed Cape Finisterre and entered the Bay of Biscay, the City of Calcutta cutting along like a destroyer, but speed has its snags. In a few minutes we ran into a swell running from the forward starboard side. Being fully laden with cargo we were low in the water and I sensed trouble when the head wind, combined with our speed and the swell, whipped some spray over the starboard side of the after well-deck where all the animals were quartered. Suddenly a big wave crashed over the crates on that side of the ship followed by a bigger one which flooded the whole deck to the depth of a foot, and smashed one of the cheetah crates. I grabbed the animal and got him clear and sent a message to the bridge to ask the captain if he would alter course while the crew shifted the animals on the starboard side to safety on the hatches. There were four leopards and Straw the lion here, and the former were definitely upset at all this commotion, but Straw remained as complacent as a sphinx while sea water crashed on deck and flooded his cage. It was fortunate that the trouble was not on the port side where Dicksi and Girlie were quartered, as their crates could never have been man-handled. 
It was a great moment when we arrived at the London docks, for there on the quayside stood Dr. Vevers and his wife whom I had not seen since r939-over six years previously-when I said good-by on leaving for an anticipated four months' trip to Madagascar.

There was quite a procession as the animals were driven through the East End in lorries and low-loaders. There had been no elephants in London during the war, so that London children up to eight years old or more had not seen one or could not remember seeing one. Thus the look of astonishment on children's faces was grand to behold as the low-loader passed and they saw Dicksi waving her trunk out of the back. I was following close behind Dicksi in a car and so heard most of the comments. When I heard the first of these-_Blimey, helephant!" as a small boy pointed excitedly-I knew without doubt what part of the world I was in.

About two months after my arrival the Crawshay's Tree Hyraxes produced an infant, which was an interesting event. The pair had been presented to me by Captain Ritchie of Nairobi, who had kept them for some years at liberty in his house. They had perfect freedom to wander at will but chose to live in a loft, from where they made excursions for food in the way of leaves, and to sunbathe.

I saw the baby a few hours after it was born and it was then seven inches long, that is, about half the length of its mother. It was even then almost as agile as its parents and had well-developed lower incisors.

The hyrax is remarkable for its long gestation period-about two hundred and twenty-five days-and appears to have no rival of similar size in this respect. It is about the same period as that of the hippopotamus. This represents an extreme in nature, for here the young one is born in such an advanced state of development that it can flee from danger and look after itself almost from birth. The other extreme is found in the non-placental animals - the marsupials - where, if we take an animal of similar size to the hyrax, such as the Virginian Opossum, the gestation period is from eight to thirteen days. As in all marsupials, the young in 
this case are born in an embryonic state of development and mature in the mother's pouch.

In October 1945, soon after my arrival from Kenya, the Council of the Zoological Society appointed me as Curator-Collector, and I thereby became the first official collector in the history of the London Zoo.

It was decided to send me back to Kenya to get an even bigger load of animals, so I returned in the winter of $1945-46$.

Traveling out in the appallingly overcrowded conditions that prevailed generally in the immediate post-war years, I thought that Mombasa Harbor looked more beautiful than ever before, probably because it heralded the opportunity of spreading out and getting away from sweaty humanity.

My light luggage I took with me to Nairobi, but the heavy stuff, including collapsible cages, tools, cage-fronts, nets, camping equipment, and a bicycle, I put in the hands of an agent to forward immediately by goods train. It was all in the customs shed and quite safe, so I thought. A couple of weeks passed and no word of my baggage, so I telegraphed the agent. His reply was to the effect that he had not seen the luggage since I left, and had presumed that I had changed my mind and taken it with me. Inquiries were then made through the Port authorities, and after I had raised heaven and earth the baggage was traced to Durban! Although every piece had my name and Nairobi stencilled on it in large print, some clerk had put it on a boat to Durban by mistake. The outcome was that I got my precious belongings over six weeks late.

The bicycle was to replace one that I had borrowed on the previous trip and which had been stolen. At this time some of the town-dwelling Africans had developed a highly organized racket in this line. Being fully conscious of this, I stood my bicycle against the curb right in front of a refreshment-bar, and while sipping my morning tea I took good care to keep my eye on the bicycle. But in came a friend who slapped me on the back and asked me a few questions. Less than a minute later I looked round to see if there was any suspicious character eying my bicycle, but to my astonishment it was gone-clean out of sight. 
House burglary is another thing that the civilized African takes to like a duck to water, though his unenlightened brother in the bush is singularly lacking in such practices. During all the years spent among uncivilized natives I had never had anything stolen in spite of the fact that I never took special precautions.

Much had to be organized on this trip if I was to accomplish all I had set out to do in the course of a few months. Motor transport was essential to cover the territory necessary to obtain the large variety of animals I had in mind, and as nothing in the way of a vehicle was on sale through normal channels so soon after the war, I approached the military authorities whom I had met in the Madagascar campaign. They were most helpful and allowed me to purchase a one-ton lorry from the army dump just outside Nairobi.

I started off for the high country in the vicinity of Lake Victoria, passing through Naivasha on the way, and made Sotik my objective, where a settler friend had offered to put me up.

On his farm were the Black Galagos mentioned in a previous chapter, and he managed to collect three on my behalf. The neighboring bush was also a haunt of the Uganda Crested Guineafowl-a beautiful species distinguished from the one from Mount Kenya by its ring of plain black feathers round the base of the neck, the latter having this area spotted with bluish-white spots as on the rest of the body. My friend was able to provide me with a few of these and so I was fortunate in being able to take home both species of this delightful bird.

They need plenty of space if they are to be induced to breed in captivity. The Uganda species was kept in an aviary at Whipsnade for some time with no signs of mating, but during a subsequent season they were given complete freedom and went to nest almost immediately.

On my way back from Sotik I made for Kaptagat near Eldoret at an altitude of over eight thousand feet. At such heights in Kenya the Pyrethrum Daisy, the roots of which furnish the pyrethrum of commerce, flourishes, and is a crop favored by many highland settlers. Here Mrs. Zoe Foster was running a school in ideal surroundings for children; a great lover of animals, she had a baby chimp that seemed to be part of the class. When I 
saw him one day he was sitting on the floor with some small children during lessons and was taking tremendous interest in a picture-book, carefully turning over the pages one by one. There was only one discrepancy-the book was upside down; but this didn't worry the chimp!

Her two most delightful pets, I think, were a pair of Colobus Monkeys which were strikingly handsome and well-behaved. The male was kept on a long chain for most of the day, but the female was allowed full liberty, though she never roamed far from her consort. Photographing them was very easy; Mrs. Foster had only to appear with a bunch of roses for them to come and sit in front of her in patient anticipation. Rose petals were in fact their favorite food, and as these grew profusely in this highland atmosphere, they were given large quantities daily of the blooms about to fall.

The female colobus had a highly developed maternal instinct and would adopt not only babies of her own kind but would nurse such things as puppies with great affection. Unfortunately, the latter are strictly terrestrial animals and are not adapted for clinging to their mothers or foster-parents, so when the colobus bounded up a tree with a puppy there was a great danger that she would release her grip, expecting it to cling to her in true monkey fashion. There was a great commotion on these occasions, for as soon as it was noticed that a puppy had disappeared and was being nursed in a tree-top, all and sundry would dash to the spot and wait underneath ready to catch the baby lest it should fall before the colobus could be enticed to earth.

From here I took the road back to Nakuru, then to Thomson's Falls and across to Nanyuki at the base of Mount Kenya.

Here I stayed a few days on Raymond Hook's farm, which I found amusing, to say the least, as he likes variety and, in fact, dabbles in everything from jungle fowl and polecats to Coypu Rats and Karakul Sheep.

The highland air and magnificent views of the snow-capped peak of Mount Kenya make this a delightful spot, but I had little time to admire scenery. My main interest here was birds. No more beautiful sight could be imagined than the male Delamere's Giant Whydahs that could be seen flitting lazily over the grass- 
land, their enormous tails trailing behind them and slowing up their flight to a pronounced degree. Although having a head and body length of only four inches, the male in the breeding season develops a tail some twenty inches long. He is mainly black, but in flight reveals his shoulder patches of scarlet, buffy-white, and buff.

Nanyuki is on the edge of the dry thorn-bush country and is rich in birds that like these conditions. It is always bewildering to the uninitiated to see birds by the thousand in some semidesert locality after finding them comparatively scarce in the
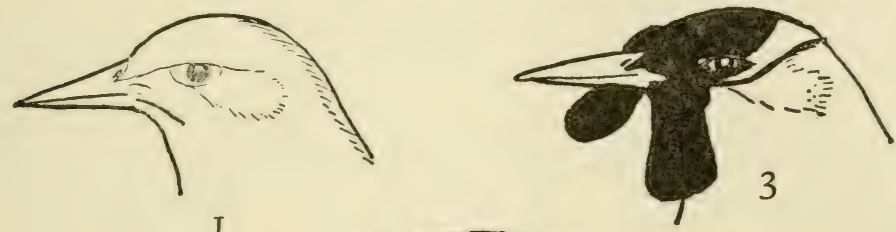

I

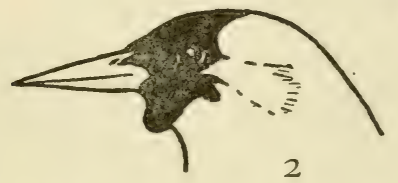

Seasonal Plumage Changes in the Wattled Starling

(I) normal; (2) intermediate;

(3) breeding head-dress showing wattles and bare skin (Drawing by W.C. Osman Hill, M.D., F.R.S.E.)

tropical forests. Both the Superb and the Wattled Starlings were common at the time of my visit. These spend more of their time on the ground than the Glossy Starlings and were much in evidence in a nearby cattle kraal stealing food from the troughs.

The male Wattled Starling has a unique seasonal change of head-dress. In the dry season, which corresponds with the nonbreeding season, he is hardly distinguishable from the female, having his head feathered in the normal way with no sign of any wattles. In the reverse season the top of the head in the adult male becomes quite bare, the skin of this part then turning yellow. At the same time the head- and chin-wattles, which are black, commence to sprout, the former eventually hanging down in the form of a lappet on one side of the bill, while the chin-wattle 
extends to the base of the throat. After about six months of this curious ornamentation the wattles slowly atrophy and the male then resumes the normal head-dress as worn permanently by the female, and by the young male for the first few years of his life.

A certain amount of mystery surrounds the nesting habits of Wattled Starlings. In South-West Africa they have been found nesting in thousands, with each thorn-bush packed with nests, and all in a restricted area where locusts were hatching. As the latter cover the ground in millions and provide excellent food for young birds it seems that the association is by design and not mere coincidence, especially as similar independent observations have been made in Kenya.

When the locust hoppers reach the flying stage the swarm is followed by flocks of Wattled Starlings, and as the locusts are attracted by greenery in the way of growing crops on farms, it is then that the starlings are much in evidence, and why they are known in many localities as "locust-birds." It has been recorded that breeding colonies of Wattled Starlings sometimes suffer disaster when the locust swarm, on which they are dependent, takes flight before the young birds are reared. In spite of all efforts by the parents, masses of young birds then perish through starvation.

It seems that locust-control measures, now in force in most parts of Africa where there is European settlement, have greatly affected the distribution of the Wattled Starling. Formerly it was plentiful over large areas (such as Rhodesia) where it is now seldom seen.

Although the Wattled Starling has a wide distribution-Aden, and from Abyssinia through East Africa to the Cape-it is not generally a well-known bird. Over large tracts of country it is scarce or absent. Dry regions are its favorite abode, and so it is most numerous in South-West Africa and northern Kenya, though, strangely enough, it has not spread westward through the vast semi-arid zone immediately south of the Sahara.

The dry zone north of Mount Kenya is interesting not only for its varied bird-life but for the many mammals which have adapted themselves to arid conditions. Most notable in the way of antelopes is the Lesser Kudu and the gerenuk, or Giraffe-necked 
$4 \frac{4}{20}$

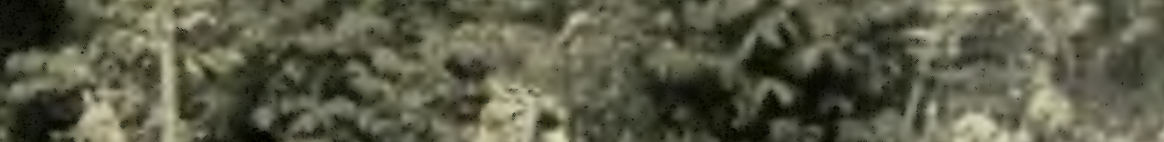

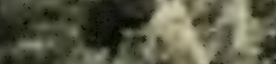

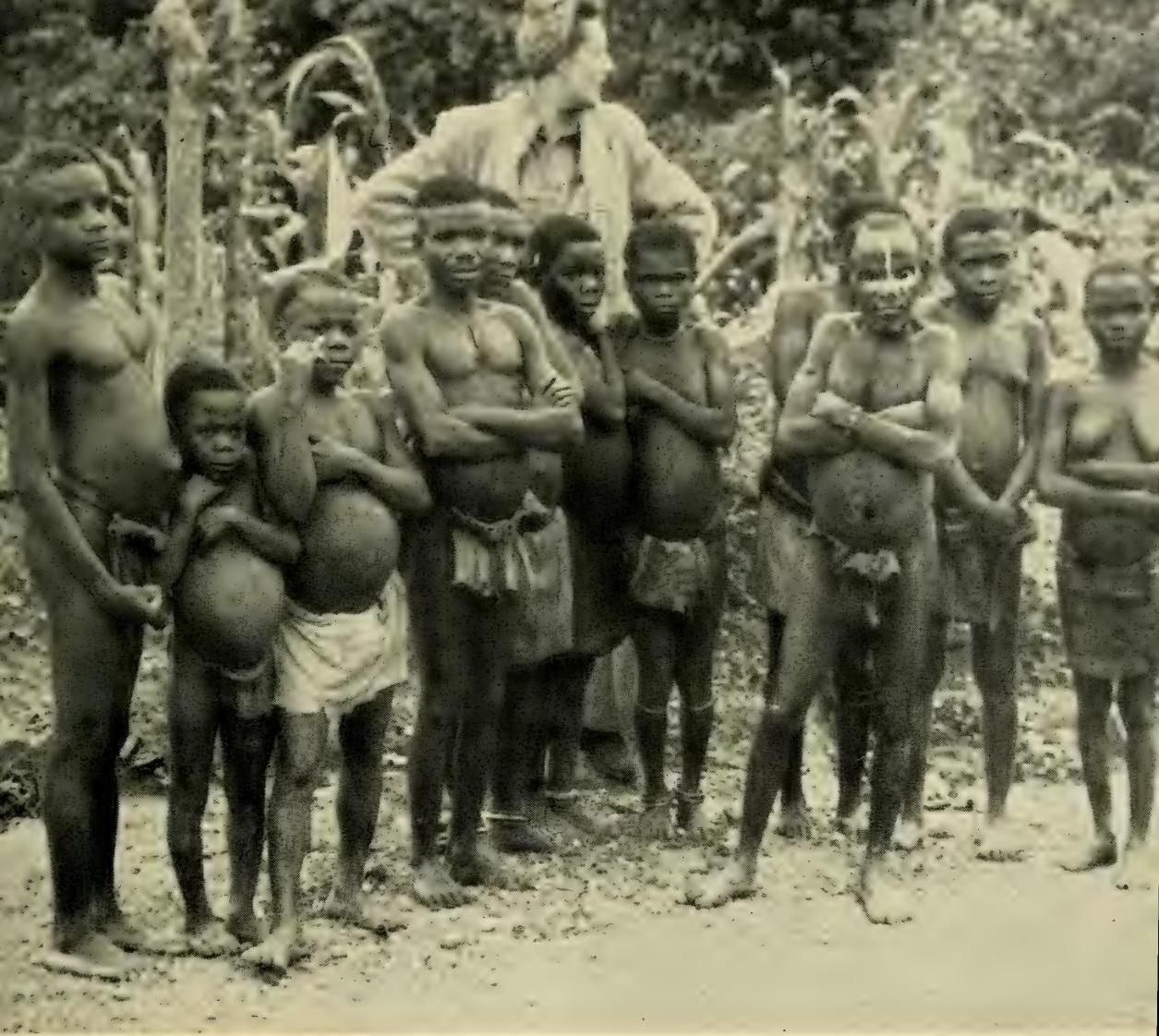

1.

S 


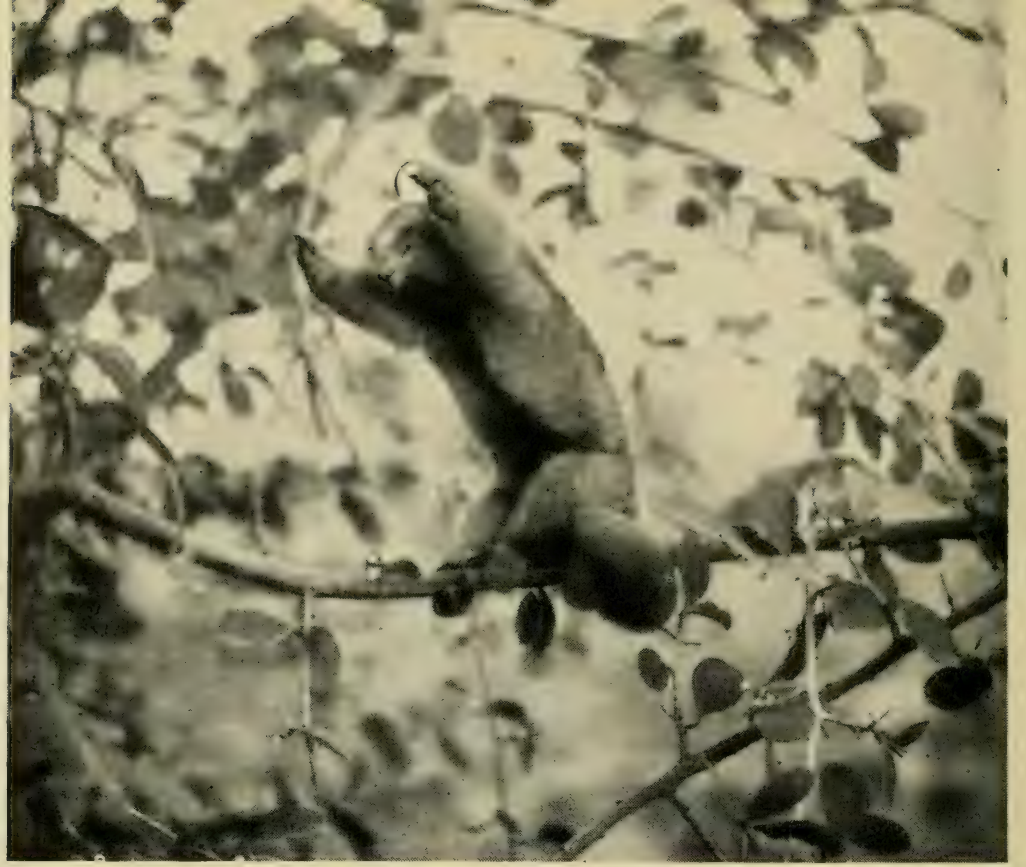

C. S. Webb

Pygmy Anteater in defensive attitude

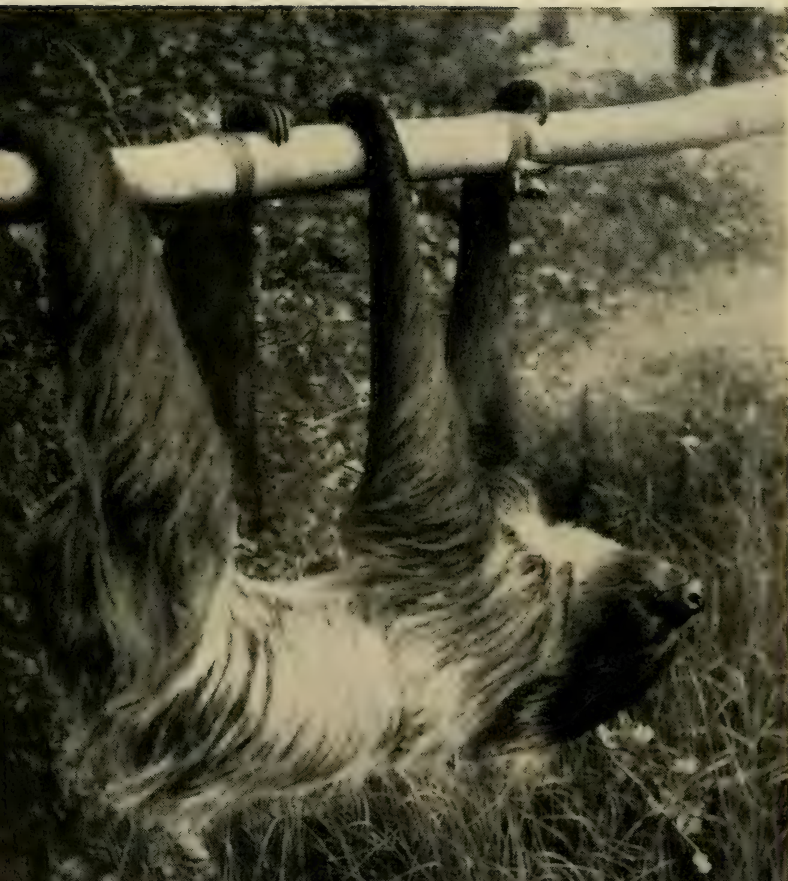

Two-toed Sloth in normal walking position 


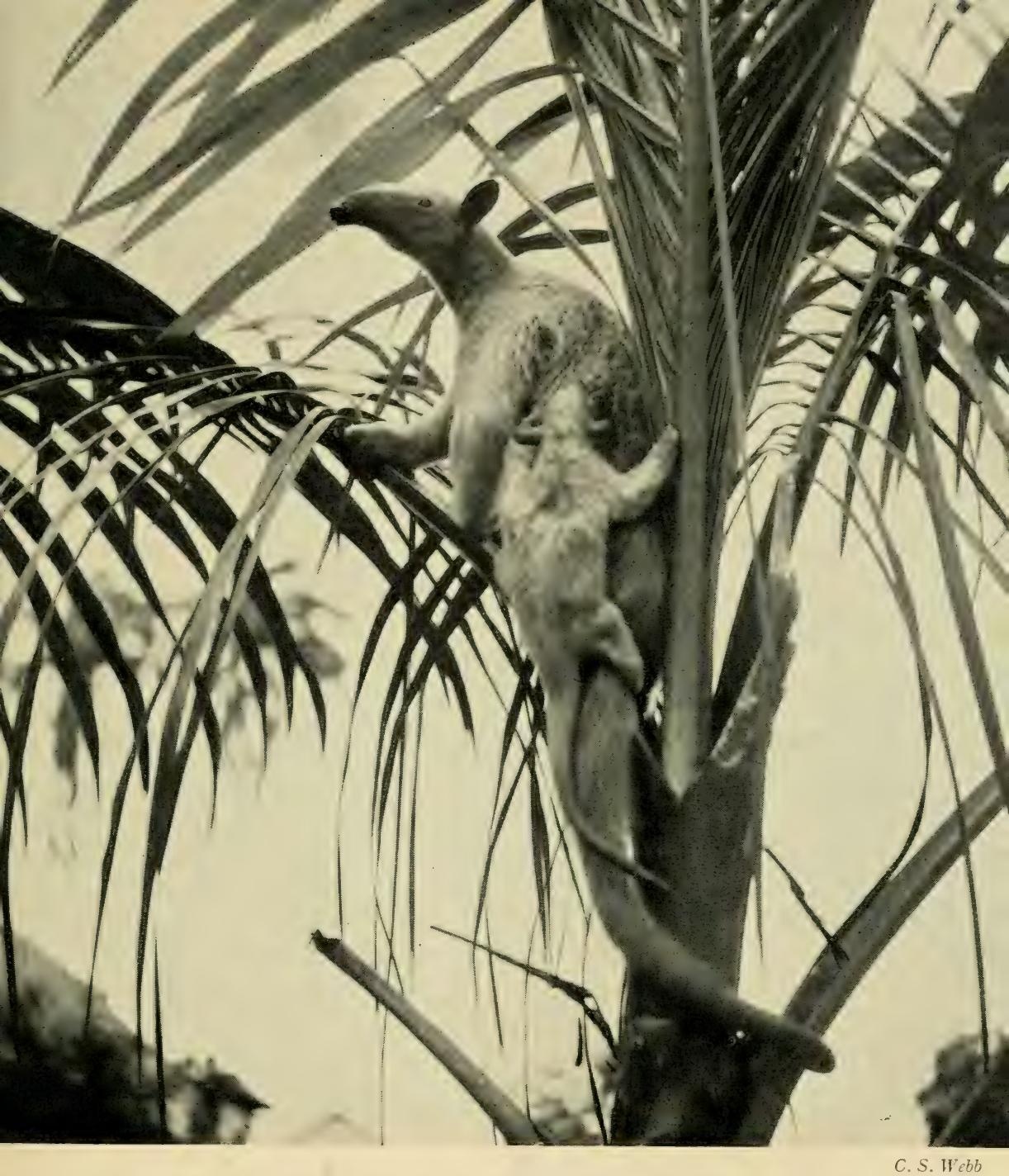

Tamandua Anteater and young, British Guiana 
$127.25 \%$

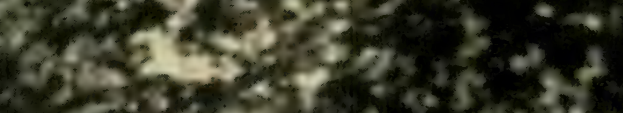

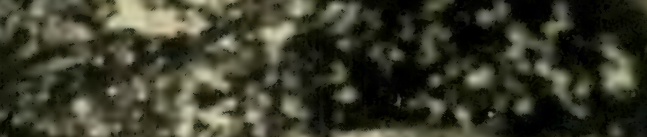

W $x$ 2
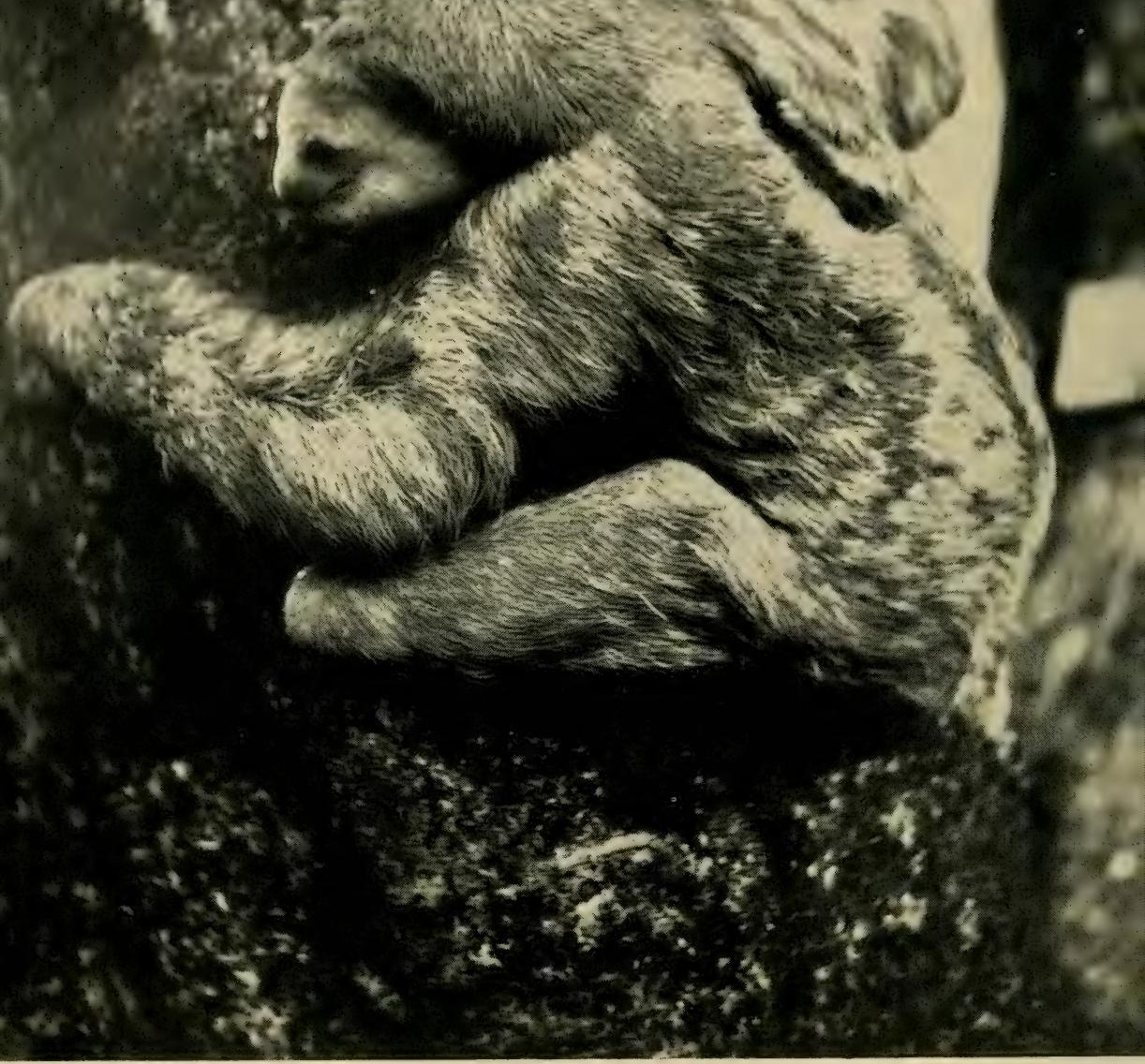

C. S. IVebb

Three-toed Sloth, British Guiana 
Antelope. A beautiful young male Lesser Kudu named "Toto" was presented to me by Mr. Gribble, a police officer at Isiolo. It had an interesting history.

It appears that in the course of police patrol somewhere in the Northern District, a tribesman offered a newly caught baby Lesser Kudu to the officer in charge. He took pity on the beautiful little creature, but the problem arose how to feed it as no such thing as a feeding-bottle was obtainable in this sparsely inhabited semidesert area. However, one of the party had a football, and it shows the resourcefulness of some humans in that this was the means of saving the little animal's life and getting it safely to headquarters. The football bladder was taken from its cover, a piece cut out of the bottom, and the bladder filled with diluted tinned milk. The mouth-piece was then employed as a teat, and Toto was thus nourished during his long lorry ride through the dry thorn-scrub.

The gerenuk, like the giraffe, is an example of adaptation to a special mode of life. It is a browser and benefits considerably by its elongated neck when reaching up to tear off its favorite acacia leaves. This is nearly always done while the animal is poised on its hind legs, bolt upright, with the front feet resting gently on some flimsy branches to give support.

The northern dry country is the home of Grevy's Zebra and the Reticulated Giraffe. This zebra is a much sturdier and hardier animal than the more common and widely distributed Burchell's Zebra and can be easily distinguished by its more numerous body stripes, there being about sixteen stripes on the flanks compared with less than half this number in the Burchell's. A further difference in the Grevy's is the striping of the legs down to the hooves. This zebra in turn can be distinguished from the Mountain Zebra by its white buttocks, the latter having a gridiron pattern of transverse stripes in this part.

Grevy's Zebra crosses readily with horses, the offspring being beautiful creatures. Raymond Hook crossed a Grevy's stallion with an Arab mare and the foal followed very closely the mother's form even to the mane; but the stripes, though less pronounced, were more numerous than in the sire.

Up to this time the London Zoo had never had a specimen of the Reticulated Giraffe, though it is by far the most attractively 
marked of the many so-called races of the common giraffe. As its name implies, this animal has network-like markings, these being of white on a darker background, whereas the others in varying degrees have the yellowish ground-coloring broader, thus giving the whole more of a blotched effect. The Reticulated Giraffe is regarded by systematists as a distinct species, with all other giraffes races of another species. The validity of this seems doubtful in view of the fact that there is no natural barrier or dividing line between the Reticulated Giraffe and races of the other species, such as Cotton's Giraffe and the Baringo Giraffe, that come nearest to it, and undoubtedly the two so-called species intergrade.

On my visit to Nanyuki I had the amusing experience of taking part in the attempted capture of some of the reticulated variety. My host had built a stockade in thorn-bush country where a small herd was in the habit of browsing. On the day in question a number of natives on horseback rounded up the herd, and as we saw the party heading towards us galloping all out, while we sat watching from the lower slopes of a kopje, it was as thrilling to me as any Grand National. As the troop stampeded past, followed closely by the horsemen, we took up the chase in Hook's rather ramshackle utility car in order to assist in heading off the herd in the right direction, and to get them between the converging "wings" leading to the stockade. This was managed all right, and then came the final spurt to make sure the animals had no time to hesitate about going through the gate. This final phase was tense and, to me, somewhat painful, for my host let the old bus go all out, crashing between thorn-bushes, over pot-holes and ant-heaps, until I thought that some of my ribs must be broken. The leading bull was only twenty yards from the stockade gate when he broke through the wings, constructed of thorn-bush branches piled to a height of seven to ten feet, and the rest followed through the gap and got away. This was the disappointing end to a long and exciting chase.

A more up-to-date method of capturing giraffes is to drive the herd into fairly open country, then single out the one required and give chase in a high-powered light lorry. By this method the animal can be overtaken quickly, and it then comes to a standstill and can be easily lassoed. In the old method of rounding up 
giraffes on horseback the chase is often much too long and in consequence permanent damage may be done to the giraffes' hearts.

The transportation of giraffes by rail presents a problem in Kenya because of the lowness of the bridges. For this reason capture is limited to animals of from seven to a maximum of eleven feet. It is surprising how quickly these creatures become tame, and once they lose their fear of humans show none of the nervous panicky mannerisms of some of the antelopes.

Giraffes, in spite of their great height, cover a very small floor space, and so a crate seven feet square allows plenty of room for moving freely around, which it should be able to do. It is a great mistake to box them like horses with no room to turn round; for one thing they need to be able to splay their legs in a rough sea to balance their great height. It is amusing to watch a giraffe when a boat has a heavy roll, for actually it remains bolt upright, usually chewing the cud with a rather supercilious look on its face, while the boat sways violently from side to side. To aid the giraffe in this balancing act the bedding must be kept very deep in the box so that the animal can get a firm purchase with its feet. A plain wooden floor in a rough sea can be very dangerous, for on it a giraffe will slip and injure itself.

Among other things I acquired here were three Ground Hornbills. These are large grotesque-looking birds with rather long legs and small feet and have a peculiar way of walking on their toes, giving the impression of a woman in high-heeled shoes that are too tight for her. To add to their bizarre appearance there are naked folds of red skin on the throat. Ground Hornbills are highly intelligent and amusing, but the feature that attracts most attention is their long upsweeping eyelashes, which are the envy of all beauty-conscious damsels.

The largest of these three specimens-the only adult-must have been really hungry when he arrived in my hands, for he devoured in quick succession six full-grown rats that had been killed in a nearby shed. These he swallowed whole, though the larger rats certainly took a lot of gulping before finally disappearing, tail last.

From Nanyuki I made the journey round the north side of the mountain to the eastern slopes and the town of Meru. Here I met 
the late Colonel Abbay, who was running the local hotel. He was a great sport and went right out of his way to help me and in all was instrumental in getting me three East African Bare-throated Francolins, one Vulturine Guinea-fowl, six Kenya Crested Guineafowl, three Kenya Crested Porcupines, and a number of Jackson's Chameleons-all of which he presented.

He had most of these on hand when I arrived, and I was particularly struck with the porcupines, which all had black-and-red quills instead of the usual black-and-white. It is known that around Isiolo, in the dry country, all the porcupines have this peculiarity, and Colonel Abbay made a special effort to get some for me. The red in the quills undoubtedly comes about through the animals eating some local plant or root that is rich in a madder-like substance, for when these same porcupines shed their quills in captivity the new ones were of the normal black-andwhite pattern. In the course of time the unshed red quills gradually became lighter in color, and by the time I reached home the three porcupines looked like any normal specimens except for a very few remaining red quills.

The Jackson's Chameleons in the Meru district have particularly long horns and are most striking creatures. As soon as I got back to Nairobi I sent them off by air to the London Zoo and they were all on show in perfect condition two days later.

At first Colonel Abbay had great difficulty in getting the Meru natives to bring in these creatures uninjured, and most of them arrived with broken jawbones. Nearly all tribes fear the chameleon, but can usually be induced to bring them in uninjured on long sticks. However, the Meru have a definite hatred for the animal, due to a legend which blames the chameleon for their backwardness and troubles, and consequently they have an urge to mutilate every one they see.

The legend runs that in the dim past a witch doctor told the Meru people about a lake situated on the slopes of Mount Kenya whose waters were supposed to have magical powers. (It is today a sacred lake.) He said that if the people bathed in these waters they would turn white, but the tribe was so large that there was not enough water for them all to bathe in. Some method had to be devised to decide who should be the fortunate people, and it 
was eventually agreed to split the tribe in two and each should choose a representative, in the form of some animal, to run a race. One side chose a dik-dik because it was a speedy runner and was small enough not to be impeded by thick bush. The other side chose the chameleon, for it was thought that speed might be a handicap and would bring about disaster on the rocky course to the sacred lake and back. However, the speedy dik-dik made it without mishap, so the winning side went to the sacred lake, bathed and all turned white. Then they left their black brethren and migrated northwards and thus became the forerunners of the white race. When the losers visited the lake it was practically dry and there remained only sufficient water to wet the soles of their feet and the palms of their hands, which alone turned white. So the existing Meru people blame the chameleon for their own color and any imaginary troubles that go with it.

Various donors and white hunters had helped to get together a large collection of animals which were distributed over a wide area on various farms.

Cleland Scott, from whom I had previously purchased Straw, now presented me with another lion and two lionesses-all about three-quarters grown-which he called the three Bs, signifying Bewitched, Bothered and Bewildered. The middle name is not as I heard it, but I changed it for the sake of propriety.

Altogether it seemed that the collection was becoming too large for a single person to cope with on the way home. I therefore cabled to the London Zoo for assistance and they responded straight away by sending out Bill Harwood of the Zoo staff.

The collection was probably one of the largest ever shipped on the high seas, and to give the reader some idea of the magnitude of the operation I quote the list in full:

2 chimpanzees

6 Brazza's Monkeys

2 Mt. Elgon Colobus Monkeys

I Stuhlmann's Monkey

r Gelada Baboon

I Ring-tailed Lemur

3 Silvery Galagos (black var.) 3 lions
I leopard

I Caracal Lynx

4 cheetahs

6 Neumann's Genets (2 black var.)

4 Egyptian Mongooses

6 White-tailed Mongooses

3 Black-tailed Mongooses 
I Marsh Mongoose

I Spotted Hyena

2 Black-backed Jackals

5 Bat-eared Foxes

2 Kenya Ground Squirrels

3 Kenya Crested Porcupines

I Crested Bush Rat

2 Rock Hyraxes

I Grevy's Zebra

I Black Rhinoceros

I Cape Buffalo

I duiker

3 Kenya Oribi
I Northern or Defassa Waterbuck

I Impala Antelope

I Thompson's Gazelle

3 Lord Delamere's Bush Bucks

I Lesser Kudu

2 Baringo Giraffes

I Cotton's Giraffe

3 Reticulated Giraffes

2 Kenya Bush Pigs

I wart-hog

3 antbears
2 Masai Ostriches

3 East African Bare-throated Francolins

2 Vulturine Guinea-fowl

2 Uganda Crested Guinea-fowl

6 Kenya Crested Guinea-fowl

I2 Common Quail

2 Gray-necked Crowned Cranes

2 Secretary Birds

I kestrel

I Woodford's Owl

2 Black Crakes

2 Striated Colies

4 Ground Hornbills

8 Superb Glossy Starlings

7 Green Glossy Starlings

II Amethyst Starlings

2 Wattled Starlings

\section{African pythons}

Finding a ship to transport the animals home was now becoming a race against time, as with everything on the open deck I had to arrive in England by the autumn if I was to avoid losses through cold. Things came to such a pass that there was only one boat with sufficient space that could get me home before the 
winter, and that was the S.S. Urlana. The captain of this slowgoing cargo boat was enjoying the tranquillity of the Indian Ocean when he received a wireless communication from the agents asking him if he could accept the above deck-cargo.

He must have been shattered to the core, probably on account of the lions, for he replied that he could not accept such a cargo. Well, a captain is master of his own ship and no one can force him to take cargo of this nature if he is unwilling. If this opportunity failed it meant that I would probably be stranded for six months in Kenya with all the animals. Sensing that the captain's first reaction was one of concern at the responsibility that would be thrust on him if he accepted the animals, I cabled the Zoo to ask the head office to bring pressure to bear on him. At the same time I got the agents to contact him, reassuring him of the tameness of all the animals, and letting him know that he would be relieved of all responsibility as there would be two alleged experts traveling home in charge of the collection to do all the feeding, etc., during the voyage.

By the time all this had taken effect the Urlana had reached Mombasa, and one day when I thought it far too late for anything to happen I unexpectedly received a telegram saying that the captain had decided to accept the consignment.

It was now my turn to be shaken, for there were only four clear days to get everything assembled at Nairobi station. My assistant was up-country, and all the giraffes and other large animals were scattered around Kenya hundreds of miles from Nairobi, being kept by various collectors until such time as I wanted them. Thus I had to send all these people telegrams to crate and deliver the animals immediately. Their difficulties were no less than mine, for they in turn had to get rail-trucks at short notice, and some had to be brought in by lorry.

It happened that I could not take the whole consignment to the coast on one train as it was too large, so it was decided to send the smaller stuff on hand the day before the others, and this went off in charge of Harwood. This arrangement allowed the maximum amount of time for the giraffes to arrive, which they did, but only just in time.

Tons of foodstuffs such as hay, lucerne, maize, bran, ground- 
nuts, fruit, and vegetables had to be arranged for. All except the perishable produce I had taken the precaution of having on hand. But this was at a time when Kenya was experiencing one of its worst droughts and the purchase of most farm produce required a permit. The thousands of pounds of meat necessary had to be ordered well in advance because of the necessity of slowly deepfreezing it before shipment.

Imagine my consternation when I learned just before leaving that the boat was capable of only five knots and that after leaving Mombasa she had to go to the Seychelles Islands to collect a large cargo of copra. These two factors upset all my calculations, and in fact doubled the estimated length of the voyage. One of the greatest problems on a cargo ship is the limited refrigeration space, as this is merely sufficient to keep such perishable foods as are required by the crew. Apart from such items as meat, which must be kept frozen, there is no cool spot for extra fruit, which may all ripen overnight going through the tropics. Another concern, which may worry the captain, is the fresh-water supply. A great deal is required daily for such a consignment, especially when the iron decks become so hot that they have to be hosed down with sea water, for then the animals, like the crew, develop a thirst that is almost unquenchable.

The first half of the collection went off by goods train from Nairobi without a hitch, but to get everything settled-paying bills, making final purchases, juggling with shipping, rail and other documents, and coping with lorry-loads of animals-was something of a nightmare.

I scrambled on to a truck just as the train was moving off. A number of animals had been thrust on me at the last minute, including a young Defassa Waterbuck and a young Delamere's Bush Buck that were still on the bottle and were due for a feed as soon as the train started. I had six giraffes, two Grevy's Zebras, the other larger mammals and all the birds, on this trip, occupying six open trucks, and among these there were certainly some characters. Some of them I was already acquainted with, but others which had been kept far from Nairobi I was now meeting for the first time. One of the former was Twiga the giraffe, caught 
in northeast Uganda when only a day or two old and brought up on the bottle; children had ridden on his back until he became too tall. He was now about three years old and nearly eleven feet high and until he came on this train he had never been in the company of his own kind, except, of course, on the day of his birth. He was so accustomed to human beings that he was inclined to frown on his fellow creatures, and when liberated with his companions in the London Zoo he completely ignored them for a long time. Nature, however, eventually had its way, and Twiga became the proud father of two children at Whipsnade.

Perhaps the most amazing character was a giraffe called Midget, after my own nickname, caught only a fortnight before I left. To look after him and his companions on the train I had to jump from truck to truck and work my way along the edge of them, as each giraffe crate occupied their full width. To do this while carrying a bucket of water or food as the train swayed round sharp bends was no easy task, and with only one hand free I might easily have been flung on to the track.

Midget at this stage was a mixture of hostility and friendliness, or perhaps the latter was merely curiosity. When I was climbing along the side of his crate he several times threatened to kick me off the train, but at night when I was so tired that I lay down on some sacks of corn near Midget and went fast asleep, he woke me up several times by stretching out his long neck and licking my face.

In passing under the lowest of the bridges the engine driver slowed down the train to a snail's pace as Twiga was very near the safety limit in height, and in fact the bridge cleared him only by a few inches.

The ship's captain greeted me by handing me a rifle and ammunition-just in case a lion escaped! But after introducing him to these animals and patting every one in turn, the rifles were put away and forgotten. Everything was finally slung on board and battened down. Truckloads of food were somehow stored away and eventually the zoo ship left Mombasa harbor with a great crowd of onlookers to see us off.

The Urlana was constructed for carrying coal from one Indian 
port to another, a job for which speed was unnecessary, but she was now commissioned under the wartime transport control, and had to proceed where ordered to do so. Her engines were now chugging wearily as we steamed almost due east across the Indian Ocean to the Seychelles Islands about a thousand miles from Mombasa. The only compensation was that it allowed me to see a group of islands I had never seen before and would be unlikely to visit again.

We anchored two miles off Victoria, the port serving Mahé, the principal island of the group. Here we took three thousand tons of copra, or dried coconut, aboard, an operation which extended over eleven days.

The island of Mahé, with its plantations of coconut palms, lovely sandy beaches, and mountainous scenery, is one of the most beautiful places imaginable. However, the wild-life is very poor indeed, and so there was tremendous excitement among the islanders, the children especially, when our boat arrived and they were given an opportunity of seeing our floating zoo and of gazing for the first time in their lives on such things as giraffes, lions, and especially chimpanzees, with their human ways and comic antics. Although, owing to shallow water, we were anchored some way out, numbers of people-including the Governor of the Seychelles-came out to visit us.

While the Governor was on board I had to fulfil an engagement ashore doing a broadcast at the local radio station. This was translated and rebroadcast in the local tongue immediately afterwards for the benefit of the non-English-speaking community. The Seychelles, like Mauritius, are populated largely by Creoles whose language is based on old French, and as I listened to my own broadcast I did not understand a word, although fairly well up in modern French.

Although our visit to the Seychelles meant such a long delay and therefore a lot of extra work and anxiety-as well as extra foodstuffs for the animals-we were more than compensated by the knowledge that our stay had meant so much to these lonely islanders.

We had plenty of time to become familiar with the ways of our 
large and assorted family. Garbo, the tame Bush Pig, was found frequently wandering around the deck, for she soon learned to lift the drop-door with her snout. However, if one swore at her in a really convincing manner she had the good sense to let herself in again.

Jimmy, the baby rhino, was happy in a pig-like fashion as long as he had plenty to eat; Peter, the Gelada Baboon, threatened to murder anyone who came near him, but was fortunately docile with me; the leopard was so full of joie de vivre that he spent most of the day tossing up an old sack I had given him and turning somersaults; Prince, the cheetah, was the essence of dignity and friendliness (he has since appeared in films); the chimps, if nothing else, kept the crew in a good mood; the three Bs were extremely friendly towards the white members of the crew but got really angry if an Indian came near them; but the most fascinating of the whole crowd were, to my mind, the giraffes. They have an irresistible appeal to me, probably on account of their calm camel-like expressions and lovely eyes; in spite of their powerfulness and great height, they are remarkably docile. They are certainly the strong silent men of the animal kingdom, for one kick from a bull would send any lion into the next world.

Often while working on board we were stripped to the waist, and then Midget loved to lick our backs; whenever a member of the crew was working near his crate oblivious of the fact that a head was towering above him, Midget would startle him by lowering his head from the heavens and licking the back of his neck. One might almost suspect a sense of humor here and certainly Midget had ideas never thought of by his companions, but I imagine the real reason for this licking habit was that he had found the skins of humans in the tropics to be moist and to have a delicious salty flavor.

Extra supplies of fruit and meat were taken on at Alexandria and after what seemed an age we reached Gibraltar. On the last lap the Urlana developed engine trouble in the Bay of Biscay and we were lucky to be able to make Falmouth harbor under our own steam. This meant a further delay while spare parts were 
being fitted. Meanwhile, I think every press photographer and reporter in England made for Falmouth, or so it seemed to us. As we finally made our way up Channel to the Thames the chilly October winds howled around the deck, though all the crates had been protected as far as possible by strips of canvas nailed over cracks and ventilation holes. It was indeed a relief when the zoo ship docked at King George V dock in London seven weeks after leaving Mombasa. 


\section{Chapter Twenty-two}

\section{BRITISH GUIANA (II)}

$\mathrm{A}^{\mathrm{S}}$ a result of my expedition to Kenya, the Zoo was by now wild-life from tropical America was poorly represented. With the idea of remedying this defect it was agreed, in February, I947, to send me to British Guiana.

The snowy spell of that season had already lasted three weeks when I boarded the train for Liverpool, consoled by the thought that in less than a fortnight I would be in tropical seas.

Liverpool, no doubt, is the center of the universe to those born and bred there, but to a visitor who has to while away a day when the city is under snow, there is little to recommend the place. So utterly dejected was I by the chill of the arctic wind and by an attack of sciatica, that I visited one of the leading hotels twice within a few hours to take a hot bath in the hope of thawing out.

The small Booker Line boat fought its way for days against a strong southwesterly wind and the Atlantic swell, but one morning we awoke to see calm waters glistening in the sunshine. The contrast was wonderful, and my sciatica disappeared under the magic influence of the sun's rays.

Georgetown, the principal port and capital of British Guiana, had changed but little since my visit seventeen years previously. On the whole, the largely colored population seemed to take life in a leisurely happy-go-lucky manner, though it was noticeable that there was a distinct anti-white attitude on the part of a certain section of the community, fostered largely by the local press, which employed much of its space harping on the color-bar-not in Guiana, but in England. 
A lot has been done for the Colony in the way of providing up-to-date hospitals and schools, in blotting out malaria, and in generally raising the standard of living, but there seems to be little appreciation of the fact that this has been accomplished mainly at the expense of the mother country.

My main task in British Guiana was to collect as great a variety of mammals as possible. Some of these I have described in a previous chapter, so my remarks will be confined mainly to new acquisitions.

The first week or so I spent leisurely in the town contacting various trappers, as a result of which I concluded it would be far more profitable for me to stay in the environs of Georgetown which is the focal point of the large river systems, and thus a convenient center for collecting any live animals brought in from almost any part of the Colony.

It was not long before I was installed on the edge of the town near the Botanical Gardens, in a pension with ample space under the house and in the grounds for my animals. Almost at once the more easily acquired things such as Red Howler Monkeys and capybaras-specimens that obviously had been in captivity for some time-began to arrive.

The Howler Monkey has a most sullen disposition, and in captivity usually looks the picture of misery, frequently roaring hate at the person who attempts to feed it. For this reason, I made it known that I was not interested and that it was therefore waste of time capturing them in the hope that I would be a buyer.

This monkey is most appropriately named, for one male can produce the terrifying noises that one would expect to hear if all the animals in the Ark had been subjected to mass carnage. To make matters worse, they frequently disturb the quiet of the night by their diabolical outbursts, which are quite alarming in their intensity when reverberating through the forest. To accomplish this the Howler possesses a special vocal apparatus in the larynx in the form of a hollow bony sac, and this is more developed in the male. Like the Spider Monkeys and Capuchins, it possesses a prehensile tail which is naked on the under surface of the extremity.

Two Red-faced Spider Monkeys came into my hands, and these 
made most delightful pets. With two other New World monkeys -the Woolly and the Capuchin-the Spider Monkey makes up the trio of the most affectionate and likable of any of the monkey tribe. One of mine, although reputed to be four years old, was brown instead of the usual black when he came into my possession, but he changed to his normal color about a year later when in the London Zoo. This specimen possessed a small thumb, though in the majority of Spider Monkeys this digit is lacking. This animal not only suspends itself by the tail, swinging to and fro by this organ, but often uses it as a hand for culling fruit.

A tame Spider Monkey will follow its owner like a dog, and I have several times seen one accompanying an aboriginal Indian on a fishing expedition in a dugout canoe.

One of my most interesting acquisitions was a Tamandua Anteater. Like the arboreal pangolins of the Old World, this animal provides an example of a perfect adaptation to a particular mode of life.

The Tamandua, whose body is about the size of that of a cat, has a long tapering face, no teeth and a tiny mouth only just large enough to permit the long viscous extensile tongue to carry out its function of mopping up ants that dwell in crevices of trees.

The tail is highly prehensile so that, if necessary, the animal can hang upside down by this organ while engaged in the business of tearing away bark to expose quantities of ants. As an aid in climbing, its feet are furnished with large pads, and its front paws are provided with powerful chisel-like claws. Its long, flexible whip-like tongue twists round any bend when thrust into a crevice, and is protruded and retracted at great speed, the ants being retained in the mouth at each outward thrust.

Rather surprisingly the Tamandua is affectionate, intelligent and playful and quickly becomes tame in captivity. My specimen was a female, and one night she escaped by tunneling through her wooden box, but returned three days later and promptly gave birth to a single baby. The young one was delightful and was carried around on its mother's back from birth, it having great strength in its claws from the beginning.

Later I acquired a male and all three lived happily together, the two adults showing great affection for each other. Often 
I let them out in a garden, where they played together like squirrels.

The Tamandua with its long tapering head is quaint enough, but hardly surpasses the Giant Ant-eater, which is a most formidable creature, being over three feet in height. Its queer form gives the impression that it is a relic of a past age. This animal is terrestrial and therefore has not the same modifications as the Tamandua, but is provided with massive claws which serve as defensive weapons as well as being highly effective for the purpose of digging up ants' nests. As ants are probably its sole diet, it might seem strange that such a large creature can get sufficient to satisfy its hunger, but one has only to witness the masses of ants that swarm out of a broken nest in the soil to realize that the Giant Ant-eater with its long sticky tongue gets its living with the greatest of ease.

The third species of ant-eater in British Guiana-the Pygmyis one of the strangest mammals extant. It is only the size of a red squirrel and, unlike the other ant-eaters, is sluggish and sloth-like in its movements. It has beautiful thick golden-brown fur and will sit motionless with eyes closed and arms raised, with its prehensile tail wrapped round a branch. With this as an extra gripping device, it will often remain poised obliquely or even horizontally looking like a stuffed specimen fixed to a perch.

One's first reaction on seeing the Pygmy Ant-eater is of incredulity. Is it alive or is someone pulling my leg? is a question which crosses the mind. Having gazed for some time at the harmless-looking mummy-like creature before me, I was at last impelled to touch it to make certain that it was really alive. The reaction was like something mechanical. Without opening its eyes, the raised forearm struck, and the large pointed needle-like claw entered my flesh and was then clinched with a powerful lock grip. It was a most painful business getting it free as tremendous force was necessary before the animal would relax its grip.

The Pygmy Ant-eater has only two claws on each forefoot, one being large and prominent and the other small and hardly discernible. It lacks the long tubular muzzle of the other two species of South American ant-eaters-its head being much more rounded. The gape, too, is much wider, suggesting much less specialized 
feeding habits. It probably eats wasp grubs and a variety of other insects in the wild state.

Unlike the two larger species, the Pygmy Ant-eater is very difficult to keep in captivity as it rarely feeds, no matter what it is offered, and soon pines away. This is a pity as it certainly ranks high in the list of nature's oddities. The other ant-eaters thrive in captivity on a diet of minced meat mixed with milk to which may be added a raw egg, and a little grass-meal as roughage.

Guiana possesses two species of the Mustelidae-that is, the family of carnivores that includes weasels and martens, etc. They are the grison and the tayra. The former is endowed with a color scheme unusual in mammals, having the upper parts much lighter than the lower, these being light gray and black respectively. The only other mammal with a similar pattern that comes to mind is the ratel or Honey Badger of Africa and India, which curiously enough belongs to the same family as the grison and has similar habits.

The normal tayra is very marten-like in form and coloration, but in Guiana a cream-colored mutation occurs occasionally. Probably not more than two or three had come to light in this territory in the previous twenty years, so I was fortunate in being presented with one by a settler in the interior. It was the first to be introduced to England alive. Like many other small carnivores, such as civets, palm-civets, genets, ferret-badgers, etc., the tayra is fond of fruit as well as meat.

One of my most amusing pets was a Crab-eating Raccoon that I brought up from the baby stage. It was ruddy-brown in color with black rings round the eyes and tail. Like its cousin the coati, it is related to the pandas and bears. Its popular name, crab-eating, derived from cancrivorus, its scientific name, is rather misleading, for it is in fact omnivorous-devouring such things as insects, fruit, eggs, frogs, birds, and small mammals, etc. When landcrabs are available they are, of course, devoured with equal relish.

This raccoon has rather bare forelegs and long flat forefeet which are very sensitive. These are used extensively for locating food (especially frogs and crabs) by sliding them under stones, and in fact it seems to locate and recognize most of its live food by touch rather than by sight or smell. 
My collecting station on the edge of Georgetown was not a place for interesting experiences such as are always cropping up in the jungle, but it enabled me to fulfil the function for which I was sent out. Animals of all sorts came in from far and wide and I soon found myself with a collection so large that catering for their daily requirements was a full-time job. Many of them were youngsters and had to be fed on the bottle. Among these was a delightful pair of tapirs which were caught when only three months old.

Besides those already mentioned, the mammals included the following species: Hairy Tree Porcupine, Brazilian Tree Porcupine, agouti, paca, capybara, Collared Peccary, White-lipped Peccary, ocelot, Margay Cat, Two-toed Sloth, Three-toed Sloth, Squirrel Monkey, Weeper Capuchin, Brown Capuchin, Humboldt's Saki Monkey, Virginian Opossum and Guiana Whitetailed Deer. The latter, called Bambi, was a great pet and was allowed to wander at will when it was certain that stray dogs could not worry her.

The bird collection was growing well, considering the limitations of operating from a town base. The prize was a magnificent Harpy Eagle which I acquired from a colored resident. He called on me one day and asked if I was interested in a large hawk which he had at home. On visiting his house I found that the so-called hawk was none other than a Harpy Eagle in fine condition. It was chained by the leg in rather sordid surroundings, so I came to terms with him and agreed to take it away there and then. It was left to me to detach the ferocious-looking creature from its chain, the prospects of which did not look too rosy in view of its powerful legs and diabolical claws, which it employs for snatching monkeys from the tree-tops. A quick unsuspected sideways grab with one hand was necessary on my part to grasp both its legs at once if I wished to avoid being transfixed. This was accomplished while a curious throng of colored folk looked on. To my surprise this great bird was remarkably docile considering it had been caught only a few days before, and I was able, by holding its legs and tucking it under my arm, to ride off with it on my bicycle.

Time has a curious way of distorting, or exaggerating, simple 
incidents. According to a Government official who returned recently from Guiana, local legend has it that I was last seen cycling through Georgetown with a Harpy Eagle under one arm and holding up an umbrella with the other hand! A strange sight indeed!

The owner of the bird told me that he had captured it by shooting it, and that there was a very slight injury to one wing. I examined this, but could find no evidence except that one of its primaries was twisted.

This harpy became so tame in a few days that he allowed me to stroke his head, and when he moulted there was no further evidence of his slight wing injury. Harpy Eagles in general do not stand the rigors of our climate as well as most tropical birds of prey, but this one appears to be in fine fettle after five years in the London Zoo.

All the smaller hawks in British Guiana are known locally as Chicken Hawks, or rather that was their original appellation. It has long since been corrupted to chickenok, and to my great amusement an English schoolmistress in Georgetown asked me if I knew the common hawk-like bird that the children called "Tickenok."

My collection by now included not only a large variety of birds and mammals, but such reptiles as iguanas, teguexins and boa constrictors. Through my boy's negligence, one of the latterquite small-was found to have escaped. This was nothing to worry about - at least, so I thought-but apparently the cook got to hear of this, and from her it got to the ears of the press. To my astonishment this news was deemed highly sensational and had pride of place in the local press over such trifling things as the rising cost of living. In fact, one might have gathered from the importance attached to the escape of a snake, albeit nonvenomous, that the whole town was in a panic. As far as a good many people were concerned I found that this was actually so, and that every sort of rustling noise caused by rats, mice, or opossums in houses at night was attributed to the dreaded snake.

After a week of this, during which time it was suggested that I should not be allowed to keep dangerous creatures in the town, a fellow came to me one night and said he had seen a snake on the 
grass verge of the road, only about fifty yards from where it escaped. I was wheeling my bicycle at the time and so I went along and found the perfectly harmless young boa constrictor, picked it up by the tail and returned home, wheeling the bicycle with one hand and holding the snake with the other.

The capture was announced in the press and then Georgetown was able to sleep peacefully!

This incident is an illustration of the gulf that separates townspeople from their natural surroundings, and the way fantastic stories arise as to the dangerous nature of the creatures that inhabit the wilds. Strangely enough, in places like Guiana, which is mainly jungle, the gulf is infinitely greater than in more civilized countries, probably on account of the fact that it is not advanced enough for its people to take an interest in natural history.

Sport, of course, has an overwhelming appeal to the coloreds, especially football, cycling, cricket, and boxing; but some of the young people showed an intelligent interest in my collection. They are probably lacking in suitable tutors, for it struck me as strange that I should be invited to lecture on the mammals of British Guiana within a few weeks of my arrival.

At last I felt justified in having a break of two or three weeks as my helper seemed sufficiently well trained to take over for a while.

My idea was to collect some of the birds of the interior, and with this object in view I took the small steamer which makes its way by sea to the mouth of the Essequibo River and then upstream to Bartica. It was interesting to cover the route that I had taken years previously and to compare the changes. The chief of these was the number of passengers, which seemed to me about four times the previous figure, but there was little evidence of expansion on the banks of the great river. It seemed as wild and unconquerable as ever.

Bartica itself had certainly changed; instead of the one street, one hundred people and one church, there were now nine streets, nine hundred people, and nine places of worship. The town is delightfully situated on the spit of land between the confluence of the Essequibo and Mazaruni Rivers, and with the increase of 
mining activities in the interior, seems destined to become a town of some importance.

I looked across the wide expanse of water to the Penal Settlement, where I had spent several interesting months with my hoatzins and other queer creatures on my previous expedition, which now seemed only a short while ago.

In those days Sir Edward Denham made a revolutionary move by sanctioning the building of a road (roads are scarce in British Guiana) from Bartica to the Potaro River-a stretch of about one hundred miles. The idea was to make a more accessible route to the great Kaieteur Falls as well as facilitating transport to and from the interior. Guiana's rivers are unfortunately not navigable for any distance at a stretch as rapids bar the way.

The road certainly served a useful purpose when it was opened, but in latter years it has fallen into disrepair, and its state when I was last there was such that a journey along it in anything but a modern highly sprung vehicle was something of an adventure. Unfortunately, I had to make the journey in a rather ramshackle bus with hard seats, and this provided me with the worst journey I can ever remember.

At the start of the memorable ride I was wearing a respectable, though old, pair of flannel trousers, but when I arrived at the gold diggings some miles beyond the Potaro River I had to don my mackintosh before presenting myself to the manager and his wife, as I found the violent tossing had worn the seat of my trousers away!

After passing through miles of jungle, the sudden encounter with a modern mining settlement seemed wholly unreal. I was able to see the large dredges at work which eat their way into the banks of a small river, extracting the precious metal and then casting out the waste soil behind. The dredges were thus always afloat, though the river was slowly changing its course all the time. The manager showed me a large bar of gold, worth several thousand pounds, that had just been smelted, and which represented the output for the month.

To me, as a naturalist, the whole scene of operations seemed one of desolation and a ghastly blot on the landscape; but gold is 
money, and is presumably necessary for the maintenance of the Colony. Nothing looks worse than mutilated primitive forest with a disorderly mass of second growth taking its place, and it was not unnatural that within easy reach of the goldfields there was little bird-life of note. After a short stay, I decided to go lower down the Potaro River to Tumatumari, a village that was formerly the headquarters for the small alluvial gold workings in the surrounding country, but had now fallen into decline.

Large mango trees abandoned by the former inhabitants were numerous and were fruiting profusely when I arrived, thus providing a feeding center for hundreds of parrots of several species. Any approach to these trees set the whole assembly in alarm, causing a most incredible hubbub as the screeching mass took the air.

Fortunately, there was a large vacant house belonging to the British Guiana Goldfields, which was put at my disposal. It overlooked the picturesque Potaro River just below the Tumatumari Rapids, the scene of several fatal accidents.

The jungle came to the very outskirts of what remained of the village and the wild character of the place was brought home to me the very first night when lying on my camp bed. As usual I was sleeping under a mosquito net, but my feet evidently became uncovered and pressed against the net at the bottom of the bed. I awoke partly conscious that all was not well with one of my big toes, and drawing up my legs, I felt for my electric torch, which was always at hand under my pillow. On inspection I found that my toe had been punctured, and realized that a vampire bat had been sucking my blood. After that I was more careful to keep my feet covered, and as an extra precaution attached some thick cloth to the foot end of the mosquito net.

There is a popular legend in Europe to the effect that any victim of the vampire bat will himself become a human vampire, issuing forth at night to suck the blood of sleeping persons. However, I am glad to be able to say that, so far, the episode in question has brought about no marked change in my feeding habits!

There are a number of species of bats belonging to different genera in tropical South America which are grouped together to form what are popularly known as vampire bats. Great confusion 
has arisen over this relationship of species, some of which subsist on fruit, some on insects, and others on blood. The confusion is enhanced by the fact that one or two take blood only occasionally, and that the largest vampire-a diabolically ugly species with a wing-span of over two feet and with the scientific name of vampirus-is not a blood-sucker at all.

The common true vampire bat of British Guiana is leaf-nosed and only three inches in size. It is distinguished from other small bats by the sharp chisel-like cutting edges of its incisors and premolars, which enable it to make a clean puncture in the skins of animals with little or no disturbance, and like most bloodsucking creatures it alights on its host softly and silently so that its presence is usually not felt. Although it occasionally preys on man, always attacking the extremities, such as the nose and toes when these parts are exposed, it feeds principally on the blood of the larger wild mammals and domesticated cattle.

Many of the small fruit-eating vampires appear to the layman to be hardly distinguishable from the purely insect-eating bats, but it was interesting that I caught dozens of the former in my nets. Although quite unlike the fruit bats and flying foxes of the Old World in flight or appearance, they nevertheless resemble them in not being able to detect such objects as nets set in their paths, which leads one to believe that radar detection in bats has been evolved primarily for the purpose of detecting insects in flight.

At Tumatumari much of my time was taken up with capturing tanagers, manakins and humming-birds, though the heavy rains made this extremely difficult.

On my return to Georgetown a lot more mammals and birds came in, including quite a large collection from Trinidad. The Government of British Guiana kindly presented me with a collection of Grant's Guans and Crested Curassows, while the Director of the Georgetown Museum gave a large collection of seed-eating birds, including Lined and Black-headed Lined Finches, and Thick-billed Seed-finches.

Although the collection, when I left, did not include all the creatures I had hoped to get, there were a number of surprise items, and in all as much as I could possibly manage. There were 
eighty-five crates of all shapes and sizes containing Tamandua Ant-eaters, tapirs, agoutis, pacas, sloths, porcupines, tayras, opossums, ocelots, Margay Cats and various monkeys, etc., and a large variety of birds from the Harpy Eagle, toucans, aracaries down to humming-birds, and also reptiles and fish. It took six lorries to transport these to the docks, the full cost of this, and of the freight to England, being borne by Messrs. Booker Bros., the shipping company - a truly magnificent gesture on their part.

To cater single-handed for all the requirements of such a mixed bag, some sort of orderly procedure is essential, otherwise the whole business becomes mental and physical torture if one has any sense of responsibility for the welfare of captive animals. But the transference of such a consignment to the deck of a small ship inevitably means disorganization. There is no such thing as arranging the crates of certain groups of animals with similar feeding-habits together; they must be put where they fit, in between winches, masts, hatches, ventilation funnels, and all the other things that are necessary for the functioning of the ship. Then there is the problem of food, for every inch of storage space aboard is designed for some specific purpose, so that there is no provision for storing food for livestock unless it be in the hold, which is most inconvenient. Frequently it is all dumped on deck and one has to pray for fine weather. Even the business of preparing all the food can be a nightmare if this has to be done on deck in a howling wind or in a rainstorm.

The actual shipping of a large collection of delicate creatures, some of which require constant attention, is in itself an exhausting business, and matters are made infinitely easier if the first few days of the voyage are fine and calm so as to give one a chance to recover and get things organized.

No such blessing was forthcoming when I left Georgetown on the small steamer Enid. For the first few days there was torrential rain, with the vessel rolling at such an angle that it became an effort to remain upright, and a bucket of food placed on the deck immediately rolled over and careered into the scuppers, scattering its contents over the water-washed decks. Under such circumstances a lot of gritting of the teeth was necessary to see things 
through, and meals and even sleep were forgotten until conditions improved.

In spite of such a beginning, everything came through, with the exception of the tropical fish, which suffered when the temperature dropped to below $50^{\circ} \mathrm{F}$. near the end of the voyage soon after passing the Azores, although it was the month of August. It was late one night when we anchored in the Mersey, where we were still exposed to bitterly cold winds, and not until we pulled alongside the docks at Liverpool early the following morning was there any relief. Then the sun came out and the temperature soared to the other extreme, to the obvious relief of the sloths and humming-birds. 


\section{Chapter Twenty-Three}

\section{BRITISH CAMEROONS}

$\mathrm{T}$

HROUGH various collections that had arrived since the war the Zoo was now fairly well stocked with the more easily acquired mammals, and so it began to turn its attention to odd creatures such as gorillas, orang-utans, gibbons and Spider Monkeys that occur in widely separated habitats.

Early in 1948 the Zoo heard from an official in Spanish Guinea that he had a young gorilla for disposal. Travel to such places was extremely difficult owing to exchange regulations, so it was decided to send me to British Cameroons, which, on the map, is a neighboring country, though as far as communications go might well be the other side of the earth.

With memories of my much earlier visit to French Cameroons I was confident that I could get a good collection of birds, which were sorely needed, and a number of interesting small forestdwelling mammals, so whether the gorilla materialized or not, the trip would be well worth while. I left for Lagos in Nigeria, where I was lucky enough to find boat transport to Victoria, the port of British Cameroons, without much difficulty.

Victoria is beautifully situated in Ambas Bay and is dominated by Cameroon Mountain (13,300 feet), whose lower slopes reach to within about five miles of the port. On a clear day the mountains on the Spanish island of Fernando Po can be seen as one looks westwards across the Gulf of Guinea.

British Cameroons is a mandated territory, administered by Nigeria, though communications between the two are, or were, exceedingly poor. Unlike French Cameroons, which boasts hotels and railways, the British section has no such refinements. On 
landing at Victoria, the capital, one may have to hire a cook and purchase all one's provisions, crockery, cooking utensils, etc., in order to get the next meal, and finally sleep under a tree-that is, if one arrives without introductions or contacts. There is a small rest-house for passing Government officials, but there had been a sudden influx of newly appointed welfare and educational officers and so forth, to fill the posts that formerly never existed, and nowhere to house them, so the rest-house was turned into a permanent residence.

Fortunately, as was the case when I visited French Cameroons, I had a letter of introduction from the head office of the United Africa Company in London, and so the local manager, who was most obliging, saw to it that I had somewhere to eat and sleep.

During my first few days I engaged a cook and houseboy, both of whom were prepared to go anywhere with me into the back of beyond.

As usual, the difficulty of finding the most suitable spot for a collecting-base presented itself. Ninety-nine per cent of the Europeans in such places have little or no interest in natural history and are vague and often misleading as to where there is an abundance of wild-life. Transport in British Cameroons is a perpetual headache. The only form of conveyance for long distances by road is the native-owned, native-driven lorry. The Government had fixed the charges so that there was no argument. Any journey was at the rate of half-a-crown a mile, but one had to pay two shillings a mile for the returning empty lorry-thus the total really worked out at four shillings and sixpence per mile. As far as I know, no native driver had ever been known to admit that he had a return load, so the hirer had always to pay for the return journey in spite of the fact that every lorry fills up in no time with native passengers and their baggage.

Under this system it is little wonder that the cost of getting any produce from the far interior to the coast by road was prohibitive.

My first trip inland enabled me to sidetrack the transport boys of Victoria, as the Public Works Department kindly gave me a lift to Ayang, about one hundred and thirty-five miles inland. This road was constructed during the last war, the only inland route previously being up the Cross River to Mamfe, a town about 
one hundred and eighty miles inland. I was given permission to stay in the P.W.D. rest-house at Ayang, which was a simple, tworoomed thatched affair with, of course, no furnishings. There are a number of such places in the interior, a few belonging to the P.W.D., but most of them to the Government. The visitor is expected to bring his own crockery, provisions, bed, etc., and cook and houseboy, who also have a certain amount of kit, so that the necessity for traveling by lorry is obvious. We were late in starting from Victoria and so were obliged to spend the night at a resthouse about ninety miles inland and thirty miles beyond Kumba, the first place of any importance up country and one that supports a District Commissioner.

The following day we were proceeding merrily through the Cameroons Forest, with an occasional Great Blue Touraco flying across our path, when a car coming from the opposite direction drew up and signalled to us to stop. A man sprang out and in explosive tones abused first the driver and then me for being on the road. He asked if we had been given permission to travel, and if so by whom. Had I known what he was driving at, communication would have been easier, but as it was he probably thought I was exceedingly dense. My simpleness was too much for him, for with a loud snort, and still in a violent rage, he jumped into his car and drove on. This was the first white man I had met in the interior, so I began to wonder what was in store.

After this human avalanche had slid out of sight my driver explained that on this particular stretch of road vehicles were permitted to travel in each direction only on alternate days, and we were going the wrong way. No one had even hinted at this to me, not even the P.W.D., and the reason was not apparent, considering the wide roads, until I had met a few hare-brained native drivers. Anyway, I regret that this was my only meeting with the person in question, for I believe his direct manner was responsible for accomplishing things at a speed unknown before in the Colonial Service.

My stay at Ayang was rather brief as the natives were quite unhelpful and bird-life not particularly interesting, though I soon got together a collection of the more desirable birds such as Snowy-headed Robin-chats, Forest Robins, Blue-billed Seed- 
crackers and Blue-billed Malimbus-all inhabitants of the forests. The only birds brought to me by a native were some newly hatched Sclater's Crested Guinea-fowl. These were mere balls of fluff and had been carried for many miles in the native's hat. They had the instinctive habit of most, if not all, wild gallinaceous chicks, of dispersing rapidly and hiding under cover when danger threatened, and when two slipped out of my hand I had a busy five minutes with the aid of my staff before recovering them. However, in a few days they became fairly tame on being given live termites to eat. To bring in these and to catch grasshoppers I engaged a young native boy. His enthusiasm was unbounded the first day, but he quickly tired of chasing grasshoppers and after a few days his daily catch dropped to a number that anyone could have captured in half an hour. It was obvious that the native boys here disliked regular work, for I was unable to find anyone whose enthusiasm extended beyond a few days.

Several of the guinea-fowl chicks succumbed after I had had them about a fortnight and a native told me that it was due to allowing them to eat soldier termites, which have diabolical tweezer-like mandibles with which they cling tenaciously to any enemy and remain so even if their bodies are torn from their heads. The native said that there was a heavy mortality among the young native chickens whenever they have access to a broken termites' nest. The older birds avoid the soldier ants and eat mainly the nymphs. To overcome this I got my boy to break the mud nest on to a metal tray and to kill all the soldiers by squashing them one by one with the handle of a teaspoon. This became a routine performance every time I wanted any of my insectivorous birds to have some live food.

As collecting was proceeding rather slowly at Ayang, I made my way by lorry to the town of Mamfe, which is an important center for the export of the produce of the interior owing to its connection by river with the port of Calabar. Here I was given permission to stay in the rest-house belonging to the United Africa Company. This was a corrugated-iron-roofed building and the shade temperature on the veranda between noon and 3 P.M. rarely dropped below $95^{\circ} \mathrm{F}$; when, later in the day, it fell to $85^{\circ} \mathrm{F}$., it seemed delightfully cool by contrast. The bank of the Cross River 
on the Mamfe side is several hundred feet above the water, so that my numerous excursions to the river-bed in the intense humid heat kept me in a constant bath of perspiration.

The most noticeable bird of the river-bed was the White-headed Wattled Plover, a water-loving species that favors sand spits and bare beaches where its favorite aquatic insects can be easily procured. In flight it is conspicuous on account of the large amount of white in the plumage which glistens in the tropical sunshine. The carpal joint of each wing is furnished with a sharp, slightly up-curved spur often over an inch in length, which the bird employs apparently for fighting (with outstretched wings).

There was an island of shingle and sand in the Cross River some four hundred yards long by fifty yards or more wide and rising a good ten feet out of the water, that was frequented by about thirty of these birds. Apparently none were breeding on the island, although, being safe from mammalian enemies, it seemed the ideal place. A flat stretch of sandy foreshore with patches of grass, herbs, and small bushes along the opposite bank of the river was occupied by a single pair of these White-headed Plovers which, by their aggressive and agitated behavior when one approached, almost certainly had eggs or young, but my attempts to find a nest were unsuccessful. I then set a spring-net trap baited with various insects, and was surprised one day to find it sprung with some apparently inanimate object in it that I was unable to recognize until I stooped and looked at it at close quarters. It turned out to be a young White-headed Plover-just a ball of fluff on two long legs - feigning death. The disguise was so perfect that at first I thought it was a piece of drift-wood, and even after recognizing it it was not until I caught hold of the bird that I realized it was alive. This comical creature continued its "freezing" act in captivity, squatting and assuming most unlife-like shapes whenever I went near it, until it became sufficiently feathered to fly.

A few days later I caught one of the parent birds, and thinking that nothing could be more natural than to keep the two together, I put this bird into the same traveling box with the youngster. Immediately the latter crouched in a corner as if frightened out of its life. Hours later it was still in the same position and refused to be tempted by termite nymphs which had previously been its main 
form of sustenance. When the parent bird was removed to another box, the youngster regained confidence almost at once and had a good feed.

The following day I caught the other parent bird and introduced this to the baby, with the same result as before.

As the baby grew I tried from time to time introducing it to one or both parents to see if they would live on friendly relations, but with no success. On the last occasion I found blood on the youngster's head-the result no doubt of the parent ramming it with one of its deadly wing-spurs. It was not until the young one was nearly full-grown that this extraordinary animosity disappeared and I was able to keep them peacefully together.

I am convinced by the behavior of these plovers, before and after capture, that they abandon their young almost as soon as they are hatched, but remain in the vicinity to draw off any would-be intruder, feigning injury and enticing the enemy in the wrong direction. The baby I caught was well able to look after itself during the fluffy stage and was certainly able to escape detection by its remarkable powers of camouflage. In a locality abounding in predators it seems likely that such a set-up between parents and young must have a high survival value.

It still remained a mystery to me why this pair had chosen to nest on a spit of land jutting out from the nearby forest, when they could have avoided any predatory mammals by nesting on the island. But instinct told them something that I had not foreseen. In the far-off Bamenda Mountains-the source of the Cross River-the first heavy rains of the season occurred, and with a mighty roar the flood-waters arrived, changing the whole aspect of this peaceful waterway. Within twenty-four hours the island was completely covered - the water rising to twenty feet above its previous level by the following day.

My bird nets were always providing evidence concerning the nocturnal habits of various fruit bats. Those set in any gap in the riverside foliage on the edge of the forest collected several specimens every night.

The ease with which fruit bats all over the world are captured in nets indicates that they do not employ the radar-like means of detecting objects by emitting high-frequency sound-waves and 
registering the rebound, as do the insect-eating bats. I have on several occasions seen the latter at dusk about to fly through some gap in foliage or dash through the branches of a bush overhanging a stream where they were used to going every night, but where I had now set fine invisible nets. In each case the bat detected the net at once, although flying fast towards it, and had plenty of time to turn and easily avoid the object. That is not to say that they never get caught, for I have from time to time caught odd specimens, but I feel sure that in each case curiosity was the bat's undoing. On the only occasion that I happened to be sitting near a net at dusk when one was caught, it had already demonstrated that it knew perfectly well that the net blocked its path along a deep waterworn gully, but it then gave the net a flick with one wing just as it turned. It had probably done this before to feel the nature of the obstruction when confronted with the strong webs of the Epeira spiders, but such action with a sensitive flue net is fatal. A wing-hook caught a thread and swung the bat off-balance sufficiently to bring its body against the net, and the resulting efforts to take off ended in helpless entanglement.

I was frequently coming across illustrations of the way in which Christianity has become linked with pagan customs.

My cook was not on good terms with the houseboy and wanted him replaced by one of his own friends. So the cook told me the houseboy was a thief and that he had entered a plantation worker's hut and had stolen ten shillings. I disbelieved the whole story and asked what evidence he had. He replied that the headman-a Christian and a friend of the cook-had put the houseboy to the test by "dropping the Bible." Further inquiry brought to light the details of this "trial."

The headman held out his hands palms upwards, on which rested the Bible. After an appeal to the Almighty the hands were tilted one way or the other according to the will of God, and if the Bible fell to the left the man was guilty, and if to the right he was innocent. When I laughed at this, the cook became quite concerned and asked if I did not believe in the Bible!

It was at Mamfe that I linked up with the greatest and most 
lovable character I have ever known-none other than Mr. Cholmondley, the chimp. He was presented to me by Mr. Craig, a former District Commissioner in British Cameroons, by whom he had been brought up as one of the family. His face was like that of no other chimp owing to malformed teeth which gave his muzzle a bulbous appearance. For all that, he had a kindly, benevolent expression and was highly intelligent-or so it seemed. Some might say that this was merely the result of being extraordinarily observant and highly imitative. His curiosity and desire to know how everything worked were evident if he was shown a locked trunk and was given a bunch of keys. Without any prompting he would quickly find the right key, and with much gleeful muttering open the lid. One of his great joys was to be given an umbrella when it was raining. The harder it rained the more he loved sitting out in it; but his unquenchable curiosity lured him into pressing the catch every now and then, so that the umbrella collapsed and water showered all over him, but this was all part of the game, and a split second was enough to restore it to its former position.

Cholmondley was about eight years old when I got him and was a very powerful animal. He had evidently been teased and perhaps maltreated by natives, for he hated them all, and for that reason had to be kept on a strong chain. His animosity was such that he would have attacked any number on sight if given the chance; but he simply loved Europeans, young or old of either sex, and although he was at an age when chimps would ordinarily be regarded as unreliable or dangerous, he never once showed the slightest malice toward any white person. He loved to wrestle and play games, but his favorite trick was to remove the shoes and socks of any visitor, undoing the laces most dexterously. The rest was a trifle embarrassing, for he would examine one's bare foot, opening the toes and searching for any foreign matter that he thought should not be there. This and any loose pieces of skin, even if of almost microscopic proportions, were removed in deadly earnest, and when one foot was considered clean he would hold out his hands to indicate that he wanted the other foot thrust forward so that he could repeat the shoe-removing operation and complete the pedicure. 
To get him to display his powers of observation and mimicry one had only to give him a mirror and comb. Holding the former high in one hand so that he could see the top of his head, he would go through all the actions of combing his hair and making a parting, but as he was almost completely bald this served little purpose other than showing off his cleverness. He would pull diabolical faces at himself in the mirror, baring his teeth and distorting his features in a fantastic manner-a thing he never did under normal circumstances.

Cholmondley was at one time kept near a hibiscus hedge, the young leaves of which he devoured with relish. Whenever I threw him a banana and it fell short of the range of his chain, without hesitation he would select a long stick from the hedge, break it off, and then rake the banana to within reach.

One of his most extraordinary spontaneous actions, which some people might interpret as mimicry but which I prefer to call intelligence, was on one occasion when I was dressing a small wound on my houseboy's arm. We were standing on a high veranda some ten feet from the ground, when I stripped the gauze covering from a piece of adhesive tape and stuck the latter over the wound. Cholmondley was watching from below with his eagle eye. The import of the whole business had registered, for as the gauze that I had thrown away floated to earth he picked it up and pressed it on a small sore just above his own right eye! If Cholmondley had suddenly burst into song, my houseboy could hardly have been more surprised.

One day when I was taking Cholmondley for a walk on his chain we passed close to my bicycle, which was leaning against a tree. He showed me in no uncertain manner that he wanted to mount the machine, so out of curiosity I sat on the saddle and he immediately took up his position in front of me, sitting on the crossbar and holding the handlebars. I took off and I could see he loved it. When we got on to the road I pedaled fast and eventually went down a hill at great speed, Cholmondley fairly grunting with delight. After that our joint cycle outings became a daily affair. The sight of us tearing along the road always set up a yell from any group of natives who witnessed this strange sight, and 
they would all come running to the road to get a closer look. My only fear was that if any of them got too near, Cholmondley would leap off to attack them while we were going at full speed and pull me over.

By taking Cholmondley for walks and allowing him to forage for whatever he fancied, I learned a lot about the natural diet of chimps. His favorite food was a leafy creeper, which trailed everywhere through the grass, and of which he devoured large quantities in preference to his artificial diet of cultivated fruits. In fact, in the end I adjusted his diet to correspond largely with that of my forest-dwelling antelopes-Ogilby's Duiker, Cameroons Bay Duiker, and Schultz's Blue Duiker-which subsisted on leaves supplemented with a little fruit. There is no doubt that chimps thrive better if they consume a fair amount of fibrous matter, which acts as roughage. It was noticeable that Cholmondley ate the stalks of plants as well as the leaves, and as an example of his love of food of a tough and fibrous nature he often climbed to the top of an oil-palm to eat its leaves, which to me appeared to be about as tasty as a ball of string.

When he had the chance he fed mainly as nature intended he should, but at an early age he had acquired the English habit of drinking tea, and was so inordinately fond of this that when offered water he filled his mouth but always squirted it out again when he thought no one was looking. If his morning cup was not forthcoming by 6:30 A.M. he let the world know that he was neglected by clapping his hands and doing a war-cry. One house where I stayed was perched on wooden stanchions about ten feet above ground, and underneath this was an ideal place for Cholmondley's kennel. His long chain enabled him to climb up and sit on the veranda, and it was here that he demanded his tea. Having received a mug of the delicious brew, he preferred for some reason to descend to his kennel to drink it. This meant climbing over the veranda rail, letting himself down so that he was hanging to the edge of the floor, and then swinging under it to the top of his kennel. I am certain that no human juggleracrobat could have performed this feat at such a speed without spilling a drop of fluid. During the act, which he performed 
thrice daily, the mug was transferred rapidly from hands to feet and back, according to whichever were free at different stages of the performance.

When it was time for me to leave, I took Cholmondley to one side while the boys put his kennel on the lorry. He loved traveling and needed no prompting to climb on the tailboard of the lorry and meekly enter his compartment, where he was safely locked out of range of the boys traveling with me.

The natives of Mamfe, as of Ayang, were of little help as far as my collecting was concerned, and as I had gathered sufficient of the things that I was able to trap myself, I thought it time to get back nearer the coast, especially as there seemed a remote possibility that a way could be found to send me the young gorilla from Spanish Guinea.

I had obtained permission to occupy a vacant manager's house on a rubber estate on the Mungo River, which divides British and French territory, about nine miles south of Kumba.

To make this journey of about one hundred and twenty miles by road, I decided to travel at night for the comfort of the birds. Thus the heat of the day was avoided and the problem of feeding en route overcome. Driving slowly for steadiness, we reached our destination at daybreak.

Some interesting mammals came into my hands here, the most noteworthy being two Martin's White-nosed Monkeys, a Pogonias Monkey and a Preuss's Monkey. The three former were babies and had to be reared on powdered milk.

A different proposition was a Long-tailed Pangolin or Scaly Ant-eater. This curious armor-plated creature rolls itself into a ball like a hedgehog for protection and hooks the tip of its prehensile tail under one of the scales as a sort of locking device. In this position it is safe from all enemies, even those with powerful teeth. The pangolin is toothless and has a long pointed muzzle, small mouth, and long extensile viscous tongue, closely resembling the Tamandua Ant-eater of South America in these adaptations to a specialized life.

The Long-tailed Pangolin is arboreal and appears to live almost exclusively on a species of black ant that attaches its honeycombed nest to branches. Unlike the Tamandua Ant-eater, which is play- 
ful and intelligent and will thrive on an artificial diet, the pangolin seems more reptilian in character and has no will to live under captive conditions. In my attempt to accustom my specimen gradually to artificial food I let it loose daily in a tree where there were several large ants' nests so that it could devour a certain quantity of its natural food. These ants become very aggressive if anything invades their territory and will give a human being an uncomfortable time owing to their nasty bites and their great numbers. Irritation is caused through the ejection of formic acid, which enters the wound. When the pangolin breaks the crust of the ants' nest with its sharp claws it is attacked immediately by thousands of ants which swarm over its face and hang on with their sharp mandibles like bulldogs. My boy, whose skin was considerably tougher and less sensitive than mine, had the task of scaling the tree and bringing down the pangolin when it had finished its meal. When I put the animal back in its box there were always numbers of ants still fixed to its face, but after a while they were all to be found lying dead on the floor. It seems probable that this creature has become so specialized that the absorption of a certain amount of formic acid in the bloodstream is necessary for its survival, for soon after elimination of its natural live food it succumbed in spite of the inclusion of large quantities of dead ants in its diet.

Soon after my arrival at the Mungo River the rains broke. They were overdue, but made up for the lost time by continuing almost incessantly day and night for the remaining twenty-four days that I was there. The humidity was such that clothes and shoes became moldy in a couple of days and one's sheets felt uncomfortably damp.

As I sat eating my breakfast on the veranda one morning, with the everlasting rain pouring down, the outlook seemed particularly gloomy, but just then my houseboy presented himself holding a bird which had been brought by one of the native employees on the rubber estate. He explained that the boy had caught it and wanted to know if I would buy it. The identification of this rainsoaked bird with longish neck and slaty-gray upper plumage at first glance completely baffled me, so I sprang to my feet to examine it more closely, and as I did so was able to see the whole 
of its head. Then I knew immediately that it was the Gray-necked Picathartes, one of the least-known and most curious birds in the world. It had been seen in the wild state by only two or three Europeans, and this was the first specimen ever captured alive. In my excitement I took it from the boy in double-quick time before he had a chance to let it slip out of his hands and put it safely in a suitable traveling-box.

On questioning the boy, I learned that he had found the bird in a snare set in the forest for a Brush-tailed Porcupine-an animal that is particularly numerous in West Africa and which is hunted extensively by the natives for its flesh. How the bird escaped injury is a mystery, for a snare of this sort, attached as it is to a strong bent sapling, flies up with such a jerk that it would normally break any bird's leg or kill it outright.

It was indeed fortunate that I was in the vicinity, for the boy was taking it home for the pot but got the idea that I might like to buy it. The most extraordinary thing was that neither he nor any of the other boys had seen such a bird before.

Later I contacted several old wood-cutters who had spent most of their lives in the forest, and they too were unfamiliar with the bird. The type specimen of the Gray-necked Picathartes was obtained in I90I near Cameroon Mountain, but the species had apparently never been observed since in what is now British Cameroons, though since my departure from the territory it has been found far in the interior where there is suitable rock formation for nesting sites in primitive forest.

The only skins in the British Museum up to this time (1948) had been obtained in the forested coastal area of French Cameroons, and these were all obtained by natives over a period of years.

The Grey-necked Picathartes has a completely bald head, the skin of which is attractively colored with blue on the forepart, pink on the hindpart, and with black on the sides of the face. The former has the appearance of closely matted short feathers. On account of its long and sturdy legs and strong bill it was formerly considered to have some affinity with the crows and received the English name of Bald Crow. Later an opportunity to examine a 
carcass revealed that anatomically the bird showed little relationship to the crows but came nearer the starlings.

By studying the living bird some of the leading systematists now consider it to be an aberrant babbler. In view of these changing opinions I have referred to my bird as the Gray-necked Picathartes, the latter word being its generic name.

One of its peculiarities, in view of its large size, is that it makes a mud nest on an overhanging rock-face in the forest. Situations suited to the bird's nesting requirements are distinctly rare in the Cameroons, and where they exist the forest is intersected with deep ravines and fallen tree-trunks, so that they are rarely in proximity to any native track. The bird's rarity, or rather the fact that it is localized, seems to be governed entirely by the lack of nesting sites.

I persuaded the boy who brought my bird to lead me to the spot where he actually caught it. As it was obviously trapped soon after daybreak I reckoned that its sleeping quarters were near at hand-probably the same rock-face where it normally nested. The boy did not know anything of the peculiar nesting habits of picathartes, and had never come across such a nesting site. I offered twenty shillings to any native who could lead me to such a place, but with no result.

I then started a search on my own, and to my surprise and joy, within a quarter of a mile of where my bird was caught I found a small rock-face in a most inaccessible situation, well concealed by the surrounding vegetation, which had the remains of six mud nests on it. The nest is of pure mud at the base, but the rest is of mud reinforced with vegetable fibers, and the rim is further reinforced with small sticks and leaves.

Greatly encouraged by this find, I revisited the place and set nets, but the rain increased and for a whole month it hardly ceased. More and more water seeped through the rocks and a considerable volume poured over the top. To ascertain if picathartes came here to roost I set off one evening and concealed myself in the undergrowth near the rock. It was a gloomy business, but I remained until it was quite dark. There was no sign of picathartes. I think they had been roosting here until very re- 
cently, but the excessive rain had made things too uncomfortable for them. It was eerie in the extreme when I tried to find my way back; the night was pitch black, and as I scrambled through the dripping undergrowth alone my main concern was whether the bulb of my torch would give out. It was a great relief to get clear of the forest onto a path, although I still had two raging torrents to wade through and a precipitous hill three hundred feet high to scale.

In spite of the rain I made this long tiring journey twice daily in order to look at my nets, but conditions were completely against catching anything. However, my efforts were not wasted, for on one occasion when I was sheltering beneath the overhanging rock and thinking how devoid of life the forest seemed to be and of the long dreary walk home through dripping vegetation and swollen streams, a picathartes arrived as silently as a phantom and settled on a sapling only a few feet away. He saw me at once, and after craning his rather long neck he flew off, but landed only a few yards away and then continued his retreat by progressing over the forest bed with a succession of tremendous hops. This cheered me up enormously, for I felt as I sat alone in this wild stretch of jungle, far from any human being, that I had experienced the sort of thrill that comes rarely in a lifetime. I was encouraged to make the strenuous journey, always in the rain, time and time again, and I was rewarded once more by seeing a pair of picathartes arrive at the rock-face. It was an exciting moment, for being partly concealed I was able to observe them only fifteen feet away, sufficiently long to realize that picathartes is one of the quickest and most alert creatures of its size in the whole of the bird kingdom, which probably explains why so few people have seen it.

In the meantime, my captive specimen was thriving on the larvae of beetles, termite nymphs, grasshoppers and meal-worms. Soon he learned to eat small pieces of raw fresh-water fish and fresh meat, but live insects comprised the bulk of his food.

For weeks on end my clothing was saturated, and owing to the difficulty of keeping dry feet, I gave up the struggle and wore old shoes with no socks. The result was that water and mud squelched loudly through the cracks as I made my way along the water- 
logged trails. This did not bother me at the time, but it had a painful aftermath.

My departure from here was delayed several weeks by a night attack by driver ants, during which a number of my birds were killed, and these I had to try to replace. Fortunately, the main attack was not near the picathartes, so he remained unharmed. The ants had arrived in millions in the dead of night without causing any alarm among the birds. I was sleeping nearby and never heard a sound. The birds seemed to know instinctively that they were about to be overwhelmed by a ruthless enemy, and gave in without struggle or sound.

At the first sign of daybreak I rose and walked on to the veranda in my pajamas. All was silent, but in the faint light I saw what looked like a black carpet stretching from the veranda posts to the row of cages. The significance of it all came as a dreadful shock, but I knew that every second might mean the saving of a bird's life. To break up the organized attack I slashed at the main stream of ants with a sack. I then shook the cages violently and carried them one by one to the opposite end of the veranda. While doing this I was covered from head to foot with biting ants. I had already called the boys, who lit fires round the feet of the veranda posts to disorganize the invading army. By quickly catching each individual bird, brushing off the ants, and then dropping the empty cage so that the shock would make the rest of the ants quit, I saved the majority of the birds, but in fifteen minutes all would have been lost.

Having eventually rid the veranda of ants, we attacked the millions that covered a wide area down below. Much as one hates these ruthless killers one cannot but marvel at their organization both in attack and retreat. Although many thousands perished in the flames and great gaps were made in their ranks, the remnants were quickly marshaled by their sergeant-majors into lines which all converged on to a single column, and in an amazingly short space of time the army was traveling in orderly retreat as though there had been no engagement.

When this was over I was exhausted, for one has to fight hard to overcome the fantastic numbers of such an invading army.

As my luck seemed to be out on this trip, I was not surprised to 
hear from my correspondent in Spanish Guinea that his young gorilla had died.

In spite of all this the collection was an interesting one and I had the satisfaction of knowing that if I could land the picathartes home alive, all would have been worth while. I decided to go home direct by an Elder Fyffes banana boat from the port of Tiko. This is the center for the banana export trade, which is in the hands of the Government-sponsored Cameroons Food Corporation. I had written to the head of this concern to see if I could get accommodation for myself and birds for one night. The blunt reply was that neither could be accommodated anywhere in Tiko.

I left the Mungo River by lorry at about eight o'clock one night and arrived at Tiko about one A.M. I tried to doze in the front of the lorry but the mosquitoes made this well-nigh impossible.

At Tiko the road terminus is some miles from the quayside and the intervening journey has to be made by Deceauville railway. When everything was led and at last loaded onto open trucks, the inevitable rain set in and it was midday before everything was loaded, by which time I was feeling exceedingly weary. The one bright spot when we arrived was the helpfulness of the captain of the banana boat, who came down to greet me and to inspect the livestock. He took an immediate liking to Cholmondley and led him up the gangway to his cabin, where he remained for hours before the rest of the livestock was shipped. Apparently Cholmondley was entertained at lunch in the Captain's cabin and behaved in an orderly dignified manner, drinking beer with the rest.

For some days I hardly saw Cholmondley at all as I gathered he helped the quartermaster to steer the ship when he wasn't entertaining the officers. It was indeed a comical sight to see a waiter of the old school, with cloth over arm, approach Cholmondley and place his food before him as if he were serving a distinguished passenger. In all due respect to Cholmondley he never once broke any crockery or knocked over a glass. It always delighted everyone to see him open a box of matches and light his own cigarette. To enjoy this to the full he invariably lay on his back with his feet up against something, blowing the smoke through his nose.

The arrival in England of the picathartes caused tremendous 
interest among aviculturists and ornithologists, not only on account of its extreme rarity but because of its strikingly unusual appearance. Although a difficult bird to establish in the first instance, it has thrived in captivity and still looks perfectly happy in the Bird House at Regent's Park, four years after its capture.

The enthusiasm which lured me on to try to find out something of the picathartes in the wild state was now beginning to tell its tale. I felt decidedly off color, and on being medically examined it was found that among other things I was suffering from malaria, amebic dysentery and hook-worm, the latter no doubt contracted through wearing leaky shoes.

Cholmondley's life in the London Zoo was a great contrast to his existence in the Cameroons, but he settled down and became a great favorite with the visiting crowds. He was at all times friendly to those who liked him and who showed no fear, but he was inclined to regard anyone unsympathetic as an enemy, no doubt due to his upbringing among African natives who teased him.

His end was tragic. One day while in the sanatorium awaiting dental treatment, he escaped, and although rounded up in a Zoo building, he was shot before anyone was called who could easily have handled him. 


\section{CONCLUSION}

7 HE Cameroons trip was my last on behalf of the London Zoo,

1 except for a voyage to Antwerp, in June, I949, to collect an okapi. In order to comply with foot-and-mouth disease regulations in England, the animal was not allowed to touch Belgian soil on its way home from the Belgian Congo, so it had to be transferred by barge to the cross-Channel boat, which was berthed several miles away in the Scheldt.

This okapi was the gift of the Government of the Belgian Congo and therefore the occasion demanded ceremony. In the committee-room of the Antwerp Zoological Gardens a select gathering of officials and consuls was present for the handing over, which was a delightful affair, and made less formal by the liberal flow of champagne. After the conclusion of the usual speeches I returned to England with the prize.

Soon after my expedition to the Cameroons, Dr. Vevers, who had held the post of Superintendent to the Zoological Society for over twenty-five years, retired. His wide knowledge, generosity, and charm had endeared him to all who came into contact with him and his parting was a sad day for the menagerie staff, who held him in the highest esteem.

About this time I was appointed Curator of Mammals and Birds. It was a job full of interest and I started in earnest on what I thought would be a happy future, with lots of friends and in close contact with a large menagerie, much of which I had helped to build up.

My experience was wide and my memories rich. I could converse with visitors from overseas about the creatures of their own countries. On looking back, I could dwell with satisfaction on the collection of such remarkable creatures as the hoatzin, the Graynecked Picathartes, and the aye-aye, and of having observed 
others such as the indris, the sifaka, and the mesoenas in their natural surroundings.

With such a pleasant past and a keen interest in all that the Zoological Society stands for, my future seemed equally rosy. But I had overlooked the human element, and in February, I95I, for reasons of my own, I handed in my resignation, and relinquished my post in September of the same year. It was a hard decision to make in view of my long association with the Zoological Society and my deep attachment for the Zoo.

Having taken one plunge, I decided to take another, and in April, I95I, I married Doris Maria Burlington-Green.

But for these two events I doubt if this book would have seen the light of day, for the first provided the necessary time, and the second someone to spur me on.

The future seemed rather uncertain, but as I lay down my pen comes the exciting news that I have been appointed Superin. tendent of the Gardens of the Royal Zoological Society of Ireland -in brief, the Dublin Zoo.

Whipsnade, July, 1952 


\section{INDEX}

$$
\text { (Note.-q. = quoted })
$$

Abbay, Colonel, 308

Aberdare Mountains, 124 125, 126

Abyssinia, 304

acacia trees, 125

Accra, 155

adders, puff (Bitis areatans), 293

Adelaide, 147,153

Aden, 297, 304

aepyornis, 272, 288

Africa, 17, 19, 23, 28, 44, 45, 52, 54, 65, $68,72,74,86,95,96,107,124,128$, 129, I33, I34, 24I, 257, 258, 274, 304, 321; East, 45, 74, 131, 155, 293, 296, 304; German South-West, I0-12; South-West, 10, 304; West, 155, 206, 342

\section{African-}

equatorial forests, 155

slaves, 45

tribes, 155

Africans, 300

Afrikaans, Io

Afrikander cattle, 4

agouti, 322, 328

Agricultural Research Station, I34

Akawai Indians, I Io

Alaotra, Lake, 74, 76, 79, 80, 82, 1 70, 244,

$$
252,258
$$

Albert, 13

albinism, 150-151

albinos, 151

Alexandria, 315

Alipore Zoo, $180,181,182$

Allied-

armies, 259

countries, 259

Allies, 259, 280

Amani, 134, I35, 136, 138
Amatongas forest, 24

Amazon River, 98, 226

Ambararatra, 254

Ambas Bay, 330

Ambatondrazaka, 83, 170

Ambatosoratra, 76, 81, 170

Ambohimavelo, 272

Ambositra, 252

Ambovombe, 276, 284, 285, 288

America, 107, 146; tropical, 113, 317

Americans, 217

Andean region, 215

Andes, 215, 216, 217, 224, 230

Andranohilany, 274

Andréba, 76, 83

Andriambavirano, 8 I

Androy country, 276, 284, 288

Anglo-Franco-American ornithological expedition, 74

animal-life, 77

animal transport, 310-316

animals, predatory, 30

Anjouan, 178

"Anna, stinking," 103

Annam, 50, 51

Annamites, 52, 53, 54, 57

Anongy, Lake, 285, 286, 287

Anororo, 78, 8o

Antaifasy, 266; tribe, 265

Antananarivo, 75

Antandroy, 288; natives, 284-285; women, 288

Antarctic, 215

Ant-eater-

Giant (Myrmecophega tridactyla), 320

Pygmy (Cyclopes didactyla), 320-32I

Scaly (Manis), 340

Spiny (Tachyglossus setosus), I 42, 145 
Tamandua (Tamandua tetradactyla), Babracot, iro

$$
\text { 319-320, 328, } 340
$$

ant-eaters, South American, 320

Antelope, Giraffe-necked (Lithocranius wal-

$$
\text { leri), 304-305 }
$$

antelope snares, $35-36$

antelopes, 123, 339

Antisana, Mount, 226

Antongil Bay, 289

ants, 138-139, 159, 195, 268, 319, 320, 340-34I; driver, 345

Antsihanaka tribe, 172

Antsirabe, 74, 246, 253

Antsirabe-Belo road, 249

Antsovelo, 286

Antwerp, 348; Zoological Gardens, 348

Arab mare, 305

Arabs, 123

aracaries, 328

army vehicles, 282

artillery, $12-13$

Ashanti, 192, 193, 197

Ashford, I

Asia, I07

Aspalathus, 33

Atáratra, 260

Athi Plains, I23, 124

Atlantic, 102, 226

atmospheric conditions, 128

Australia, 54, 96, I3 I, I 42, I 43, I 45, I 49, I52, I53, I70; Eastern, I 43; Western, I 42, 2 I I

Australians, I 44

aviaries, 39

aviary for ducks, I 7I

aviculture, $39-40$

Ayang, 331, 332, 333, 340

aye-aye (Daubentonia madagascariensis),

$$
83-84,173,174,348
$$

Azores, I2I, 329

Babblers, Fries' Scimitar-billed (Pomatorhinus tickelli friesi), 58

Babies, Bush, 292

Baboon-

East African Olive, 293

Gelada (Peter) (Theropithecus gelada), 315

Sacred (Papio hamadryas), 293

baboons, 3I, 44-45, 63, 7I, I4I

Badger, Honey, 321

Bamboo Grass (Olyra latifolia), 136

Bamenda Mountains, 335

bananas, rum-soaked, 105-106

Bandro, 79, I7I

Baobab, Grandidier's (Adansonia grandidieri), 270

baobab trees, 247

Bara-

country, 262

natives, $26 \mathrm{I}$

people, 254

bararata (Phragmites communis), 79

Baras, 288

Barberton district, 26

Barbet-

Blue-throated (Cyanops asiatica), I 85

Bourcier's (Eubucco bourcieri), 220

d'Arnaud's (Trachyphonus darnaudii), 126

Toucan-like (Semnornis ramphastinus), 232

White-eared (Buccanodon leucotis), I36

barbets, $160,213,220$

Bartica, I03, I05, 324, 325

Bastard, Monsieur, 249

bats, 137, 335-336; vampire (Desmodus rufus), 326-327

Bats, Straw-colored Fruit (Eidolon helvum), 242-243

Bear, Nandi, I3I

bears, 32I; koala (Phascolarctus cinereus), 143

Bechuanaland, 24

Bee-eater-

Australian (Merops ornatus), 145

Blue-necked (Nyctyornis athertoni), r3r, I $83-185$

Carmine (Merops nubicus), 97, 210-2I I

Green (Merops viridis), 58

Little (Melittophagus pusillus), 46

Madagascar (Merops superciliosus), 78 , 178

White-fronted (Melittophagus bullockoides), 96-97, 125

bee-eaters, 6,63

Beetle, Goliath (Goliathus cacicus), I 66

bee-traps, 34-35 
Beira, 24, 26, 38, 42, 63, 64

Belgian Congo, 348

Belgium, 74, 259

Belo-sur-Tsiribihina, 246, 248, 249, 270, 287

Berbice River, I00-IoI

Beroboka, 247, 267

Betsileos, 288

Betsimisaraka-

myths, 177

tribe, $175-176$

Bevilany, 287

Bhutias, 188

Bible, 336

bicycle, 300

bird-

catching, I 8

collecting, $14-15,23-24$

collection, 322-323, 324

food, 29

shipment, I5-I6

Bird-

Dayal (Copsychus saularis), I 86

Umbrella (Cephalopterus ornatus) ( $p a-$ jaro toro), 219

bird-life, 27, 63, 98, I16-I17, 123, 124, 125, 127, 133, 134, 155, 157, 165, $202,203,216,217,237,257$

bird-lime, I95-196

birds, 6, I4-2I, 302-303, 328, 332-333; bishop, 15; importation of, 40; seedeating, I67-168; trapping of, 207208; trumpeter, 103

Birds of Indo-China, Jabouille, Delacour, $5 \mathrm{I}$

birds-of-paradise, 64

Birds-of-paradise, Wattled (Paradigalla carunculata), 257

Biscay, Bay of, 298, 315

black labor, 104-105

blow-gun, 224-225

blue rollers, 6

Blüntschli, Prof. H., $178 \mathrm{n}$.

boa constrictor, $75,76,177,323-324$

Boa Constrictor, Madagascar (Constrictor madagascariensis), 75, 76

Boas, Sganzin's Tree (Sanzinia madagascariensis), 177

Bolivia, I 0 I

Bombay, 142, 147, 153, 180, 190
Booker Brothers, 328

Booker Line boat, 317

boomslang (Dispholidus typus), 293

Boomslangs, 9I

botanist's paradise, 272

bourjanes, 174

Bower-bird-

Gardener (Amblyornis subalaris), 152

Regent (Sericulus chrysocephalus), I5I

Satin (Ptilonorhynchus violaceus), 15I, 152

Brahmaputra River, I8I

Brazil, 216, 226; north, I01

bridges, bamboo, 218

Britain, 48, 6I

British, 156, 237, 279, 282

Army of Occupation, 284

attack, 277, 278, 279

Consul, 259, 260

convoy, 279

Dominion, 259

Government, 260

subjects, 259, 260, 27 I

British Guiana, 98, 99, 100, 10 1, 109, I I I , II3, II $4,117,122,317,318,320$, $321,323,324,325,327$; Goldfields, 326; Government of, 327

British Museum, 74, 76, 98, 155, 235, $244,255,342$

brugmansia, 221-222, 223

Buck, Delamere's Bush, 312

budgerigar cult, 39

Buff Orpingtons, 2

buffalo, 126, 292, 293; bull, 57; (Bully), 297

bulbuls (Pycnonotus), 127, 196-197

Bunyip, r3 I

burglary, $30 \mathrm{I}$

Burlington-Green, Doris Maria, 349

bus-driving, 22-23

bush babies, 68, 69

bush-life, 275

Bush-robins, White-starred, 127

Bush-shrike-

Bakbakiri, 18

Burchell's Crimson-breasted, 18

Fiery-breasted, 167

Gladiator, 167

Gray-headed, 38

"bush" tea, 32-33 
bushbuck, 69

bushveldt farm, 3-7

Busi sugar estates, 26

butterflies, 99, 105-106

Buxton, Earl, 16

Buzzards, Augur (Buteo rufofuscus augur), 293

"Bwana Ndegi," I 34

"Bwana Nzige," 134

cacao, 193

cage-trap, 68, 200-20I

Caia, 42, 45

Calabar, 333

Caladium, Giant (Caladium arborescens), IOI

Calcutta, I80, I82, I86, I87, I89, I90, I9I; Zoo, r89

Cameroon-

forests, I 59

Mountain, 330, 342

Cameroons, I62, I64, I92, I94, 201, 343, 347,348

avi-fauna, 162

British, 330, 33I, 342

Food Corporation, 346

Forest, 332

French, 155, 156, 168, 193, 330, 331, 342

South, 157

Canje Creek, 98, roo

Cape, I4, I5, 26, 304

Cape Town, 10, 12, 24, 86; Botanical Gardens, I4; docks, 15

Capuchin-

Brown, 322

Weeper, 322

capuchins, 318, 319

capybara (Hydrochoerus capybara), I08, 318,322

car, 238, 239

caracal (Caracal caracal), 298

carnivores, $32 \mathrm{I}$

carp, 76

Casuarina trees, 182

Cat-

Black-footed (Felis ocreata), 138

Margay (Felis tigrina), 322, 328

catbirds (Chlamydera maculata), 151, 152
Catfish, Electric (Malapterurus electricus), 155-156

Cats, Native, I5I

cattle, native, II 6, 24I

Ceylon, I9I

Chamberlain, 253

Chameleon-

Jackson's (Chamaeleon jacksoni), 308

Meller's (Chamaeleon melleri), 138

chameleons, 138, 155, 178, 309

Channel, 316

Chat, Mountain, 18

cheetah (Acinonyx jubatus), 293; (Prince), 315

Chef de Canton, 174,250

Chile, 215, 234

Chimborazo, Mount, 230

Chimoio district, 26

chimp (Pan troglodytes) -

baby, 301-302

intelligence, 338

(Mr. Cholmondley), 337-340, 346, 347

chimps, 3 I5

China Sea, 5 I

Chinese-

life, 50

sampans, 50

Chiriboga, 230

Christianity, 336

Cissa, Chaulet's (Cissa hypoleuca chauleti), 51, 55-57

City of Calcutta, 296, 297

civet-cats, 30, 33-34

civets, I29, 321

Clères, 62

climate, 215, 216

coati (Nasua nasua), ro6, 321

Cobra, Black-and-yellow, 208, 2 I I

Cockatoos, Banksian (Calyptorynchus banksii), $15 \mathrm{I}$

Cock-of-the-rock, Red, 23 I

cocks-of-the-rock (Rupicola rupicola), 232

Col des Nuages, 52, 55, 56, 59

Coleoptera, 166

colies, 223-224

collection, 309-310

Colombia, I0I

Commandos, ro

commotion, $282-283$

communism, $264-265$ 
Comoro group, 178

Congo, 201

Continent, 29

convent sisters, 199

Cooden, 12

Coots, Red-knobbed (Fulica atra cristata), 125

Cordon-bleus (Uraeginthus bengalus), 203

Coua, Blue (Coua caerulea), 258

coucals, 258

Courrier Bay, 279, 280

Crake, Black (Limnocorax flavirostra), 9I, 125

Crane, Crowned (Balearica pavonina), 64 crates, traveling, 292

Creoles, 314

Crimson-wings, Red-eyed (Cryptospiza reichenowi), $\mathrm{I} 36$

crocodiles, $86-87,177,2$ II-21 2

Cross River, 331, 333, 334, 335

Crow-

Bald, 342

pied (Corvus albus), I93

Cuckoo, Renauld's Ground (Carpococcyx renauldi), 5I, 55

Curassows, Crested (Crax alector), 327

Curator-Collector, 300

Curator of Mammals and Birds, 348

"cures," I55

Cuyuni, Upper, I 4

cycling, $186,323,33^{8-339}$

Daisy, Pyrethrum (Pyrethrum roseum), 301

dance, native, 210

Dandenong Hills, I44

Dar-es-Salaam, 98, 236, 237

Darjeeling, $183,186, \mathbf{1} 89$; area, 180

Dasyures, I5I

Death-adders-

Shaw's (Acanthophis antarcticus), 153

Superb (Denisonia superba), 153

Deceauville railway, 24, 346

Deer, Guiana White-tailed (Bambi), 322

Delacour, Monsieur Jean, 50, 51, 55, 62, 74,75

Delys, 170, 172, 180, 187, 189, 191, 204, 206, 2II, 2I3, 2I 4, 215, 216, 217, 218, $224,229,234,236,240,24 \mathrm{I}, 244$

Demarara, 45
Denham, Sir Edward, I00, 325

Devils, Tasmanian (Sarcophilus ursinus), I 42, 151

didieria (Fantsilotra), 285

diet, 174-I75; of chimps, 339-340

Diego Suarez, 74, 279, 280, 282, 283, 284 dik-dik, 309

Dik-dik, Kirk's (Rhynchotragus kirki), 240-24I

diphtheria, avian, 6r

District Commissioner, 289

Dodoma, 237, 242

dog, ridge-back, 32

dogs, Malagasy, 176-177

Dormice, Bushy-tailed (Claviglis crassicaudatus), 202

dreamland, 290

Drongos, Racket-tailed (Dissemurus paradiseus), 185

dry conditions, 272-273

Duala, I55, 156, I 57, 169

Dublin Zoo, 349

Duck-

Fulvous (Dendrocygna bicolor), 76-77, 82

Meller's (Anas melleri), 82, 178

Pink-headed (Rhodonessa caryophyllacea), I8I

Red-billed (Anas erythrorhyncha), 82, I 78

Torrent (Merganetta armata colombiana), 232-233

White-backed (Thalassornis leuconotus), $77,82,87,90,178$

White-faced Tree (Dendrocygna viduata), $77,82,87$

Duiker-

Cameroons Bay (Cephalophus dorsalis castaneus), 339

Hinde's (Cephalophus grimmi), 293

Ogilby's (Cephalophus ogilbyi), 339

Schultz's Blue (Cephalophus caeruleus schultzei), 339

Dungeness, 12

Durban, 244, 300

Dutch-

boat, 98

colonists, 109

Dutch Guiana, 98, 100

Dutch Line, 244 
Dutchmen, ro

Dymchurch-on-Sea, I

dysentery, II ; amebic, 347

\section{Eagle-}

Harpy (Harpia harpyja), 322, 323, 328

Vulturine Fish (Gypohierax angolensis), I 68

\section{Eagle-owl-}

Fraser's (Bubo poensis), 196

Giant (Bubo lacteus), 30-3I

Milky (Bubo lacteus), 30

Eagle-owlets, Giant, 30

eagle-owls, 213

earthworms, I 46-1 47

East African-

mammals, 317

Territories, 135

Timber Control, 283

East End, 299

East Indies, 98

East, Middle, 283

echidna (Echidna aculeata), I45, I50, 151

Ecuador, 101, 215, 216, 217, 224, 233;

$$
\text { fleas, 220, } 221
$$

Ecuadorian-

country folk, 233

degenerates, 219

families, 217

government, 228

politeness, 229

eggs, 213

Egrets (Leucophoyx thula), Snowy, 99

Egyptian coastline, 298

eland (Taurotragus oryx), 126, 292, 293

Elder Fyffes banana boat, 346

Eldoret, 301

elections, Presidential, 229-230

elephant (Dicksi), 293, 294-295, 296-297, 298, 299

elephants, 299

Elementeita, Lake, 129

England, I1, 12, 15, 17, 22, 23, 38, 42, $47,64,84,86$, 100, 121, 131, 132, 141, 147, 158, 170, $174,189,199$, $214,220,243,244,248,270,271$, $295,310,316,317,321,328,346,348$

English, 217; farmers, 24; missionaries, 276, 28I; people, 271, 282

English (language), 209; pidgin, 157, 212
Englishmen, 75

Enid, 328

Entebbe, 293

Eseka, 157, 161; children of, 166

Essequibo River, 103, 106, I18, 120, 324

Essex, 2

eucalyptus tree, I 43, 230

Europe, 55, I13, 125, 160, 215; southern, 96

European-

hunters, $\mathrm{x} 64$

travelers, 267

Europeans, 3, 33-34, 52, 57, 103, II 151 I 6, 123, I67, 174, 175, 213, 262, 288, $331,337,342$

explosion, 107

Falmouth, 316; harbor, 315

Fananimpitoloha, 81, I3I

Far East, 65, 257

Farafangana, 265

fauna, Australasian, I 45

feeding-bottle, 305

Fernando Po, 330

ferns, 126

Ferrand, Captain Geoffrey, 129, 133, I34, 137,138

ferret-badgers (Helictis), 321

ferry, 51, 246-247, 248, 249

fever, 42

fig, wild, 65

filanjana, 174, 175

Finches-

Black-headed Lined (Sporophila bouvronides), 327

Fire-tailed (Zonaeginthus bellus), I5 I

Fondia (Fondia madagascariensis), 178

Lined (Sporophila lineola), 327

Usambara Blue-billed, 136

Finisterre, Cape, 298

firefinches, 72

Firefinches, Bar-breasted (Lagonosticta rufopicta), 203

fish, $215,235,328$

fishing, 265-266

Fish-owls, Oriental, 60

Flamingo-

Greater (Phoenicopterus antiquorum), 130

Lesser (Phoeniconaias minor), I29, 131 
flamingoes, I29-I3I

fleas, jigger, 249

flesh, daily supply of, 213

flooding, 87-88

floods, $42-43$

flood-waters, 335

floor in flames, $115-116$

flora of Madagascar, 83

flue nets, 19-2I

Flycatcher-

Fairy (Erannornis longicauda), 203

Spectacled (Platysteira cyanea), 203

Verditer (Stoparola melanops), 188

flycatchers, 46, 127, 186, 213

Fooks, Herbert, I8r q. -183 q.

forest, 135, 172; deciduous, 267-268; destruction, 245-246; gallery, 209, 286; primitive, 176 ; road, 332

forests, 105-108; equatorial, I6I

Forestry Department, 83, 84, 256

Forestry Station, 183

Forktails, Spotted (Enicurus maculatus guttatus), 183

\section{Formosa, 55}

Foster, Mrs. Zoe, 301-302

fowl, jungle, 302

Fowl, Red Jungle (Gallus g. jabouillei), I 86

fowls, 27, 30; in Africa, 207

Francolins, East African Bare-throated (Pternistis leucoscepus infuscatus), 308

Freetown, 155

"freezing" act, 334

Fremantle, 142, 147

French (language), 59, 157, 158, 174, 247, 278,314

French (people), 13, 14, 74, 75, 156, 259, $279,28 \mathrm{o}, 28 \mathrm{r}, 282$

Government, 259

ship, 50

visitors, 278

Friesland bulls, 4

frog (Rana goliath), $162-163$

frogs, 209

Frogs, Giant, $16_{3}-16_{4}$

fruit, 47; trap, 47

Galago-

Black, 30 I
Demidoff's (Galago demidoff), I99, 200, 201

Garnett's (Galago crassicaudatus garnetti) , 67, 68, 200

Kikuyu (Galago crassicaudatus kikuyuensis), 295

Moholi (Galago senegalensis moholi), $48,67,69$

Thick-tailed (Galago crassicaudatus), 293

galagos, 295

Galapagos Islands, 216

gale, 189

Gallinule, 82

Allen's (Porphyrula alleni), 178

Green-backed (Porphyrio madagascariensis), 178

Ganges River, I8I

garden, 294

gardens, 98

Gazelle-

Grant's (Gazella granti), 123

Thompson's (Gazella thompsoni), 123, 126, 293

gazelles, 63

geckos, 137

Geese-

Bar-headed (Anser indicus), 182

Maned (Chenonetta jubata), I5I

Pygmy (Nettapus auritus), 77, 87, 9091, 97, I72, I78, 290

genets, 30, 69, 129, 293, 298, 321

Genoa, 236

Georgetown, 99, 100, 103, 104, 105, 120, $121,317,318,322,323,324,327$, 328; Botanical Gardens, 99, 100, 318; Museum, 327,

Gerbil, Madagascar (Macrotarsomys bastardi), 244, 249, 251, 253, 255, 260, $262,268,269,271,274,286,287$

gerenuk (Litocranius walleri), 304, 305

German-

boat, 236

overboard, 236-237

satellite, 259

surrender, 290

Germans, 10, 12, 134, 156, 280

Germany, 216, 236

gestation period, 299

Ghum, I 86 
gibbons, 330

Gibraltar, 315

gifts, 39, 153, 292-293, 308, 309, 327, 337, 348

Gillingham, 23

Giraffe-

Baringo (Giraffa camelopardalis rothschildi), 306; (Girlie), 293, 295, 298

Cotton's (Giraffa camelopardalis cottoni), 306

(Midget), 313, 315

Reticulated (Giraffa reticulata), 305-306

(Twiga), 312-313

giraffes, 123, 315; capturing, 306-307; transport of, 307

Goannese, 123

God, 187,336

Gogo tribe, 239

gold, 325-326

Gold Coast, 192, 194, 198, 199, 201, 204; boys, 157; forest, 193, 199, 200; heat of the, 194-195

Goodfellow, Walt, 215

gorges, 218

gorilla (Gorilla gorilla), 330, 340

Government House, I2 I

Government Rest-House, I00, 192, 203

Governor-General, 276

Grand Hotel, 246

Great Island, 244

Gribble, Mr., 305

grison (Galictis vittatus), 234-235, $32 \mathrm{I}$

Ground-tyrant-

Black-rumped, 226

Red-rumped, 226

Guamani Pass, 225

Guano, Grant's, 327

Guayaquil, 215, 216, 234

Guiana, I04, II4

Guianas, 99

Guinea, Gulf of, 330

Guinea, Spanish, 340, 346

Guinea-fowl-

Kenya Crested (Guttera pucherani), 136, 308

Sclater's Crested (Guttera edouardi sclateri), 333

Uganda Crested (Guttera edouardi sethsmithi), $30 \mathrm{I}$

Vulturine (Acryllitum vulturinum), 308
Guyas, River, 215

Hainault Forest, 2

hammerkops (Scopus umbretta), 42, 4344

Hare, Water, 109

Harwood, Bill, 309, 311

Hausa, 209; chief, 209 q.-210 q.; tribe, 193

Hawk-

African Harrier, 197

Chicken, 323

West African Harrier (Gymnogenys typicus pectoralis), I 68

hawks, 197-198, 213

"Heath Robinson" device, 95, 135, 200

hemipodes, $36-37$

Hereford bulls 4

Herne Bay, 22

herons, 42, 43, 88

Herons, Tricolored (Hydranassa tricolor), 99

High Command, 279, 280, 282

Hill, W. C. Osman, 303

Himalayan-

foothills, 185

snows, I 89

Himalayas, 6o, $180,189,218$

hippopotamuses (Hippopotamus amphibius), 288

hippos, I $82-183$

Hippos, Pygmy (Choeropsis liberiensis), I $8 \mathrm{I}-\mathrm{I} 82$

hoatzin (Opisthocomus hoazin), 100-103, I04, II 4 -II5, I2I, I22, I3I, 348

Hobart, 145, 151

Holland, 74

Hondo-hondos, 135

honey-eaters (Melithreptidae), I43-I44, I 45, 15 I

Hook, Raymond, 129, 302, 305, 306

hook-worm, 347

Hornbill-

Allied (Lophoceros semifasciatus), 194

Black (Ceratogymina atrata), I6o, I68I69

Black-and-white Casqued (Bycanistes subcylindricus), 194

Great Indian (Dichoceros bicornis), 6667 


\section{Hornbill-continued}

Ground (Bucorvus cafer), 307

Silvery-cheeked (Bycanistes cristatus), 135

Trumpeter (Bycanistes buccinator), 64 $65,67,135,200$

White-crested (Tropicranus albocristatus), I96

hornbills, 6, 63, 135, 169

horse, 8 , 10-1 I

horse-flies, 59-60

house, empty, I36-137

Hova nobility, 282

Hovas, 288

Hué, 51

human heads, 227-228

Humboldt current, 215

Humming-bird-

Blue Sylph (Aglaiocercus coelestis), 231232

Bouquet's Puff-leg, 22I

Cayenne Wood-hermit, I 7 , I I 8, I I9

Comte de Paris (Celigena lutetiae), 227

Giant (Patagona gigas), 225

Hill Angel (Heliangelus viola), 232

Hill Star (Oreotrochilus), 226, 230

King, I 10

Shining Sunbeam (Agleactis cupripennis), 227

Sword-billed (Ensifera ensifera), 22I223

Temminck's Sapphire-wing (Pterophanes temmincki), 227

Thornbill (Ramphomicron microrhynchum), 22 I

Trainbearer (Lesbia victoriae), 230

Violet-ear (Colibri coruscans), 230

White-bellied Emerald (Amazilia leucogaster), 99

White-booted Racket-tailed (Ocreatus underwoodi), 232

Wood-hermit (Phaethornis), II7

Wood-nymph (Thalurania furcata fissilis), II6-II7

humming-birds, II7-II9, 216, 234, 328 hunting lamp, 68-70

huts-

grass, 204

native, $274-275$
Hyrax-

Crawshay's 'Tree (Dendrohyrax arboreus crawshayi), 293, 299

Tree, 128,292

ibises, 42, 88

iguanas (Iguana iguana), 323

Ihosy, 250, 253, 254, 255, 260, 262; district, 265; River, 253

Imerimandroso, 252

impala (Aepyceros melampus), I26, 293

India, $39,60,105,147,180,186,190,283$,

Indian32I; northwestern, I3I

continent, 180

cook, I 86-1 88

Indian Ocean, 3II, 314

Indians, 105, I10, I14, 123, 217, 218, 219, 224

India's teas, $\mathrm{I} 88$

Indo-China, 50, 5I, 55, 6I

Indo-Chinese forests, 54

indris (Indri indri), 173, 174, 349

insect life, 99

Irish Sea, 297

Isiolo, 305, 308

Ivohibe, 262; Mountain, 262, 263

Ixulus (Ixulus flavicollis), I 88

Jabouille, Monsieur J., 5 I

jacana, 46, 88-89, 290

Jacana, African (Actophilornis africana), 125

jackal, black-backed (Thos mesomelas), 7

Jalpaiguri, 183

Jamaica, 45

Japanese-

boat, 50

ladies, 50

Jardin des Plantes, 6r, 84

Jay-thrushes-

Diard's (Garrulax leocolophus diardi), 58

Pasquier's (Garrulax pasquieri), 58

White-cheeked (Dryonastes chinensis), 58

Joe, 104, 108, 109

Joffreville, 75

Johanna, I 78

Johannesburg, 26 
jungle, 23I, 326

Kabaka, 295

kagu (Rhynochetos jubatus), 258

Kaieteur Falls, 325

Kapiti Plains, 123

Kaptagat, 301

Karati Bush, I25, I26

Kellaway, Dr., 153

Kent, I

Kenya, 123, 238, 284, 290, 292, 295, 300, 301, 304, 307, 311, 312, 317; Colony, 124; Game Department, I24; Highlands, I24, I3I, I33, I4I; Highlands plains, I3I; Mount, 301, 302, 304, 308; settlers, 124

Kew Gardens, 83

Kilimanjaro, Mount, I24, 238

Kilimatinde, 238

Kimberley, 10, 26

Kinangop Mountain, I 24

King of the Buganda, 295

King George V dock, 316

Kingfisher-

Black-capped (Halcyon pileata), 58

Giant (Dacelo gigas), 96

Malachite (Corythornis cristata), 207

Pygmy (Ipsidina picta), 96, 97, 207

Shining Blue (Alcedo quadribrachys), 207,208

kingfishers, $160-161,203,213$

Kiskadee, 99

knobkerry, 7, 9, 44, 45

kongoni (Alcelaphus cokei), I23, 126

Krantz, 26, 27, 28, 30, 32, 33, 37, 38, 39, 73

Kruger National Park, 86

Kudu, Lesser (Strepsiceros imberbis), 304305

Kumasi, I93, 194, 202, 203, 207, 213, 214; Hospital, 193

Kumba, 332, 340

Kurseong, 187

laboratories, 134-135

Lagos, 155, 330

lake mammals, 78,79

lamps, hurricane, 157

Lapwings, Crowned (Stephanibyx coronatus), 18
Laughing Jackass (Dacelo novaeguineae), 96

leeches, $83-84,263-26_{4}$

Lemur-

Black (Lemur macaco), 84

Brown (Lemur fulvus), 293

Fat-tailed (Opolemur medius, samati), 270

Fork-crowned (Phaner furcifer), 270

Gentle (Hapalemur), 79

Giant, 246

Mouse (Cheirogaleus), 270

Pygmy (Microcebus), 270, 272

Ring-tailed (Lemur catta), 78, 292, 293

Ruffed (Lemur variegatus), 83, $172-$ 173

Variegated (Lemur variegatus), 290

Weasel (Lepilemur), 270, 286

White-fronted (Lemur albifrons), 290

lemur traps, I73-I 74

lemurs, 78-79, 84-85

leopard (Panthera pardus), 69, 315; tame (Sandy), 296

leopards, 30, 63, 129, 293, 298

Lepchas, 188

Leslie, 2

lily-trotter, 46, 88-90, r25

Limpopo River, 12

lion (Panthera leo) (Straw), 293-294, 298, 309

lions, $30,123,124$

Liverpool, 297, 317, 329

livestock, 4

Lizard-

Agama, 206

Moloch (Moloch horridus), 153

Stump-tailed (Trachydosaurus rugosus), 153

Lloa, 220, 221

Loch Ness monster, I3I

locusts, $\mathrm{x}_{34}, 304$

London, 16, 62, 84, 142, 151, 244, 297, 299, 316, 331; docks, 50, 299; Missionary Society, 171, 252; Stock Exchange, 2; Zoo, 13, 18, 62, 65, 73, 76, $89,121,132,142, I 44, I 50, I 78, I 81$, 290, 292, 293, 297, 300, 305, 308, $309,313,317,319,323,330,347$, 348, 349; Zoological Society, I 42, 300, 348,349 
lorry, 267, 331, 332, 333, 346

Lourenço Marques, 86, 97

lovebirds, 15

Lovebirds, Fischer's (Agapornis fischeri),

$$
241-242
$$

Lowe, Willoughby, 75

Lucas, 212

luggage, $156-157,300$

Lushoto, I 4 I

Lydd, 12

lyre-birds (Menura novae-hollandiae), I44

Madagascar, 74, 75, 84, I31, I70, I77, I $78,244,245,252,254,259,260,263$, $264,266,267,271,272,274,281$, $282,283,284,291,292,299$; birdlife, 257; campaign, 30I ; forests, 256; Governor-General, 259-260; Representative of the East African Timber Control, 284; superstitions, 264-265; western, I3 I

Madagascar Times, 28I

Madeira, 98

magpie-larks (Grallina cyanoleuca), I 45

Magpie-robin (Copsychus saularis), I 86

Magpies, Black Racket-tailed (Chrypsirhina varians), 6I

Mahanadi, r $86, \mathbf{1} 88$

Mahananda, I 83

Mahé, 3I 4

Mailly-Maillet, 13

Majunga, 278, 279, 280, 28 I

Malagasy, I73, I75, I76, 247, 25I, 266, 281, 289; language, 17 1 , natives, 78; rodents, 269; tradition, I73; tribes, 285 ; village, 262

malaria, 194, 213, 270, 347

Malaya, II 3

Malimbus, Blue-billed (Malimbus nitens), 333

Mamba-

Andrew Smith's Green (Dendroaspis angusticeps), 293

Green, 91

Mamfe, 331, 333, 334, 336, 340

Mampong, 193, 197, 202, 213

mammals, 48; Australian, I42, I45; Madagascar, 78-79; swamp-dwelling, II 3I1 4; tree-dwelling, of South America, I I I manakins (Pipridae), II7

Manakins, Coroneted, 219

Mananantanana River, 25I

manatees (Manatus manatus), 100

Mandraka, $\mathrm{La}, 278$

Mangabe Island, 289-290

mango trees, 326

Mangoky River, 25I

Manica tribe, 34

Manicaland, 24

Manombo, 265, 266

Manombovo River, 288

marabous, 42, 43

Maria, I 71

Maroantsetra, 289, 290

Marseilles, 6I, 74

martens, $32 \mathrm{I}$

Masikoro, 272

Mau Escarpment, 295

Mauritius, 3 I 4

Mazaruni River, 103, I 10, 324

meal-worms, 29

Medical Research Institute, 153

medicine market, 155

Mediterranean Sea, 298

melanism, 295

Melbourne, I42, I43, I 44, I5I, I53; Botanical Gardens, I43; Zoo, I43

menagerie van, I90-19I

Mersey, 329

Meru, 307; district, 308; natives 308309

Mesias, Silver-eared (Mesia argentauris), I 85

mesoenas, 349

Messageries Maritimes boat, 74

Miandrivazo, 246

Midongy-de-l'Ouest, 249, 250, 25 I

Minivets, Scarlet (Pericrocotus brevirostris), 185

missionary teaching, 239

Mombasa, 123, 296, 311, 312, 313, 314, 316; Harbor, 300

Mongolia, 142, 147, 151

Mongoose, Graceful (Galidia concolor), 266

mongooses, 274

monkey, saki, 103

Monkey-

African Colobus, 252

Colobus (Colobus polykomos), 302 
Humboldt's Saki (Pithecia monachus), 322

Johnston's Vervet (Cercopithecus aethiops johnstoni), 293

L'Hoest's (Cercopithecus l'hoesti), 293

Lonnberg's, 293

Martin's White-nosed, 340

Pogonias (Cercopithecus pogonias), 340

Preuss's (Cercopithecus preussi), 340

Red Howler (Alouatta seniculus), 318

Red-faced Spider (Ateles paniscus), 318

Spider, 318-319, 330

Squirrel (Saimiri sciurea), 322

Stuhlmann's (Cercopithecus mitis stuhlmanni), 293

Uganda White-nosed (Cercopithecus nictitans mpangae), 293

Woolly, 319

monkeys, 63, I27, I4I, 328; rare, 293; rhesus, $181-182$

Moramanga, 76,83

Moreau, R. E., 28 q., I34

Morondava, 247, 249, 267, 270; district, 252; River, 245, 247

Morondava-Ambositra road, 249

Morpho, Blue, I05

Moses, 211 , 212 q.

mosquitoes, 44; diurnal, ror

moths, 137

motor transport, 301

mountains, 287

mousebirds, 223-224

Mozambique, 32 , 42; natives, 36 ; Territory, 86

Muisenberg, II

mules, riding, $2 \mathrm{I} 7$

Mungo River, 340, 34I, 346

Mustelidae, $32 \mathrm{I}$

Mycelium, 37

Naboom Spruit, Io

Nairobi, 123, 124, 283, 295, 299, 300, 308, 3 I 2 ; station, 294, 296, 3 II

Naivasha, 124, 301 ; Lake, 124, 215

Nakuru, 302

Nanyuki, 302, 303, 307

Napo, River, district, 227

Natal, 223

native customs, $8-9$
Negro-finches, 168

Gray-headed (Nigrita canicapilla), 194

nerves, state of, $27 \mathrm{I}$

nesting, 162; habits of hornbills, 65-67

New Amsterdam, I 00

New Caledonia, 258

New Guinea, 152, 257

New South Wales, 145

New World, 216

Newington, 22

Ngobit, 294

Nhatrang, 5I

Nigeria, 155, 330

Nightjar, Standard-wing (Macrodipteryx longipennis), 206

nightjars, 223

Niltava-

Greater (Niltava grandis), 188

Rufous-bellied (Niltava sundara), 188

Nimmo, Johnny, 29

Njok Etong, 164

nocturnal-

lemurs, 270

mammals, 289

noise, $165-166$

Northern District, 305

Northern Territory, 213

Norwegian Mission, 250

Nosy Bé, 84

Nuthatches, Chestnut-bellied (Sitta castaneoventris), 185

Nyasaland, 42, 45, 134; tribe, 45

ocelot (Felis pardalis), 322, 328

okapi, 348

Old World, 96, 327

Olifant, I0-I I

olives, wild, $127-128$

Onilahy River, 272, 273

Opossum-

Brush-tail (Dromicia nana), I5I

Ring-tail (Pseudochirus cookii), I5I

Virginian (Didelphis marsupialis virginiana), 299, 322

opossums, I 42,328

orang-utans (Pongo pygmaeus), 330

orchids (Angraecum germinyanum), 258; (Angraecum superbum, sesquipedale), I 70 
Orinoc River, 98

Oriole-

African Golden (Oriolus auratus), 136

Babbler (Hypergerus atriceps), 209, 213

European Golden (Oriolus oriolus), 136

Golden, 213

Green-headed (Oriolus chlorocephalus), I 36

oryx (Oryx beisa), 293

ostrich (Struthio camelus), 4-6, 123, 126 owl, I 96-197; stuffed, 94-96

Owl-

La Touche's (Otus spilocephalus latouchii), 60

Oriental Scops (Otus bakkamoena lettia), 60

West African Wood (Strix woodfordi), 196

owlets, 213

Ouzels, Gray-winged, $\mathbf{1} 88$

Oxpeckers, Red-billed (Buphagus erythrorynchus), 24I

paca (Coelogenys paca), 322, 328

Pacific, 216; coast, 226

pack-mules, 218

palanquin, $x 74,250$

Palm, Traveler's (Ravenala madagascariensis), 265,287

palm-civets (Paradoxurus), 321

palmleaf hut, 287-288

Panda, Giant (Ailuropoda melanoleuca), I 43

pandas, $189-190,321$

Pangolin, Long-tailed (Manis longicaudata), 340

pangolins, 319

Papallacta, 224, 226, 227, 228; Lake, 226

Paramaribo, 98, 99

paramo, 226, 228

paratilapia, 76

Paris, 6r, 84, 244; Ministry of Colonies, 260; Museum, 54

Parrakeets, Yellow-bellied (Platycercus flaviventris), $\mathrm{I} 5 \mathrm{I}$

\section{Parrot-}

Gray (Psittacus erithacus), I7

Greater Vasa (Coracopsis vasa), 253

Masai Red-headed (Poicephalus gulielmi massaicus), 127
Red-headed (Poicephalus gulielmi fantiensis), 194

parrots, 326

partridges, $x>8$

Peafowl, Spicifer (Pavo muticus), 52

peccaries, 109-I10

Peccary-

Collared (Pecari tajacu), ro9, 322

White-lipped (Tayassu pecari), rog, 322

pedicure, 337

Penal Settlement, 103-104, I13, I14, I2I, 325

penguins, 215-216

Perinet, 256, 258; district, 263

periscope, $275-276$

Perth, 142

Peru, I0I, 215, 221

Peters, 64, 71, 72

pets, 292, 293-294, 296-297, 319, 321 , $322,337-340,346,347$; hand-reared, 206

phalangers (Phalangeridae), I 42

Phalangers, Short-headed Flying (Petaurus breviceps), $15 \mathrm{I}$

pheasant-

basket, 53-54

snares, 52-53

Pheasant-

Bel's Silver (Gennaeus nycthemerus beli), 6I

Edward's Blue (Hierophasis edwardsi), $5 \mathrm{I}, 6 \mathrm{I}$

Fireback (Diardigallus diardi), 6r

Ghigi's Peacock (Polyplectron bicalcaratum ghigii), 61

Rheinart's Argus (Rheinardia ocellata). 51, 52-53, 61

pheasants, 39; Indo-Chinese, $6 \mathrm{r}$

philepittas, 257,258

picathartes, 346-347

Picathartes, Gray-necked (Pithecartes oreas), $342-345,348$

Pichincha, Mount, 220, 221, 230

pickaninnies, 3 I

Pied Piper of Hamelin, 8r

Pietersburg, 8

pig-

bush (Potamochoerus porcus koiroptamus), 293 
wild, 70-71, 176

Pig, Bush (Potamochoerus porcus koiroptamus) (Garbo), 315

Pigeons-

Olive (Columba arquatrix), 127

Wonga-wonga (Leucosarcia melanoleuca), $15 \mathrm{I}$

pilfering, 212

pits, concealed, $x 6_{4}$

Pitta-

Annamese (Pitta soror), 54

Elliot's (Pitta ellioti), 51, 54, 58

Swinhoe's (Pitta nympha), 55

Velvet (Philepitta castanea), 257

pittas, 257

platypus (Ornithorhynchus anatinus), I 42, 145-149, 151, 153; poison, 148I 49

Plover-

Blacksmith (Hoplopterus armatus), 125

Spur-winged (Lobibyx novaehollandiac), I5I

White-headed Wattled (Xiphidiopterus albiceps), 334-335

Yellow-wattled (Afribyx senegallus lateralis), 97

Pochard, Madagascar (Aythya innotata), 82,178

polecats, 302

police, 271, 272, 275-276, 296

Police, Commissioner of, 102

Porcupine-

Brazilian Tree (Coendou prehensilis), 322

Brush-tailed (Atherurus africanus), 342

Hairy Tree (Coendou villosus), 322

Kenya Crested (Hystrix cristata), 308 porcupines, 328

Porphyrio, Allen's (Porphyrula alleni), 82

Port Elizabeth, 45

Port Said, 297

porters, $174-175$

Portugal, 86

Portuguese (language), 25

Portuguese (people), 25

Portuguese East Africa, 23-24, 26, 33, 35, $42,63,86,97,140,200,259$

Potaro River, II7-II8, 325, 326

Potgietersrust, 7
Potto, Bosman's (Perodicticus potto), 201202

poultry, 2-3

Prang, 203, 204, 213

Pretoria, 7, 86

prisoner of war at large, 260

progress of the human race, 288-289

Protestant churches, 28I

Pru, River, 203, 206, 212

Public Works Department, 331, 332

Pungwe flats, 63

punting, 93

Pygmies, 157

pyrethrum, 301

python, 293

Quaaks, Blue, Ioo

quail, 298

Quail, Button, 36-37, 178

Quangtri, 5I

Quito, 216, 217, 220, 224, 225, 228, 229, 230,233

Raccoon, Crab-eating (Procyon cancrivorus), 321

radar, $327,335-336$

Rails, Cuvier's (Dryolimnas cuvieri), 178 rainfall, $172,263-264$

rains, $341,343,344,346$

rainy season, $217-218$

Rand, 26

Rat-

Black (Rattus r. frugivarus), 256

Brown (Rattus norvegicus), 256

Cane (theryonomys swinderianus), 206

Crested (Lophiomys ibeanus), 128-129

Coypu, 302

Cutting-grass (Thryonomys swinderianus), 206

Malay Giant, 244, 245, 246, 247, 248, $25 \mathrm{I}, 266,267,269$

Tufted-tailed (Eliurus), 256, 263

ravines, $126-127,128,129$

reed-beds, 78,79

reed-lemurs, 79-80

Regent's Park, 347

reptiles, 323, 328

Revue River, 24

rhino, baby (Jimmy), 315

Rhodesia, 24, 26, 304 
rice-fields, 5 I

Rift Valley, 124, 129

Ritchie, Captain, I24, 299

riverside vegetation, 209

road, 325

Roatelo (Mesoenas variegata), 258

Robin, Cape, 18

Robin-chat-

Blue-shouldered (Cossypha cyanocampter), I 65

Heuglin's (Cossypha heuglini), 28, 136

Natal (Cossypha natalensis), 28

Red-capped (Cossypha natalensis), 136

Snowy-headed (Cossypha niveicapilla), 332

White-shouldered, 97

White-throated (Bessonornis humeralis), 18

robin-chats, 38,213

Robins-

Forest (Stiphrornis erythrothorax), 332

White-starred Bush (Pogonocichla stellata), $14 \mathrm{I}$

Rockthrush, Short-toed, 188

Rollers-

Cinnamon (Eurystomus afer), 38

Long-tailed (Coracias caudatus), 126

Pitta-like Ground (Atelornis pittoides), 257

Scaly Ground (Geobiastes squamigera), 257

Rondebosch, II

Rooibosch tea, 32

Rothschild, Lord, 150

Royal Engineers, 282

Royal Zoological Society of Ireland, 349

Rushbrooke, Lieutenant-Commander, I00

Rustenburg, 9, I2, 17

Sahara, 304

Saigon, 50; Botanical Gardens, 50; River, 50

Sakalava, 270, 272; country, 247; natives, 246,269

Saloya, River, 230, 231

sandpipers, 42, 125

Santo Domingo de los Colorados, 217, 218, 219, 220

Saranda, 237

Sauvage, Gilbert, 295, 296 savanna country, 202-203, 205

scenery, 51, 218, 226; coastal, 289

scent glands, I09-I I0

Scheldt, 348

school-boy trappers, 158, 159

sciatica, 3I 7

scorpion's sting, 2 II

Scotland, I3I

Scott, Cleland, 293-294, 309

seasonal plumage changes, 303-304

second growth, 165

Seed-cracker-

Black-bellied, I 67

Blue-billed (Sphermophaga haematina), 332-333

Seed-finches, Thick-billed (Oryzoborus crassirostris), 327

seeds, I25-1 26

Sekondi, 192

selling bird shipment, $x 6-17$

Sena Sugar Estates, 42

Senegalese troops, 279

serval, black, 293, 295

servals (Felis serval), 30, 129, 298

servant code, 186

servants, 192-193

Seychelles, 98; Governor of the, 314; Islands, 312, 314

Shangaan, 8; women, 9

Sharpe, Major, 294-295, 296

Sheep, Karakul, 302

Shelduck, Australian (Tadorno tadornoides), $15 \mathrm{I}$

shipping collection, 48-49, 310-316, 328329

shrew-

British, 154

(Suncus), 290

tree, $57-58$

Shrike-

Greater Puff-back (Dryoscopus cubla), I 8

Long-tailed (Urolestes melanoleucus), I 8 Southern Helmet (Prionops poliocephala), 97

shrimps, 80

Siafu, $138-139$

sifaka, 274, 349

Sifaka, Verreaux's (Propithecus verreauxi), 252 
Sigi, 136; River, 137

Sihanaka tribe, 77,79

silence, $\mathrm{I} 6 \mathrm{I}$

Siliguri, 183,185 ; forests, 183

Siluvu Hills, 63, 64, 75, 71

Silverbills (Euodice cantans), 237

Singapore, 50

sisal, I35, I4 I

Sittingbourne, 22, 23

skies, 265

Skinks, Blue-tongued (Tiliqua scincoides), I 53

Sloth-

Three-toed (Bradypus tridactylus), IroI I 3, I I 5, 322

Two-toed (Choloepus didactylus), III, I I 2-1 I3, 322

sloths, 328

Snails, Giant Land, 155

Snake-

Black (Pseudechis porphyriacus), I53

Brown (Demansia textilis), 153

Green Sharp-nosed Tree (Clorosoma viridissimus), 108

Kangaroo, 153

Red-bellied Black, 153

Sharp-nosed, 177

Sharp-snouted (Rhamphiophis oxyrynchus), 293

Tiger (Notechis scutatus), 153

Snake Park, 45

snakes, 45-46, 91-93, 94, 108, 137, 153, I78, 269; Australian, I49; (Ithycyphus), 177

snake-stick, 92, 137

soda, 129

Somme, 13

songbirds, 28

Sotik, 295, 301

South Africa, 3, 13, 15, 26, 32, 125, 255;

Western Province of, 33

South African Government, Io

South America, 98, 258, 326, 340; wild pigs of, 109-1 I0

South American rivers, roo

Southampton, I 6

Spanish (language), 217, 219

Spanish-

countries, 217

women, 216
Spanish Guinea, 330

Sparrow-

Chestnut (Sorella eminibey), 237

Pectoral (Arremon aurantiirostris), 219

Sparrow-hawk, African Little (Accipiter minullus), 197

spider (Olios), 285

Spider-hunter, Great Indian (Arachnothera magna), 188-189

spiders, Epeira, 336

Springbok, 7

Squirrel-

Gambian Tree (Heliosciurus gámbianus), 198-199, 204-205

Ground (Euxerus erythropus), 206

White-striped (Funisciurus leucostigma), 198

Starling-

Amethyst (Cinnyricinclus leucogaster), 242

Blue-eared Glossy (Lamprocolius chalybeus), 125

Glossy, 205, 303

Superb (Spreo superbus), I25, 303

Wattled (Creatophora carunculata), 303304

starlings, 213; glossy, 6

steinbok (Raphicerus campestris), 293

storks, 88

sub-Antarctic, 215

sub-desert region, 284-285

Sumatra, 3

Sunbird-

Anjouan (Cinnyris comorensis), I 78-179

Beautiful (Nectarinia pulchella), 203, 205

Black-bellied (Nectarinia melanogastra), 237-238

Bronzy (Nectarinia kilimensis), I 26

Buff-throated (Chalcomitra adelberti), I 94

Coppery (Cinnyris cupreus), 203, 205

East African Mariqua (Cinnyris mariquensis suahelicus), I4I

Falkenstein's (Cinnyris venustus falkensteini), 126

Falkenstein's Buff-breasted (Cinnyris venustus falkensteini), 125

Golden-winged (Drepanorhynchus reichenowi), I4I 
Sunbird-Continued

Kenya Buff-breasted (Cinnyris venustus falkensteini), I4I

Kenya Highlands Amethyst, 126

Kenya Highlands Scarlet-chested (Chalcomitra senegalensis lamperti), 126

Kenya Malachite (Nectarinia famosa aenigularis), 126

Lesser Bifasciated (Cinnyris bifasciatus microrhynchus), I4I

Mombasa Collared (Anthreptes collaris elachior), I4I

Scarlet-chested, I40, I4I

Senegal Scarlet-breasted (Chalcomitra senegalensis senegalensis), 205

Splendid (Cinnyris coccinigaster), 205

Superb (Cinnyris superbus), I64, 194, 205

Tiny (Cinnyris minullus), $x 67$

Uluguru Violet-backed, I4I

Usambara Double-collared, I4 I

Usambara Gray-chin, I 4 I

sunbirds (Nectariniidae), 18-19, 46, 94-95, 126, 164-165, 178, 194-196, 213

sun-bittern, I 19-120, 258

superstition, 80, 81, 83-84, I 78, 254, 265,266

Supplies and Transport Unit, 28I

Surinam, 98; River, 98, 99

Sussex, 12

Swakopmund Hospital, II

swamps, tropical, 93

swans, 182

Swaziland border, 86

swifts, 223

Swifts, Palm (Tachynautes parvus), 135I36

Table Mountain, II

Takoradi, 155, 192

Tamatave, 74, 75, 265, 279, 280, 289

Tanager-

Blue (Thraupis episcopus), 98-99

Greenish Blue (Tangara labradorides), 219

Orange-bellied, 228

Orange-billed (Arremon aurantiirostris), 219

Palm (Thraupis palmarum), 99, 108

Scarlet-bellied (Poecilothraupis lunulata), 226,228
Sclater's Orange-headed (Tangara lunigera), 220

Silver-beaked (Ramphocelus carbo), 99

Vassor's (Procnopsis vassori), 228

Western Swallow Fruit-eater, 219

Yellow-backed (Ramphocelus icteronotus), 219

tanagers, 108, 219-220

Tanala-

fleas, 263

tribe, $262-263$

Tananarive, $74,75,245,246,252,253$, $255,258,259,260,271,277,278$, $281,282,288$

Tanga, I33

Tanganyika, I33, I41, 236, 238, 239; Governor of, 239

Tapir, Brazilian (Tapirus terrestris), I1 3

tapirs, I I 3-I I 4, 328

Tasmania, 145

Tasmanian lakes, I45, I 49

taxes, $158-159$

tayra (Tayra barbara), 321, 328

Teal-

African Cotton (Nettapus auritus), $\mathbf{1} 72$

Andean (Anas flavirostris andium), 226

Hottentot (Anas punctata), 76, 82, 172 , 178

teguexins (Tupinambis teguixin), 323

temperature, 99

Tenrec-

Mole-like (Oryzoryctes tetradactylus), 256, 289, 290

Pygmy (Microgale melanorrachis), 256, 257

Shrew-like, 257

Spiny (Ericulus), 257, 290

Tailless (Tenrec ecaudatus) (tandraka), 177-1 78

Telfair's, 272

tenrecs (Centetidae), 178

termites, soldier, 333

Terrapins, Long-necked (Chelodina longocollis), 151, 152-153

Thames, $3 \mathrm{r} 6$

Thick-knees, Water (Burhinus vermiculatus), 38

Thomson's Falls, 294, 302

Thorns, Pimpler (Drepanocarpus lunatus), I01, 102 
Thrush-

Groundscraper (Geokichla litsipsirupa), 18

Himalayan Whistling (Myiophoneus temminckii), 185

Olivaceous, 18

Thua Luu, 5I, 54, 60, 61

thylacine (Thylacinus cyanocephalus), I 45

ticks, 94

Tiko, 346

Tilbury, 142

timber, 282, 283-284

Tinayre, Monsieur and Madame, 289

Tinker-barbet (Pogoniulus pusillus), Redfronted, 126

Tinker-bird, 160

tinker-bird, 213

Tit-babblers, Red-vented (Parisoma subcaeruleum), I 8

Tongobory, 272

torpidity, 223-224

tortoises, 155

toucans, 328

Toucans, Swainson's (Ramphastos swainsoni), 220,234

Touraco-

Great Blue (Corythaeola cristata), 332

Hartlaub's (Tauraco hartlaubi), 127

Purple-crested (Gallirex porphyreolophus) , 38, 47

touracos, $128,200,213,258$

Tourane, 5 I

train, goods, 233-234

transport, 331

transporting animals, 296-299

Transud, 253

Transvaal, $3,12,15,17,22,26,86$

trappers, 55, 56-57; Annamite, 60

trapping, 256-257; antelopes, 35-36; birds, 19-2I

traveling cages, 58-59

tree-

African mahogany, 24

Bombax (Ceiba pentandra), 194-196

Silk Cotton (Ceiba pentandra), 194196

tree-frogs, 43

Trinidad, 121, 327

Trogon-

Black-throated (Trogon rufus), 108
Green (Trogon viridis), 108

Narina (Apaloderma narina), 127 trogons, 106-108; South American, 107

trolleys, 24

trout, 129

tsetse flies, 203

Tsihombe, 288

Tsiribihina River, 245, 246, 247

Tulear, 271, 272, 273, 276; police, 275

Tulear-Ihosy road, 273

Tumatumari, 326, 327; Rapids, 326

Tumbaco Valley, 225

Twi (language), 209

Twi (people), 193; natives, 197

Typhonodorum, 290

Tyrant, Sulphury (Pitangus sulphuratus), 99

tyrants, 216

Uganda, 124, 293, 296, 313

Umbeluzi River, 86,87

Umbrella Tree (Cecropia), II I

Umtali, 24

Umtali-Beira railway, 24

Union Castle-

boat, 15,48

steamer, 244-245

Union of South Africa, 23

United Africa Company, 157, 331, 333

Urlana, 3II, 313, 315

Usambara Mountains, 133

Usambaras, I $4 \mathrm{I}$

van, $190-191$

vegetation, Madagascar, 272-274

Vervet-

Abyssinian, 293

Uganda, 293

Vevers, Dr. Geoffrey M., 13, 73, 98, 290, $297,299,348$

Vichy Government, 259, 280

Victoria, I 44-145, 314, 330, 331, 332;

Lake, 30 I

Vila Pery, 24, 38

Voalavo Voutsotse, 246

vultures, 124

waders, I25

Wallabies, Bennett's (Macropus rufogriseus fruticus), 142, 151 
Wagogo, 239, 240

Walvis Bay, II

war declared, 8, 9, 253

Ward, Major and Mrs., I24

Wards, 127

wart-hog (Phacochoerus aethiopicus), 293

water, 63,273 ; fermented coconut, 140I 4 I ; fête, 229

Water Haas, 109

Waterberg, 12; Commando, 10

water-birds, 46

Waterbuck, Defassa (Kobus defassa), 312 waterfowl, 76-77, 82, 87-88, I 70, I 71, 252 water-hyacinth (Eichornia crassipes), 77 water-lilies, $82-83$

Watras, 109

Waxbill-

Black-capped (Estrilda atricapilla), I57

Orange-cheeked, 203

Peters', I39-1 40

Peters' Spotted (Hypargos niveoguttatus), 38, 238

Purple Grenadier (Granatina ianthinogaster), 125,238

Ruddy, 72

Violet-eared (Granatina granatina), I25 waxbills, 15,46

weasels, 321

Weaver-bird-

Black (Ploceus nigerrimus), 162

V-marked (Ploceus cucullatus), I 62

weaver-birds, I6I-I62, 203, 209

weavers, 15

Weavers-

Malimbus (Malimbus), I67

Social (Philetairus socius), 237

Whipsnade, 301, 313; Park, 295; Zoo, I 42 White, Dr. Errol, 74 white settlers, 124 white-eyes, 178

whydahs, 15, 203

Whydahs-

Delamere's Giant (Diatropura progne delamerei), 302

Jackson's (Drepanoplectes jacksoni), 13 r, I32

wild life, 7

wildebeeste, 123

Williams, Mr., I7 1

witch-doctors, 27, 33

Wolf, Tasmanian (Thylacinus cyanocephalus), I 45

wombats (Phascolomis ursinus), 142

Wood-hoopoes-

Red-billed (Phoeniculus purpureus), 125

White-headed (Phoeniculus bollei jacksoni), 127,131

World War, First, 3, 12, 84

World War II, I 45

worms, filaria, 89

Wynberg Hospital, II

yam, wild (Dioscorea), 273

Yaounde, 157

Yellow Fever Research Station, 293

youth, 283

Ypres, I3

Yuhinas (Yuhina gularis), I 88

Zambezi, 42

Zebra-

Burchell's (Equus burchelli), I23, I26, 305

Grevy's (Equus grevyi), 305

Zoo collection, 309-310

zorilla (Ictonyx striatus), 129

zosterops, I27, I 88 


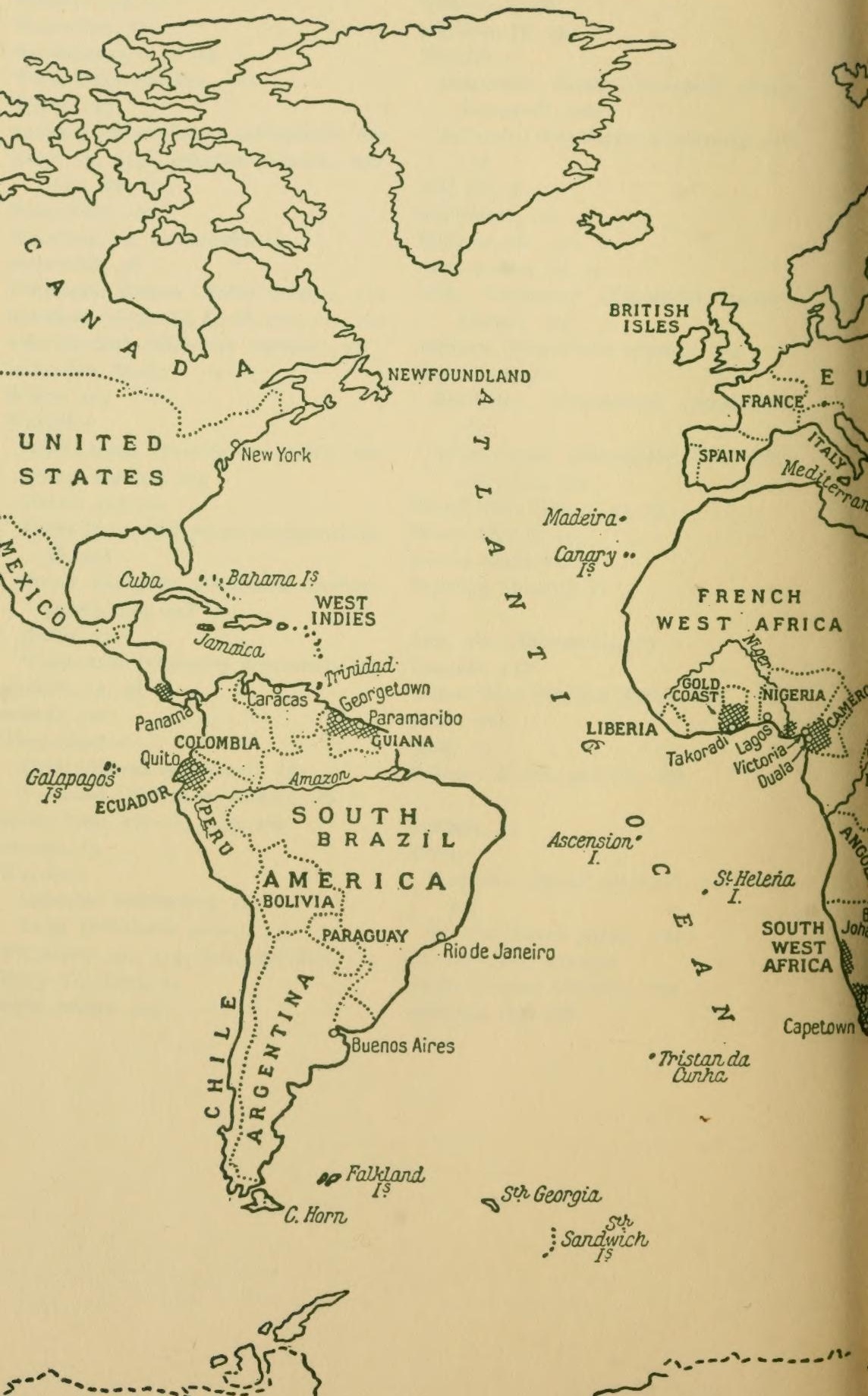




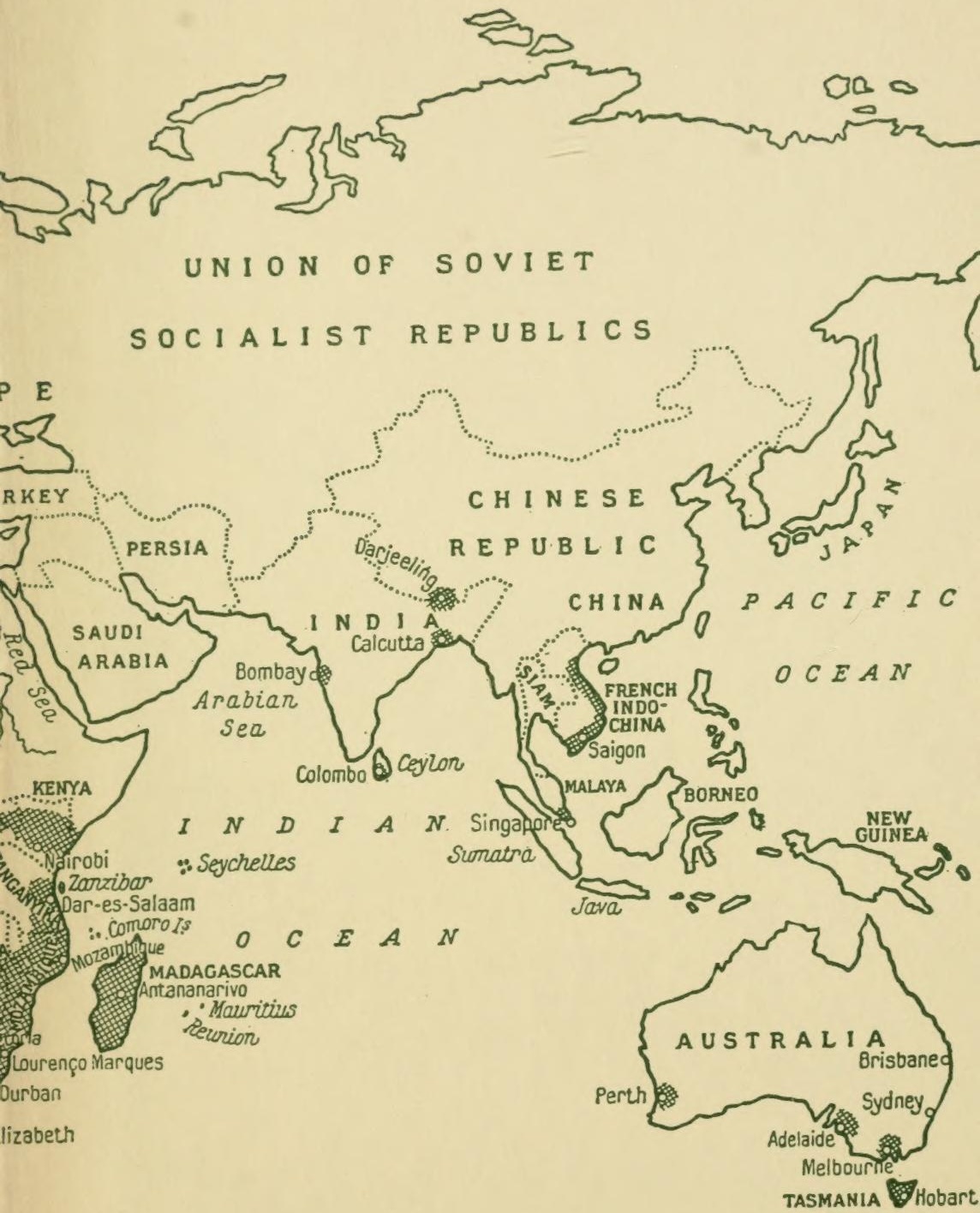


